NUREG/CR- -5683

TI91 010667

\title{
Laboratory Testing of Cement Grouting of \\ Fractures in Welded Tuff
}

Manuscript Completed: January 1991

Date Published: March 1991

Prepared by

C. J. Sharpe, J. J. Daemen

Department of Mining and Geological Engineering

University of Arizona

Tucson, AZ 85721

Prepared for

Division of Engineering

Office of Nuclear Regulatory Research

U.S. Nuclear Regulatory Commission

Washington, DC 20555

NRC FIN L1476

\section{MASTER}

DISTRIBUTION OF THIS DOCUMENT IS UNLIMITE 


\section{DISCLAIMER}

This report was prepared as an account of work sponsored by an agency of the United States Government. Neither the United States Government nor any agency thereof, nor any of their employees, make any warranty, express or implied, or assumes any legal liability or responsibility for the accuracy, completeness, or usefulness of any information, apparatus, product, or process disclosed, or represents that its use would not infringe privately owned rights. Reference herein to any specific commercial product, process, or service by trade name, trademark, manufacturer, or otherwise does not necessarily constitute or imply its endorsement, recommendation, or favoring by the United States Government or any agency thereof. The views and opinions of authors expressed herein do not necessarily state or reflect those of the United States Government or any agency thereof. 


\section{DISCLAIMER}

Portions of this document may be illegible in electronic image products. Images are produced from the best available original document. 
The objective of this investigation is to experimentally determine the effectiveness of fracture sealing in welded tuff using ordinary portland cement and microfine cement grouts.

Laboratory experiments have been performed on seventeen tuff cylinders with three types of fractures: 1) tension induced cracks, 2) natural fractures, and 3) sawcuts. Prior to grouting, the hydraulic conductivity of the intact rock and of the fractures is measured under a range of normal stresses. The surface topography of the fracture is mapped, and the results are used to determine aperture distributions across the fractures.

Grouts are injected through axial boreholes at pressures of 0.3 to 4.1 $\mathrm{MPa}$ while holding fractures under a constant normal stress. Five grout formulations have been tested. Bentonite ( 0 to 5 percent by weight) has been added to these grouts to increase their stability. Water to cement ratios range from 0.45 to 1.0 . Permeability testing of grouted fractures is used to evaluate the effectiveness of fracture grouting. Posttest visual inspection of grout distribution confirms that permeability testing in an injection hole is not a reliable method to assess the effectiveness of grouting. Grout distribution is highly non-uniform. 
TABLE OF CONTENTS

$\underline{\text { Page }}$

LIST OF FIGURES $\ldots \ldots \ldots \ldots \ldots \ldots \ldots \ldots \ldots \ldots \ldots \ldots \ldots \ldots \ldots$

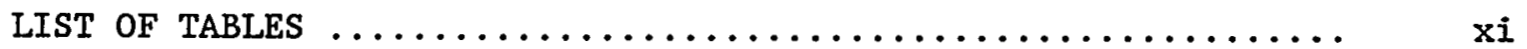

ACKNOWLEDGMENTS .............................. xiii

LIST OF SYMBOLS $\ldots \ldots \ldots \ldots \ldots \ldots \ldots \ldots \ldots \ldots \ldots \ldots \ldots \ldots \ldots$

EXECUTIVE SUMMARY $\ldots \ldots \ldots \ldots \ldots \ldots \ldots \ldots \ldots \ldots \ldots \ldots \ldots \ldots \ldots \ldots \ldots \ldots \ldots \ldots \ldots$

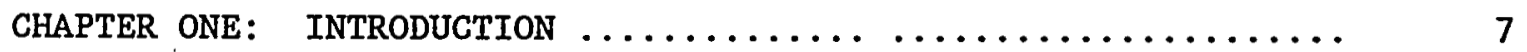

CHAPTER TWO: FLUID FLOW IN FRACTURED ROCK . . . . . . . . . . . . . 10

2.1 Introduction $\ldots \ldots \ldots \ldots \ldots \ldots \ldots \ldots \ldots \ldots \ldots \ldots \ldots \ldots$

2.2 Theory of Fluid Flow Within a single Fracture ......... 11

CHAPTER THREE: FRACTURE GROUTING ....................... 14

3.1 Introduction .............................. 14

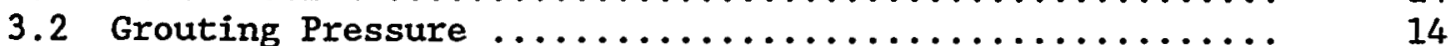

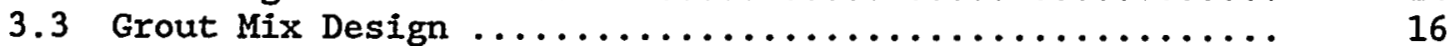

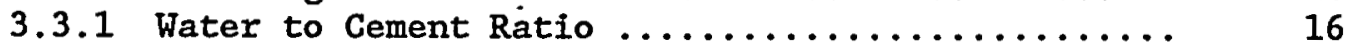

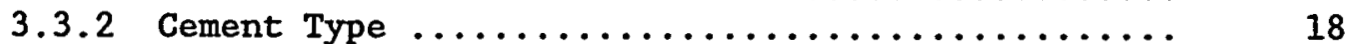

3.3 .3 Admixtures $\ldots \ldots \ldots \ldots \ldots \ldots \ldots \ldots \ldots \ldots \ldots \ldots \ldots \ldots$

3.4 Grout Rheology ............................... 19

CHAPTER FOUR: EXPERIMENTAL PROCEDURE ................... 23

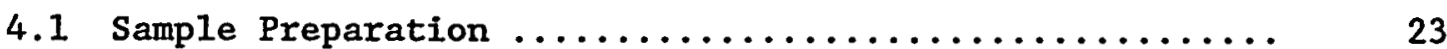

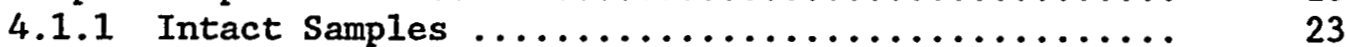

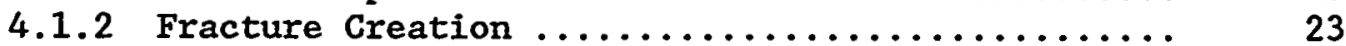

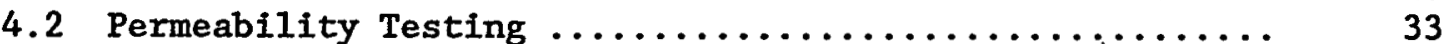

4.2 .1 objective ..........................

4.2 .2 Apparatus $\ldots \ldots \ldots \ldots \ldots \ldots \ldots \ldots \ldots \ldots \ldots \ldots \ldots \ldots \ldots$

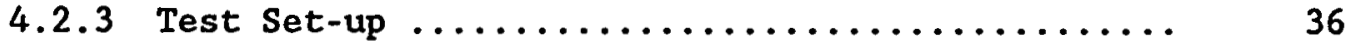

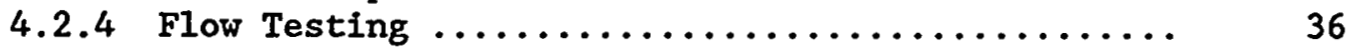

4.3 Surface Roughness Characterization .................

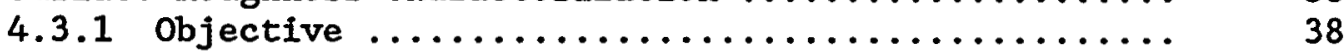

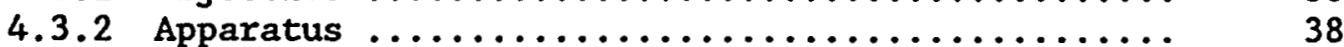

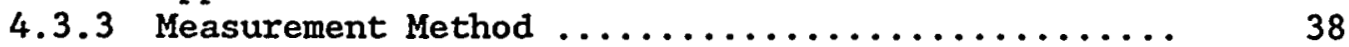

4.4 Grout Preparation ............................ 40

4.4 .1 Introduction ........................ 40

4.4 .2 Apparatus ........................... 42

4.4.3 Procedure for Preparing $\mathrm{MC}-500$ and SSII

Bentonite Grouts ........................ 42 
TABLE OF CONTENTS--Continued

Page

4.5 Grout Characterization ..................... 43

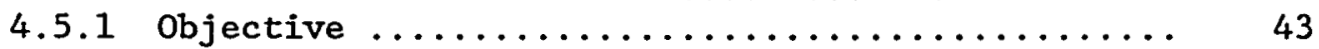

4.5.2 Uniaxial Compressive Strength Testing ......... 44

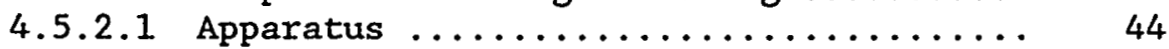

4.5.2.2 Testing Procedure .............. 44

$\begin{aligned} 4.5 .3 & \text { Determination of Viscosity and Cohesion } \\ \text { (Fann Viscometer) } \ldots \ldots \ldots \ldots \ldots \ldots \ldots \ldots \ldots \ldots \ldots & 44 \ldots \ldots \ldots \ldots \ldots\end{aligned}$

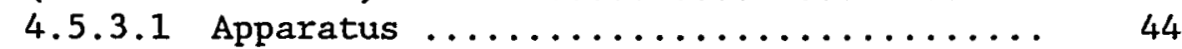

4.5.3.2 Test Procedure ...................... 44

4.5.4 Marsh Viscosity or Flow Time ................. 45

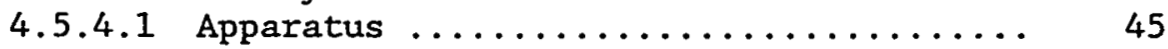

4.5.4.2 Test Procedure .................. 45

4.5.5 Determination of Slurry Density ........... 48

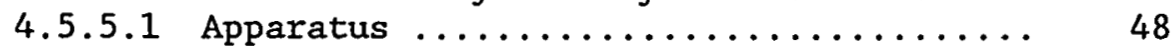

4.5.5.2 Test Procedure ................. 48

4.5.6 Determination of Bleed Capacity ........... 48

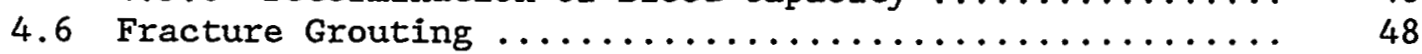

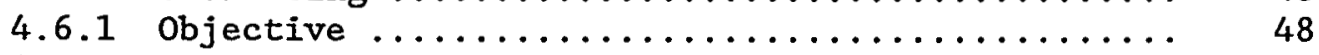

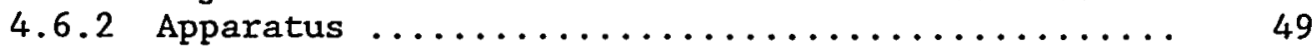

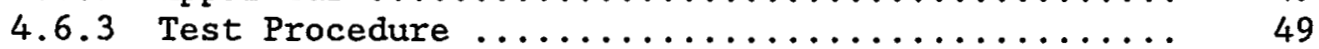

4.7 Determination of Fracture Compression Behavior ........ 49

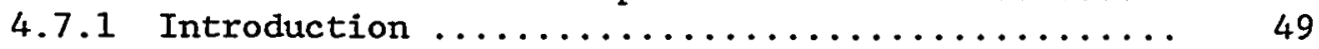

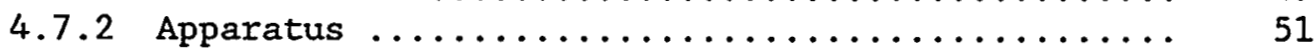

4.7.3 Measurement Method .................... 51

CHAPTER FIVE: EXPERIMENTAL RESULTS ................. 54

5.1 Permeability of Intact Tuff .................. 54

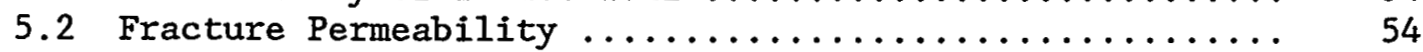

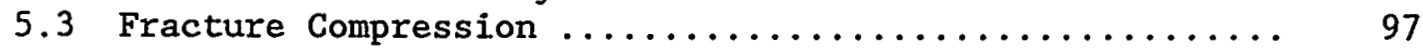

5.4 Surface Roughness Characterization .............. 97

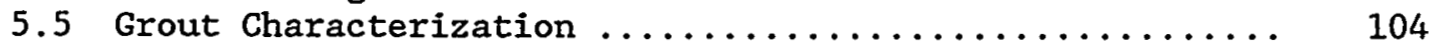

5.6 Grouting Effectiveness ..................... 104

CHAPTER SIX: CONCLUSIONS AND RECOMMENDATIONS ............ 134

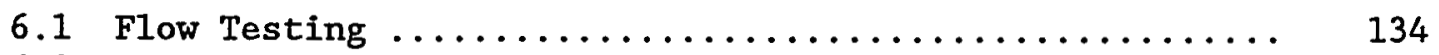

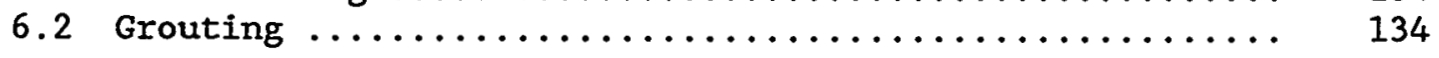

REFERENCES $\ldots \ldots \ldots \ldots \ldots \ldots \ldots \ldots \ldots \ldots \ldots \ldots \ldots \ldots \ldots \ldots \ldots \ldots \ldots \ldots \ldots \ldots \ldots \ldots$

APPENDIX A: PERMEABILITY GALCULATIONS ................ 143

APPENDIX B: ROCK SAMPLE DESIGNATION CODING SYSTEM .......... 147 


\section{LIST OF FIGURES}

Figure

Page

3.1 Maximum allowable grouting pressures $\ldots \ldots \ldots \ldots \ldots \ldots \ldots$

3.2 Effect of water to cement ratio on grout properties ..... 17

3.3 Flow behavior of Newtonian and Bingham fluids ......... 20

3.4 Flow velocity cross section $\ldots \ldots \ldots \ldots \ldots \ldots \ldots \ldots \ldots \ldots \ldots \ldots . \ldots \ldots$

3.5 Maximum radius of penetration $\ldots \ldots \ldots \ldots \ldots \ldots \ldots \ldots \ldots \ldots \ldots$

4.1 Nominal sample dimensions $\ldots \ldots \ldots \ldots \ldots \ldots \ldots \ldots \ldots \ldots \ldots$

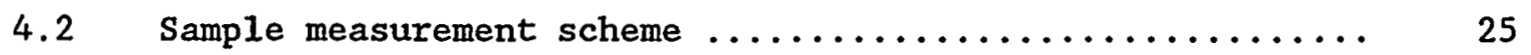

$4.3 \quad 3 \mathrm{HP}$ Acker and $2 \mathrm{HP}$ Century coring crills $\ldots \ldots \ldots \ldots \ldots . . \ldots$

4.4 Kent automatic surface grinding machine $\ldots \ldots \ldots \ldots \ldots \ldots$

4.5 Apache Leap tuff cylinder $\ldots \ldots \ldots \ldots \ldots \ldots \ldots \ldots \ldots \ldots \ldots \ldots \ldots$

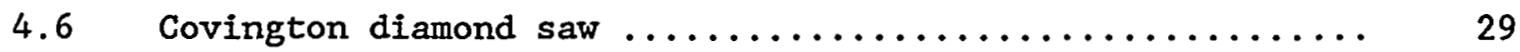

4.7 Sawcut surfaces of sample AP4-1-6-FG2 $\ldots \ldots \ldots \ldots \ldots \ldots \ldots . \ldots$

4.8 Modified point load test used to induce tensile fractures 31

4.9 Fracture surfaces produced by modified point load test ... 32

4.10 Coring of blocks containing a single natural fracture .... 34

4.11 Cored samples containing natural fractures ........... 35

4.12 Laboratory arrangement for flow testing and grouting..... 37

4.13 Guide plate and needle probe used to characterize fracture

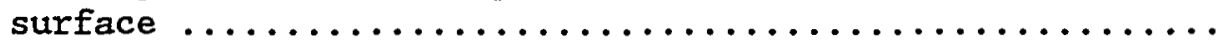

4.14 Grain size distribution of O.P.C, Colloid, and MC-500

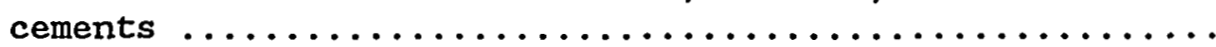

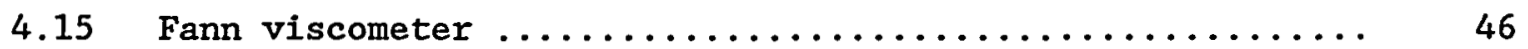

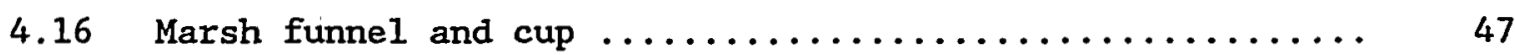




\section{LIST OF FIGURES--Continued}

Figure

Page

4.17 Single piston grout pump with gauge saver ........... 50

4.18 Fracture compression monitoring system ............. 52

5.1 Three types of welded tuff $\ldots \ldots \ldots \ldots \ldots \ldots \ldots \ldots \ldots \ldots$

5.2 Hydraulic conductivity of intact tuff $\ldots \ldots \ldots \ldots \ldots$

5.3 Effect of axial stress on hydraulic conductivity of intact Apache Leap tuff ...................... 57

5.4 Effect of axial stress on the permeability of intact sample AP7-1-6-FG4 .......................

5.5 Hydraulic conductivity as a function of normal stress for sample AP21-3-6-FG1 .......................... 64

5.6 Equivalent fracture aperture as a function of normal stress for sample AP21-3-6-FGI .................

5.7 Hydraulic conductivity as a function of normal stress for

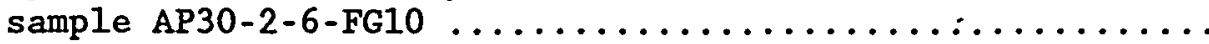

5.8 Equivalent fracture aperture as a function OF normal stress for sample AP30-2-6-FG10 .....................

5.9 Hydraulic conductivity as a function of normal stress for sample AP30-1-6-FG11 .......................

5.10 Equivalent fracture aperture as a function of normal stress for sample AP30-1-6-FG11 ....................

5.11 Hydraulic conductivity as a function of normal stress for

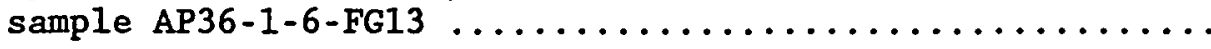

5.12 Equivalent fracture aperture as a function of normal stress for sample AP36-1-6-FG13 ....................

5.13 Hydraulic conductivity as a function of normal stress for sample AP4-1-6-FG2 .......................

5.14 Equivalent fracture aperture as a function of normal stress for sample AP4-1-6-FG2 .....................

5.15 Hydraulic conductivity as a function of normal stress for sample AP7-2-6-FG5 
LIST OF FIGURES--Continued

Figure

Page

5.16 Equivalent fracture aperture as a function of normal stress

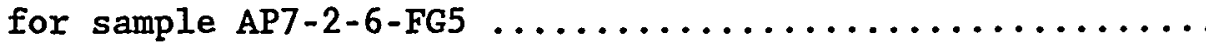

5.17 Hydraulic conductivity as a function of normal stress for

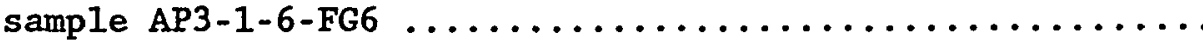

5.18 Equivalent fracture aperture as a function of normal stress

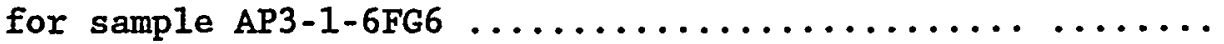

5.19 Hydraulic conductivity as a function of normal stress for

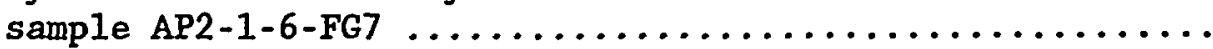

5.20 Equivalent fracture aperture as a function of normal stress

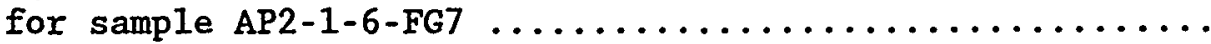

5.21 Hydraulic conductivity as a function of normal stress for

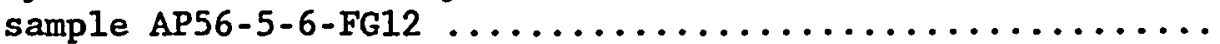

5.22 Equivalent fracture aperture as a function of normal stress for sample AP56-5-6-FG12 ....................

5.23 Hydraulic conductivity as a function of normal stress for

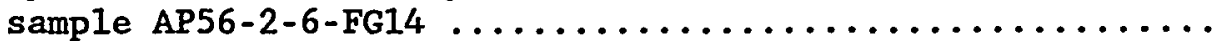

5.24 Equivalent fracture aperture as a function of normal stress

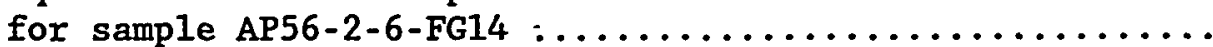

5.25 Hydraulic conductivity as a function of normal stress for

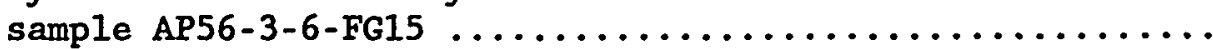

5.26 Equivalent fracture aperture as a function of normal stress

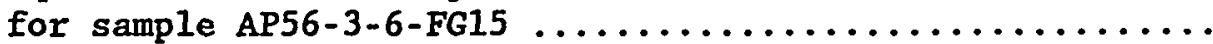

5.27 Effect of normal stress on fracture closure .......... 98

5.28 Fracture compression and equivalent fracture aperture for final loading cycle of Sample AP36-1-6-FG13 ..........

5.29 Three-dimensional image of fracture surface of Sample AP21-3-6-FG1 (80 degree tilt off of the z-zxis) ........

5.30 Three-dimensional image of fracture surface of sample AP21-3-6-FG1 (30 degree tilt off of the z-axis) ........ 101

5.31- Topographic plot of fracture surface roughness of sample 102-

5.32 AP21-3-6-FG1 (top and bottom fracture surfaces) ......... 103

5.33 Fann viscosity as a function of rotor speed ........... 108 


\section{LIST OF FIGURES--Continued}

Figure

Page

5.34 Hydraulic conductivity of sample AP21-3-6-FGI as a function

of normal stress ............................ 109

5.35 Filter blockage of sample AP21-3-6-FG1 ............. 110

5.36 Hydraulic conductivity of sample AP21-3-6-FG1 before and

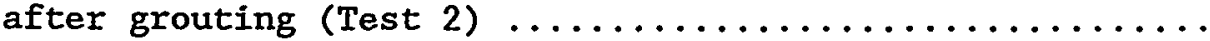

5.37 MC-500 Grout flowing from the fracture of sample AP21-3-6-

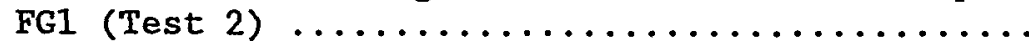

5.38 Surfaces of sample AP21-3-6-FG1 after grouting (Test 2) .. 114

5.39 Filter blockage of sample AP30-2-6-FG10 (Tests 1 and 2) .. 115

5.40 Filter blockage of shimmed sample AP30-2-FG10 (Test 3) .. 116

5.41 Decrease in hydraulic conductivity of sample AP30-2-6-FG10 due to filter blockage (Test 3) ................. 117

5.42 Grouted sample AP36-1-6-FG13 with shims ........... 119

5.43 Clogging of one inch borehole of sawcut sample AP4-1-6-FG2 120

5.44 Ring of cement causing filter blockage of sample AP3-1-6-FG6

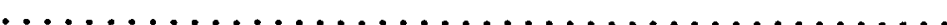

5.45 Grouting of sawcut sample AP3-11-6-FG6 ............. 122

5.46 Shims used to prop open the aperture of sample AP-SHAFT6-FG16 ................................ 124

5.47 Grouted surfaces of shimmed sample AP-SHAFT6-FG16 ...... 125

5.48 Reduction in permeability resulting from grouting of (shimmed) sample AP-SHAFT6-FG16 ................... 126

5.49 Post-grouting surface appearance of sample AP-SHAFT6-FG16

5.50 Hydraulic conductivity vs. normal stress for sample AP56-2-

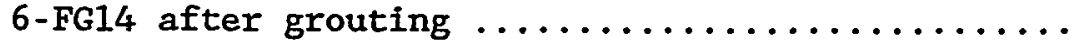

5.51 Filter blockage of sample AP56-2-6-FG14 ............ 130

5.52 Pockets of grout emplaced in sample AP56-3-6-FG15 ....... 131

5.53 Reduction in hydraulic conductivity from grouting

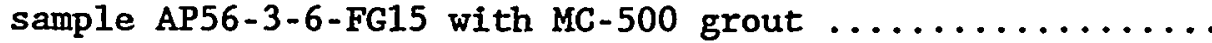


LIST OF TABLES

Table

Page

4.1 Mix Proportions for Grout Formulations .............. 42

4.2 Speed and Time Sequence for Fann Viscometer Measurements . 45

4.3 Slurry Composition for Marsh Viscosity Tests .......... 48

5.1- Results of Falling Head Test on Intact Samples

5.3 AP21-3-6-FG1, AP4-1-6-FG2, and AP10-8-6-FG3 .......... 59

5.4 Results of Flow Testing Intact Sample AP7-1-6-FG4 ....... 60

5.5 Results of Falling Head Test on Intact Sample AP7-2-G-FG5 60

5.6- Results of Falling Head Test on Intact Samples

5.8 AP3-1-6-FG6, TPS-6-FG8, and T-1-6-FG9 ............ 61

5.9 Fracture Permeability and Equivalent Fracture Aperture for Sample AP21-3-6-FG1 with a Tension Induced Fracture ......

5.10 Fracture Permeability and Equivalent Fracture Aperture for Sample AP30-2-6-FG10 with a Tension Induced Fracture .....

5.11 Fracture Permeability and Equivalent Fracture Aperture for Sample AP30-1-6-FGl1 with a Tension Induced Fracture .....

5.12 Fracture Permeability and Equivalent Fracture Aperture for Sample AP36-1-6-FG13 with a Tension Induced Fracture .....

5.13 Fracture Permeability and Equivalent Fracture Aperture for Sample AP4-1-6-FG2 with Sawcut Surfaces .............

5.14 Fracture Permeability and Equivalent Fracture Aperture for Sample AP7-2-6-FG5 with Sawcut Surfaces.$\ldots \ldots \ldots \ldots \ldots$

5.15 Fracture Permeability and Equivalent Fracture Aperture for Sample AP3-1-6-FG6 with Sawcut Surfaces ............

5.16 Fracture Permeability and Equivalent Fracture Aperture for Sample AP2-1-6-FG7 with a Natural Fracture ............

5.17 Fracture Permeability and Equivalent Fracture Aperture for Sample AP56-5-6-FG12 with a Natural Fracture ..........

5.18 Fracture Permeability and Equivalent Fracture Aperture for Sample AP56-2-6-FG14 with a Natural Fracture .......... 


\section{LIST OF TABLES--Continued}

Table

Page

5.19 Fracture Permeability and Equivalent Fracture Aperture for Sample AP56-3-6-FG15 with a Natural Fracture ......... 96

5.20 Uniaxial Compressive Strengths of Cured Grouts ......... 105

5.21 Fann Viscosities of Grout Formulations ............. 106

5.22 Plastic Viscosities and Yield Values of Grout Formulations 106

5.23 Marsh Funnel Viscosities and Bleed Capacities .......... 107

5.24 Groutability Ratios Corresponding to Penetration ........ 133 


\section{ACKNOWLEDGMENTS}

The research reported on has been performed by the University of Arizona, Department of Mining and Geological Engineering, for the U.S. Nuclear Regulatory Commission (NRC). Project monitor for the NRC is Mr. Jacob Philip. The project is under Mr. M. Silberberg, Chief, Waste Management Branch, Division of Engineering, Office of Nuclear Regulatory Research.

Dr. Jaak J.K. Daemen, Associate Professor, Department of Mining and Geological Engineering, University of Arizona, is the Principal Investigator. Dr. James G. McCray, Acting Director, Nuclear Fuel Cycle Research Program, Department of Nuclear and Energy Engineering, University of Arizona, has provided project management assistance and nuclear waste technical assistance. Colin J. Sharpe has performed the theoretical and experimental work as part of his M.S. degree requirements. Experimental assistance has been provided by Robert Morgan, Carrie Anderson, Dave Smith, Baldemar Dagnino, Dave Pelletier, and Kittitep Fuenkajorn. Mike Porter has typed, assembled, and produced the report.

We gratefully acknowledge the assistance of Dowell-Schlumberger, Tulsa, $\mathrm{OK}$, in donating cement and additives, and especially the technical help provided by Mr. Pat Gill and Mr. Tom Griffin. American Colloid Co., Arlington Heights, IL, has provided $\mathrm{C} / \mathrm{S}$ granular bentonite, and Lorra Crave of American Colloid gave valuable advice on some testing procedures.

We gratefully acknowledge the cooperation of Magma Copper Co., and in particular of $\mathrm{Mr}$. Frank Florez, in providing access to their Superior, $\mathrm{AZ}$, property and for allowing us to collect tuff blocks. 

Greek Symbols

$\begin{array}{ll}\alpha & \text { degree of non-linearity in turbulent flow equation } \\ \gamma & \text { unit weight of water } \\ \Delta h & \text { water head difference } \\ \Delta S & \text { piston travel length } \\ \Delta W & \text { weight difference } \\ \in / D & \text { relative roughness } \\ \eta & \text { plastic viscosity coefficient } \\ \theta & \text { angle } \\ \mu & \text { dynamic viscosity } \\ \nabla & \text { gradient operator } \\ \rho & \text { fluid density } \\ \sigma_{\alpha x} & \text { axial stress } \\ \sigma_{n} & \text { normal stress } \\ \tau & \text { shear stress } \\ \tau_{0} & \text { yield strength (cohesion) } \\ v & \text { kinematic viscosity } \\ \psi & \text { friction factor } \\ \text { Roman Symbols }\end{array}$

$\begin{array}{ll}\text { a } & \text { diameter of pipette } \\ \text { 2b } & \text { parallel plate aperture } \\ \text { c } & \text { cohesion or yield value } \\ \text { d } & \text { representative pore length } \\ \text { e } & \text { equivalent fracture aperture } \\ f & \text { correction factor in cubic law flow equation } \\ g & \text { gravitational constant } \\ h^{\prime} & \text { water head } \\ h_{i}, h_{f} & \text { initial and final water head } \\ h_{0} & \text { starting height in falling head pipette } \\ \text { i } & \text { hydraulic gradient } \\ i_{f} & \text { projected hydraulic gradient }\end{array}$




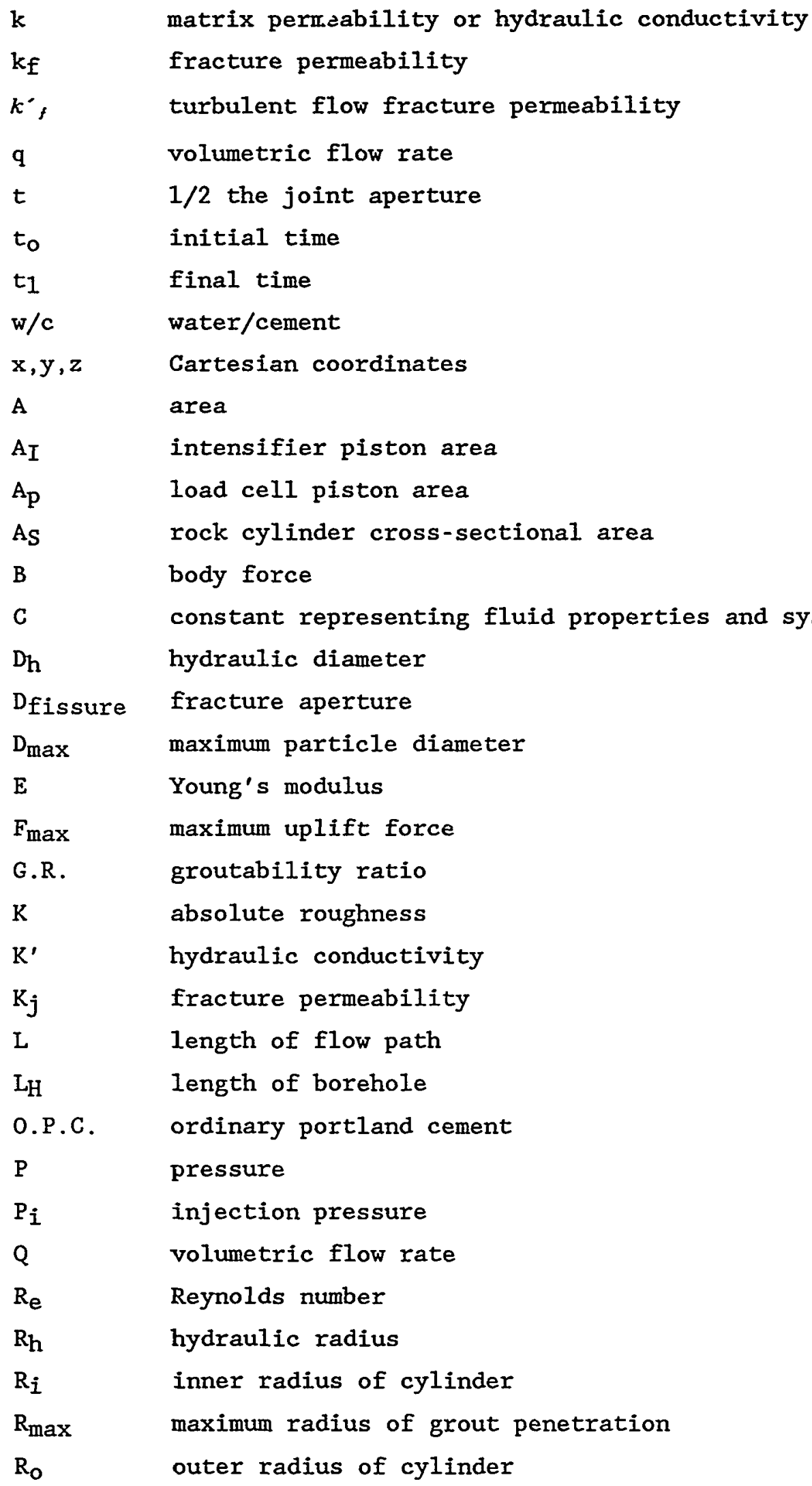


R.R. relative roughness

SD standard deviation

$\mathrm{T}_{1}, \mathrm{~T}_{2} \quad$ initial and final temperatures for viscosity measurements

$\mathrm{V}$ fluid velocity

$\mathrm{V}_{\max } \quad$ maximum volume of injected grout 
EXECUTIVE SUMMARY

1. Introduction

Fractures in the rock mass surrounding a repository and its shafts, access drifts, emplacement rooms and holes, and exploratory or in-situ testing holes, may provide preferential flowpaths for the flow of groundwater or air, potentially containing radionuclides. Such cracks may have to be sealed. The likelihood that extensive or at least local grouting will be required as part of repository sealing has been noted in numerous publications addressing high level waste repository closing (e.g. Koplick et al., 1979; Kelsall et al., 1983, 1985a,b,c). The most explicit and detailed use of fracture grouting for repository sealing probably is given in the conceptual seal designs for the Nevada Nuclear Waste Storage Investigations Project (Fernandez and Freshley, 1984; Fernandez, 1985).

The objective of this work is to determine the effectiveness of fracture sealing (grouting) in welded tuff. Experimental work includes measurement of intact and fracture permeability under various normal stresses and injection pressures. Grout is injected into the fractures. The effectiveness of grouting is evaluated in terms of grout penetration and permeability reduction, compared prior to and after grouting. Analysis of the results include the effect of normal stress, injection pressure, fracture roughness, grout rheology, grout bonding, and the radial extent of grout penetration.

The relationship between normal stress and the permeability of a single fracture is obtained by injecting deaired distilled water into the fracture and monitoring the flow rate as a function of the applied normal stress. Fractured samples are loaded, unloaded, and reloaded incrementally to obtain the dependence of permeability on stress history and normal stress. This is illustrated with graphs of hydraulic conductivity versus normal stress. Alternately, the measurement of fracture closure as a function of normal stress provides information on the fracture closing nature and on the influence of the stress history.

Three types of fracture surfaces are used to investigate the effect of surface roughness on fracture groutability. These fracture types include sawcut surfaces, tension induced and natural fractures. Surface roughness is characterized by measuring the height of asperities on the fracture surfaces. Three dimensional plots of these surfaces provide insight into the rough and tortuous paths that the fluid must follow. Roughness comparisons between the top and bottom faces of a fracture provide an aperture distribution in the form of a topographical plot, which may be used to identify flow paths and their geometry. 
The maximum particle size in a grout slurry dictates its ability to enter a fracture. Mitchell (1970) sets this maximum particle diameter at one third the width of the aperture. In this study, two types of cement are used, type I/II ordinary Portland (OPC) and ultrafine (MC500). These grouts have a maximum grain size of 100 and $10 \mathrm{~m}$, respectively. If the maximum particle size in a grout is too great compared to the fracture aperture, premature grout refusal takes place. Permeability measurements performed on clogged fractures may result in permeability values that are not indicative of the surrounding fracture permeability.

Grout rheology plays a significant role in a grout's ability to enter and travel inside a fracture. Admixtures such as dispersants and water reducing agents are added to a grout to improve performance characteristics such as stability and viscosity.

Water is the main ingredient in a cementitious grout that gives the slurry mobility. Excess water added to transport the grout but beyond the hydration requirements affects strength, stability, surface bonding, and complete void filling. Stability is a measure of the free water that bleeds to the top of the grout slurry during its setting.

Viscosity, a measure of a grout's internal fluid resistance, determines the rate at which a grout travels away from the grout hole. Cohesion, a measure of a grout's interparticle attraction, determines the grout's final distance of penetration (Deere and Lombardi, 1985).

\section{Sample Preparation}

Rock samples are obtained from the densely welded unit of the Apache Leap tuff. Fuenkajorn and Daemen (1991) give the mechanical and petrographical properties of the rocks. Cylindrical tuff specimens with a diameter of $15.2 \mathrm{~cm}$ are obtained by coring tuff blocks parallel to the ash flow layering. A $2.54 \mathrm{~cm}$ borehole is cored coaxially through the samples. Samples have a nominal length of $20 \mathrm{~cm}$. Single fractures are normal to the longitudinal axis of the cylinder. Smooth parallel fractures are created by cutting cylindrical samples at their midsection. Artificially produced tension fractures are created using a modified point load test. Tuff blocks containing single natural fractures are obtained in the field. In the laboratory these blocks are positioned so as to have their fractures perpendicular to the coring direction.

\section{Mix Design and Characterization}

Six grout formulations have been designed for fracture grouting. Water to cement ratios for these mixes vary from 0.45 to 1.0 . Mixing proportions are given with respect to the weight of cement.

Admixtures are added to improve grout performance. $C / S$ granular bentonite used to stabilize OPC grouts is added in amounts ranging from zero to five percent. One percent D65 (a dispersant) is added to OPC grouts to reduce sedimentation. One percent NS-200 (napthalene sulphonate) is 
added to MC-500 grouts to decrease viscosity. Mix formulations can be found in Section 4.4.3. Mixing is performed in accordance with American Petroleum Institute Specification No. 10 (API, 1986).

\section{Experimental Results}

Fracture permeability and intact rock permeability are given in Tables 5.9 through 5.19 and Tables 5.1 through 5.8, respectively. Table 5.20 contains results of 7,8 and 28 day uniaxial compressive strength testing in addition to fluid densities. Table 5.21 contains results of viscosity measurements as a function of rotor speed. Table 5.22 contains results of plastic viscosity and cohesion tests. Table 5.23 contains Marsh funnel viscosities and bleed capacities for various grout formulations. Section 5.4 contains three-dimensional plots of the surface roughness of a tension-induced fracture. Included are topographical plots of the fracture's surface elevations.

\subsection{Fracture Grouting}

Sample AP21-3-6-FG1. Test 1 - Grouting of the tension induced fracture in sample FGI was conducted at an injection pressure of $5.0 \mathrm{MPa}$ under a normal stress of $2.0 \mathrm{MPa}$ with mix number three. Fracture blockage at the inlet of the fracture allowed no grout to enter the fracture and resulted in a misleading apparent reduction in permeability. The groutability ratio for this test was 0.04 .

Test 2 - MC-500 grout was injected into the borehole at a pressure of $0.62 \mathrm{MPa}$. The normal stress on the fracture was held at $1.5 \mathrm{MPa}$. Grout flowed from the fracture. After curing and permeability testing, an increase in flow rate was observed and is possibly attributed to a misalignment of the fracture surfaces prior to grouting.

Sample AP30-2-6-FG10. Tests 1 and 2 - Two attempts at grouting sample FG10 with MC-500 grout resulted in filter blockage with the formation of a characteristic ring of cement at the entrance to the fracture. The groutability ratio for these tests was 0.65 .

Test 3 - In an attempt to increase the aperture of this sample, shims were placed on the fracture's surface. The groutability ratio for this shimmed sample was 4.19. No grout flowed into the fracture and inspection revealed that filter blockage was again present.

Sample AP4-1-6-FG2. Sawcut sample FG2 was grouted with mix formulation one at an injection pressure of $4.5 \mathrm{MPa}$ and under $2.0 \mathrm{MPa}$ normal stress. This test corresponds to a groutability ratio of 0.01 . Filter blockage was again evident.

Sample AP3-1-6-FG6. Test 1 - Sawcut sample FG6 was grouted at an injection pressure of $4.0 \mathrm{MPa}$ under a normal stress of $0.43 \mathrm{MPa}$ with mix formulation two. Filter blockage occurred in the borehole. Only clear bleed water traveled through the fracture. 
Test 2 - This second attempt to grout sample FG6 was performed at an injection pressure of $3.5 \mathrm{MPa}$ under a normal stress of $0.23 \mathrm{MPa}$ with mix formulation three. As before, only clear bleed water traveled through the fracture due to filter blockage.

Sample AP-SHAFT6-FG16. Sawcut sample FG16 was grouted with MC-500 grout at a normal stress of $1 \mathrm{MPa}$ and an injection pressure of $2.1 \mathrm{MPa}$. This sample had its aperture propped open to correspond to a groutability ratio of 4.8. Grout flowed from the fracture but did not completely seal it, due to the high bleed capacity of the grout and the resulting inability for the grout to bond with the upper portion of the fracture.

Sample AP56-2-6-FG14. Natural fracture sample FG14 was grouted at an injection pressure of $6 \mathrm{MPa}$ under $5 \mathrm{MPa}$ normal stress. Grout penetrated the fracture for a distance of 1.5 to $2.0 \mathrm{~cm}$, and created a vertical fracture in the top half of the sample. This vertical fracture is responsible for the increase in permeability after grouting.

\section{Conclusions and Recommendations}

\subsection{Flow Testing}

Intact tuff samples show a decrease in hydraulic conductivity with increasing stress. This decrease is presumably due to closing of pore spaces and pre-existing microfractures within the rock as the normal load increases. Intact tuff permeabilities are at least four to eight orders of magnitude lower than those of fractures, even at high normal stress, and are therefore neglected in the fracture permeability calculations.

Results of permeability testing indicate that fracture closure depends on the stress history of the fracture. Testing shows aperture reductions with each new loading cycle (at least for the two cycles to which most testing was limited). This is presumably due to fracture deformation, although the maximum normal stress never exceeded $35 \%$ of the rock's uniaxial compressive strength.

Equivalent fracture apertures are calculated from the measured inflow through the application of the cubic law. A lack of complete saturation could be responsible for the apparent reduction in equivalent fracture aperture. Future testing should include the measurement of outflow as well as the degree of saturation. In general, it would be desirable to determine a complete water (and grout) mass balance.

Fracture closure is observed to be time-dependent. This phenomenon is evident by the waiting time needed to allow permeability measurements to become quasi-steady-state and by observations during fracture closure measurements. Time dependence is most severe at each initial change in normal stress. Measurements of this time dependence were not obtained due to the initial interest in only the steady-state values. Further testing should include some measurement of this phenomenon. 
The greatest reduction in flow rate through fractures is observed at low normal stress. This behavior is presumably due to initial surface mating. This closing phenomenon parallels fracture compression results (Section 5.3) where two distinct stiffness regions are observed, with remarkable repeatability for both, and with a well-defined transition stress between the two.

\subsection{Grouting}

Grouts with high water-to-cement ( $w / c)$ ratios suffer from excess bleed water, which affects bonding to the upper fracture surfaces. The use of ordinary Portland cement (OPC) grouts with greater w/c ratios (up to $0.9)$ did not increase grout admittance.

The addition of bentonite (2-58) to OPC grouts with various $w / c$ ratios $(0.6$ to 0.9 ) reduces bleed water to less than 18 , but causes a marked decrease in uniaxial compressive strength. This decrease in strength is due to the increase in bentonite content, as well as the increasing $\mathrm{w} / \mathrm{c}$ ratio.

Comparisons between the grout slurries' rheologic properties is hardly possible due to differing $w / c$ ratios and bentonite contents. Future testing should include characterization of grout properties at similar w/c ratios.

Results from over ten grouting tests confirm the extreme difficulty in emplacing OPC grouts in tight fractures. Attempts at emplacing ultrafine grout (MC-500) fare somewhat better than OPC grouts, although filter blockage occurred with all grouting attempts when the groutability ratio was less than three.

Filter blockage was a prevailing problem, with the formation of a characteristic ring of cement at the entrance to the fracture. Accompanying this type of blockage was an apparent reduction in permeability not indicative of the surrounding fracture permeability.

Future laboratory studies of fracture grouting should include investigations of grout distributions along fractures by relating preferential flowpaths and flowpath dimensions, as determined from fracture surface roughness characterizations, with grout distributions. Permeability, durability, and longevity testing should be performed to confirm the usefulness of cementitious grouts for nuclear waste repository sealing. Such durability studies should include determination of the mechanical resistance of grout emplaced in fractures, and of the chemical resistance, e.g. by leach studies. 
CHAPTER ONE

\section{INTRODUCTION}

The Nuclear Waste Policy Act of 1982 requires the Department of Energy to develop the technology to ensure safe and permanent disposal of HLW. Proposed HLW repository designs must be economically feasible, while inspiring a high degree of confidence that all performance requirements can be satisfied.

The Department of Energy's (DOE) principal design goals for seals in an unsaturated medium, such as at the proposed Yucca Mountain site should be (1) prevent significant amounts of surface or groundwater from reaching emplaced waste, and, (2) prevent significant amounts of gaseous radionuclides from escaping through shafts, ramps, and boreholes to the accessible environment (Gupta and Buckley, 1989).

Grouting, the emplacement of a cementitious or chemical slurry, is one of the proposed means of forming a water- and air-tight barrier between the waste and the accessible environment. Grouting may be used to create or augment the multibarrier system that will be needed. Admixtures most probably will be added to the grout slurries to enhance material properties and improve flow characteristics to aid in their emplacement. Such additives include expansive agents used to reduce syneresis, plasticizers, accelerators, and pozzolans used to reduce porosity while increasing strength and durability.

Cement based grouts are considered most appropriate for sealing due to their known material properties and well documented longevity and durability. The use of chemical grouts is still in question due to their unknown stability over long periods of time. Chemical grouts, however, posses desirable characteristics such as high strength and bonding properties, impermeability, and low viscosity, needed for grout emplacement.

Anticipated performance characteristics of emplaced grout should be (Gyenge, 1980):

- form a dense, impermeable solid,

- low wetting, drying and thermal shrinkage,

- sufficient deformability to allow for rock movement without developing cracks,

- a coefficient of thermal expansion similar to that of the surrounding rock,

- inert to sulfate, $\mathrm{H}^{+}$, chloride ions, and other sulfates in the groundwater of the disposal site,

- low leach rate in the presence of groundwater,

- good bonding strength, 
- the ability to immobilize radionuclides by sorption or other means, and

- exceptionally long-term durability.

Grouting may be needed to seal connecting fracture networks around the waste repository to deter or slow down groundwater inflow and to eliminate flowpaths that may allow migration of gaseous radionuclides. Grouting can also improve rock mass strength and stability.

Other applications for grouting involve the sealing of access routes needed for repository construction and waste emplacement as well as seals for boreholes used to characterize the host rock and evaluate its suitability. Desired performance characteristics of seals include low hydraulic conductivity, physical properties that will retain sealing effectiveness under natural and thermally induced states of rock stress, chemical compatibility with groundwater and host rock as well as resistance to erosion under hydraulic heads up to several MPa (Gnirk, 1988).

Common uses of grouting include civil engineering projects such as underground containment caverns and tunnels. For dam construction and remedial repair, grout curtains are used to reduce destabilizing uplift pressures while reducing water losses. Grouting is used in foundation control to stabilize and consolidate soil masses as well as to lift and level building foundations. Mining applications include rock mass stabilization, the backfilling of drift liners (contact grouting), and the control of groundwater inflow.

This report presents a study of cementitious grouts used to seal single fractures in welded tuff (a proposed nuclear waste repository host rock). The objective of the grouting is to reduce fracture permeability. Experimental work includes the measurement of permeability of intact welded tuff and of fractures under ranges of normal stresses and injection pressures, the determination and characterization of fracture roughness, and the injection of grout into the fractures. The effectiveness of grouting is evaluated in terms of the permeability reduction as well as by visual inspection of bond quality and grout penetration and distribution. Results are analyzed to study the effects of normal stress, injection pressure, fracture roughness and grout formulations on sealing effectiveness.

Chapter Two contains a review of the basic concepts of fluid flow through rock and of factors affecting permeability, such as aperture, contact area, and surface roughness. Equations used in this study to calculate permeability are presented.

Chapter Three contains a review of fracture grouting practices. Grout mix design and fracture characterization are discussed.

Chapter Four presents the experimental procedures, such as sample preparation, permeability testing, grout preparation and characterization, as well as fracture characterization and fracture compression behavior. 
Chapter Five includes the results. Chapter Six presents conclusions drawn as well as suggestions for future work.

Appendix A gives methods to calculate normal stress on the fracture and permeabilities of the rock sample and fracture, based upon the presented test configurations. Appendix B gives the sample designation coding system. 
CHAPTER TWO

\section{FLUID FLOW IN FRACTURED ROCK}

\subsection{Introduction}

Modeling the flow of fluids through rock and soil is a difficult task due to the inability to easily and accurately define the flow system. It is not within the scope of this report to review the voluminous work on this subject, but only to briefly describe important aspects needed to characterize permeability and grouting.

\subsection{Theory of Fluid Elow Within a Single Fracture}

The flow of an incompressible viscous fluid through rock fractures is generally modeled as flow between open, smooth parallel plates (Snow, 1965; Louis, 1969, 1974; Maini, 1971; Zeigler, 1976, Iwai, 1976; Witherspoon et al., 1980). Gale et al. (1985) provides an excellent review of the literature on this subject.

A common approach to the flow analysis starts by considering the NavierStokes equations. The basic assumptions are that flow is governed only by mechanical and thermal energy within the system, the flow is isothermal, the flow is Newtonian and homogeneous, and Stokes' equation is valid (Bawden and Roegiers, 1979).

For most boundary conditions, the Navier-Stokes analysis of flow behavior becomes cumbersome and difficult, making a Darcy parallel plate model analysis more attractive. Darcy's law describes flow of a viscous incompressible fluid in a porous medium. Darcy showed experimentally that the rate of water (q) flowing through clean sand of cross sectional area (A) is proportional to the imposed hydraulic gradient (i) (Holtz and Kovacs, 1981):

$$
\begin{gathered}
\frac{q}{A} \sim i \\
q=K i A
\end{gathered}
$$

The coefficient of proportionality $k$ has been called the permeability.

Darcy's relationship can be expressed for fracture flow as (Louis, 1974):

Laminar or steady flow:

$$
V=k_{f} i_{f}
$$


Turbulent flow:

$$
V=k_{f}^{\prime}\left(i_{f}\right)^{\alpha}
$$

where $V$ stands for the mean velocity, $k_{f}$ for the fracture permeability, $k^{\prime} f$ for the turbulent fracture permeability, $i_{f}$ for the perpendicular projection of the hydraulic gradient on the plane of the fracture, and $\alpha$ for the degree of non-linearity.

As previously implied, the Darcy relation (Equation 2.1) is valid if the fracture behaves similarly to a porous medium. This empirical flow relation can be derived directly from the Navier-Stokes equation by taking an average velocity of flow instead of velocities for each fluid particle, provided the inertia forces are negligible and the flow is steady state (Iwai, 1976). Mongan (1985) verified the validity of this equation through application of Hankel transforms to linearized Navierstokes equations for transient flow conditions.

If the flow is steady and isothermal, the flux per unit drop in head can be developed from Darcy's law and may be written in simplified form as (Witherspoon et al., 1980):

$$
q=C(2 b)^{3} \Delta h
$$

where $C$ represents the geometry of the system and the fluid properties, $2 \mathrm{~b}$ is the fracture aperture, and $\Delta h$ is the hydraulic head difference.

In the case of radial flow:

$$
C=\left(\frac{2 \pi}{\ln \left(\frac{R_{0}}{R_{\imath}}\right)}\right)\left(\frac{\rho g}{12 \mu}\right)
$$

where $R_{i}$ and $R_{0}=$ initial and final radii of flow path

$\rho=$ fluid density

$g=$ universal gravitational constants

$\mu=$ fluid viscosity.

and in the case of straight flow:

$$
C=\left(\frac{W}{L}\right)\left(\frac{\rho g}{12 \mu}\right)
$$

where $W, L=$ width and length of flow path.

The flow rate through an open fracture is a function of the aperture, the hydraulic gradient and the roughness of the fracture surfaces. Iwai (1976) showed that fracture permeability is a unique function of the fracture aperture independent of the loading path or how the loading is 
repeated. Conversely, no two different apertures will result in the same permeability given identical hydraulic gradients and surface roughness.

In actual rock fractures, the surfaces are far from smooth, and the validity of the cubic law is in question. For flow in open fractures, the transition from laminar to turbulent takes place at very low Reynolds numbers ( 100 or even 10$)$, decreasing as the relative roughness of the fracture increases (Louis, 1974).

The Reynolds number $\left(R_{e}\right)$ as defined by Louis $(1976$, p. 54) is:

$$
R_{\mathrm{e}}=\frac{V D_{h}}{\mu}
$$

where $V=$ mean fluid velocity, $\mu=$ dynamic viscosity, and $D_{h}=$ hydraulic diameter. This number is difficult to determine since it can vary from point to point along a fracture for a given type of flow.

For flow through a porous medium, the Reynolds number is defined as:

$$
R_{\mathrm{e}}=\frac{q d}{v}
$$

where $q=$ specific discharge

$\mathrm{d}=$ representative length of the porous media

$v=$ kinematic viscosity.

Darcy's law is valid in porous media as long as the Reynolds number does not exceed some value between 1 and 10 (Bear, 1972, p. 127).

Lomize (1951 as referenced by Gale et al., 1985) introduced the concept of relative roughness $(\epsilon)$ which he defined as the ratio of the absolute height of the surface asperities to the fracture opening or aperture (2b). The aperture was calculated by dividing the volume of fluid contained in the fracture by the length and width of the fracture. He demonstrated the validity of the cubic law as long as the flow remained laminar and presented the empirically derived roughness equation:

$$
\psi=\frac{96}{R_{e}^{\prime}}\left[1+6.0\left(\frac{E}{2 b}\right)^{1.5}\right]
$$

which is valid for $\epsilon / 2 b>0.065$

and where $R_{e}^{\prime}=R_{e} / 4$

$\psi=$ friction factor. 
Louis (1976) contributes to Lomize's concept of relative roughness while defining different flow regimes corresponding to the Reynolds number. He provides empirical equations to describe the flow in each regime, as illustrated in Schaffer and Daemen (1987, Fig. 2.1). The relative roughness (R.R.) is defined by Louis as:

$$
R \cdot R \cdot=\frac{K^{\prime}}{D_{h}}
$$

where $K^{\prime}$ - height of the asperities or absolute roughness

$D_{h}=$ hydraulic diameter -4 times the hydraulic radius or 2 times the aperture.

Other workers have performed flow experiments to establish the laws of flow in similar flow regimens. Flow laws for parallel plate models are summarized by Iwai (1976).

Contact area is of great importance in defining apertures and the area available for flow. Under compression as the fracture surfaces come in contact and the surface asperities begin to mesh the flow is effectively halted at these points. Sharp and Maini (1972) describe contact area as dead water areas, which divide the fracture into discrete flow channels, such that the flow is effectively concentrated within a limited area of the joint. This resulting flow area is termed effective flow area. The geometry of the effective flow area dictates the paths or channels available for fluid movement. The surface roughness induces numerous changes in flow direction. These changes account for the increase in travel distance required for the fluids tortuous path and the associated pressure drop away from the initial flow potential.

Detournay (1980) carried out a regression analysis on calculated conductivity coefficients and joint closure data under straight flow conditions and found the parallel-plate cubic law to be valid provided that one introduces an initial aperture, which is computed from the conductivity-closure data.

Witherspoon et al. (1980) analyzed Iwai's data and concluded that the cubic law was valid (down to apertures of $4 \mathrm{\mu m}$ ) whether the fracture surfaces were held open or were closed under stress. The effect of deviating from the ideal parallel plate concept only caused an apparent reduction in flow and could be accounted for by incorporating into the cubic law a factor $f$, which varied from 1.04 to 1.65 :

$$
\frac{Q}{\Delta h}=\left(\frac{C}{f}\right) e^{3}
$$

where $e$ is the equivalent fracture aperture. 
GHAPTER THREE

FRACTURE GROUTING

\subsection{Introduction}

This chapter deals with cement grouts. Their well documented material behavior and longevity are important to satisfy design criteria for underground nuclear waste repositories. Chemical grouts are not evaluated because of their high cost, toxicity, and unknown longevity (Gnirk, 1988), even though they offer advantageous properties such as low viscosity, low permeability and good surface bonding (Karol, 1982).

For successful grouting, grout slurries must be fluid enough to be efficiently pumped at limited pressures. Their maximum grain size must allow admission into fractures without premature clogging. The hardened grout must possess performance characteristics such as complete void filling, impermeability, bond strength, and longevity.

\subsection{Grouting Pressure}

Grout under pressure stresses the rock mass. Injection pressures not under control can quickly get the grouter into trouble. Particular attention must be paid to ground movement when grouting in the vicinity of the surface, near surface structures or near underground excavations.

Rules of thumb can be used to select appropriate injection pressures. They must be site tested to confirm their suitability. Figure 3.1 shows maximum allowable grouting pressures dictated by rock mass strength and hole depth.

High injection pressures are condoned by European grouting experts (approximately four times greater than pressures accepted by U.S. engineers) (Shannon and Wilson, Inc., 1987). Pressures of up to $4.4 \mathrm{psi}$ $(30.3 \mathrm{kPa})$ per foot of depth are deemed necessary to dilate fractures so they will accept grout. High pressures are assumed to squeeze out and drive off excess bleed water so as to achieve better grout filling in the fractures. In addition to this, lower water to cement ratios can be used with higher injection pressures.

Confidence can be placed in using higher injection pressures since this process requires grout flow and pressure meters to be watched diligently so that any hydrofracturing can be identified early (Deere, 1982). At any sudden increase in flow or drop in pressure, the pumping pressure can be lowered immediately, thus avoiding fracture propagation and ground movement. 


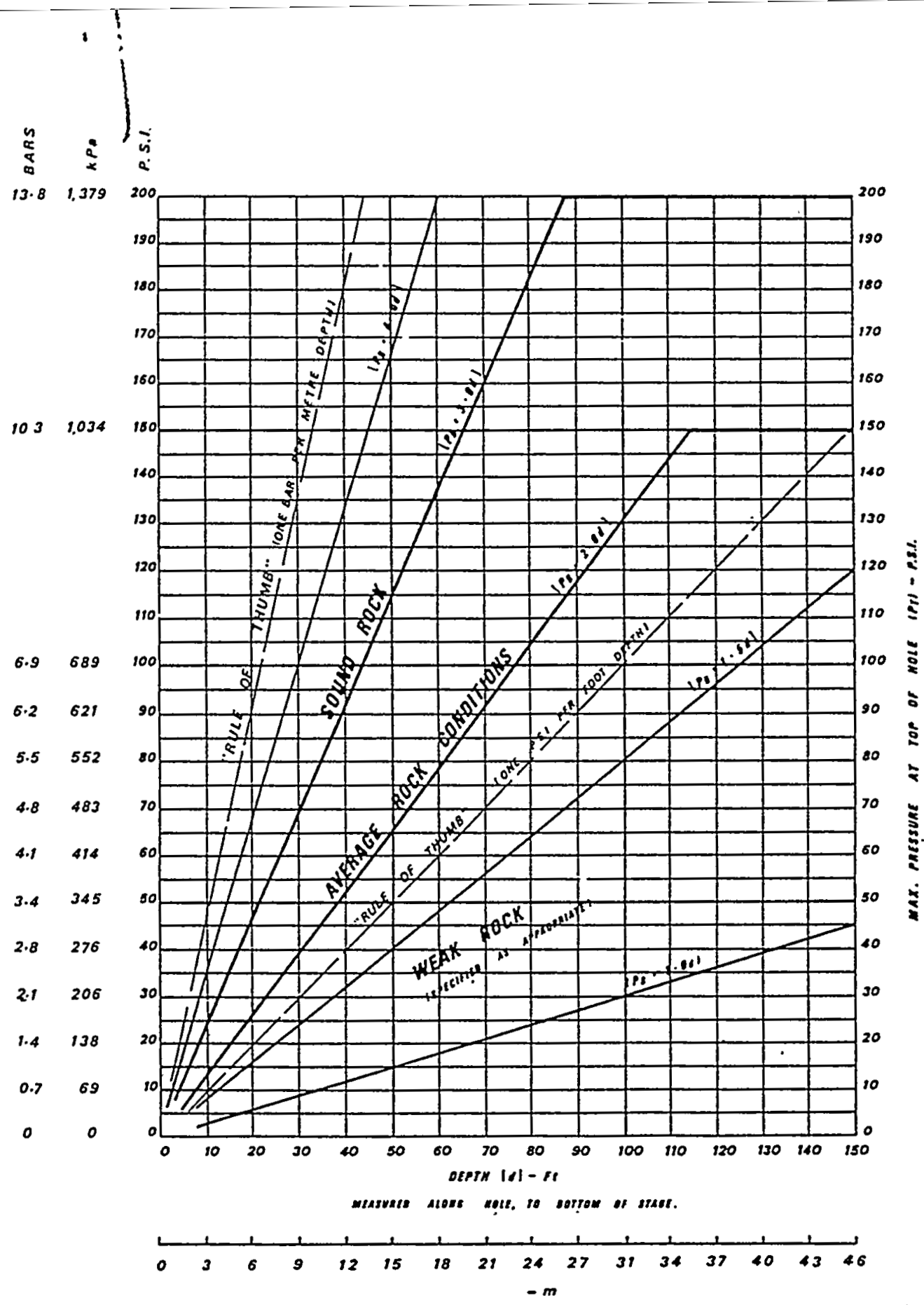

Figure 3.1 Maximum allowable grouting pressures.

(Reprinted by permission of Thomas Telford, Ltd., from A.C. Houlsby, 1977, "Towards Appropriate Metric Units for Grouting," Ground Engineering, July, Figure 2, p. 41. Copyright 1977, by Thomas Telford, Ltd., London.) 


\subsection{Grout Mix Design}

\subsubsection{Water to Cement Ratio}

Water is the main ingredient that gives a slurry mobility. After the transportation role of water has ended and the grout is positioned where it will stay, excess water not needed for cement hydration and curing detrimentally affects grout bonding, strength, shrinkage, durability, and permeability. The greater the amount of water used the more severe these problems become (Houlsby, 1985).

The effect of the water to cement (w/c) ratio on compressive strength, viscosity, and bleed capacity of cement slurries is well documented (Farmer, 1970; Littlejohn, 1982) (Figure 3.2). w/c ratios are defined as a volume or weight ratio. Thin grouts with w/c ratios greater than $1: 1$ and up to $9: 1$ by weight are not uncommon and allow considerable grout travel. When grouting pressures are reduced, fracture dilation is reduced and excess or bleed water is presumably squeezed out. Thick grout advocates question this line of thought and try to avoid excess fracture dilation and potentially dangerous hydrofracturing that can actually increase rock mass permeability by fracture propagation.

Thick grouts are usually defined as grouts with water to cement ratios of $0.5: 1$ to $1: 1$. Without high grouting pressure and large fracture dilation, the penetration and fracture admittance of thick grouts are basically limited by the maximum grain size of the grout (Karol, 1985). Too thick a grout can cause inadequate penetration and premature fracture blockage. Too thin a grout can cause excessive penetration which wastes grout and increases the possibility of rock movement.

Based on examination of grout films obtained in the U.S. Army Corps of Engineers research in regard to durability and sealing effectiveness, the use of a final w/c ratio greater than $1: 1$ is not desirable. The bleed water from these grouts becomes trapped in the grout film and reduces the area available for complete cement filling (Kennedy, 1958).

Houlsby (1982a) references numerous case histories where large w/c ratios used in dam grouting produced grout films that had completely leached away. The view that bleed water is driven off during grouting was not supported.

It is worthwhile to note that numerous case histories record the success of both w/c ratio methods. No one method can be singled out as being superior. However, it is desirable to use the lowest w/c ratio and injection pressure that will get the job done (Houlsby, 1982b; Deere and Lombardi, 1985). In the field, pressure tests, fracture openings and grout takes on previous grout holes help determine the lowest w/c ratio that can be started with to ensure that filter blockage and loss of the grout hole does not take place. As the rate of grout take increases and pressures decrease the grout mix is slowly thickened to grout refusal. 


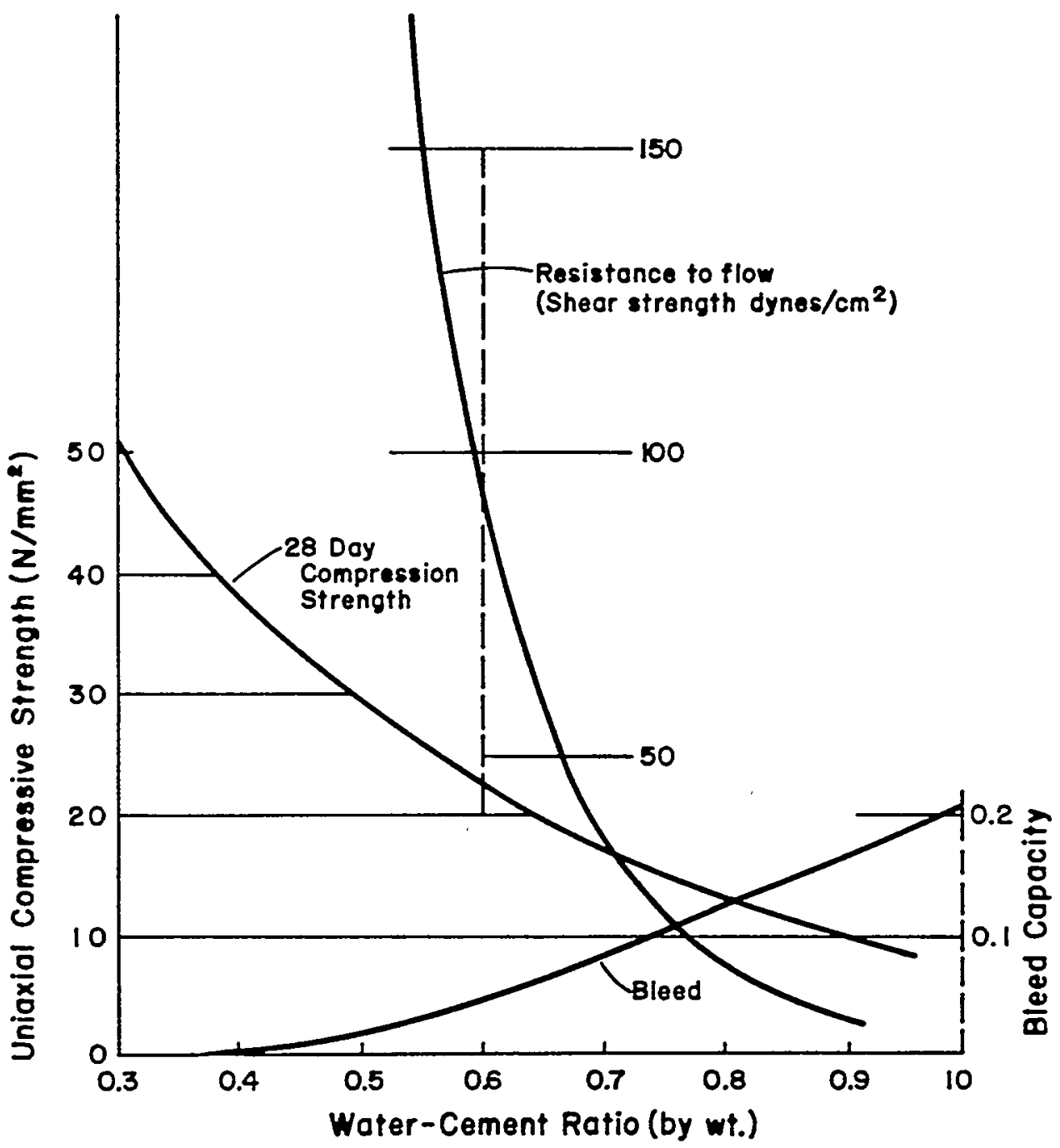

Figure 3.2 Effect of water-cement ratio on grout properties. (After Farmer, 1970, p. 5). 


\subsubsection{Cement Type}

Appropriate cement types are site dependent and must be chosen on the basis of maximum grain size versus fracture opening, depth at which grouting will take place, intended admixtures used to improve flow properties, geochemical and thermal compatibility with the country rock in regard to nuclear waste storage, and appropriate resistance to leaching and chemical attack, especially in the presence of salts, sulfates and sulfides.

Once an approximation of the average aperture of the fractures has been made then the performance of a selected cement type can be evaluated in terms of its ability to penetrate the fracture. Mitchell (1970) defines the groutability ratio (G.R.) as:

$$
G \cdot R \cdot=\frac{D_{\text {fissure }}}{\left(D_{\max }\right)_{\text {grout }}}
$$

where $D_{\text {fissure }}=$ fracture aperture

$$
\left(D_{\max }\right)_{\text {grout }}=\text { maximum grout particle size. }
$$

For successful penetration this ratio of fissure aperture to maximum particle size must be greater than about 3. This ratio corresponds to an aperture of $0.3 \mathrm{~mm}$ as the lower limit of penetration for ordinary portland cements. Shannon and Wilson, Inc. (1987) also set this limit at $0.3 \mathrm{~mm}$ for grouts without a lubricating additive. The Consulting Engineer (1969) sets this lower limit at $0.1 \mathrm{~mm}$, which corresponds to a groutability ratio of 1.0 . In the case of ultra fine cements, the groutability ratio predicts a lower limit of penetration into apertures of $0.03 \mathrm{~mm}$ (Shimoda and Ohmori, 1982).

In theory, when the groutability ratio is less than 3 the entrance to the fracture becomes clogged with cement. This phenomenon is known as filter blockage. Karol (1985) defines this no flow situation as "blinding". A few larger particles in the slurry try to enter the fracture at the same location at the same time, causing the crack to become clogged, and resulting in premature refusal of cement.

\subsubsection{Admixtures}

Admixtures are used to improve the flow properties of the grout. Bentonite, a colloidal material prepared from montmorillonite clays, transforms sedimentation unstable grouts to sedimentation stable grouts (Cambefort, 1977). Stable grouts are desirable. They do not settle out and clog grout lines, and help in the complete filling of voids. Lombardi (1985) states that bentonite increases viscosity and cohesion, thereby limiting the extent of grout travel. 
Other commonly used admixtures include accelerators that speed up set time by increasing the rate at which chemical reactions occur, dispersants and inhibitors that reduce interparticle attraction, thereby slowing down set, emulsifiers and wetting agents that modify surface tension of the grout particles to reduce sedimentation and facilitate penetration, fluidifiers which improve flowability without changing the water-to-cement ratio, expansive agents that reduce shrinkage and cracking, and fillers that increase grout volume while reducing total grout cost.

\subsection{Grout Rheolegy}

Probably the most important rheological properties of a cementitious grout slurry in regard to penetration and grout travel are viscosity and cohesion. As the water to cement ratio of a cementitious grout slurry is increased the viscosity and cohesion decrease.

In the field the Marsh funnel is used to measure the apparent viscosity of a grout slurry. The term apparent is used because what is measured is a combination of rheological properties (viscosity, rigidity, and specific weight) of the slurry, as well as the effect of the roughness of the flow cone (Cambefort, 1977). Lombardi (1985) found that cohesion, which is analogous to rigidity, is generally low. The flow time through the Marsh funnel is approximately a function of the viscosity only. No information on the cohesion value results from the Marsh test. Many different types of flow cones are used in industry and results are hardly comparable. A rotary or coaxial viscometer is used to obtain the actual viscosity and cohesion in the laboratory.

Bentonite markedly increases the viscosity of grouts and must be accounted for in all measurements (Consulting Engineer, 1969). Deere (1982) also found that bentonite appreciably increases the funnel viscosity of a grout slurry. Viscosity is an important index property for quality control of field mixes, particularly of the bentonite content.

According to Deere and Lombardi (1985), the radial penetration and rate of penetration of a grout mix are governed by the cohesion, $\tau_{0}$ and dynamic viscosity, $\mu$. A stable grout slurry is characterized as a viscoplastic or Bingham fluid with rheological properties controlled by viscosity and cohesion. It is well established that under conditions of laminar flow that cementitious grouts behave in a similar manner to Bingham fluids (Deere and Lombardi, 1985; Farmer, 1970; Nonveiller, 1989). Figure 3.4 shows the flow behavior of Newtonian and Bingham fluids. The shear stress $(\tau)$ needed to overcome the cohesion of the grout slurry and cause flow at a constant rate of strain (Figure 3.4 ) is given by:

$$
\tau=\tau_{0}+\eta \frac{d v}{d z}
$$




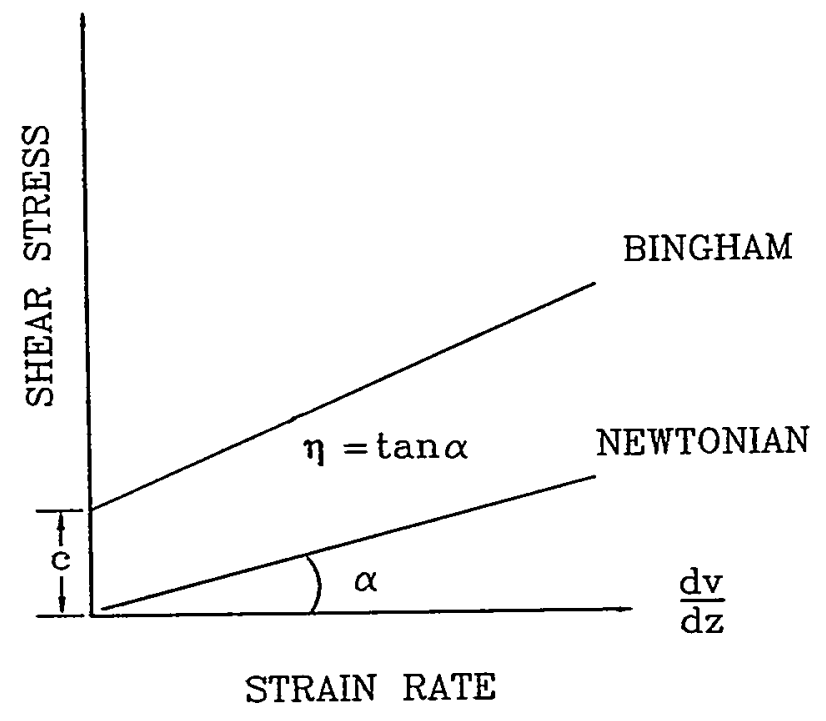

Figure 3.3 Flow behavior of Newtonian and Bingham fluids.

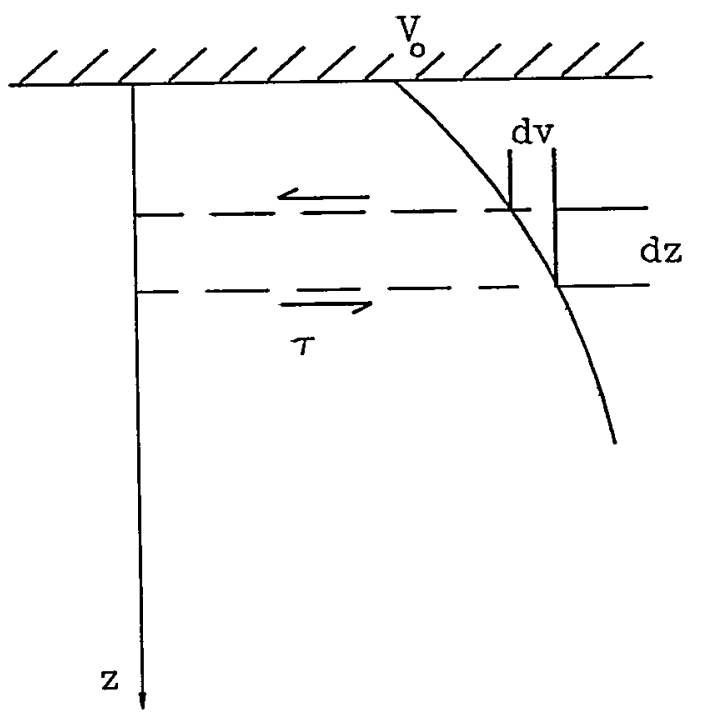

Figure 3.4 Flow velocity cross section. 
where

$$
\begin{aligned}
& \tau_{0}=\text { yield strength (cohesion) } \\
& \eta=\text { plastic viscosity coefficient } \\
& \frac{d v}{d z}=\text { velocity gradient (rate of strain). }
\end{aligned}
$$

The viscosity component determines the flow rate at which a grout travels away from the grout hole under a given pressure and aperture. The cohesion determines the final distance of penetration. Lombardi (1985), Wallner and Wittke (1974), and Ruiz and Leone (1970) develop equations which allow an approximation of the maximum radius of penetration $\left(R_{\max }\right)$, the maximum volume of injected grout $\left(\nabla_{\max }\right)$, and the maximum total uplift force $\left(F_{\max }\right)$, to be computed:

$$
\begin{gathered}
R_{\max }=\frac{P_{\max } t}{c} \\
V_{\max }=\frac{2 \pi P_{\max }^{2} t^{3}}{c^{2}} \\
F_{\max }=\frac{\pi P_{\max }^{3} t^{2}}{3 c^{2}}
\end{gathered}
$$

where $\quad P_{\max }=$ final injection pressure

$t=1 / 2$ the joint thickness (aperture)

$c=$ cohesion (yield strength) $=\tau_{0}$.

These equations are developed from an equilibrium of forces and correspond to empirical findings on grouting jobs (Lombardi, 1985) Assumptions include the use of stable grout on a single dry rough horizontal open planar joint with laminar flow. These equations are valid for fractures that are wider than the maximum grain size in the grout. Figure 3.5 shows the maximum radius of penetration as a function of grout consistency. Thin, medium, and thick grouts correspond to Marsh flow times of 30,40 , and 50 seconds respectively.

The only rheological property of the grout slurry needed to use the above equations is the cohesion or yield strength. This value may be obtained with a rotary viscometer or with a plate cohesion meter developed by Lombardi (1985). The latter simple test is readily used in the field. 


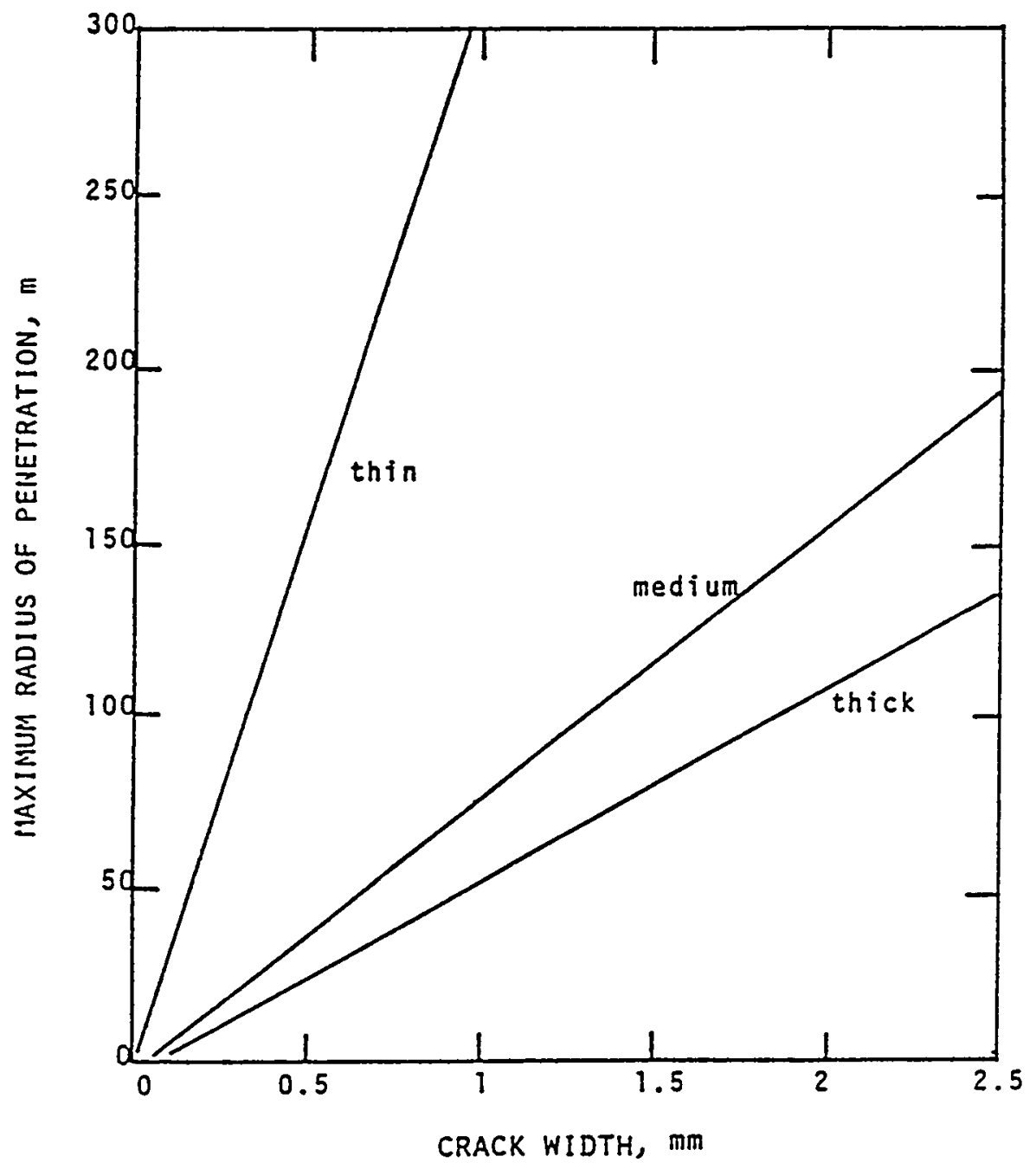

Figure 3.5 Maximum radius of penetration as a function of crack width and grout consistency (After Deere and Lombardi, 1985, p. 11).

(Reprinted by permission of American Society of Civil Engineers, D.U. Deere and G. Lombardi, 1985, "Grout Slurries - Thick or Thin?" Issues in Dam Grouting, W.H. Baker, ed., Figure 4, p. 11.

Copyright 1985, by American Society of Civil Engineers, New York.) 
CHAPTER FOUR

\section{EXPERIMENTAL PROCEDURES}

\subsection{Sample Preparation}

The rock samples used in this study are from the densely welded brown unit of the Apache Leap tuff. Fuenkajorn and Daemen (1991) give mechanical and petrographical properties of the rock, and the location from which it was obtained.

\subsubsection{Intact Samples}

Cylindrical tuff specimens are obtained by coring tuff blocks parallel to the ash flow layering using a $15 \mathrm{~cm}$ inside diameter diamond coring bit. Samples have a nominal length of $20 \mathrm{~cm}$ (Figure 4.1 ). Figure 4.2 shows the measurement scheme. Figure 4.3 shows the $3 \mathrm{HP}$ Acker and $2 \mathrm{HP}$ Century drills used to core samples.

A $2.54 \mathrm{~cm}$ diameter borehole cored through the axis of the sample provides access to the interior of the sample. Boreholes are closed off at the bottom of each sample using a tuff and epoxy adhesive plug.

To ensure even loading during testing, the ends of each cylinder are ground parallel and flat using a Kent automatic surface grinding machine (Figure 4.4). Figure 4.5 shows a prepared sample.

\subsubsection{Fracture Creation}

Three types of fracture surfaces are used in this study: sawcut, tension induced and natural fractures. Even though sawcuts are not true fractures, they will be referred to as such. Fractures are normal to the longitudinal axis of each cylinder.

Sawcuts are made using a Covington diamond saw (Figure 4.6). Alignment marks are placed on each sample prior to cutting to ensure correct orientation during testing. Figure 4.7 shows the resulting sample halves with smooth sawcut surfaces.

Artificially produced tension fractures are created using a modified point load test. Figure 4.8 shows the equipment used to create such fractures. Two $5 \mathrm{~mm}$ diameter holes $3 \mathrm{~mm}$ in depth are drilled diametrically apart at the midsection of each sample. These holes hold the tips of the \#316 stainless steel loading points, ensure proper alignment, and direct the load. An SBEL load frame with servocontroller is used to load the sample to failure. The failure load and time as well as the angle between the fracture surface and core axis are recorded. Figure 4.9 shows an example of resulting fracture surfaces. 


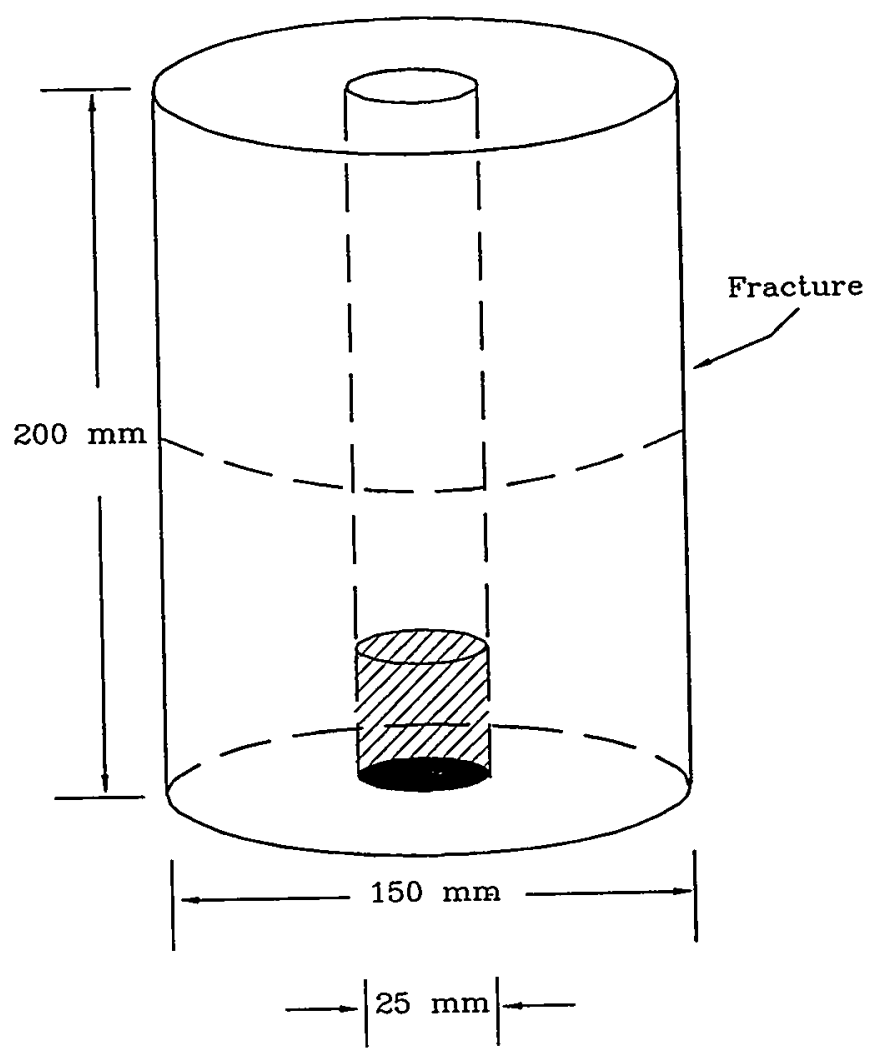

Figure 4.1 Nominal sample dimensions. 


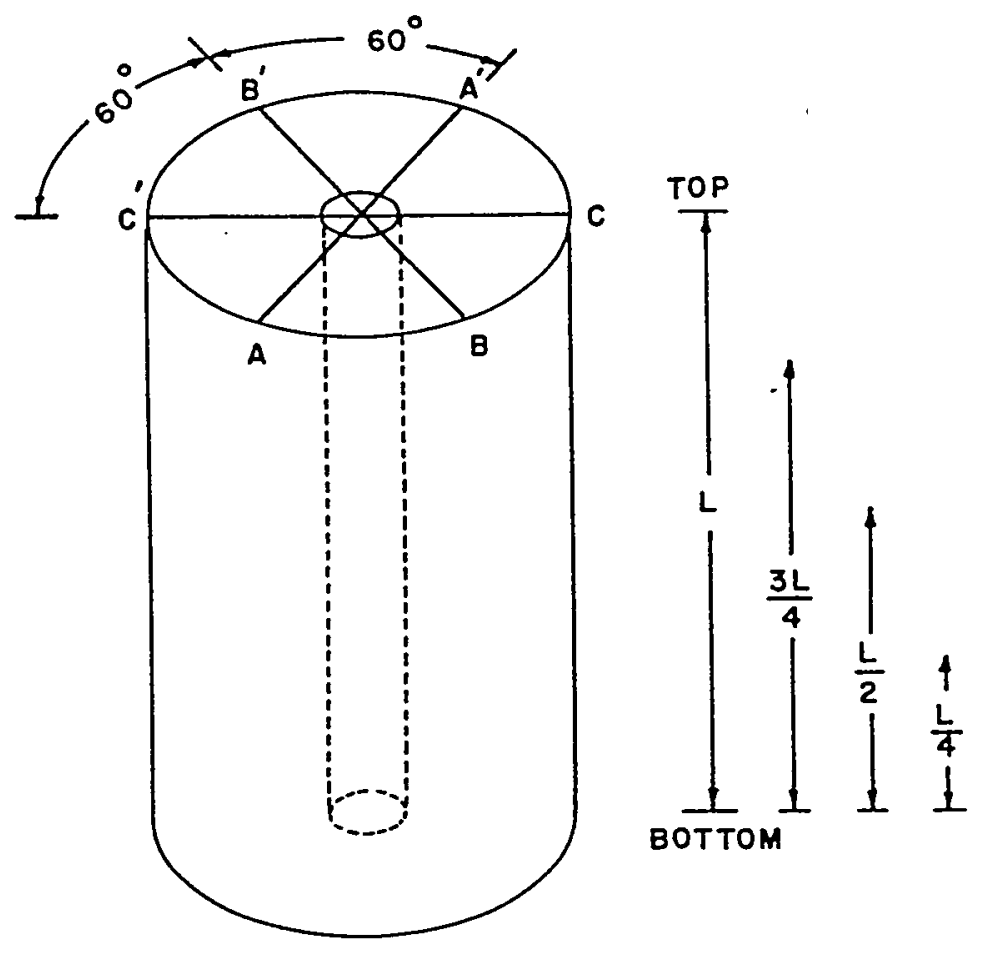

Figure 4.2 Sample measurement scheme. Sample diameters are measured along three diameters at five positions along the length of each cylinder. 

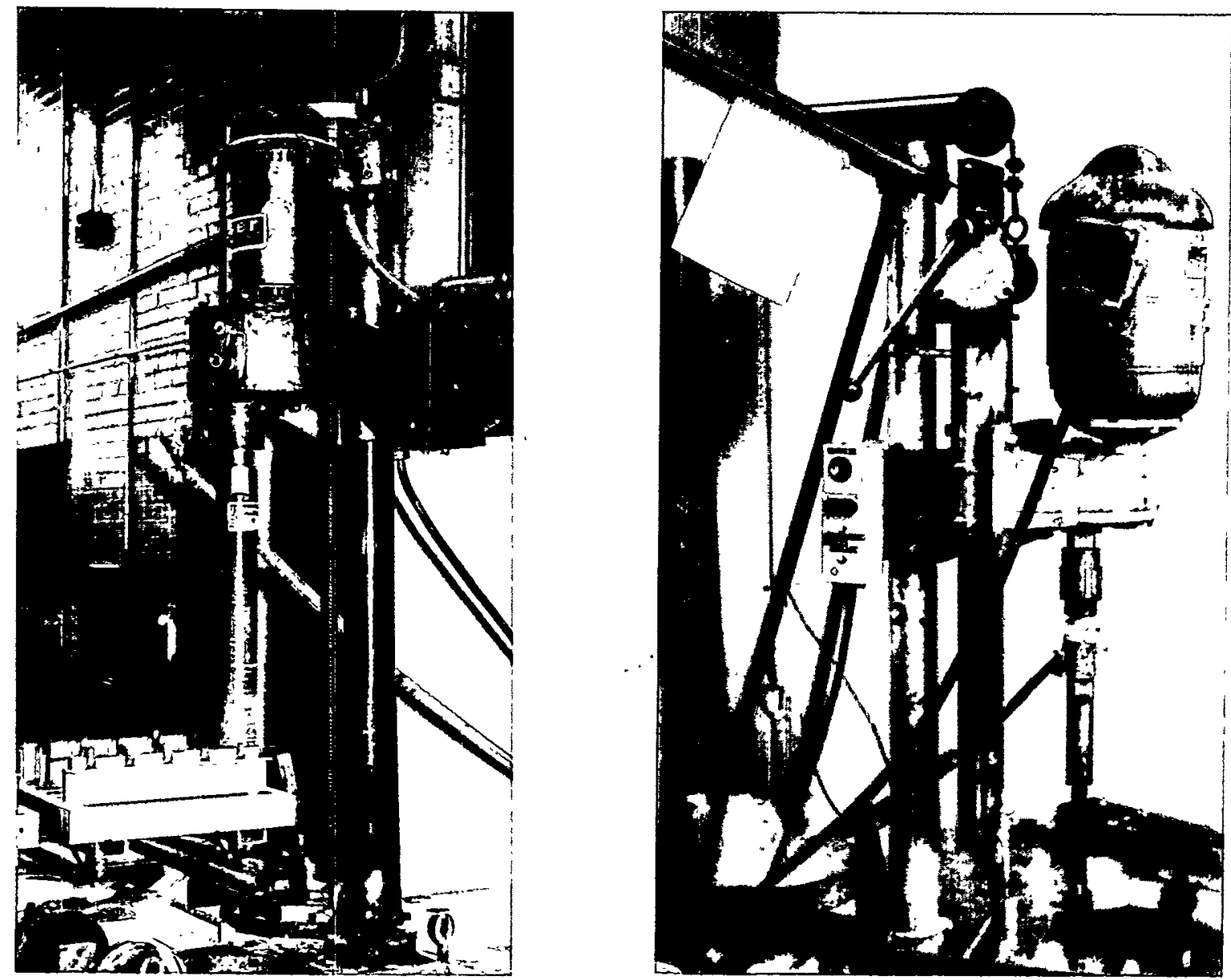

Figure 4.3 3-hp Acker (left) and 2-hp Century (right) drills used to core samples. 


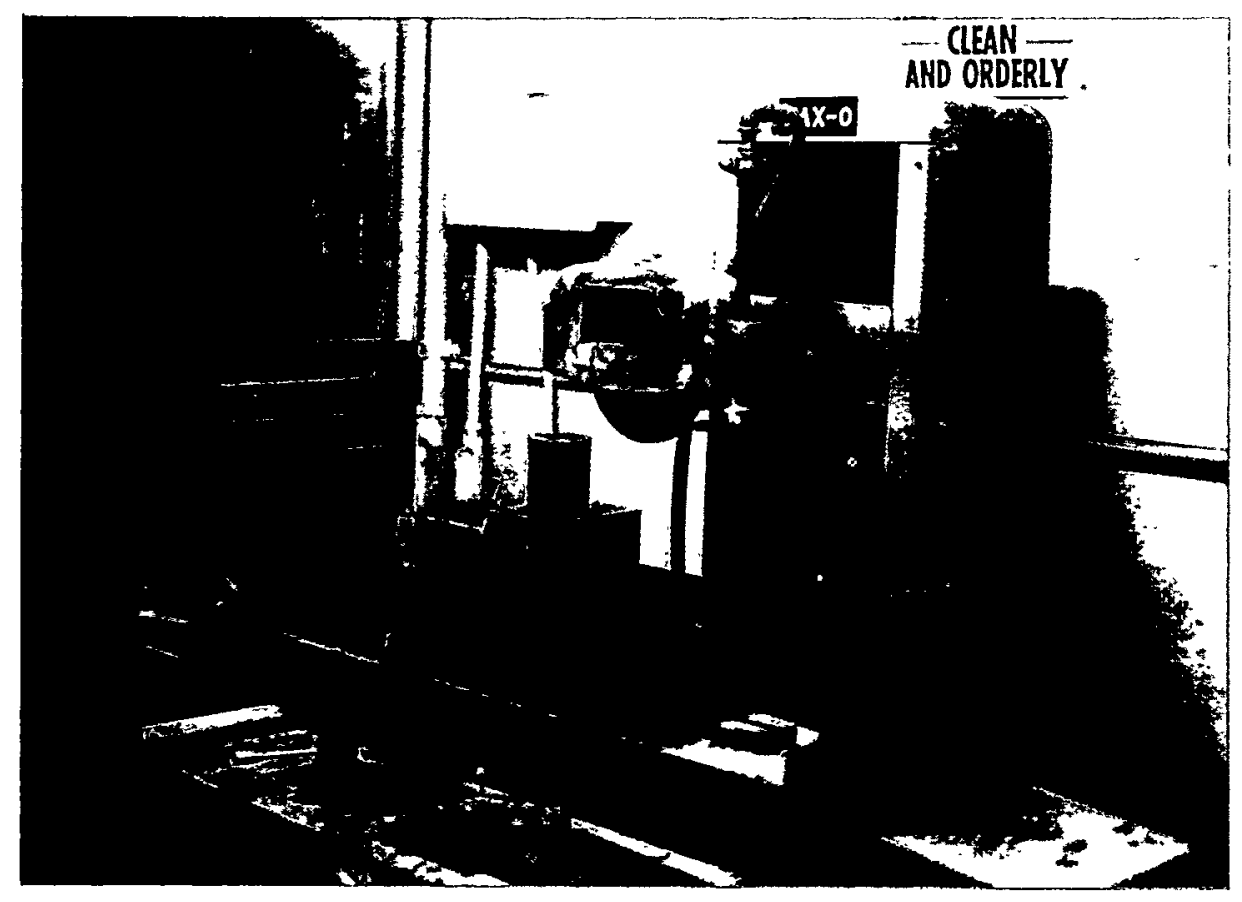

Figure 4.4 Kent automatic surface grinding machine. 


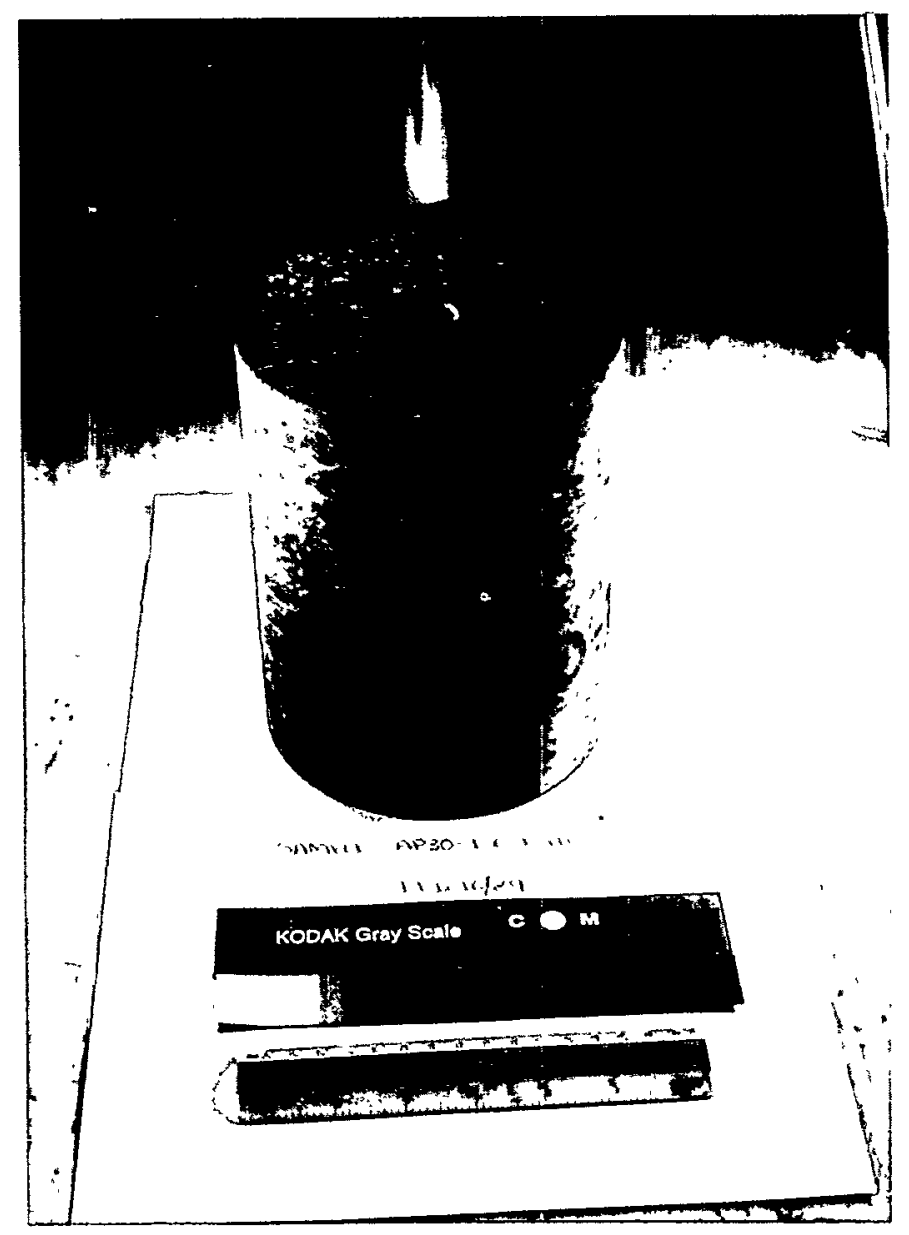

Figure 4.5 Apache Leap tuff (densely welded brown unit) cylinder. 


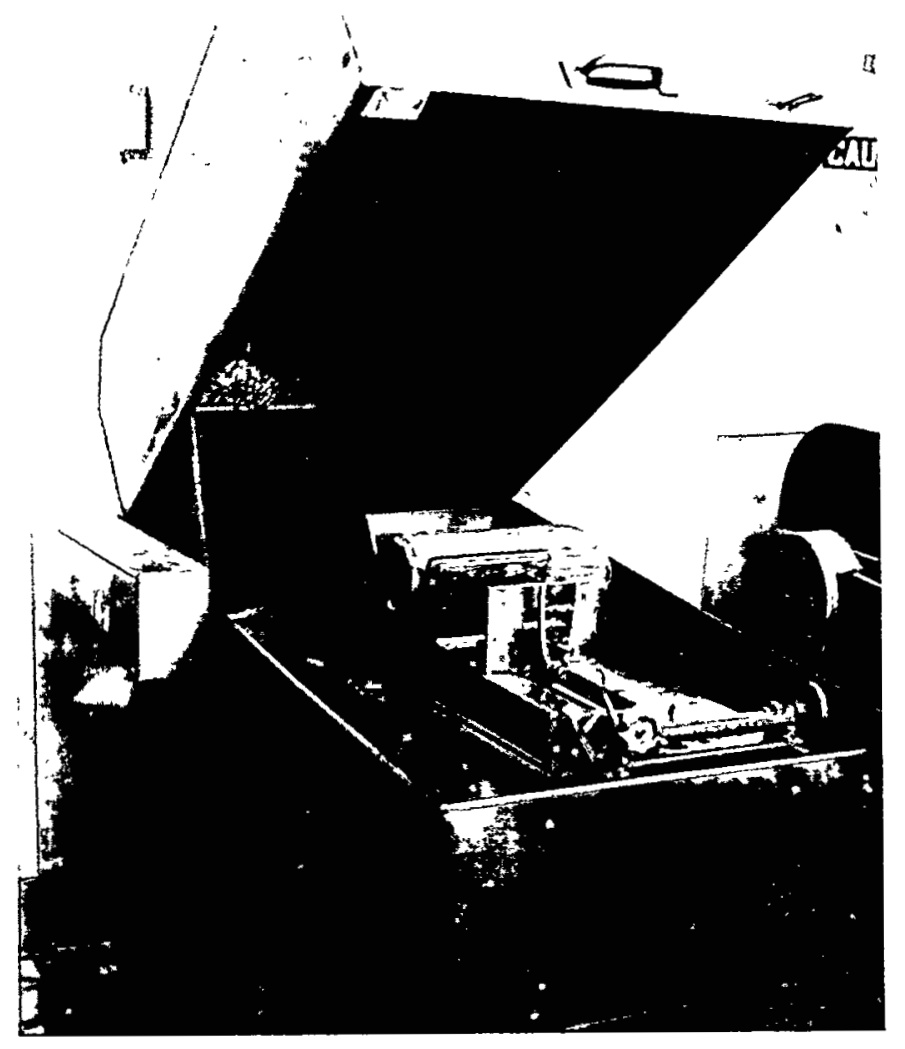

Figure 4.6 Covington diamond saw used to cut sawcut surfaces. 


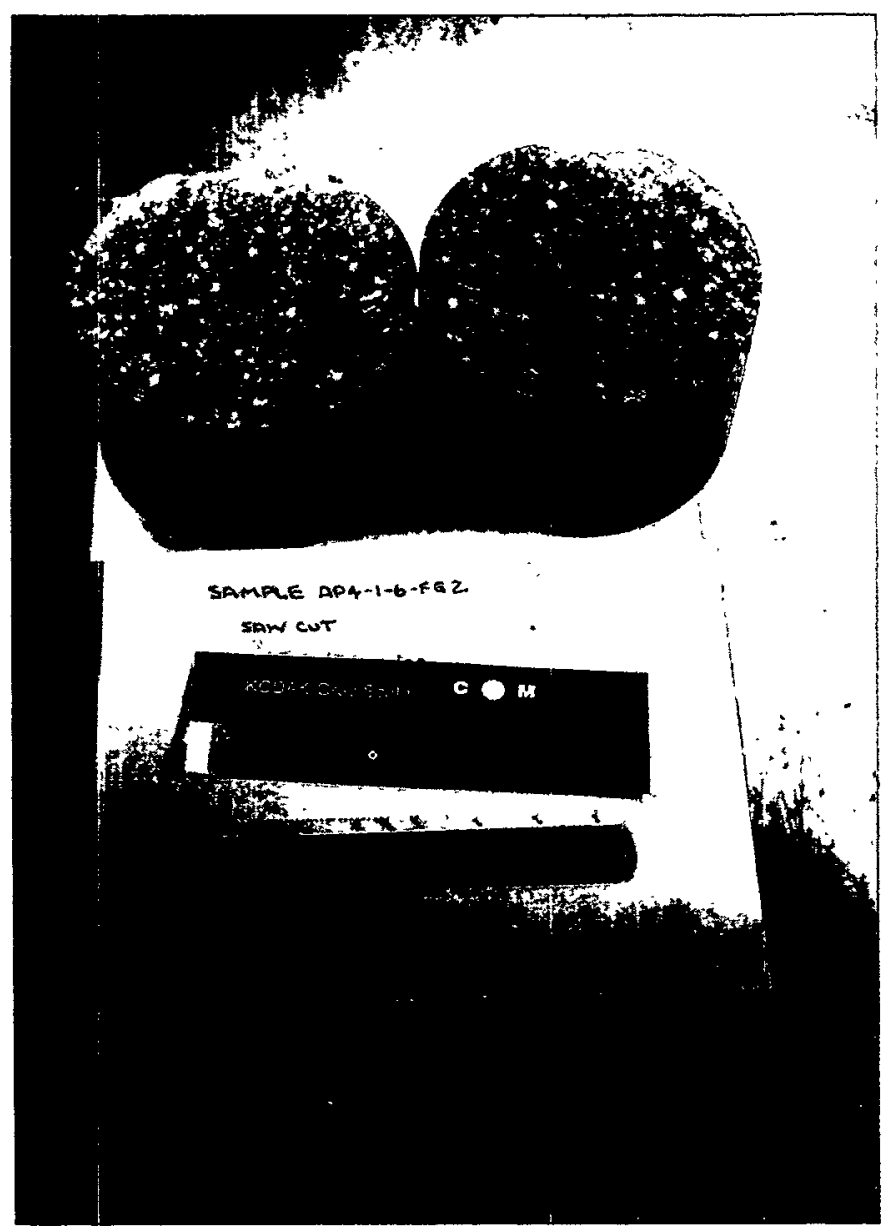

Figure 4.7 Sawcut surfaces of sample AP4-1-6-FG2. 

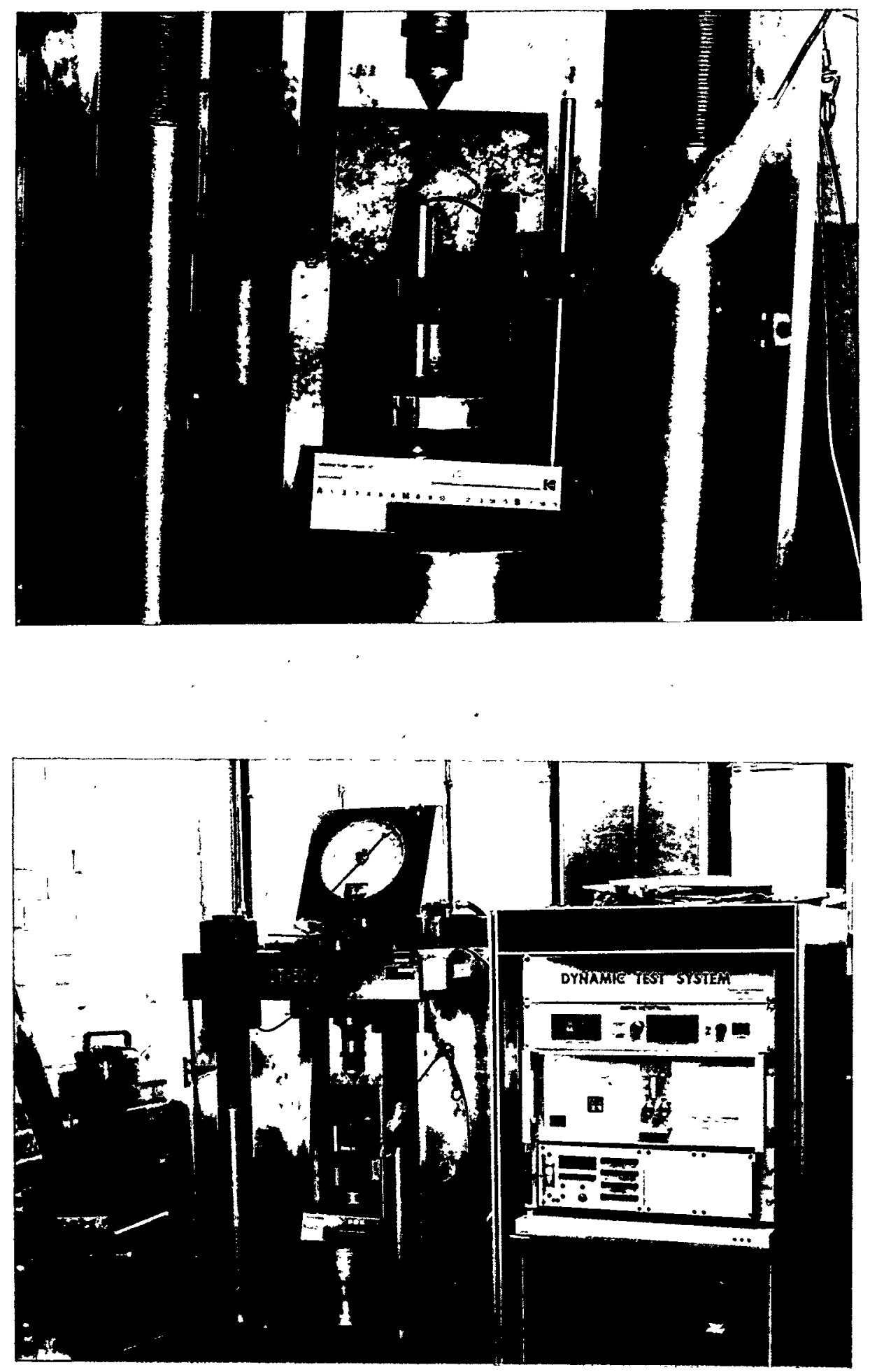

Figure 4.8 Modified point load test used to induce tensile fractures. 


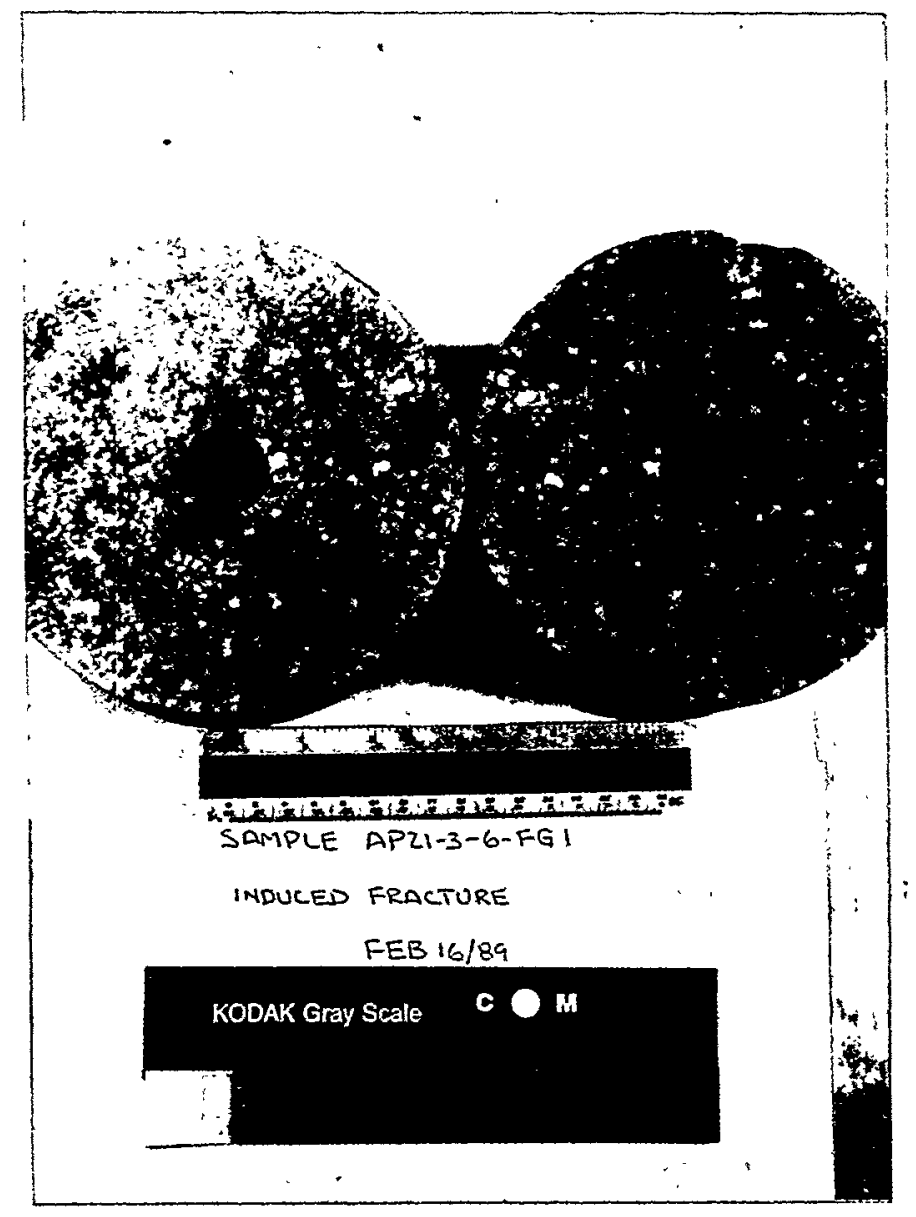

Figure 4.9 Fracture surfaces produced by modified point load test. 
Blocks containing single natural fractures are collected in the field. Due to the great weight of these blocks, their fractures are pried apart in the field to facilitate transportation. They are put back together prior to coring. These blocks are aligned and positioned to have their natural fractures perpendicular to the proposed coring orientation. The fractured blocks are tightly clamped together to prevent block shifting. Figure 4.10 shows such a block being cored. As the coring bit reaches the fracture, the top core is removed to prevent damage to the fracture surface due to rotation.

During surface grinding and the drilling of the $2.54 \mathrm{~cm}$ center borehole the sample halves of the natural fracture are tightly clamped together. Figure 4.11 a shows a core containing a single natural fracture.

The only exception in the preparation of naturally fractured samples was sample AP2-1-6-FG7 which was left intact and contains a complex nonplanar fracture geometry (Figure 4.11b). Black lines trace the fractures as they appear on the surface of this sample.

\subsection{Permeability Testing}

\subsubsection{Objective}

The objective of this test is to determine the permeability of intact, fractured, and grouted rock under uniaxial compression. Permeability is measured as a function of normal stress and injection pressure.

\subsubsection{Apparatus}

- load frame (1 MN capacity) (Cobb and Daemen, 1982, pp. 35-36)

- hydraulic load cell (Enerpac JSL-1002)

- hydraulic hand pump (Enerpac EH-80)

- shut-off valve

- pressure gauge (Heise; $7 \mathrm{MPa}$ range, 10kPa accuracy)

- cut-away loading platens (Schaffer and Daemen, 1987, p. 59)

- falling head permeameter (2 and $50 \mathrm{ml}$ high-precision pipettes)

- nitrogen gas tank

- regulating valve (Victor model VTS-250D)

- pressure intensifier (Fuenkajorn and Daemen, 1986, pp. 257-260)

- water-tight plexiglass pan (300 mm diameter and $200 \mathrm{~mm}$ height)

- Micronta stop watch (1/100 second accuracy)

- Omega digital thermometer (Model HH22)

- displacement dial gauge (Starrett; $25.4 \mathrm{~cm}$ displacement, 0.025 $\mathrm{mm}$ accuracy) 


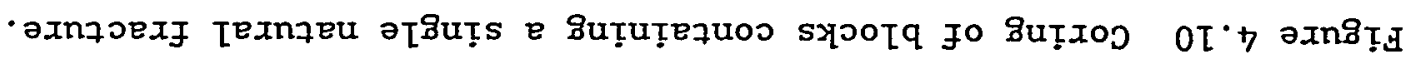

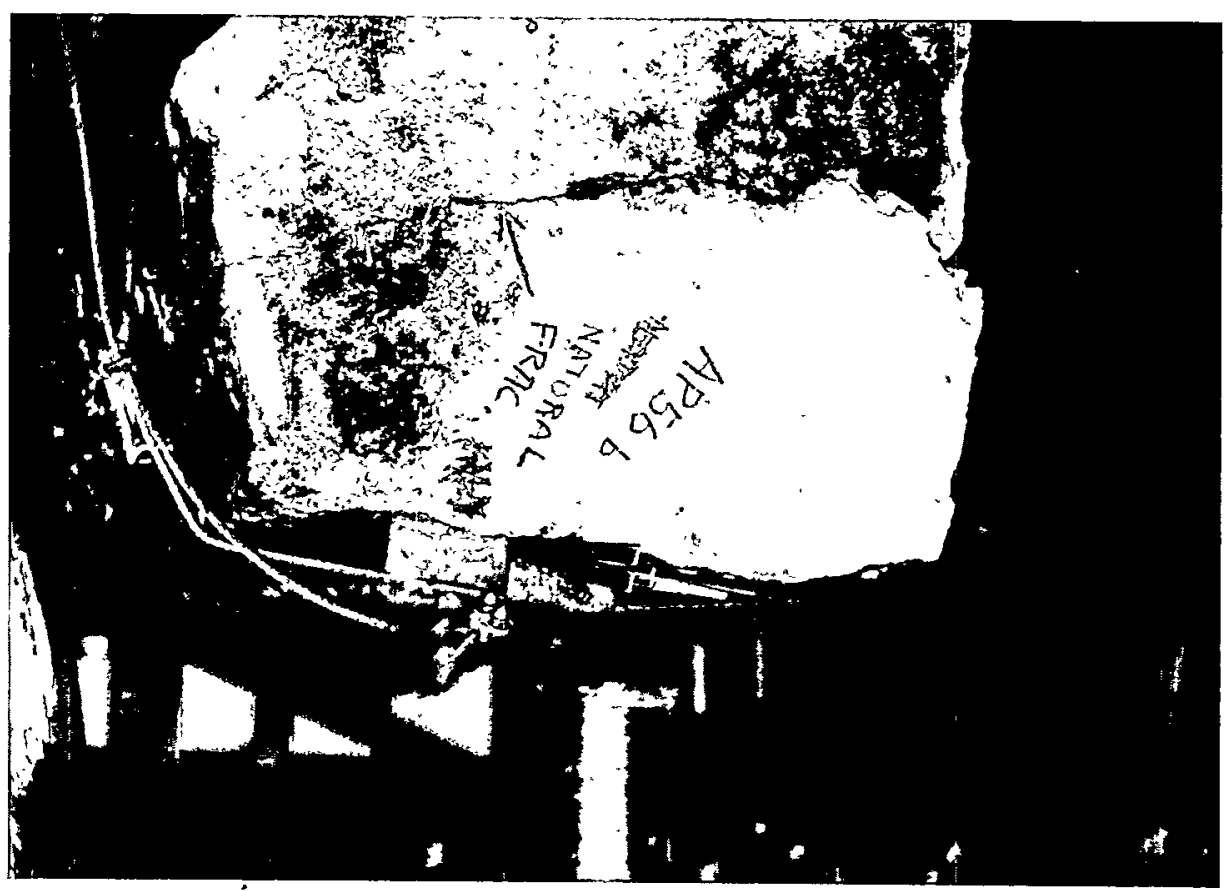


(a)

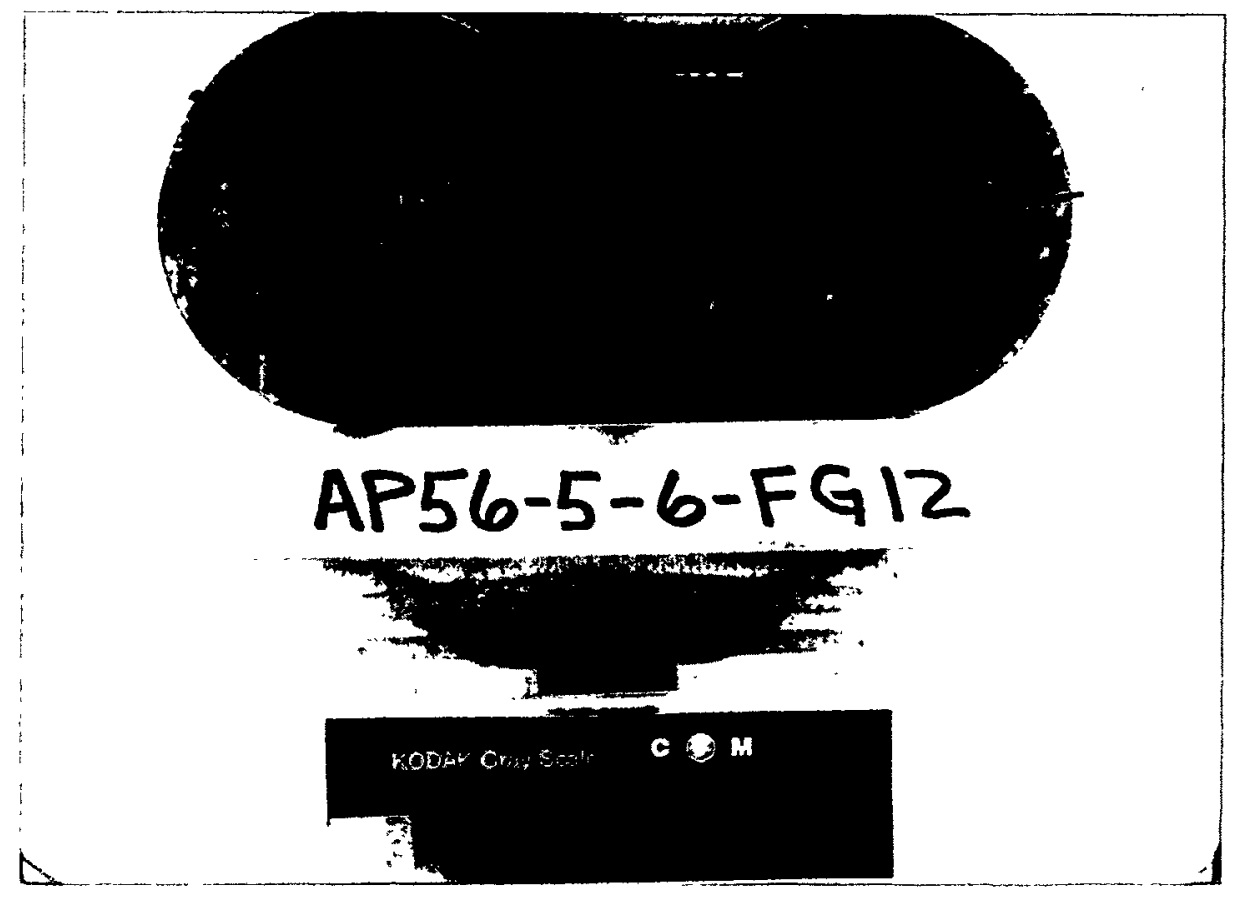

(b)

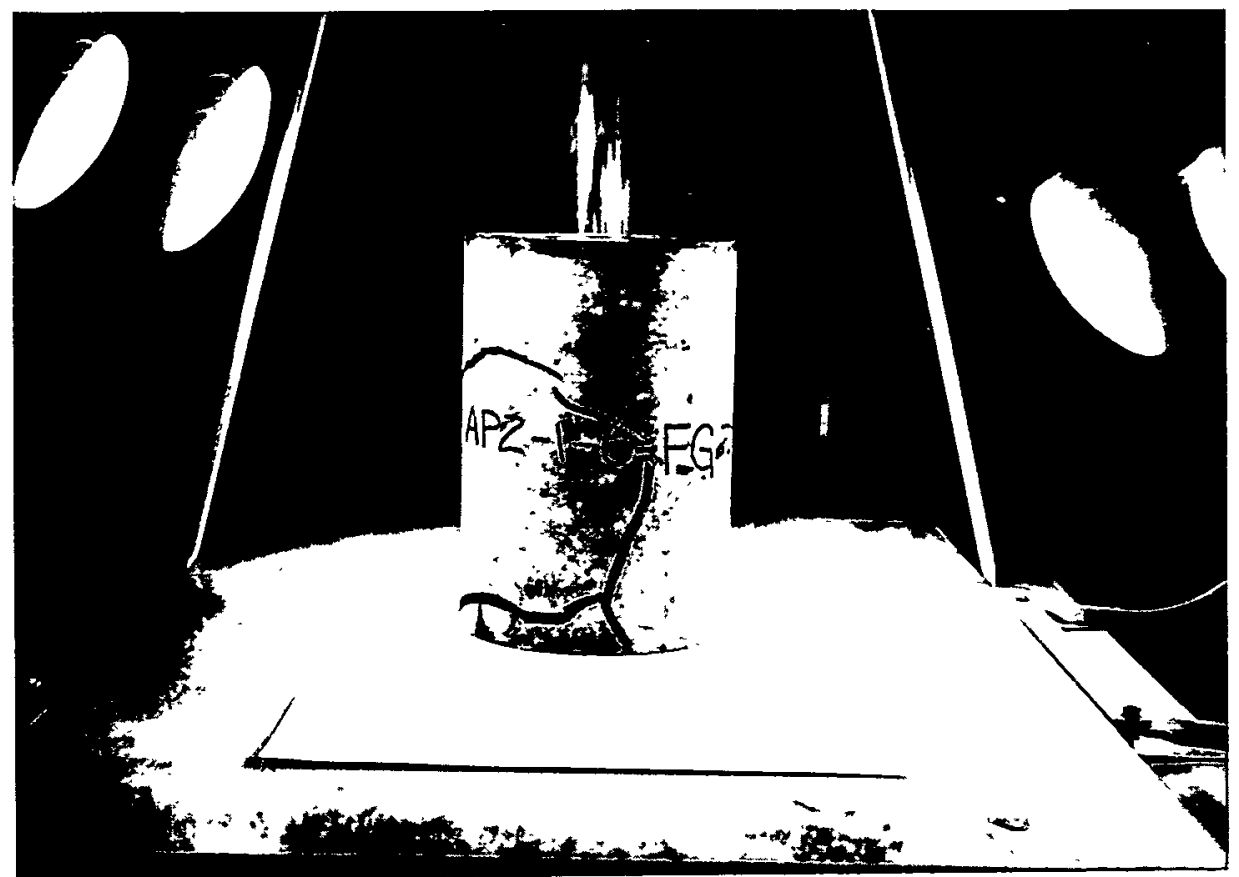

Figure 4.11 (a) Cored sample (AP56-3-6-FG15) containing a single natural fracture; (b) complex nonplanar fracture geometry of sample AP2-1-6-FG7. 


\subsubsection{Test set-up}

Figure 4.12 gives the laboratory arrangement for permeability testing and for grouting. A hydraulic load cell, cutaway loading platens, rock sample and water-tight plastic pan are placed in a 1 MN capacity load frame. The rock sample is placed in the water pan and the pan is filled with water. A Teflon gasket is placed between the lower platen and the rock sample. The hydraulic load cell is connected to a hydraulic hand pump via a pressure gauge and a shut-off valve. A vertical force (normal load on the sample) is applied to the sample by pressurizing the load cell. The shut-off valve is used to maintain the cell pressure constant during permeability testing. The loading platens transmit the force from the cell to the sample. The vertical load on the sample is calculated from the oil pressure. The lower loading platen is connected to a falling head permeameter or pressure intensifier for permeability testing. The temperature of the testing room is monitored and is expected to remain constant at $22 \pm 2^{\circ} \mathrm{C}$. Distilled water is allowed to pass through the rock sample for 24 hours prior to testing. During testing, the rock sample is visually inspected to see whether the flow is radial from the cylinder hole, not leaking from connections, and uniformly damp on the surface of the sample.

\subsubsection{Flow Testing}

This section describes the methods used to measure the permeability of a hollow rock cylinder with or without a fracture. Distilled deaired water is used as the testing fluid. The flow test is conducted while a constant axial load is applied to the sample. The laboratory arrangement shown in Figure 4.12 allows both steady-state and falling head tests to be performed.

For steady-state flow testing, the lower loading platen is connected to the high-pressure (top) cylinder of a gas-over-water pressure intensifier. The low-pressure (bottom) cylinder is connected to a nitrogen gas tank via a regulating valve. The regulating valve is used to adjust the injection pressure. The water inflow rate is measured by monitoring the displacement of a push-rod attached to the piston in the intensifier. The measurement is made by means of a displacement dial gauge. For each injection pressure and each normal load, steady-state flow testing is conducted as a function of time and is terminated after a constant flow rate is established.

If the rock sample has so high a permeability that the water in the intensifier runs out before a steady-state flow rate can be established, a falling head test is conducted. For falling head testing the lower loading platen is connected to a high-precision pipette using a plastic (Tygon) tube. Distilled-deaired water is then filled into the pipette, tube and center hole of the sample. The inside diameter of the pipette can be selected from 1 to $20 \mathrm{~mm}$, depending upon the permeability of the rock sample. The height of the water level is measured from the midsection of the rock cylinder (the approximate location of the fracture). The measurement is made to the nearest millimeter. The decrease of the water level in the pipette is measured as a function of time. The 


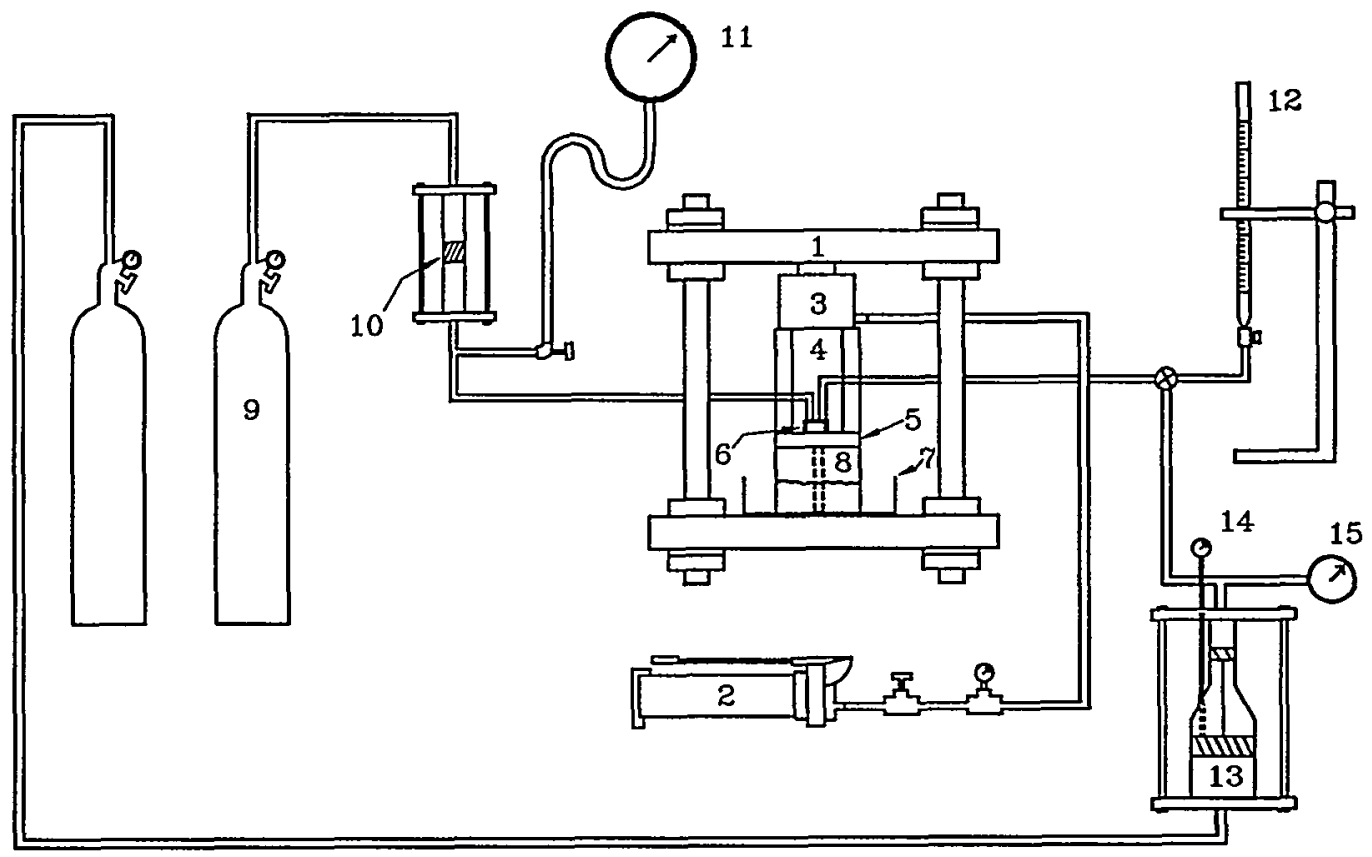

1) Load frame

2) Hydraulic hand pump

3) Hydraulic lifting cylinder

4) Cut-away loading platens

5) Quick connect platen

6) Injection nozzle

7) Plastic pan

8) Rock sample
9) Nitrogen tank

10) Grout pump

11) Pressure gauge with Gauge Saver

12) Falling head permeameter

13) Pressure intensifier

14) Displacement dial gauge

15) Water injection pressure gauge

Figure 4.12 Laboratory arrangement for flow testing and grouting. 
permeability of the intact rock or of the fracture is calculated from each reading as described in Appendix A. For each normal load, the test is terminated when the permeability no longer changes with time. The flow test is repeated after the normal load is changed (increased or decreased). The permeability of the fracture after grouting is determined in accordance with the procedure given here:-

\subsection{Surface Roughness Characterization}

\subsubsection{Objective}

The immediate purpose of this procedure is to measure the roughness of a fracture surface. The ultimate objective is to characterize the true flowpaths along the fracture, and relate them to observed grout penetration. The method is applicable to a rock cylinder having $25.4 \mathrm{~mm}$ ID and a maximum $150 \mathrm{~mm}$ OD, with a fracture perpendicular to the cylinder axis.

\subsubsection{Apparatus}

1) guide plate (178 mm diameter)

2) displacement dial gauge (Starrett; $5.1 \mathrm{~cm}$ displacement, $0.025 \mathrm{~mm}$ accuracy, $0.0025 \mathrm{~mm}$ precision)

3) surface grinder (Rockwell Delta)

4) needle probe (1 $\mathrm{mm}$ diameter, $70 \mathrm{~mm}$ length).

The guide plate is made of a $3.18 \mathrm{~mm}$ thick plexiglass template. A 25.4 $\mathrm{mm}$ diameter and $176 \mathrm{~mm}$ long plexiglass rod is glued at the center of the plate (Figure 4.13a). Holes ( $1.47 \mathrm{~mm}$ diameter) are drilled into the plate in a square grid pattern. The template contains 100 holes per square inch. The distance between the center of adjacent holes is 2.54 $\mathrm{mm}$. The template has sufficient holes to cover a $152 \mathrm{~mm}$ diameter (circular) surface.

The needle probe is attached to the dial gauge probe with a straight alignment.

\subsubsection{Measurement Method}

Place the guide plate on top of the rock surface to be measured, inserting the plexiglass rod into the center hole of the sample (Figure 4.13a). The distance between the plate and rock surface should be approximately 4-6 cm. Be sure that the rod is tight (i.e. does not allow rotation) and that the plate is perpendicular to the hole axis.

Mount the displacement dial gauge on a stationary point on top of the grinding table. The needle probe must be vertical (Figure 4.13b).

Place the rock sample with the guide plate on the grinding table underneath the dial gauge.

Stabilize the sample using a steel clamp. Be sure that there is no relative displacement between the rock sample and grinding table. 
(a)

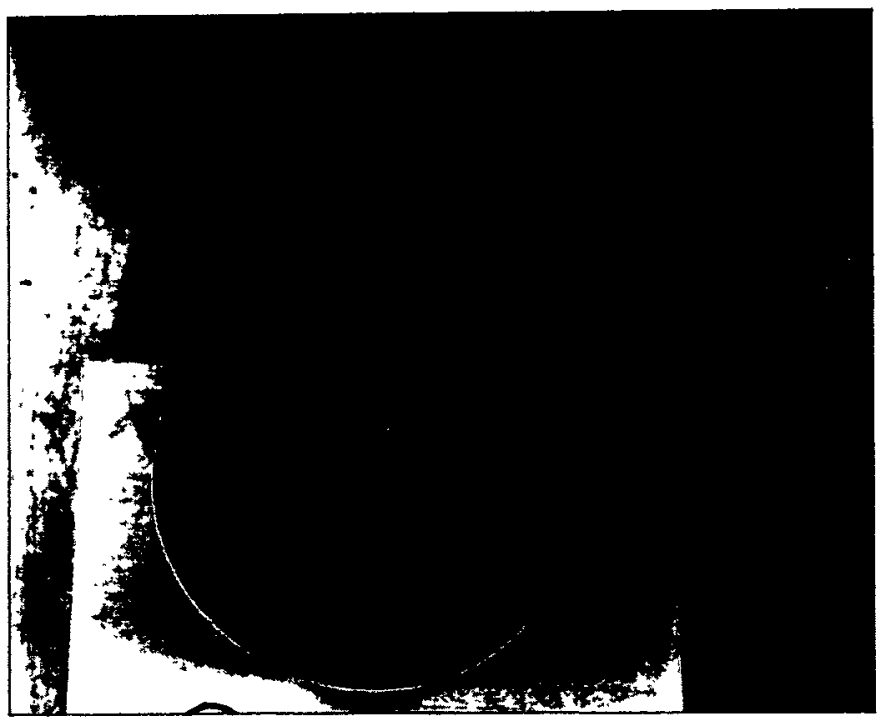

(b)

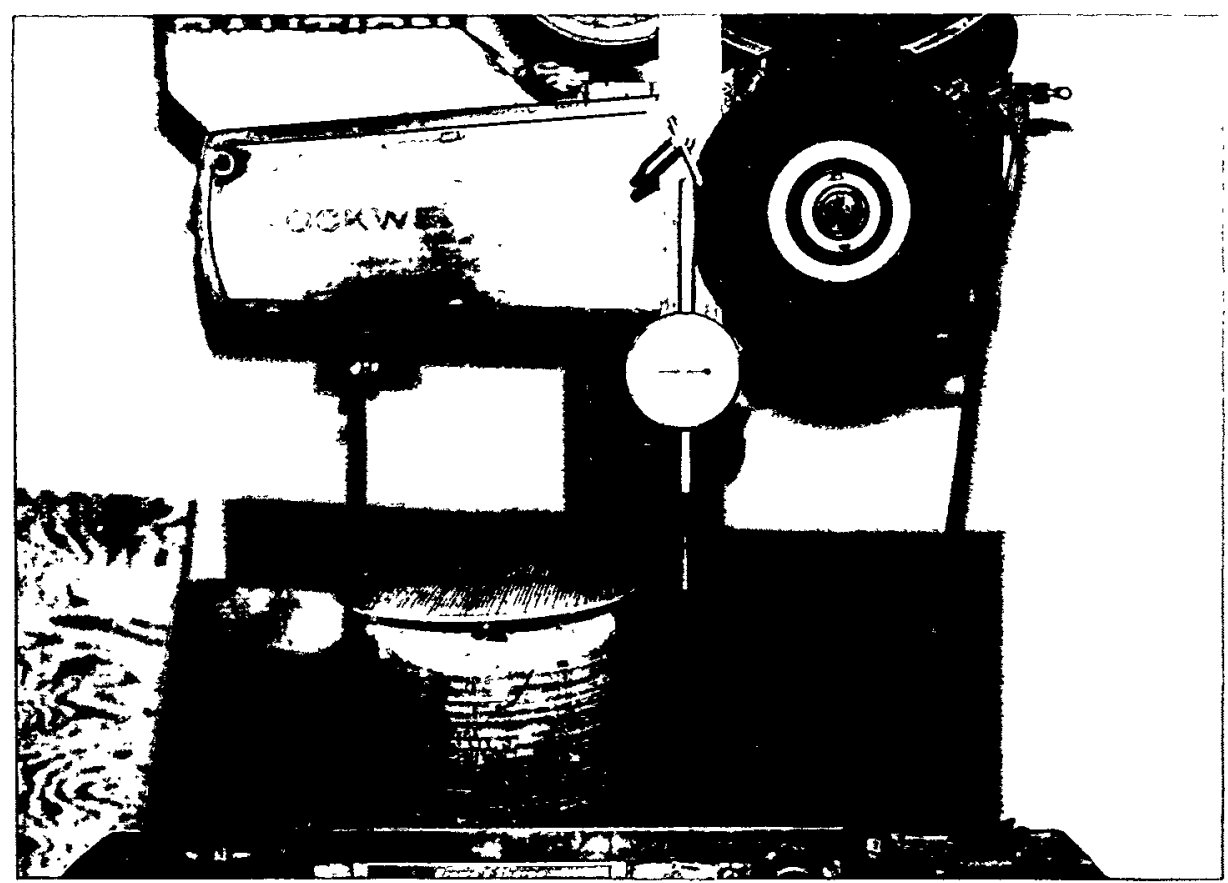

Figure 4.13 (a) Guide plate installed on fracture surface of $150 \mathrm{~mm}$ diameter cylinder of Apache Leap tuff. (b) Plexiglass rod (25 mm diameter) glued at the center of the plate, and inserted into the center hole. 
There are three control wheels on the grinder; two are used to slide the table in two (mutually perpendicular) horizontal directions; the third wheel is used to move the table up and down in the vertical direction.

Adjust the grinding table (vertically) so that the needle probe can reach the highest and lowest points of the rock surface. If the maximum difference between the highest and the lowest points on the fracture surface is larger than $70 \mathrm{~mm}$, a longer needle probe is required. After a desired elevation is obtained, lock the wheel and be sure that the elevation does not change until all measurements are complete.

Select a datum plane on the rock cylinder. The lowest point on the fracture surface may be selected as a datum plane. Set the dial gauge to read zero when the needle touches the datum plane.

Use the horizontal control wheels to move the sample until the needle probe slips through the guide hole and touches the rock surface. Record the dial gauge reading to the nearest $0.0025 \mathrm{~mm}$.

Since the guide holes are drilled in a square grid pattern, the points of measurement can be sequenced in a rectangular coordinate system ( $x$ and $y$ axes with the origin at the center of the template). A measurement is made at every guide hole until the entire fracture area is covered.

Make the measurements in a systematic row or column pattern in order to minimize the risk of skipping guide holes. Check the notebook records to assure that all measurements have been taken before unclamping the sample.

After the measurement for the last guide hole is made, remeasure the first guide hole and compare the result with the reading previously made. The two results should be identical if no vertical movement of the table and no relative movement between the sample and the table occur during the measurement.

\subsection{Grout Preparation}

\subsubsection{Introduction}

The grouts are mixed according to API Specification No. 10 (American Petroleum Institute, 1986, pp. 14-19). The types of cement tested include Ideal Type I/II, referred to as Self-Stress II or SSII, and Micro Fine Cement MC-500. The type of bentonite used is C/S granular (provided by American Colloid Co. Arlington Heights, I1l.).

Self-Stress II cement (provided by Dowell Schlumberger, Tulsa, OK) is composed of Ideal Type I/II portland cement (from Tijeras Canyon, NM), mixed at the factory with 108 D53 (an expansive agent), 18 D65 (a dispersant), and prepared at a water-to-cement ratio ranging from 0.45 to 0.9. MC-500 cement has an ultra fine grain diameter (Figure 4.14) with a mean grain size of $4 \mathrm{\mu m}$ and a maximum grain size of approximately 10 $\mu \mathrm{m}$. It is mixed with $18 \mathrm{NS}-200$ (Napthalene Sulphonate) at a water to 


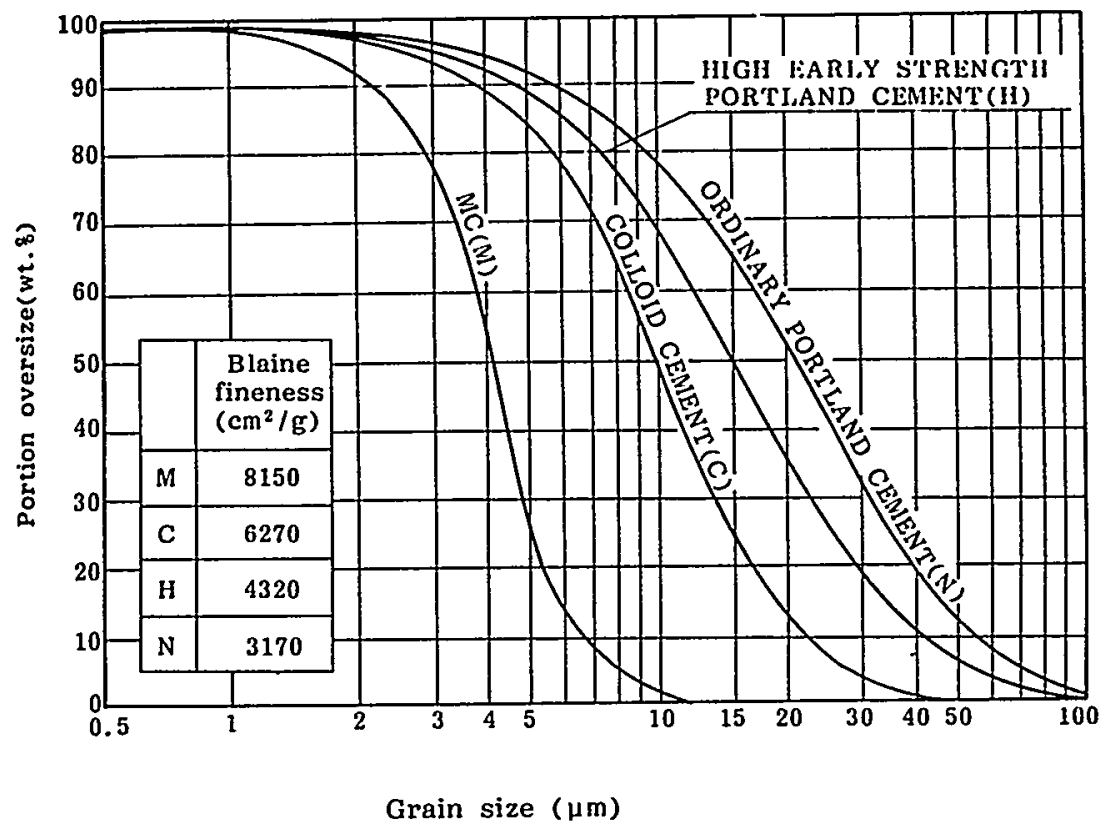

Figure 4.14 Grain size distribution of O.P.C, Colloid, and MC-500 cements.

(Reprinted by permission of American Society of Civil Engineers, M. Shimoda and H. Ohmori, 1982, "Ultra Fine Grouting Material, "Grouting in Geotechnical Engineering, Figure 1, p. 78. Proc. of the Conf. on Feb. 10-12, New Orleans, W.H. Baker, ed., Vol. 1, pp. 77-91.

Copyright 1982, by American Society of Civil Engineers, New York.) 
Table 4.1 Mix Proportions for Grout Formulations

\begin{tabular}{|c|c|c|c|}
\hline $\begin{array}{c}\text { Mix } \\
\text { Number }\end{array}$ & $\begin{array}{c}\text { Cement } \\
(\mathrm{g})\end{array}$ & $\begin{array}{c}\text { Bentonite } \\
(\mathrm{g})\end{array}$ & $\begin{array}{c}\text { Water } \\
(\mathrm{g})\end{array}$ \\
\hline 1 & 772 & 15 & 463 \\
2 & 772 & 23 & 540 \\
3 & 772 & 38 & 695 \\
4 & 772 & 0 & 348 \\
5 & 666 & 13 & 885 \\
\hline MC-500* & 746 & 0 & 746 \\
\hline
\end{tabular}

* Contains 18 NS -200 .

cement ratio of $1: 1$ by weight of cement. C/S granular bentonite is added to SSII cement in amounts ranging from 2 to 5\%. All percentages are weight percent with respect to cement. Table 4.1 contains mix proportions of all tested grout formulations.

Parameters involved in grout preparation are: 1) mixing time and temperature, 2) grout viscosity, density, and bleed capacity, 3) time between grout mixing and pouring, 4) weight control of grout ingredients, and 5) curing conditions, i.e. water bath at room temperature, pressure and relative humidity, along with curing time.

\subsubsection{Apparatus}

1) plastic scoop, spatula

2) American Scientific balance (12 kg capacity, readable to $1 \mathrm{~g}$ )

3) Oster commercial blender (Mode1 44006E); 2-speed; 2.3 liter

4) Fann 35A/SR 12 viscometer (part no. 30166)

5) plastic bags ( 0.25 and 2.0 liter capacity)

6) $1000 \mathrm{ml}$ graduated cylinder

7) Omega digital thermometer (Model HH22)

8) VWR Dylatherm hot plate with container

9) funnel

10) plexiglass curing molds ( $150 \mathrm{~mm}$ long, $57.2 \mathrm{~mm}$ OD, $50.8 \mathrm{~mm}$ ID)

11) stirring rod (250 mm long, $6 \mathrm{~mm}$ diameter)

12) laboratory stirrer (Stir-pak Model R-4554-00)

13) Micronta stop watch (1/100 second accuracy)

\subsubsection{Procedure for Preparing MC-500 and SSII Bentonite grouts}

1) Prepare the grout slurry at ambient room temperature $\left(27 \pm 6^{\circ} \mathrm{C}-\mathrm{API}\right.$, 1986) and a relative room humidity not less than 508 (ASTM C305-82, Sect. 4). Make certain that the temperature of the distilled water prior to mixing is $27 \pm 3^{\circ} \mathrm{C}$. Record the room temperature, relative humidity and atmospheric pressure. Raise the temperature of the mixing water if necessary. 
2) Weigh out the cement, bentonite and 858 of the mix water and place in individual sealed plastic bags (2 liter capacity). Add $15 \%$ of the total mix water to the bentonite and allow to prehydrate for two hours in a small ( 0.25 liter capacity) plastic bag prior to mixing with other ingredients (Deere, 1982a, p. 296).

3) After two hours have elapsed since the addition of water to the bentonite, pour the remaining mix water ( 858 of the total) into blender. Add bentonite. Scrape all bentonite remaining on the sides of the plastic bag into the mix. Mix 15 seconds. 1 Scrape down bentonite from sides of blender. At low speed add cement to blender in not more than 15 seconds. After all the cement has been added, mix at high speed for an additional 35 seconds. 2 MC-500 grouts contain no bentonite. Omit steps involving preparing bentonite for these grouts. Pour mixed cement grout into curing mold, viscometer cup, or graduated cylinder. Use a funnel to direct the slurry into its container to avoid violent turbulence and possible sedimentation, layering, and trapped air bubbles. Fill the curing mold with slurry up to $13 \mathrm{~cm}$ above the base of the mold. Fill the viscometer cup up to the line inscribed on the cup (approximately $350 \mathrm{ml}$ ). Fill the graduated cylinder with $1000 \mathrm{ml}$ of slurry. When pouring, submerge the bottom end of the funnel in the slurry and gradually raise the funnel as the cement slurry level increases. Record pouring time. Immediately after pouring slurry into the curing mold, puddle the specimen 25 times with a stirring rod. After 20 minutes of curing in molds, pour distilled water on top of the sample to prevent cement drying. For MC-500. grouts, add water one hour after pouring in curing molds.

\subsection{Grout Characterization}

\subsubsection{Objective}

The objective of this test procedure is to characterize grouts in terms of their uniaxial compressive strength, Fann viscosity/cohesion, Marsh flow time, density, and bleed capacity.

1 Personal communication with Lorra Craver, American Colloid, regarding thorough mixing of bentonite.

2 ASTM 6305-82 (Section 4) differs from API Śpecification. No. 10, 1986 (with respect to mixing cement) in the following regards: 1) Pour the distilled water into the mixing container, 2) add the cement to the water and allow 30 seconds for the adsorption of water, 3) start the mixer and mix at slow speed (140 $\pm 5 \mathrm{rpm})$ for 30 seconds, 4) stop the mixer for 15 seconds, and during this time scrape down into the batch any paste that may have collected on the sides of the bowl, and 5) start the mixer at medium speed $(280 \neq 10 \mathrm{rpm})$ and $\operatorname{mix}$ for 1 minute. 


\subsubsection{Uniaxial Compressive Strength Testing}

\subsubsection{Apparatus}

1) Hammer

2) Chisel

3) Kent automatic surface grinding machine

4) 2 and 5 inch ( 5.1 and $12.7 \mathrm{~mm}$ ) micrometers

5) Displacement dial gauge (Starrett; $0.0025 \mathrm{~mm}$ precision)

6) Mettler balance (Model P1200-1/100 g accuracy)

7) Versa Tester compression machine.

\subsubsection{Testing Procedure}

Cure each grout specimen for 7, 8 or 28 day testing. Free each specimen from its mold by gently cracking the mold longitudinally using a hammer and chisel. Take care not to chip the specimen. Keep each specimen in contact with water except when freeing it from its mold, when measuring dimensions and weighing, or during compression testing.

Grind the ends of each specimen flat and parallel.

Measure specimen diameter, height, side smoothness, and end perpendicularity (ASTM D2938-79, Section 4).

Just prior to compression testing remove the specimen from its water bath, pat dry with a paper towel, and weigh to the nearest 0.01 gram.

Place specimen in the Versa Tester compression machine and load to failure at a loading rate of approximately $460 \mathrm{kPa} / \mathrm{s}$ (API Spec. No. 10, 1986, p. 18). Record the failure load and draw a post-failure sketch.

\subsubsection{Determination of Viscosity and Cohesion (Using Fann Viscometer)}

\subsubsection{Apparatus}

1) Fann 35A/SR12 viscometer (Part No. 30166)

2) Stir-Pak laboratory stirrer (Mode1 4554)

3) Omega digital thermometer (Model HH22)

4) Micronta stop watch ( $1 / 100$ second accuracy).

\subsubsection{Test procedure}

Stir the slurry previously poured into the viscometer cup (Section 4.4.3) with the laboratory stirrer at speed 1.4 (approximately $300 \mathrm{rpm}$ ) for 20 minutes. Measure and record the temperature $\left(\mathrm{T}_{1}\right)$ in the cup. ${ }^{3}$ Record dial readings in descending order at the speeds and time intervals given in Table 4.2 .

3 Procedure deviates from API (1986) due to lack of an atmospheric consistometer. 
Table 4.2 Speed and Time Sequence for Fann Viscometer Measurements

\begin{tabular}{|c|c|}
\hline Speed (rpm) & Time Interval (seconds) \\
\hline 300 & 60 \\
\hline 200 & 20 \\
\hline 100 & 20 \\
\hline 6 & 20 \\
\hline 3 & 20 \\
\hline
\end{tabular}

Measure the temperature $\left(\mathrm{T}_{2}\right)$ in the cup after the final viscosity reading. Report the rheological properties at the average of the temperatures $T_{1}$ and $T_{2}$. Figure 4.15 shows a Fann viscometer. Newtonian viscosities are read directly from the viscometer at a rotor speed of $300 \mathrm{rpm}$. Plastic viscosities are obtained by subtracting the $100 \mathrm{rpm}$ reading from the $300 \mathrm{rpm}$ reading, then multiplying by a factor of 1.5 . The yield strength or cohesion values are obtained by subtracting the plastic viscosity from the $300 \mathrm{rpm}$ reading. 4

\subsubsection{Marsh Viscosity or Flow Time}

\subsubsection{Apparatus}

1) Marsh flow cone (Figure 4.16)

2) Marsh cup

3) Micronta stop watch (1/100 second accuracy)

\subsubsection{Test Procedure}

Slurry preparation is performed in accordance with section 4.4.3 with the mix proportions given in Table 4.3 to produce the 1.5 liters of slurry needed for this test.

The prepared slurry is poured into the funnel until it just touches the screen, a volume of 1.5 liters. Record the time for 0.946 liters of slurry to pass through the funnel into the measuring cup. This flow time, to the nearest second, is the Marsh funnel viscosity.

4 Personal communication from Pat Gill of Dowell-Schlumberger, Inc. 


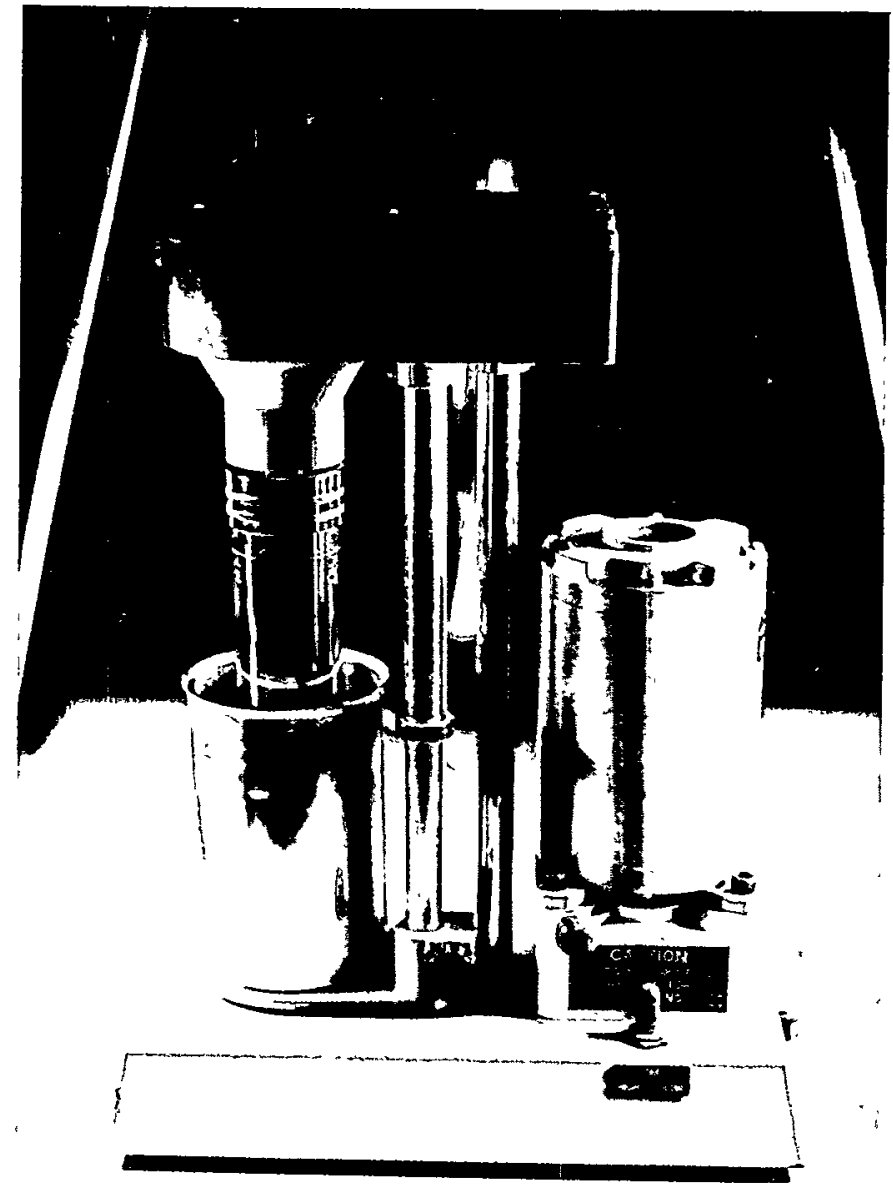

Figure 4.15 Fann viscometer used to measure viscosity and yield point. 


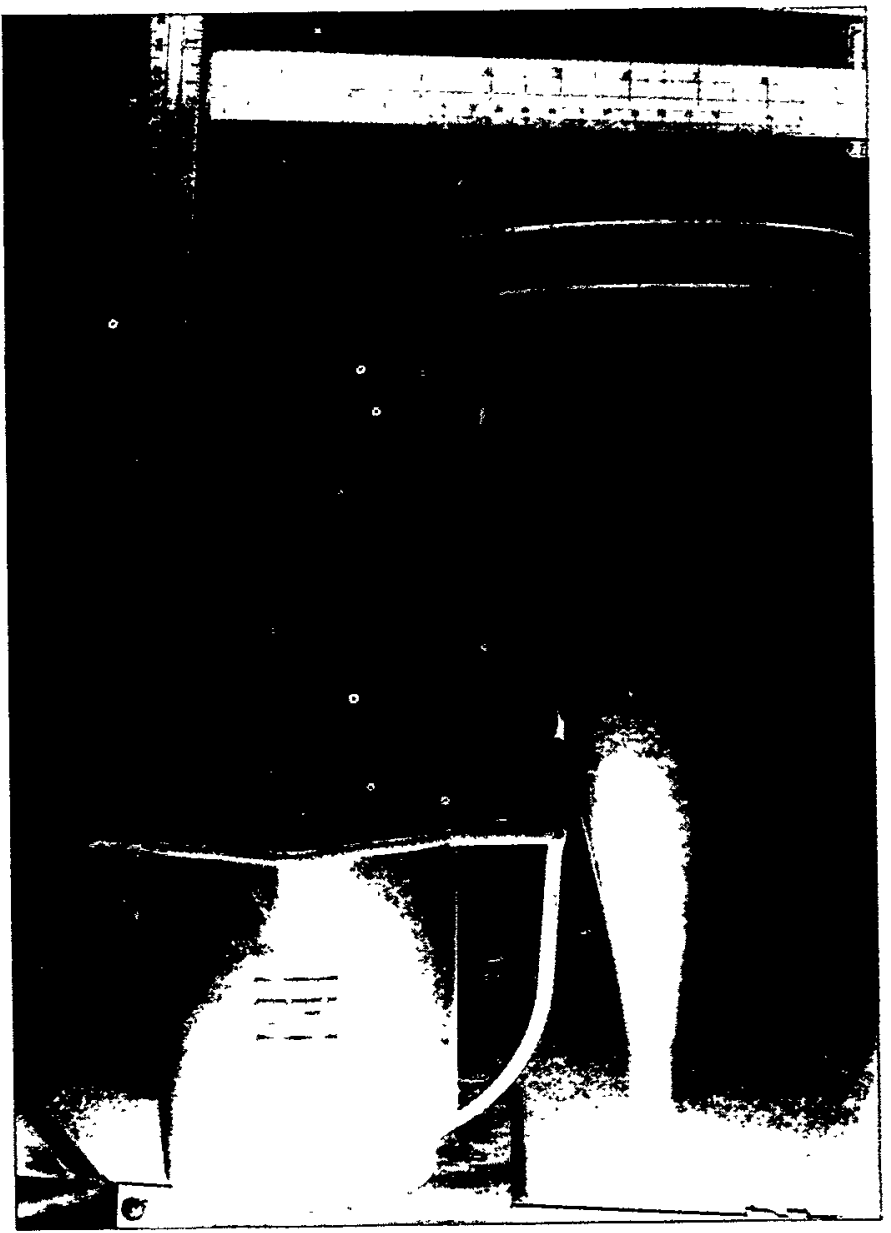

Figure 4.16 Marsh funnel and cup used to measure apparent viscosity. 
Table 4.3 Slurry Composition for Marsh Viscosity Tests

\begin{tabular}{|c|c|c|c|c|}
\hline Mix\# & Cement $(\mathrm{g})$ & Water $(\mathrm{g})$ & Bentonite $(\mathrm{g})$ & $\mathrm{w} / \mathrm{c} * *$ \\
\hline 1 & 1666 & 1000 & 33 & 0.6 \\
\hline 2 & 1544 & 1080 & 46 & 0.7 \\
\hline 3 & 1544 & 1390 & 76 & 0.9 \\
\hline 4 & 1000 & 450 & 0 & 0.45 \\
\hline 5 & 666 & 885 & 2 & 1.33 \\
\hline MC-500* & 1492 & 1492 & 0 & 1.0 \\
\hline
\end{tabular}

* MC-500 Microfine cement with 18 NS -200

** Water to cement ratio with respect to weight of cement

Mixes 1 through 5 contain Self-Stress II cement.

\subsubsection{Determination of Slurry Density}

\subsubsection{Apparatus}

1) Ertco hydrometer (S.G. = 1.00-2.00)

2) $1000 \mathrm{ml}$ graduated cylinder

\subsubsection{Test Procedure}

Prepare grout in accordance with Section 4.4.3. Gently pour approximately $600 \mathrm{ml}$ into a $1000 \mathrm{ml}$ graduated cylinder. Gently lower the hydrometer into the slurry until it floats freely. Record the density. Perform this measurement as quickly as possible to minimize any possible thixotropic behavior.

\subsubsection{Determination of Bleed Capacity}

Prepare grout in accordance with Section 4.4.3. Pour $1000 \mathrm{ml}$ into a $1000 \mathrm{ml}$ graduated cylinder. Record the volume of the slurry in the cylinder. Measure the free water above the slurry two hours after pouring. This is the bleed water. The volume of bleed water divided by the initial slurry volume is the bleed capacity (Shannon and Wilson, Inc., 1987, pp. 14-15).

\subsection{Eracture Grouting}

\subsubsection{Objective}

The objective of this procedure is to inject grout into a fracture. 


\subsubsection{Apparatus}

1) Uniaxial loading system described in the permeability testing procedure (Section 4.2.1)

2) Grout pump with vented piston (Schaffer and Daemen, 1987, p. 58)

3) Buffered pressure gauge (Ashcroft; $4 \mathrm{MPa}$ range, $10 \mathrm{kPa}$ accuracy)

4) High pressure tubing with pressure release valve

5) High pressure Victor regulator (L-TEC TYPE-89)

6) Micronta stop watch (1/100 second accuracy).

\subsubsection{Test Procedure}

Fracture grouting is performed using a single piston grout pump. This pump is capable of delivering $280 \mathrm{ml}$ of slurry at a maximum pressure of $13 \mathrm{MPa}$ (Figure 4.17).

After a constant normal load is applied to the fracture a high-pressure grout tube, equipped with a quick-fit adaptor, is attached to the lower loading platen. The other end of the tube is attached to the grout pump and pressure release valve. Teed into the high-pressure tubing at this point is a water buffered gauge used to monitor the grout injection pressure.

Prior to grouting, remove the top plate of the grout pump. Fill grout slurry previously prepared into the pump. Force the pump piston, with its bleed vent open, down into the pump until grout free of air bubbles can be seen exiting the vent. Close the vent. Bolt the top plate of the pump securely to the pump housing. Do this as quickly as possible.

Nitrogen gas is used to drive the piston and pressurize the grout slurry into the rock sample. A regulating valve is used to control the grouting pressure. The grouting pressure is maintained constant during grouting and should not exceed the normal stress applied to the fracture. The pressure is measured to the nearest $10 \mathrm{kPa}$. The test is terminated after the grout slurry flows out of the fracture or when displacement of the piston is not detectable for 5 to 10 minutes. Immediately after grouting, the grout tube is removed from the lower loading platen. The borehole is flushed with distilled water to remove excess grout slurry. Distilled water is then used to fill the hole during curing of the grout. Grouting and curing times are recorded. The permeability of the fracture after grouting is determined in accordance with the procedure given in Section 4.2.1.

\subsection{Determination of Fracture Compression Behavior}

\subsubsection{Introduction}

The aperture or width of a fracture is an important parameter for determining the ability of a grout to enter and travel along a fracture. To measure the actual aperture directly is virtually impossible due to the limited access and aperture variability. 


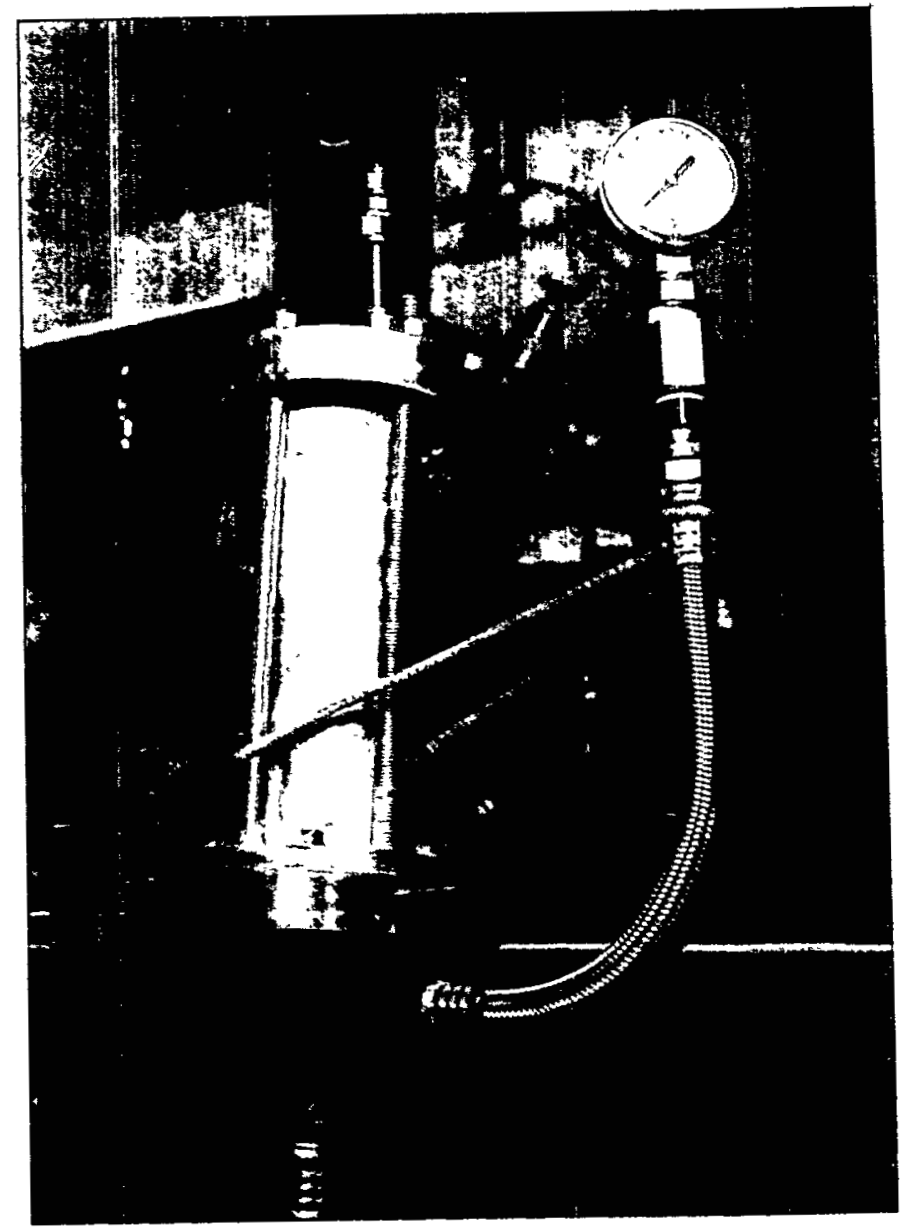

Figure 4.17 Single piston grout pump with gauge saver. 
One important aspect of the compression behavior of a fracture that can be measured easily is its stiffness or opening and closing behavior under normal stress. This procedure does not give the fracture aperture at any point but does provide information as to how the fracture width changes as a function of the axial stress applied to the sample.

This procedure assumes that the fracture compresses uniformly. Figure 4.18 shows the monitoring system.

\subsubsection{Apparatus}

1) clamping rings (O.D. $=21.0 \mathrm{~mm}$, I.D. $=16.0$ )

2) displacement dial gauge (Scherr-Tumico; $0.00254 \mathrm{~mm}$ precision)

3) caliper (0.0254 mm precision)

4) load frame (Cobb and Daemen, 1982, pp. 35-36)

5) loading platens (Schaffer and Daemen, 1987, p. 59)

6) hydraulic load cell (Enerpac JSL-1002)

7) hydraulic pump (Enerpac EH-80) with 41.4 MPa Acco Helicoid gauge

8) Micronta stop watch (1/100 second accuracy).

The loading system is identical to the one described in the procedure for measuring the permeability (Section 4.4.2).

\subsubsection{Measurement Method}

Mount the dial gauge vertically on the upper clamping ring.

Fix the top clamping ring with dial gauge attached to the top half of the specimen. Bolt the ring approximately $38 \mathrm{~mm}$ above the fracture. Use a bubble level to ensure that the ring is horizontal with respect to the top and bottom of the sample.

Fix the lower clamping ring on the bottom half of the sample and bolt approximately $38 \mathrm{~mm}$ below the fracture. As before, use a bubble level to ensure that the ring is horizontal.

Use a caliper to measure the vertical distance between the dial gauge mounting point and the end of its probe. Record this distance.

Place the sample, with both rings attached, in the loading frame with loading platens and hydraulic load cell resting on the sample. The weight of the platens and load cell correspond to a normal stress of $0.05 \mathrm{MPa}$.

At zero gauge pressure zero out the dial gauge.

Take readings in the following sequence of normal stresses: $0.05,1,2$, $3,4,5,6,7,8,9,10,9,8,7,6,5,4,3,2,1,0.05,1,2,3,4,5$, $6,7,8,9,10 \mathrm{MPa}$. Use a stop watch to time the reading interval between each stress level. Readings are taken thirty seconds after the desired normal stress is reached to allow some immediate time dependent compression to take place. 


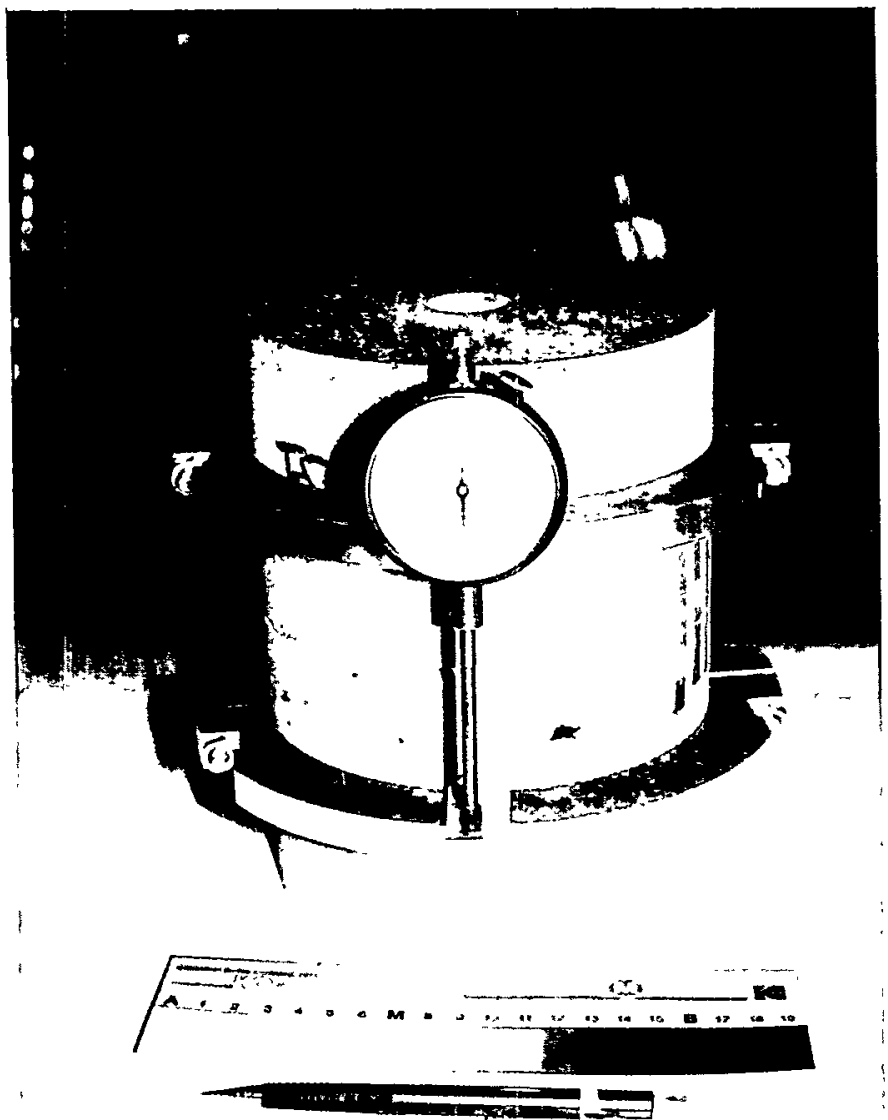

Figure 4.18 Fracture compression monitoring system. 
Run three sequential tests for each loading cycle described above. Zero the dial gauge prior to each test to account for surface deformation.

The fracture compression is obtained by subtracting the calculated intact rock compression from the measured dial gauge reading. The intact rock compression is calculated from $\left(\sigma_{a x} / E\right) L$, where $\sigma_{a x}$ is the axial stress, $E$ is the Young's modulus of the rock, and $L$ is the length in between the measuring points.

If the angle $\theta$ between the normal to the fracture surface and the cylinder axis deviates appreciably from 0 , the normal stress across the fracture surface may be calculated by $\sigma_{n}=\sigma_{a x} \sin ^{2} \theta$ (Jaeger and Cook, 1979, p. 141). 


\section{CHAPTER FIVE}

\section{EXPERIMENTAL RESULTS}

\subsection{Permeability of Intact Tuff}

Prior to determining the permeability of a fracture within a rock sample, the permeability of the "intact" rock itself is measured. The matrix permeability of eight samples prepared from three types of densely welded tuff has been tested. Figure 5.1 shows samples of the three types of tuff. Figure 5.2 shows the hydraulic conductivities of samples of the three types of tuff as a function of axial stress. The maximum load on each sample is less than 35 percent of its estimated uniaxial compressive strength. Fuenkajorn and Daemen (1991) give detailed descriptions of the rocks, of their source locations and of their properties.

One would expect that the greater the density and degree of welding, indicating a smaller void ratio, the greater the resistance to flow. This presumption is supported by Figure 5.2. Sample T-1-6-FG9 (nonweIded A-Mountain tuff) shows the greatest permeability, sample AP3-1-6FG6 (Apache Leap tuff) ${ }^{1}$ the lowest permeability. All three samples show the same magnitude of permeability (approximately $10^{-7} \mathrm{~cm} / \mathrm{s}$ ). Related work on Apache Leap Tuff and on A-Mountain Tuff shows similar permeabilities (Fuenkajorn and Daemen, 1991).

Figure 5.3 shows the effect of axial stress on the permeability of Apache Leap tuff. Permeability decreases as axial stress increases. This is presumably due to the closing of microfractures, or due to a change in the geometry of the pore spaces, or both. Permeabilities range from $10^{-9}$ to $10^{-9} \mathrm{~cm} / \mathrm{s}$ at $0.05 \mathrm{MPa}$ axial stress and $10^{-8}$ to $10^{-9}$ $\mathrm{cm} / \mathrm{s}$ at $10 \mathrm{MPa}$ axial stress. Sample AP7-1-6-FG4 (Figure 5.4) developed a fracture at $5 \mathrm{MPa}$ axial stress, which accounts for the large increase in flow at that point. On all samples the greatest reduction in flow occurs at low axial stress. Tables 5.1 through 5.8 contain test data. Test data are averaged at each axial stress.

\subsection{Fracture Permeability}

The permeability of a fracture is calculated by assuming that the intact rock permeability is negligible, that the fracture has smooth parallel surfaces, and that the radial flow normal to the borehole is laminar. The relation between flow and the pressure gradient is governed by the "cubic law" using the theory of incompressible viscous flow (Snow, 1965;

1 All Apache Leap tuff tested in work reported on here is from the densely welded brown unit, Superior, Arizona. 


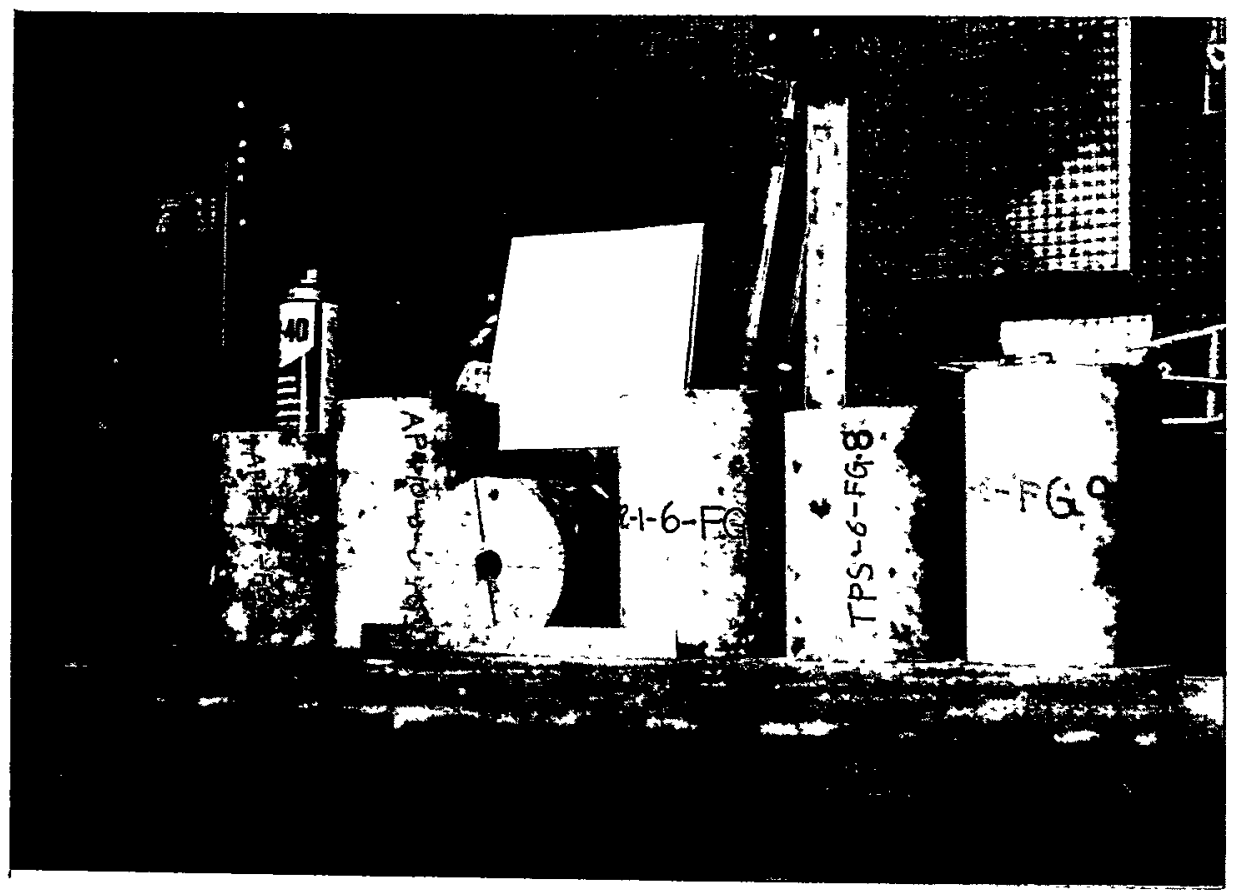

Figure 5.1 Three types of tuff. A-Mountain (far right), Topopah Spring (second from right), and Apache Leap (four samples on left). 


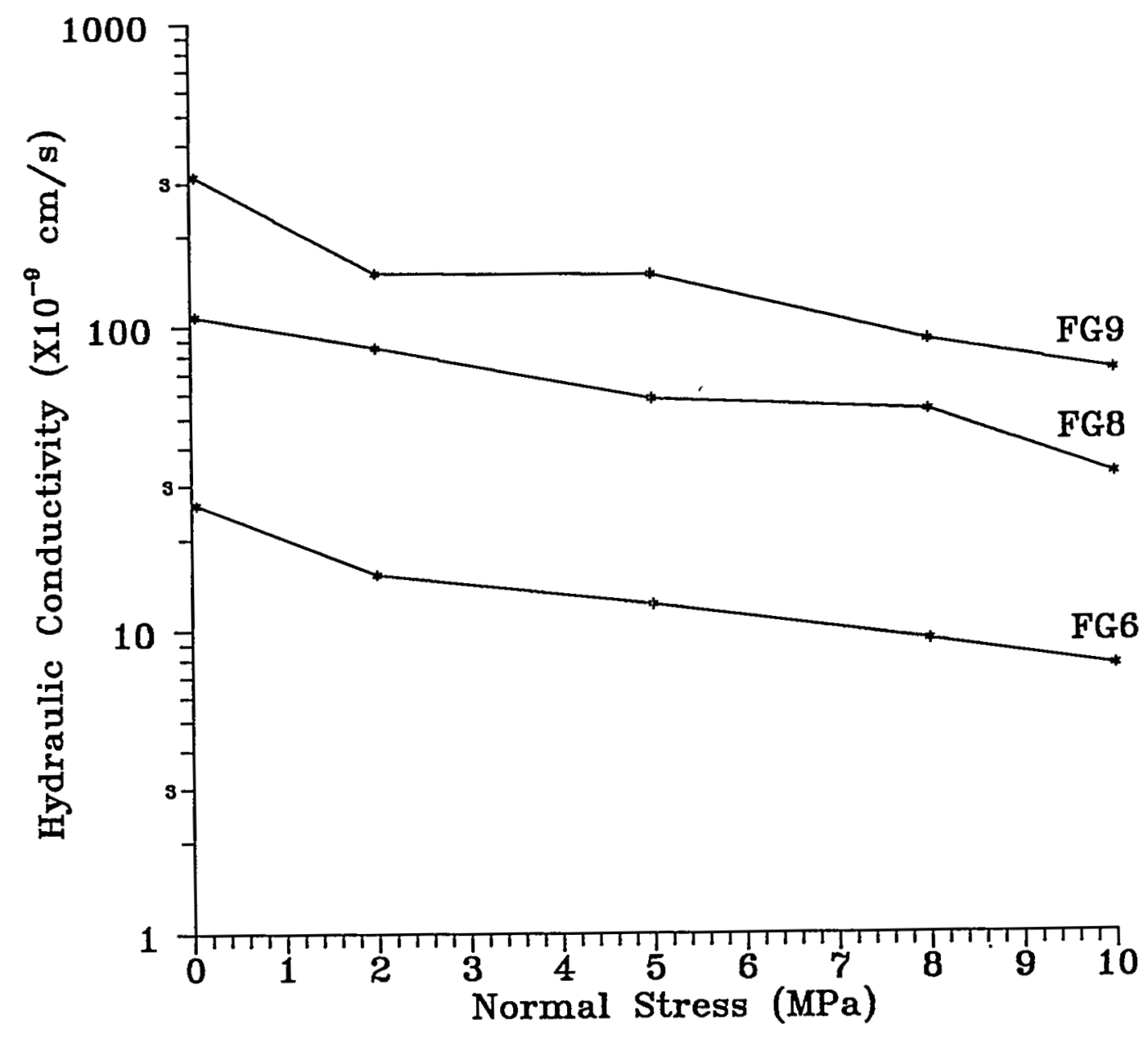

Figure 5.2 Hydraulic conductivity of intact Apache Leap tuff (FG6), Topopah Spring tuff (FG8), and A-Mountain tuff (FG9) cylinders as a function of axial stress. Each data point represents the average of all test runs for each normal stress. 


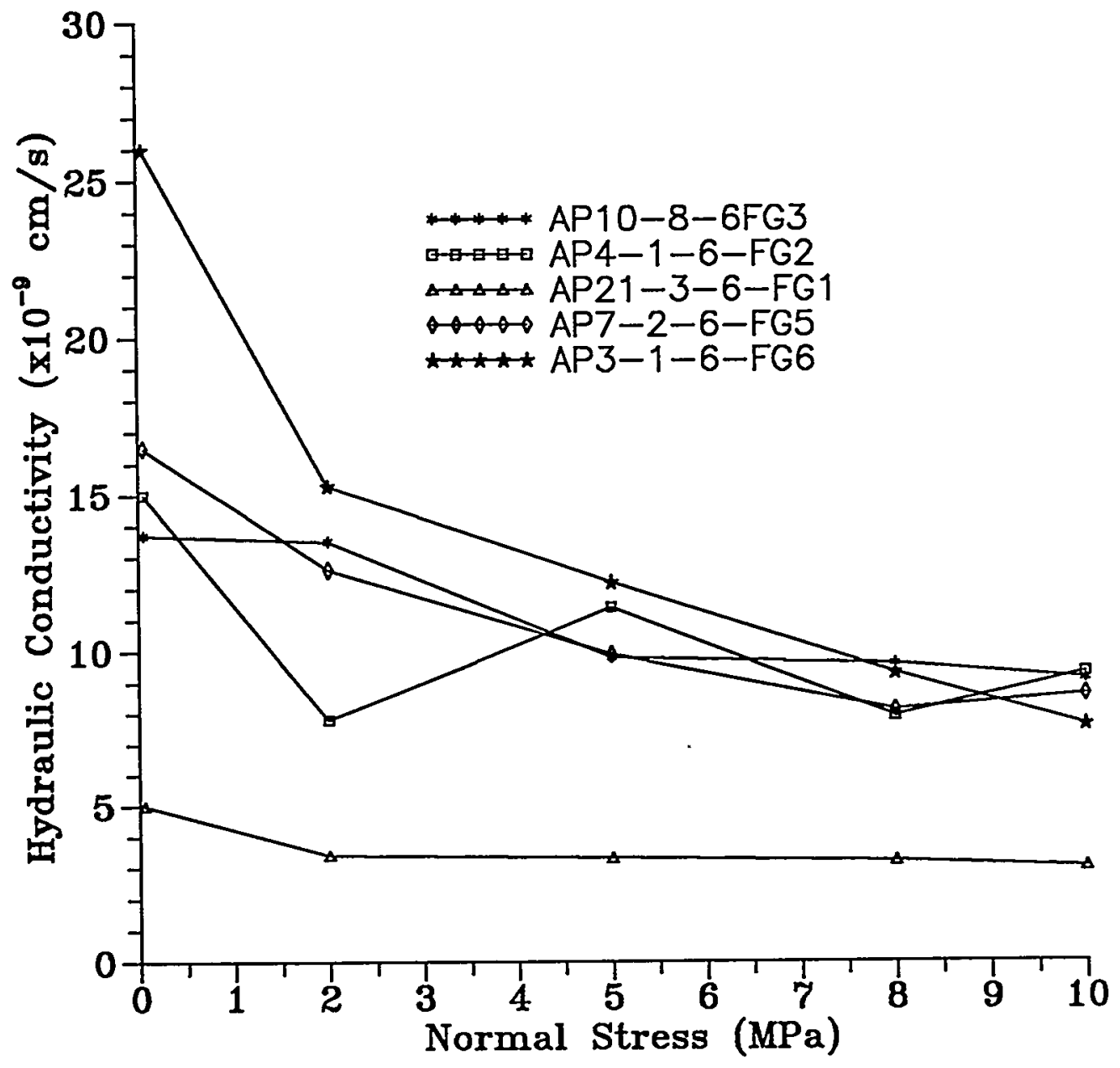

Figure 5.3 Effect of axial stress on hydraulic conductivity of intact Apache Leap tuff. 


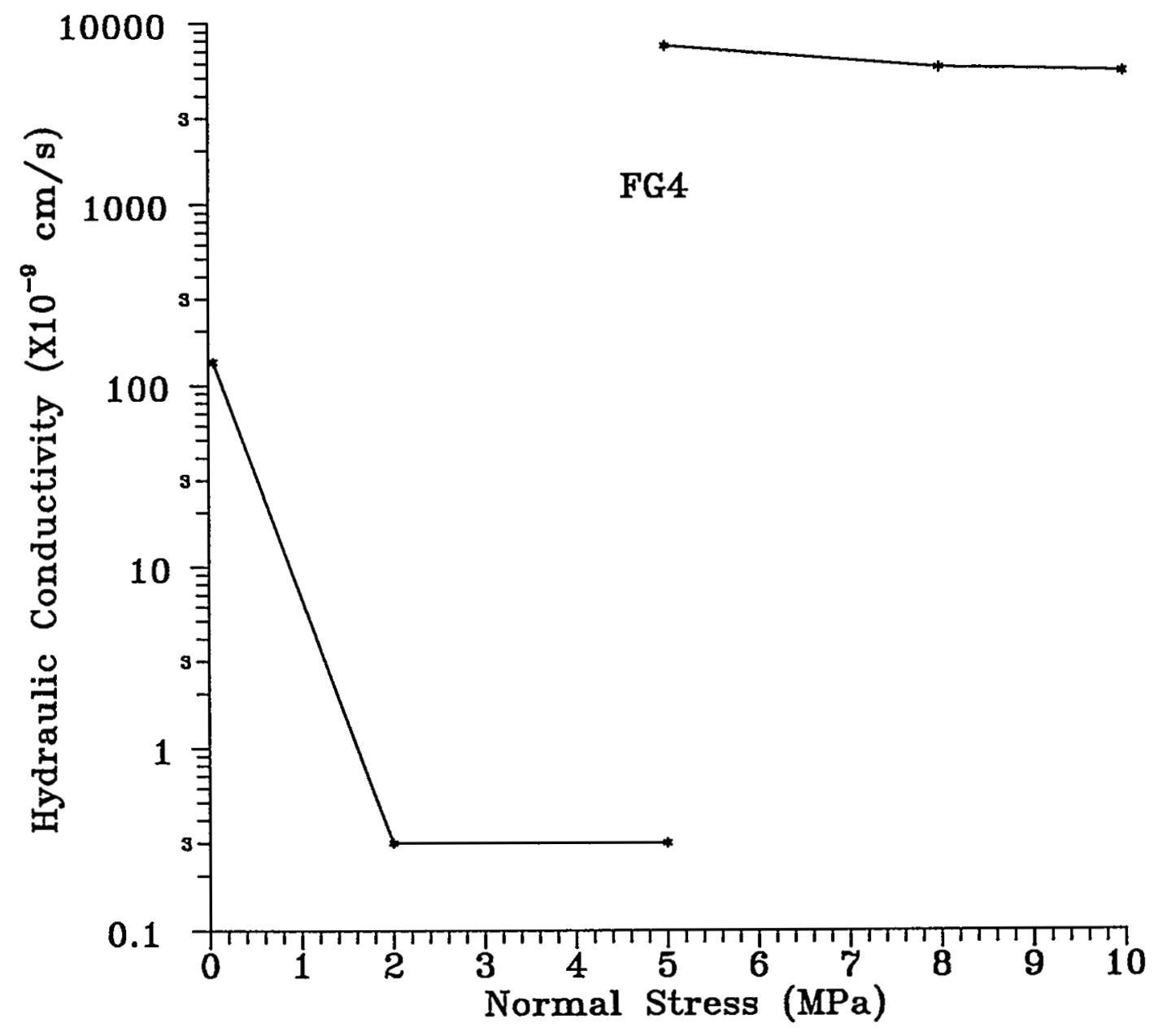

Figure 5.4 Effect of axial stress on the permeability of intact sample AP7-1-6-FG4. The break in the graph at $5 \mathrm{MPa}$ normal stress is a result of the development of a vertical crack. 
Table 5.1 Results of Falling Head Test on Intact Sample AP21-3-6-FG1.

\begin{tabular}{|c|c|c|c|c|c|}
\hline $\begin{array}{c}\text { Number of } \\
\text { Readings }\end{array}$ & $\begin{array}{c}\sigma_{\alpha x} \\
(\mathrm{MPa})\end{array}$ & $\begin{array}{c}\mathrm{K} \\
\left(\mathrm{x} 10^{-9} \mathrm{~cm} / \mathrm{s}\right)\end{array}$ & $\begin{array}{c}\mathrm{h}_{\mathrm{O}} \\
(\mathrm{cm})\end{array}$ & $\begin{array}{c}\mathrm{h}_{f} \\
(\mathrm{~cm})\end{array}$ & $\begin{array}{c}\mathrm{SD}(\mathrm{K}) \\
\left(\mathrm{x} 10^{-12}\right)\end{array}$ \\
\hline 3 & 0.05 & 5.0 & 126.7 & 119.7 & 0.6 \\
\hline 3 & 2 & 3.4 & 121.2 & 111.2 & 0.2 \\
\hline 2 & 5 & 3.3 & 121.2 & 116.4 & 0.1 \\
\hline 3 & 8 & 3.2 & 126.0 & 120.8 & 0.1 \\
\hline 2 & 10 & 3.0 & 126.0 & 122.6 & 0 \\
\hline
\end{tabular}

Table 5.2 Results of Falling Head Test on Intact Sample AP4-1-6-FG2.

\begin{tabular}{|c|c|c|c|c|c|}
\hline $\begin{array}{c}\text { Number of } \\
\text { Readings }\end{array}$ & $\begin{array}{c}\sigma_{\alpha x} \\
(\mathrm{MPa})\end{array}$ & $\begin{array}{c}\mathrm{K} \\
\left(\mathrm{x} 10^{-9} \mathrm{~cm} / \mathrm{s}\right)\end{array}$ & $\begin{array}{c}\mathrm{h}_{\mathrm{o}} \\
(\mathrm{cm})\end{array}$ & $\begin{array}{c}\mathrm{h}_{f} \\
(\mathrm{~cm})\end{array}$ & $\begin{array}{c}\mathrm{SD}(\mathrm{K}) \\
(\mathrm{x} \mathrm{10-9})\end{array}$ \\
\hline 3 & 0.05 & 15 & 126.0 & 108.6 & 0 \\
\hline 3 & 2 & 7.8 & 126.0 & 116.6 & 1.6 \\
\hline 3 & 5 & 11.4 & 126.0 & 117.1 & 2.6 \\
\hline 2 & 8 & 7.9 & 126.0 & 119.0 & 0.3 \\
\hline 2 & 10 & 9.3 & 126.0 & 120.6 & 0.1 \\
\hline
\end{tabular}

Table 5.3 Results of Falling Head Test on Intact Sample AP10-8-6-FG3.

\begin{tabular}{|c|c|c|c|c|c|}
\hline $\begin{array}{c}\text { Number of } \\
\text { Readings }\end{array}$ & $\begin{array}{c}\sigma_{\mathrm{ax}} \\
(\mathrm{MPa})\end{array}$ & $\begin{array}{c}\mathrm{K} \\
\left(\mathrm{x} 10^{-9} \mathrm{~cm} / \mathrm{s}\right)\end{array}$ & $\begin{array}{c}\mathrm{h}_{\mathrm{o}} \\
(\mathrm{cm})\end{array}$ & $\begin{array}{c}\mathrm{h}_{\mathrm{f}} \\
(\mathrm{cm})\end{array}$ & $\begin{array}{c}\mathrm{SD}(\mathrm{K}) \\
\left(\mathrm{x} 10^{-9}\right)\end{array}$ \\
\hline 2 & 0.05 & 13.7 & 126.0 & 111.5 & 1.7 \\
\hline 2 & 2 & 13.5 & 126.0 & 116.8 & 4.7 \\
\hline 3 & 5 & 9.8 & 126.0 & 110.1 & 0.2 \\
\hline 2 & 8 & 9.6 & 126.0 & 118.5 & 0.1 \\
\hline 3 & 10 & 9.1 & 126.0 & 116.8 & 0.2 \\
\hline
\end{tabular}

\footnotetext{
$\sigma_{a x}=\operatorname{axial}$ stress

$\mathrm{K}$ - intact hydraulic conductivity

$h_{0}=$ initial height of water in pipette measured from the midsection of the sample

$h_{f}=$ final height of water in pipette

SD = standard deviation about the mean.
} 
Table 5.4 Results of Flow Testing Intact Sample AP7-1-6-FG4.

\begin{tabular}{|c|c|c|c|c|c|}
\hline $\begin{array}{c}\text { Number of } \\
\text { Readings }\end{array}$ & $\begin{array}{c}\sigma_{a x} \\
(\mathrm{MPa})\end{array}$ & $\begin{array}{c}\mathrm{K} \\
\left(\mathrm{x} 10^{-9} \mathrm{~cm} / \mathrm{s}\right)\end{array}$ & $\begin{array}{c}\mathrm{P}_{i} \\
(\mathrm{~cm})\end{array}$ & $\begin{array}{c}\Delta h \\
(\mathrm{~cm})\end{array}$ & $\begin{array}{c}\mathrm{SD}(\mathrm{K}) \\
\left(\mathrm{x} \mathrm{10^{-9 }}\right)\end{array}$ \\
\hline 3 & 0.05 & 134.3 & 0.15 & 1496 & 56.1 \\
\hline 3 & 2 & 0.3 & 1.0 & 9993 & 0.06 \\
\hline 3 & 5 & 0.3 & 2.0 & 20033 & 0.1 \\
\hline \multicolumn{6}{|c|}{ SAMPLE FRACTURES ALONG A PREXISTING DISCONTINUTIY } \\
\hline 1 & 5 & 7500 & 2.0 & 19993 & 0 \\
\hline 1 & 8 & 5700 & 2.0 & 19991 & 0 \\
\hline 1 & 10 & 5400 & 2.0 & 19990 & 0 \\
\hline
\end{tabular}

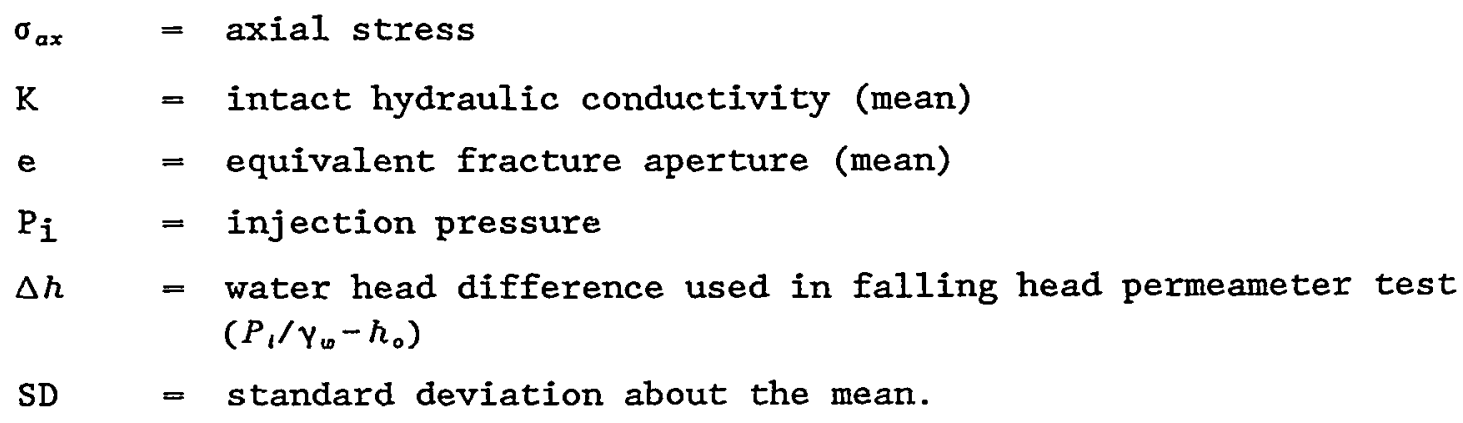

Table 5.5 Results of Falling Head Test on Intact Sample AP7-2-6-FG5.

\begin{tabular}{|c|c|c|c|c|c|}
\hline $\begin{array}{c}\text { Number of } \\
\text { Readings }\end{array}$ & $\begin{array}{c}\sigma_{a x} \\
(\mathrm{MPa})\end{array}$ & $\begin{array}{c}\mathrm{K} \\
\left(\mathrm{x} 10^{-9} \mathrm{~cm} / \mathrm{s}\right)\end{array}$ & $\begin{array}{c}\mathrm{h}_{\mathrm{o}} \\
(\mathrm{cm})\end{array}$ & $\begin{array}{c}\mathrm{h}_{\mathrm{f}} \\
(\mathrm{cm})\end{array}$ & $\begin{array}{c}\mathrm{SD}(\mathrm{K}) \\
\left(\mathrm{x} \mathrm{10^{-9 }}\right)\end{array}$ \\
\hline 2 & 0.05 & 16.5 & 126.0 & 112.0 & 0.6 \\
\hline 3 & 2 & 12.6 & 126.0 & 109.0 & 0.2 \\
\hline 2 & 5 & 9.9 & 126.0 & 119.6 & 0.6 \\
\hline 2 & 8 & 8.1 & 126.0 & 115.5 & 0.1 \\
\hline 2 & 10 & 8.6 & 126.0 & 120.5 & 0.4 \\
\hline
\end{tabular}

\footnotetext{
$\sigma_{a x}=$ axial stress

$\mathrm{K}=$ intact hydraulic conductivity

$h_{0}=$ initial height of water in pipette measured from the midsection of the sample

$h_{f}=$ final height of water in pipette

$\mathrm{SD}=$ standard deviation about the mean.
} 
Table 5.6 Results of Falling Head Test on Intact Sample AP3-1-6-FG6.

\begin{tabular}{|c|c|c|c|c|c|}
\hline $\begin{array}{c}\text { Number of } \\
\text { Readings }\end{array}$ & $\begin{array}{c}\sigma_{\alpha x} \\
(\mathrm{MPa})\end{array}$ & $\begin{array}{c}\mathrm{K} \\
\left(\mathrm{x} 10^{-9} \mathrm{~cm} / \mathrm{s}\right)\end{array}$ & $\begin{array}{c}\mathrm{h}_{\mathrm{O}} \\
(\mathrm{cm})\end{array}$ & $\begin{array}{c}\mathrm{h}_{f} \\
(\mathrm{~cm})\end{array}$ & $\begin{array}{c}\mathrm{SD}(\mathrm{K}) \\
\left(\mathrm{x} 10^{-9}\right)\end{array}$ \\
\hline 7 & 0.05 & 26.0 & 126.0 & 117.8 & 0.8 \\
\hline 7 & 2 & 15.3 & 126.0 & 103.5 & 0.5 \\
\hline 6 & 5 & 12.2 & 126.0 & 118.3 & 0.4 \\
\hline 9 & 8 & 9.3 & 126.0 & 117.3 & 0.9 \\
\hline 9 & 10 & 7.6 & 126.0 & 117.6 & 0.5 \\
\hline
\end{tabular}

Table 5.7 Results of Falling Head Test on Intact Sample TPS-6-FG8.

\begin{tabular}{|c|c|c|c|c|c|}
\hline $\begin{array}{c}\text { Number of } \\
\text { Readings }\end{array}$ & $\begin{array}{c}\sigma_{a x} \\
(\mathrm{MPa})\end{array}$ & $\begin{array}{c}\mathrm{K} \\
\left(\mathrm{x} 10^{-9} \mathrm{~cm} / \mathrm{s}\right)\end{array}$ & $\begin{array}{c}\mathrm{h}_{\mathrm{O}} \\
(\mathrm{cm})\end{array}$ & $\begin{array}{c}\mathrm{h}_{f} \\
(\mathrm{~cm})\end{array}$ & $\begin{array}{c}\mathrm{SD}(\mathrm{K}) \\
\left(\mathrm{x} 10^{-9}\right)\end{array}$ \\
\hline 3 & 0.05 & 107.7 & 126.0 & 110.8 & 6.1 \\
\hline 3 & 2 & 85.3 & 126.0 & 116.8 & 14.1 \\
\hline 3 & 5 & 58.0 & 126.0 & 113.2 & 1.7 \\
\hline 2 & 8 & 53.0 & 126.0 & 116.6 & 1.4 \\
\hline 3 & 10 & 32.7 & 126.0 & 111.1 & 3.1 \\
\hline
\end{tabular}

Table 5.8 Results of Falling Head Test on Intact Sample T-1-6-FG9.

\begin{tabular}{|c|c|c|c|c|c|}
\hline $\begin{array}{c}\text { Number of } \\
\text { Readings }\end{array}$ & $\begin{array}{c}\sigma_{a x} \\
(\mathrm{MPa})\end{array}$ & $\begin{array}{c}\mathrm{K} \\
\left(\mathrm{x} 10^{-9} \mathrm{~cm} / \mathrm{s}\right)\end{array}$ & $\begin{array}{c}\mathrm{h}_{\mathrm{O}} \\
(\mathrm{cm})\end{array}$ & $\begin{array}{c}\mathrm{h}_{\mathrm{f}} \\
(\mathrm{cm})\end{array}$ & $\begin{array}{c}\mathrm{SD}(\mathrm{K}) \\
(\mathrm{x} \mathrm{10}-9)\end{array}$ \\
\hline 14 & 0.05 & 314.3 & 126.0 & 102.0 & 49.3 \\
\hline 17 & 2 & 150.0 & 126.0 & 107.7 & 10.0 \\
\hline 7 & 5 & 148.6 & 126.0 & 106.0 & 3.8 \\
\hline 4 & 8 & 90.0 & 126.0 & 105.5 & 18.3 \\
\hline 6 & 10 & 71.7 & 126.0 & 107.3 & 4.1 \\
\hline
\end{tabular}

\footnotetext{
$\sigma_{a x}=\operatorname{axial}$ stress

$\mathrm{K}=$ intact hydraulic conductivity

$h_{0}=$ initial height of water in pipette measured from the midsection of the sample

$h_{f}=$ final height of water in pipette

$\mathrm{SD}=$ standard deviation about the mean.
} 
Wilson and Witherspoon, 1970). Equations for the equivalent fracture aperture and fracture permeability are given in Section 2.2, which also discusses the validity and some limitations of these flow laws.

At low normal stresses ( $<2 \mathrm{MPa}$ ) the relationship between permeability and stress is non-linear. A small change in stress produces a large change in the slope of the curve. This effect will later be seen to be less pronounced at intermediate normal stresses ( $2 \mathrm{MPa}<\sigma_{n}<5 \mathrm{MPa}$ ). In some cases at high normal stress ( $>5 \mathrm{MPa}$ ), the relation is almost linear.

A simplified relation between permeability and stress is used to describe the flow behavior of several samples. This relation can be affected by several factors such as the initial seating or orientation of the fracture surfaces, the presence and resulting opening or closing of microfractures in the sample, the formation of new fractures resulting in new flow conduits, and the deformation of surface asperities making initial surface contact and thereby carrying a higher percentage of the load.

The initial seating of the fracture surfaces, with their once perfectly mated asperities, controls the equivalent fracture aperture and thereby dictates the permeability at low normal stress. Any surface misalignment, even a minuscule one, leads to a large change in the slope of the curve at low normal stress. This large change in slope is observed in all samples tested, and continues until the fracture surfaces are again in very close proximity to each other. At this point fracture deformation presumably becomes uniform over all of the fracture surface, accounting for the more continuous slope of the permeability versus stress curves.

Under compression the cross-sectional area available for flow decreases, and resistance to flow increases. As the fracture surfaces come in contact and the surface asperities mesh, the flow is effectively halted at these points. Any resulting flow is forced to find alternative pathways resulting in discrete fingers of flow. The assumption of radial flow may not be valid when these preferential flow paths are created (Tsang and Witherspoon, 1981). If the fractures remain open the velocity profile would most likely take the form of a two dimensional parabolic surface with a viscous sublayer effect at the surface boundaries. With the tight fractures studied here fluid travel probably resembles flow through a porous medium (Detournay, 1980).

The geometry of the effective flow area dictates the paths or channels available for fluid movement. The surface roughness along these paths induces numerous changes in flow direction. These changes increase the travel distance and the associated pressure drop away from the injection hole. 
Figures 5.5 through 5.26 show the effect of normal stress on fracture permeability and equivalent fracture aperture. Each sample is loaded, then unloaded, and reloaded without interrupting the flow. Arrows on the curves show the loading path. Each data point represents the average of all readings at each normal stress. Tables 5.9 through 5.19 contain test data.

The greatest reduction in flow occurs at low normal stress on the first loading cycle, presumably due to initial surface mating and the closing of microfractures, or due to a change in the geometry of the pore spaces. Also evident is an irreversible decrease in permeability after the first loading/unloading cycle. Some hysteresis occurs due to the permanent deformation of asperities and the resulting better mating of the fracture surfaces. As the fracture surfaces come closer together and surface asperities deform the fracture aperture decreases. The aperture never regains its former width on subsequent loading/unloading cycles. These irreversible reductions in fracture permeability and equivalent fracture aperture agree with many results, e.g. Schaffer and Daemen (1987), Iwai (1976), Johnson (1983).

Tension-induced fractures created by point loading generally are planar and normal to the core axis. Surface asperities seem evenly distributed on both surfaces. When placed back together these fractures are easily mated in their original position. Fracture permeabilities for these samples range from $10^{-3} \mathrm{~cm} / \mathrm{s}$ at $0.05 \mathrm{MPa}$ to $10^{-5} \mathrm{~cm} / \mathrm{s}$ at $10 \mathrm{MPa}$ normal stress. Tables 5.9 through 5.12 show the permeability parameters.

The sawcuts are smooth to the touch and more closely match the assumption made in calculating hydraulic conductivity of smooth parallel plates. These surfaces match at any rotation, with little chance of surface mismatch. The lack of surface asperities lessens the possibility of the fractures being propped open, which would result in high permeabilities. The hydraulic conductivity of this type of fracture ranges from $10^{-1} \mathrm{~cm} / \mathrm{s}$ at $0.05 \mathrm{MPa}$ to about $10^{-5} \mathrm{~cm} / \mathrm{s}$ at $10 \mathrm{MPa}$ normal stress (Tables 5.13 through 5.15). Figure 5.15 shows the higher permeability of sawcut sample (FG5) due to an initially unobserved natural fracture and the eventual failure of the sample under the applied injection pressure.

The final type of fractures tested are natural fractures. These natural fracture surfaces are discolored, presumably due to mineral staining (alteration products of rock forming minerals). They are generally clean, with little gouge present. Fracture permeabilities for natural fractures range from $10^{-1} \mathrm{~cm} / \mathrm{s}$ at $0.05 \mathrm{MPa}$ to $2 \times 10^{-3} \mathrm{~cm} / \mathrm{s}$ at $10 \mathrm{MPa}$ normal stress (Tables 5.16 through 5.19). In an attempt to speed up testing for natural fracture sample AP56-3-6-FG15 (Figure 5.25) permeability measurements were taken only during the final loading cycle after the sample had been loaded in the usual sequence. 


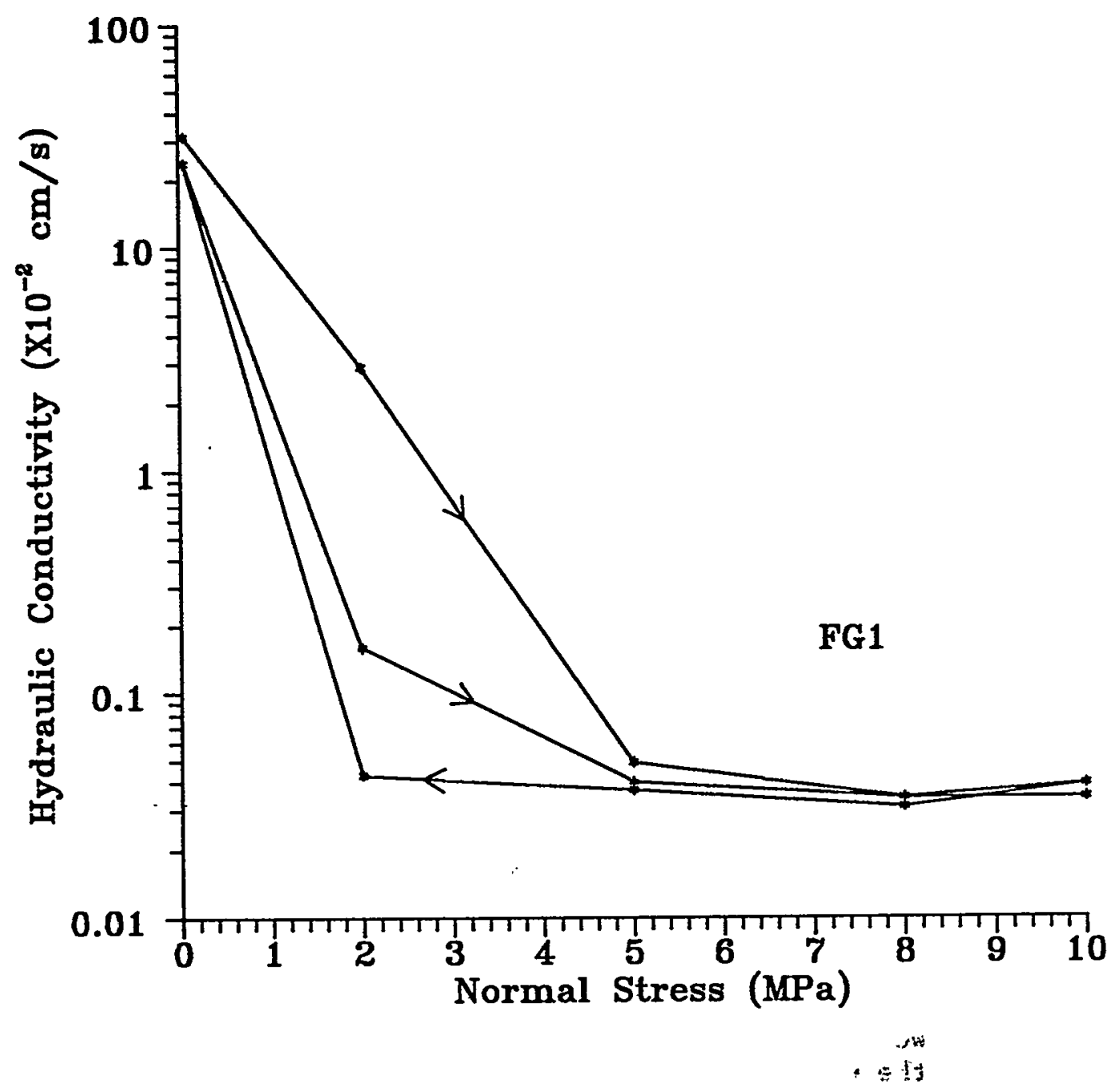

Figure 5.5 Hydraulic conductivity as a function of normal stress for sample AP21-3-6-FG1 (tension-induced fracture). Arrows indicate the loading sequence. 


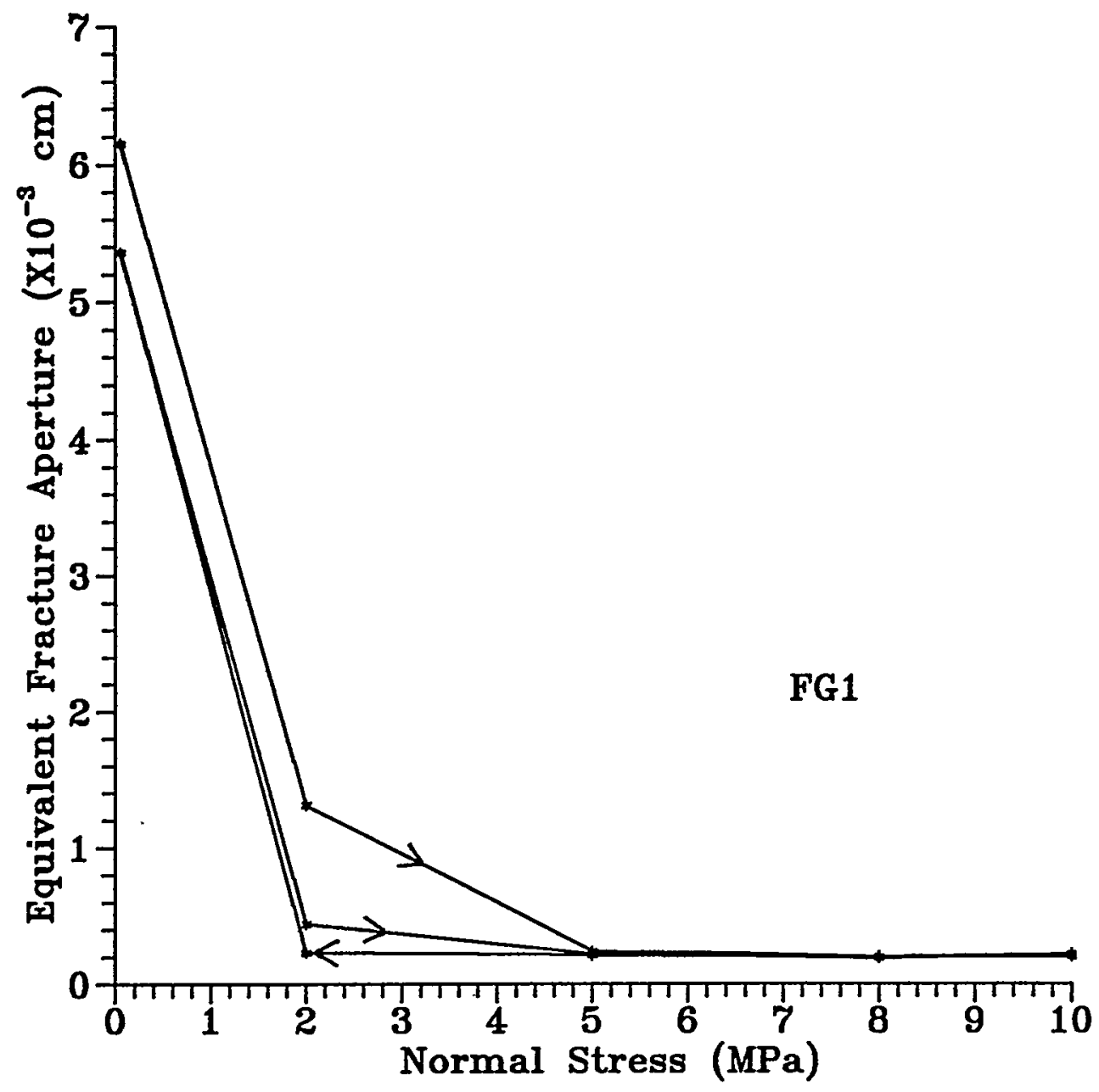

Figure 5.6 Equivalent fracture aperture as a function of normal stress for sample AP21-3-6-FGI (tension-induced fracture). Arrows indicate the loading sequence. 


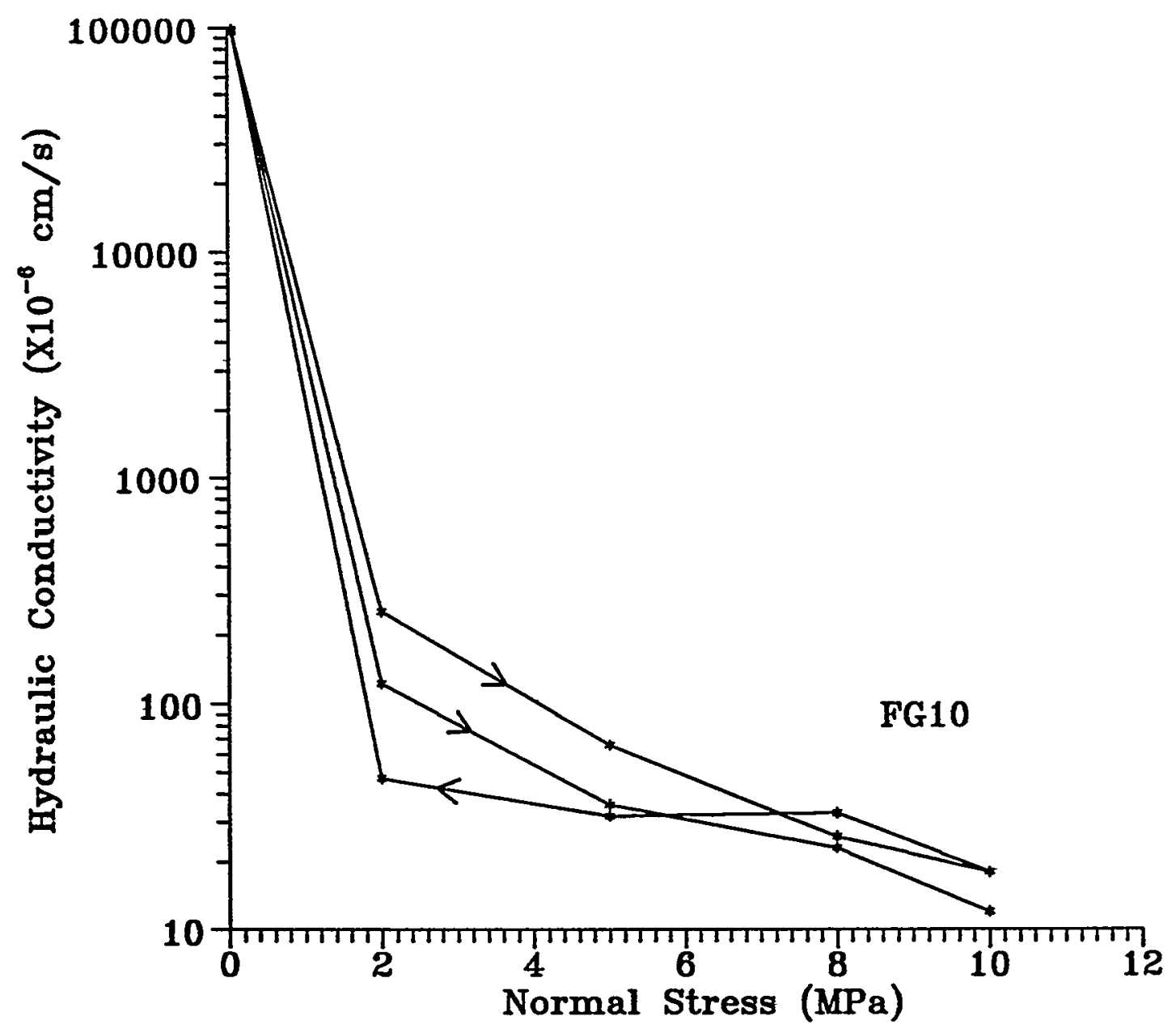

Figure 5.7 Hydraulic conductivity as a function of normal stress for sample AP30-2-6-FG10 (tension-induced fracture). Arrows indicate the loading sequence. 


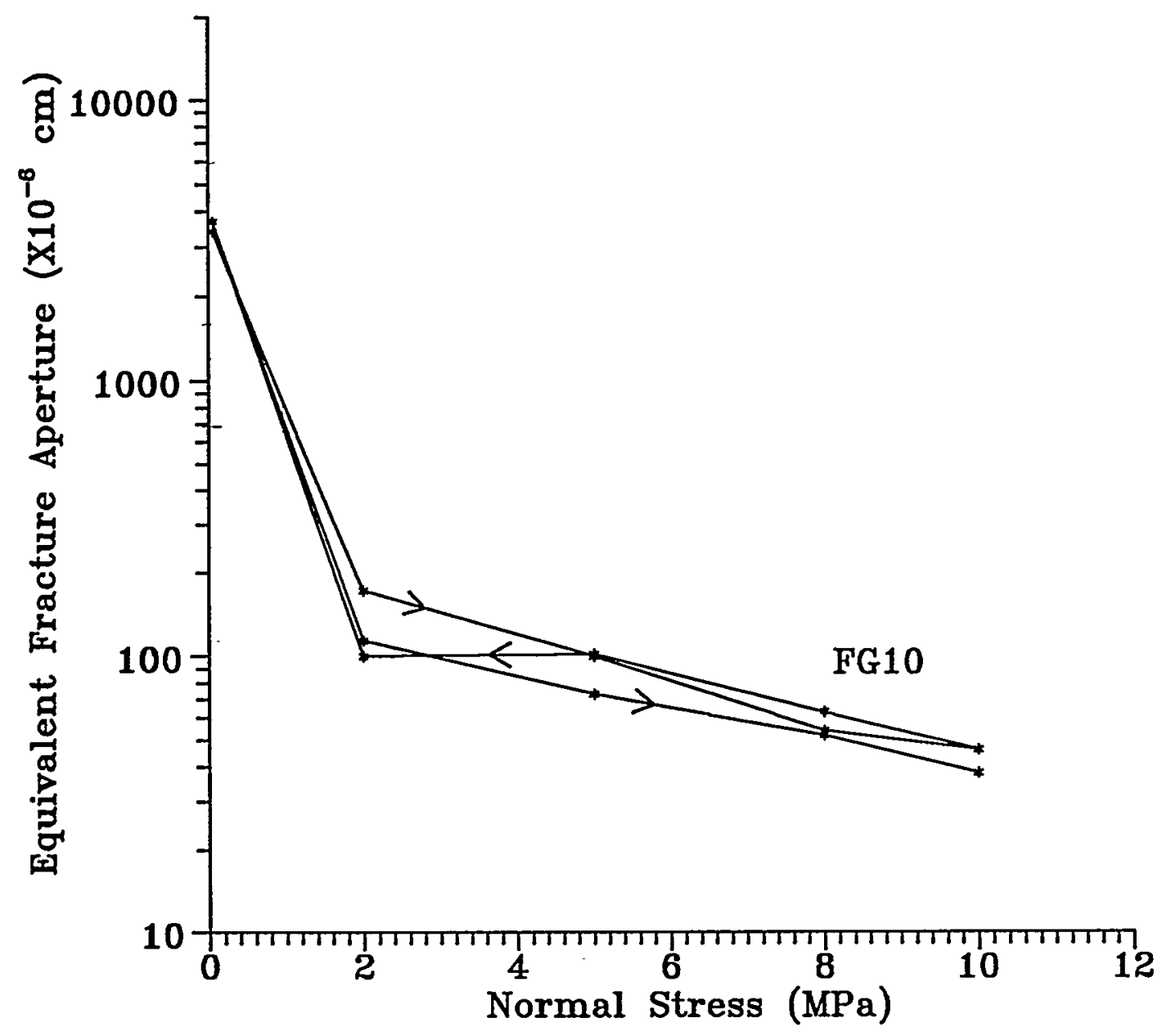

Figure 5.8 Equivalent fracture aperture as a function of normal stress for sample AP30-2-6-FG10 (tension-induced fracture). Arrows indicate the loading sequence. 


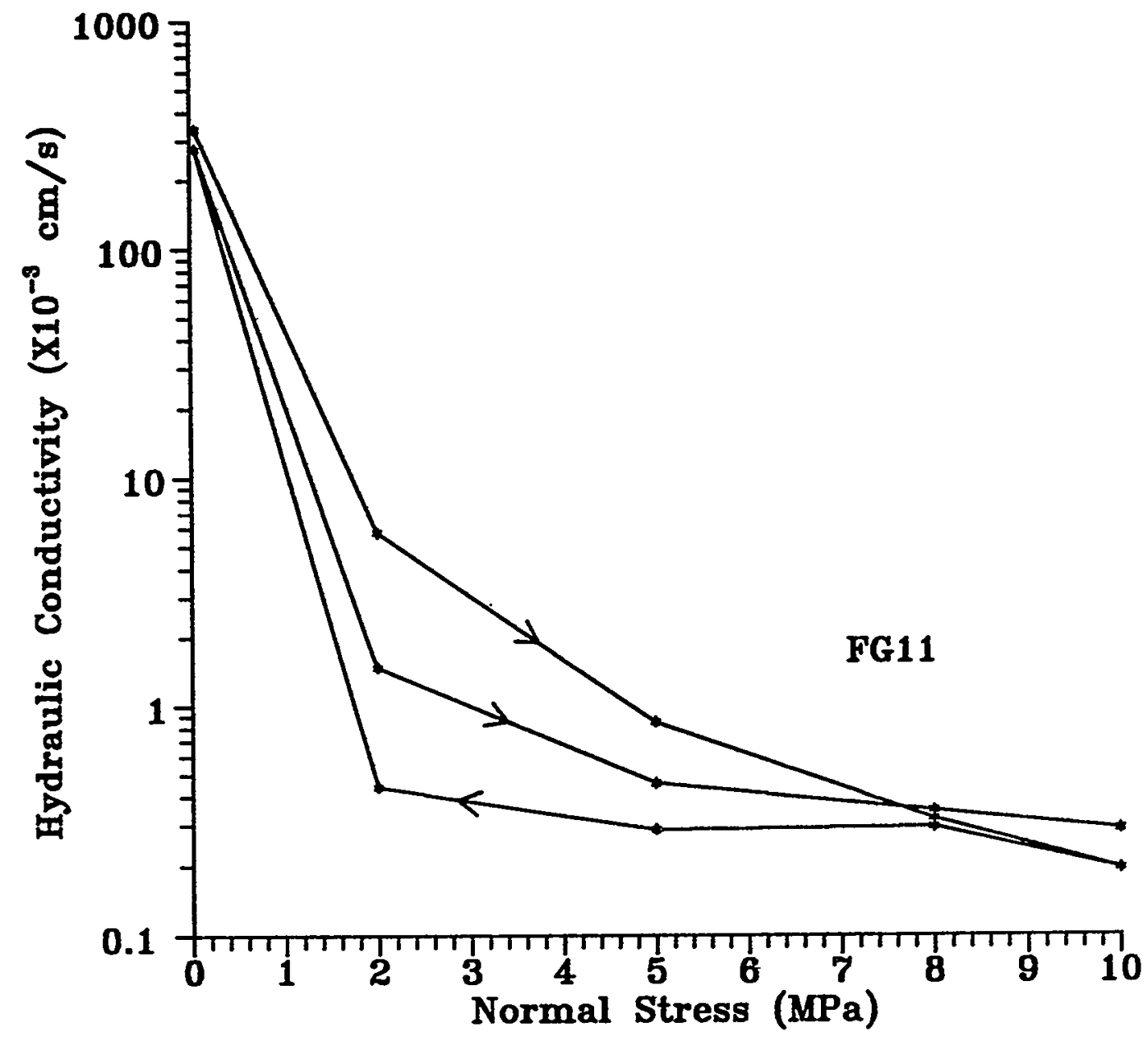

Figure 5.9 Hydraulic conductivity as a function of normal stress for sample AP30-1-6-FG11 (tension-induced fracture). Arrows indicate the loading sequence. 

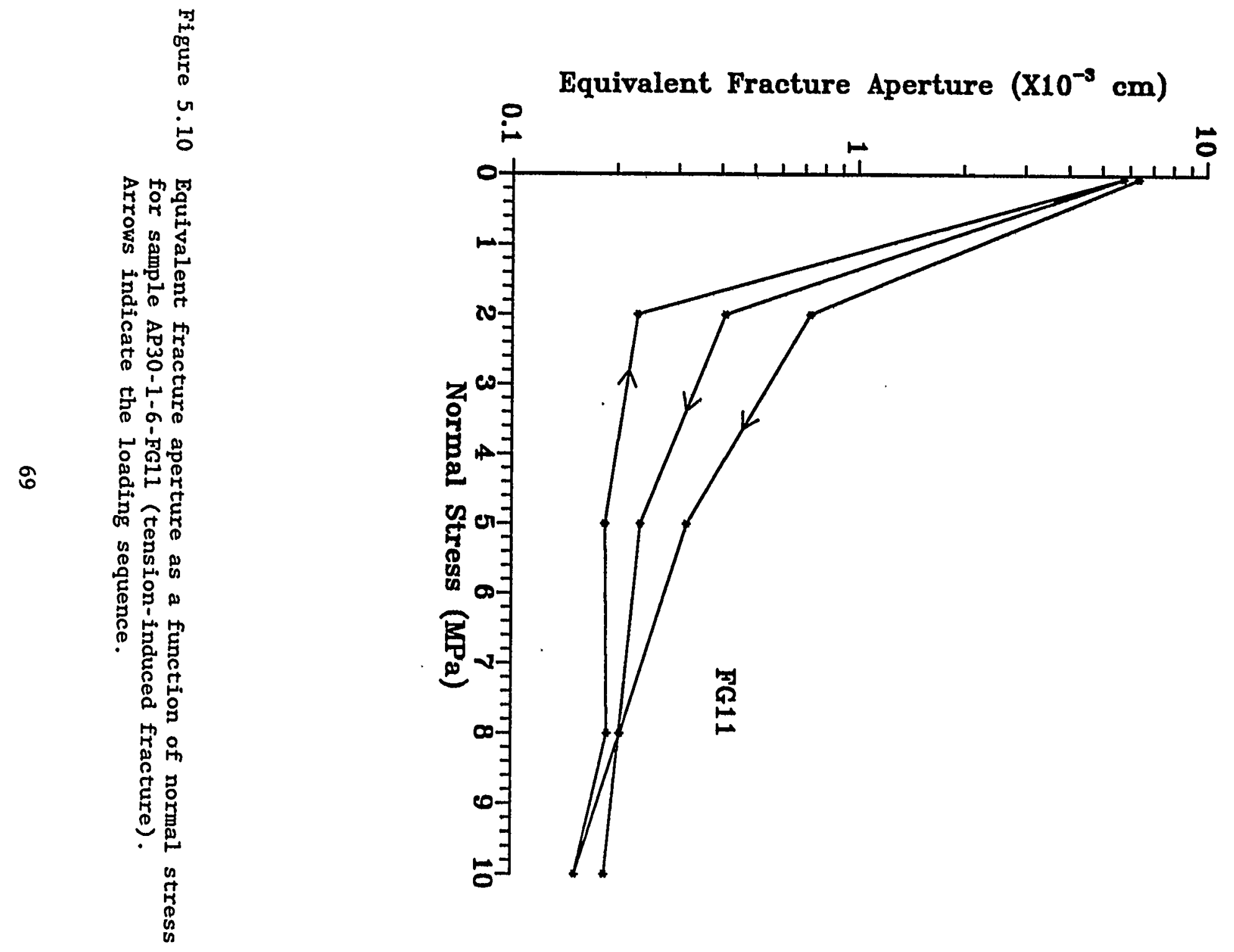


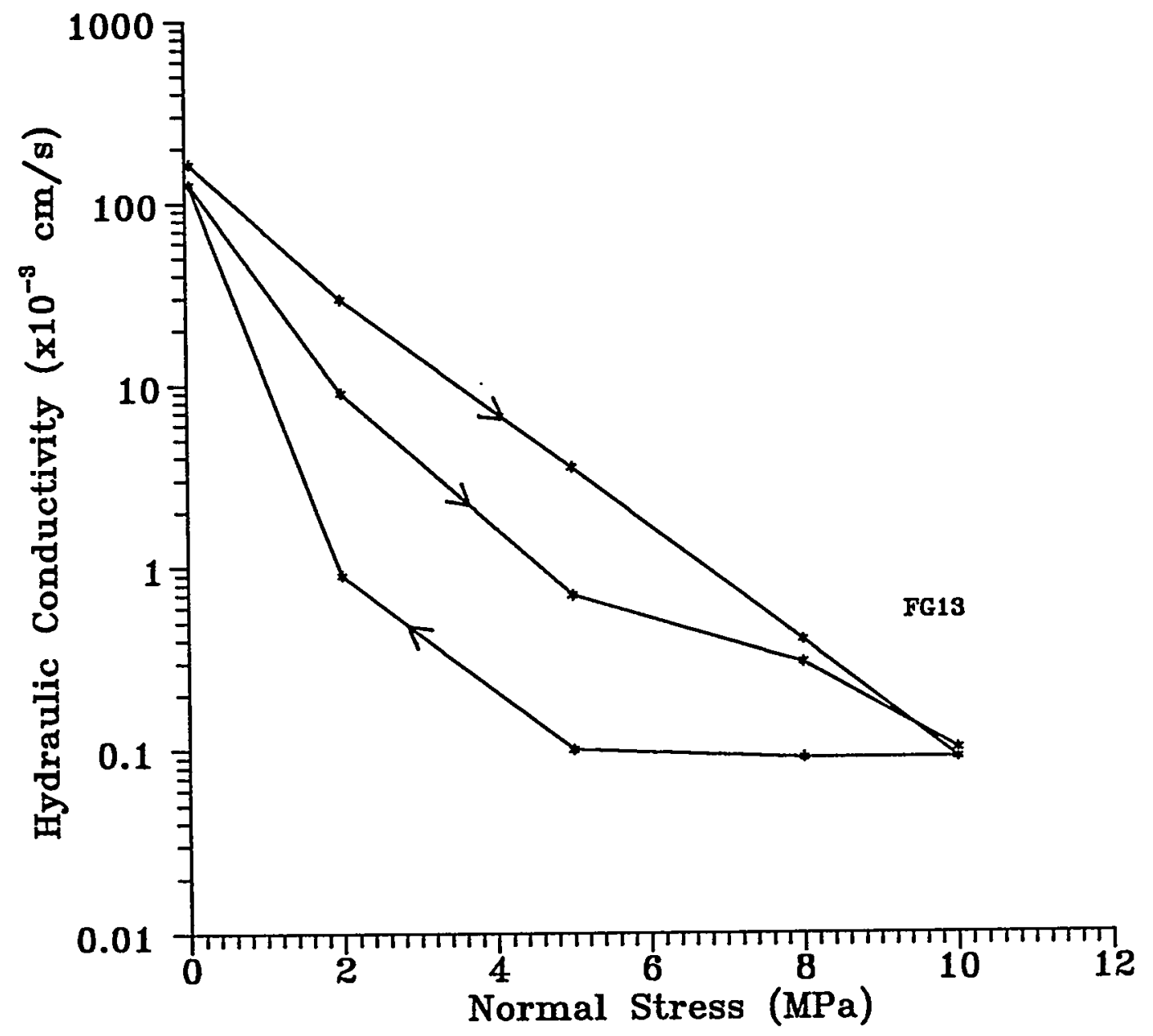

Figure 5.11 Hydraulic conductivity as a function of normal stress for sample AP36-1-6-FG13 (tension-induced fracture). Arrows indicate the loading sequence. 


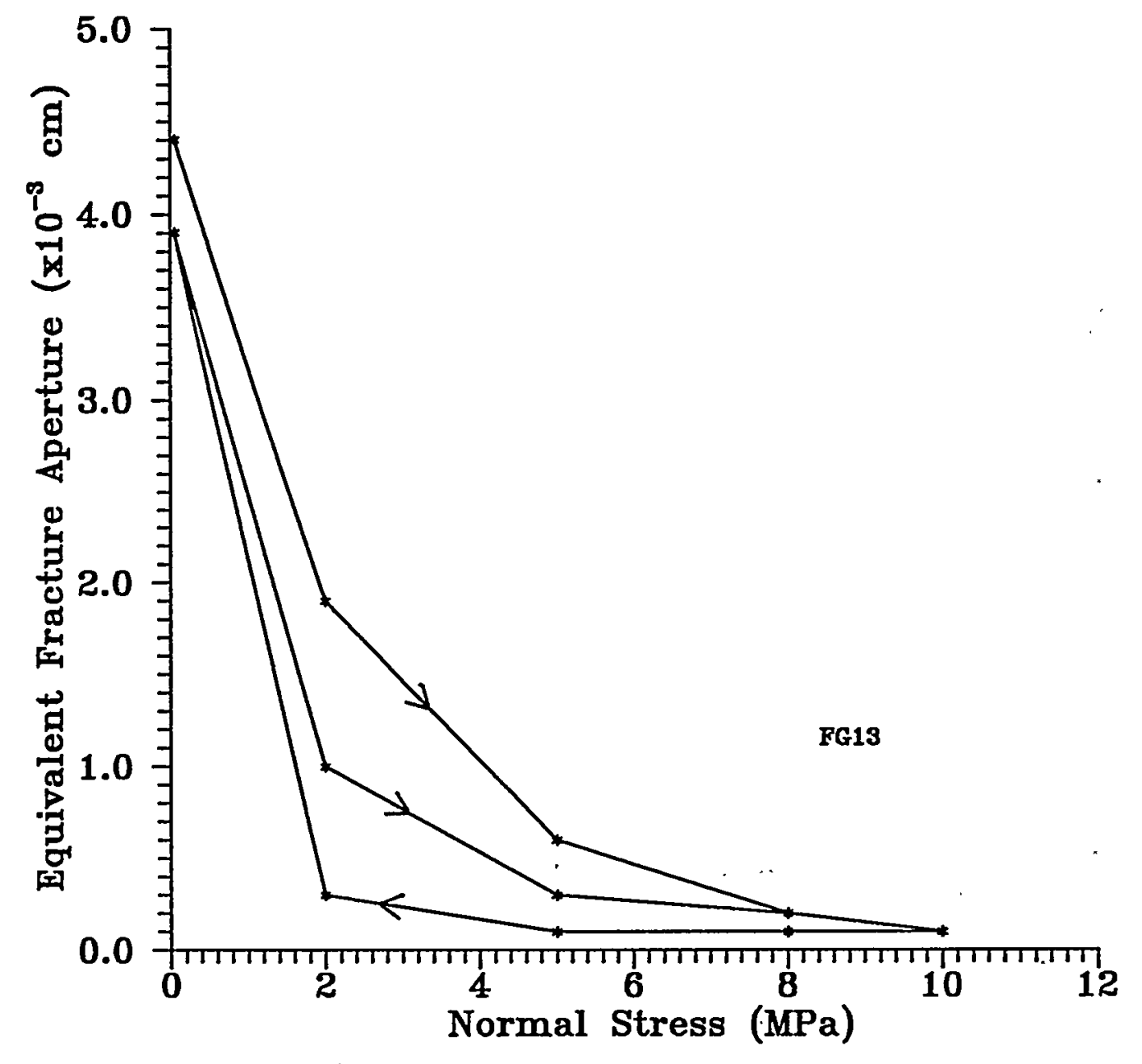

Figure 5.12 Equivalent fracture aperture as a function of normal stress for sample AP36-1-6-FG13 (tension-induced fracture). Arrows indicate the loading sequence. 


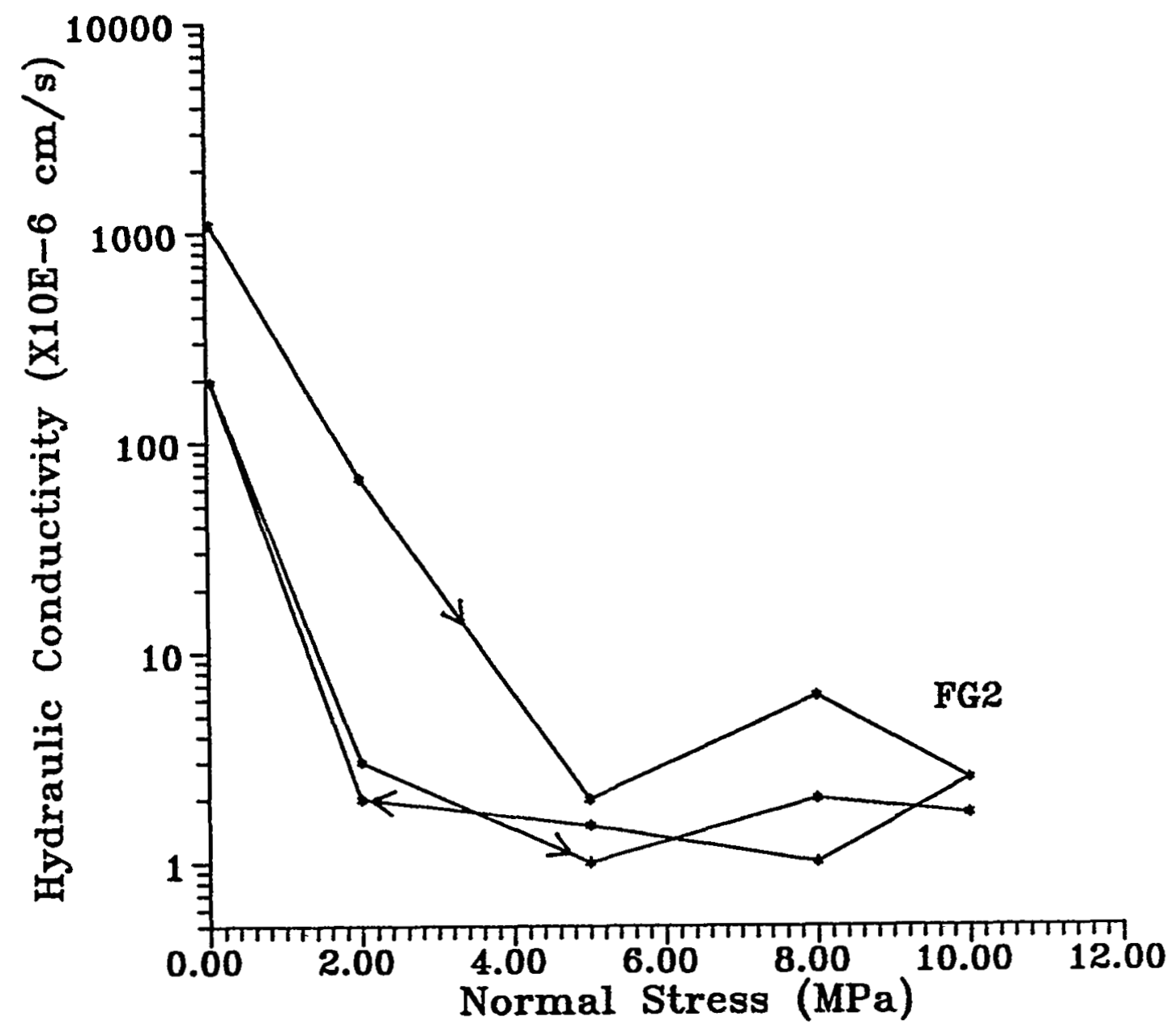

Figure 5.13 Hydraulic conductivity as a function of normal stress for sample AP4-1-6-FG2 (sawcut). Arrows indicate the loading sequence. 


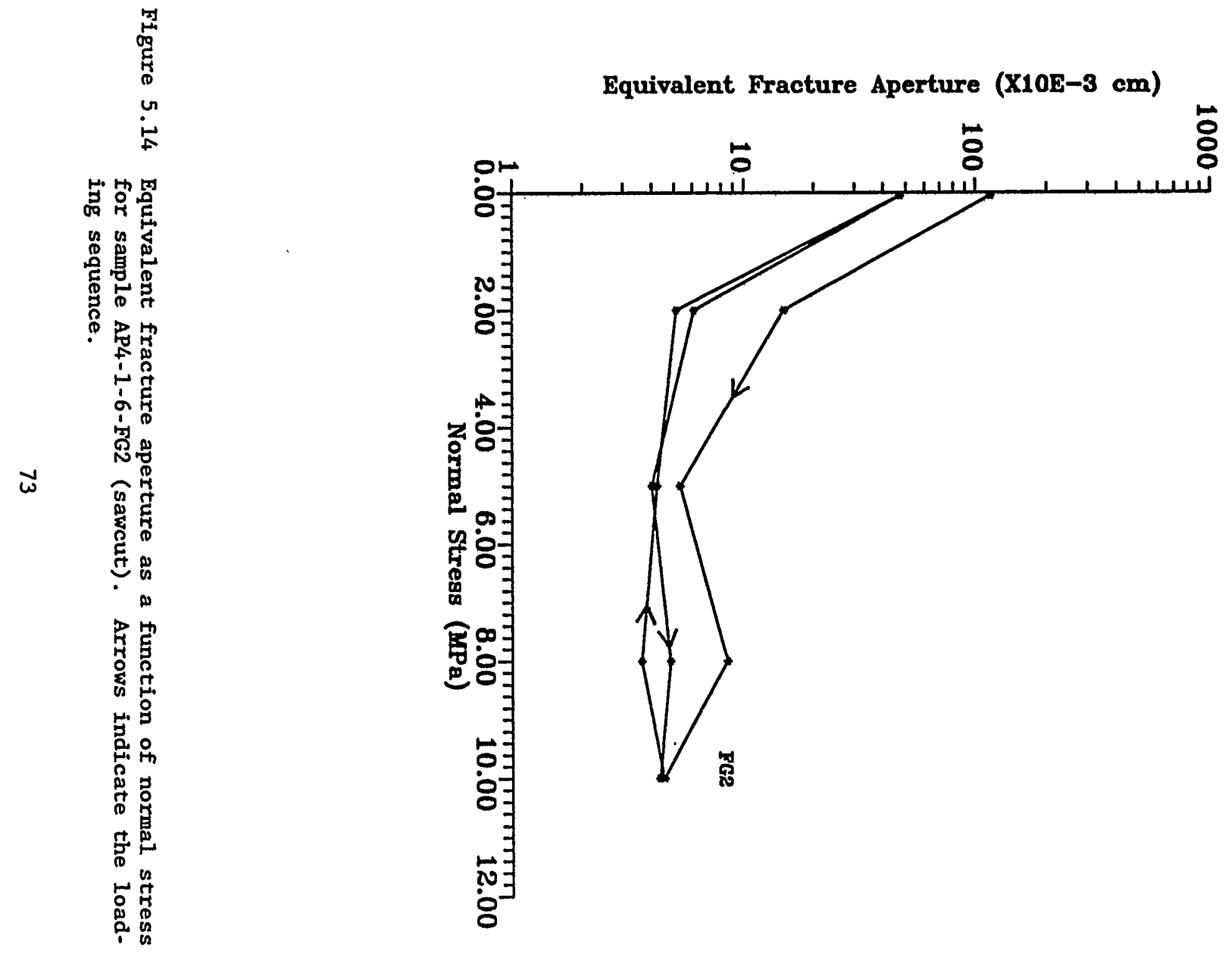




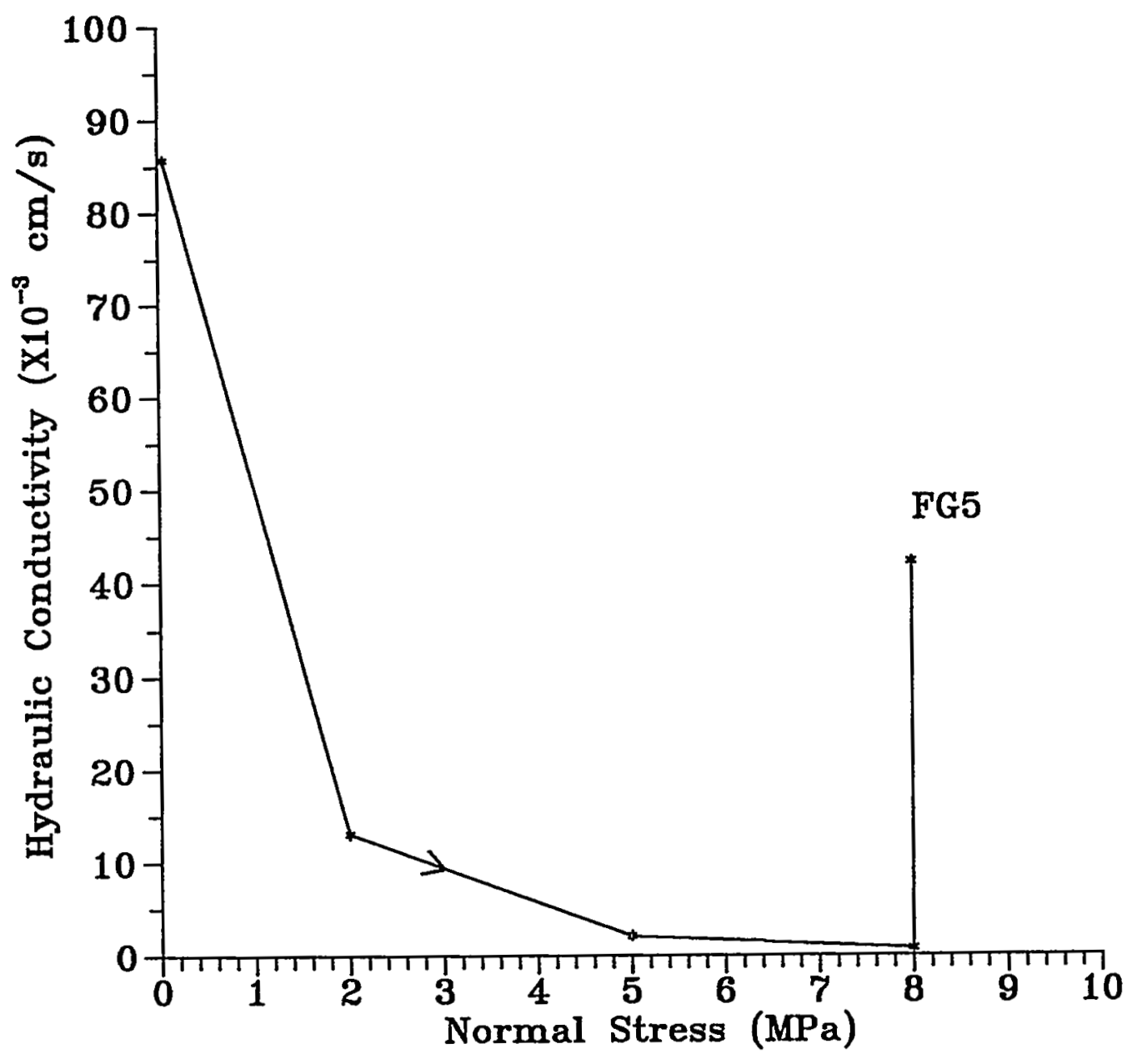

Figure 5.15 Hydraulic conductivity as a function of normal stress for sample AP7-2-6-FG5 (sawcut). Arrows indicate the loading sequence. The increase in permeability at $8 \mathrm{MPa}$ normal stress is due to the development of a vertical fracture. 


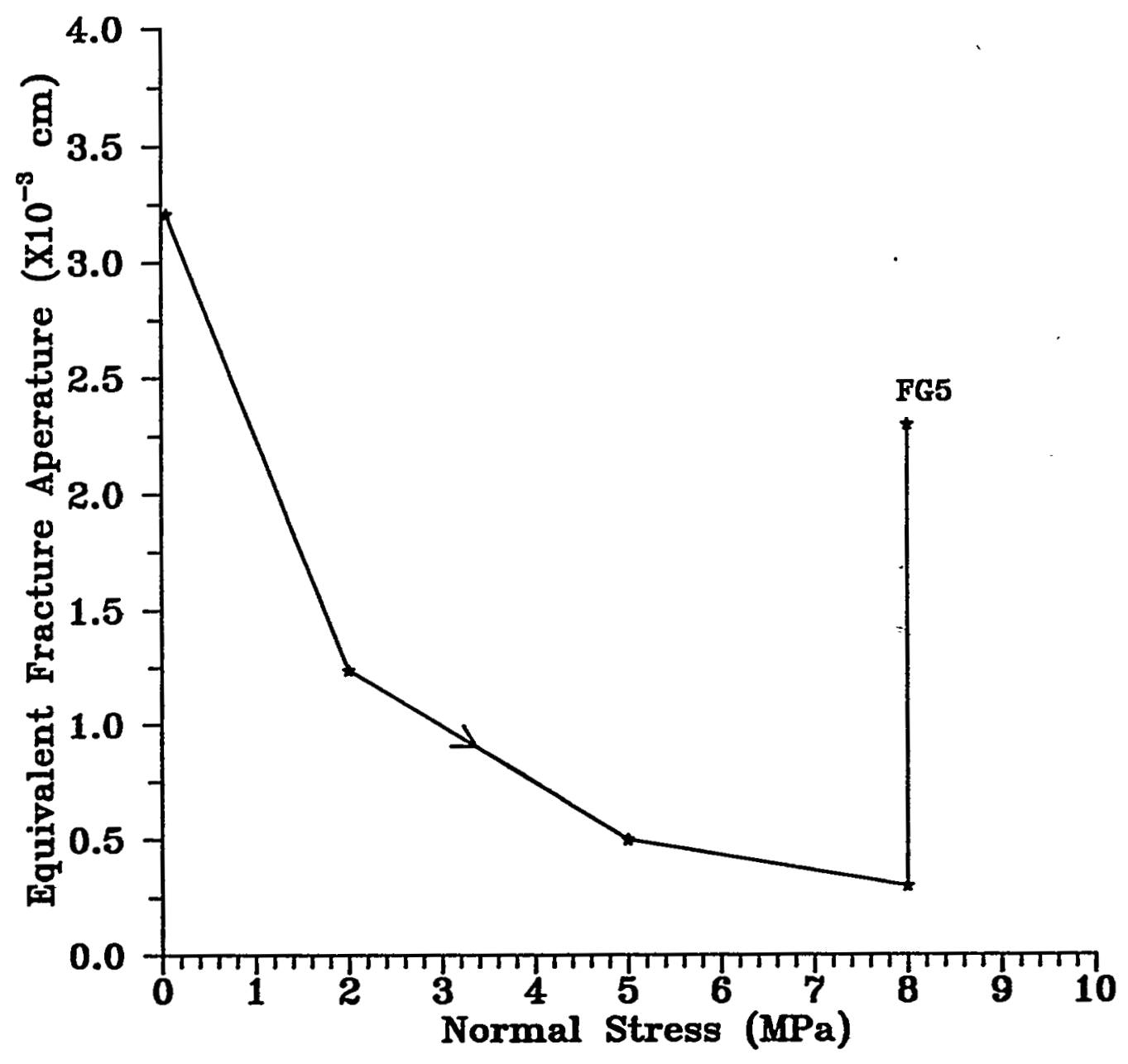

Figure 5.16 Equivalent fracture aperture as a function of normal stress for sampIe AP7-2-6-FG5 (sawcut). Arrows indicate the loading sequence. The increase in the equivalent fracture aperture at $8 \mathrm{MPa}$ normal stress is due to the development of a vertical fracture. 


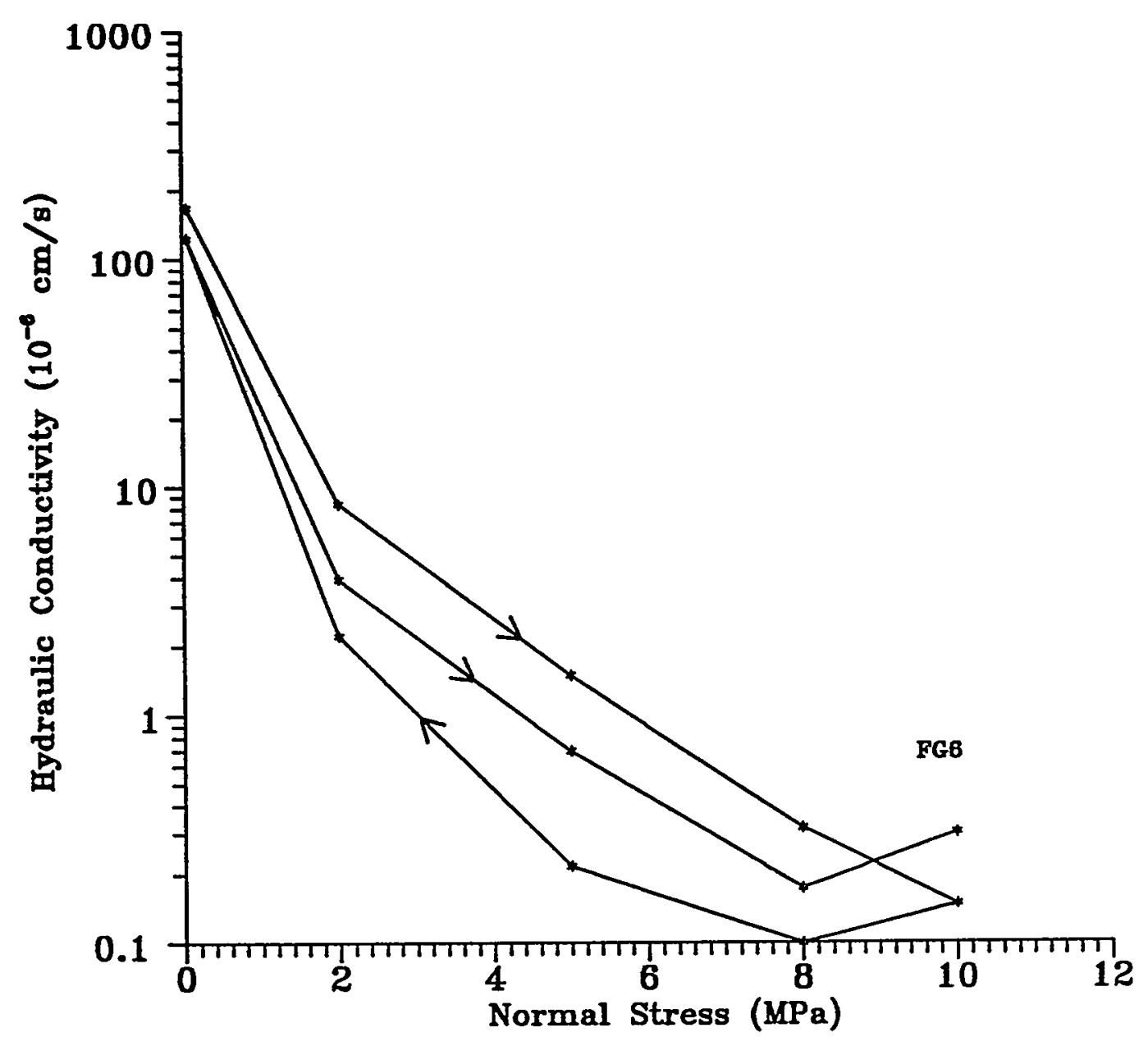

Figure 5.17 Hydraulic conductivity as a function of normal stress for sample AP3-1-6-FG6 (sawcut). Arrows indicate the loading sequence. 


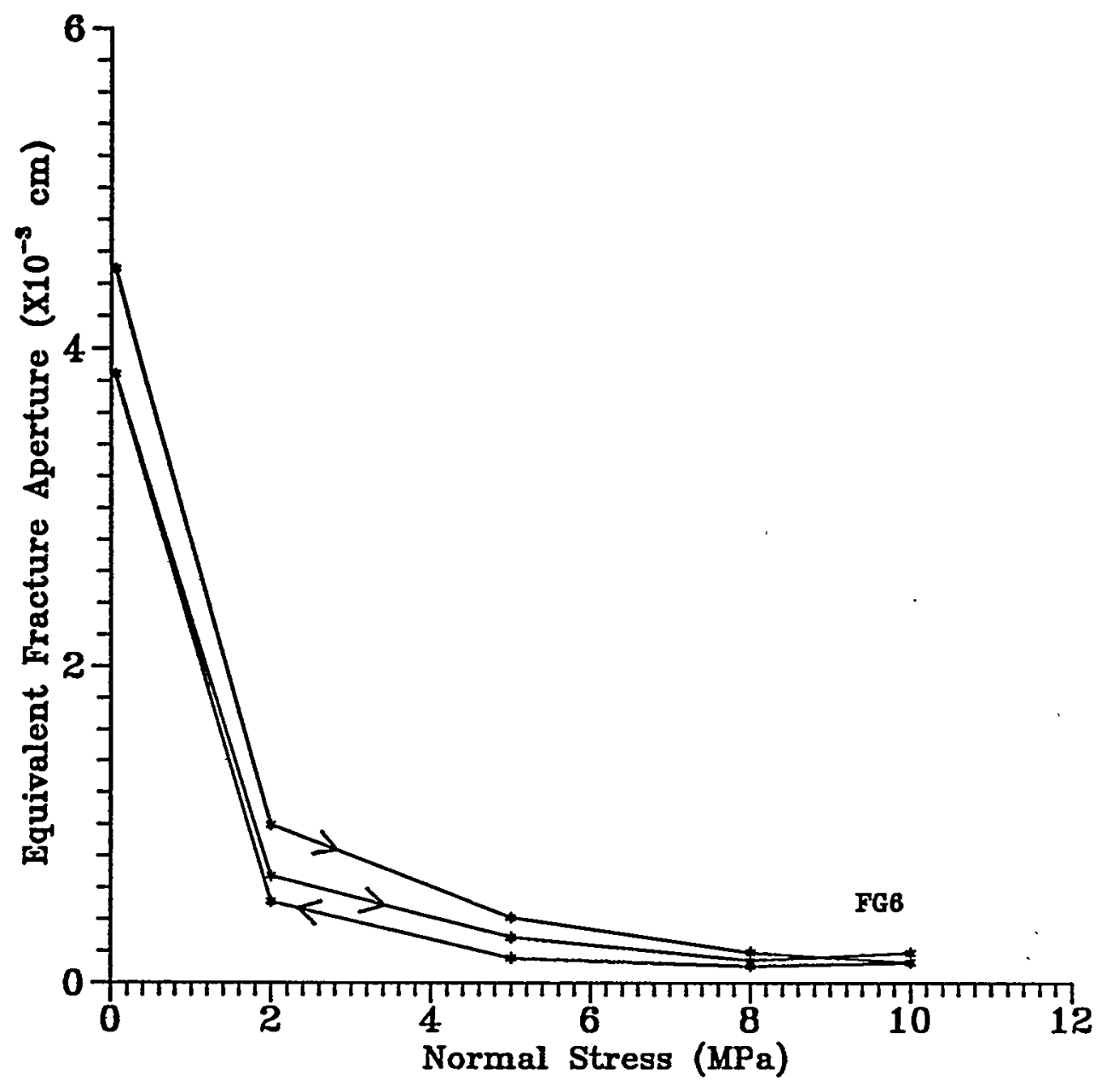

Figure 5.18 Equivalent fracture aperture as a function of normal stress for sample AP3-1-6-FG6 (sawcut). Arrows indicate the loading sequence. 


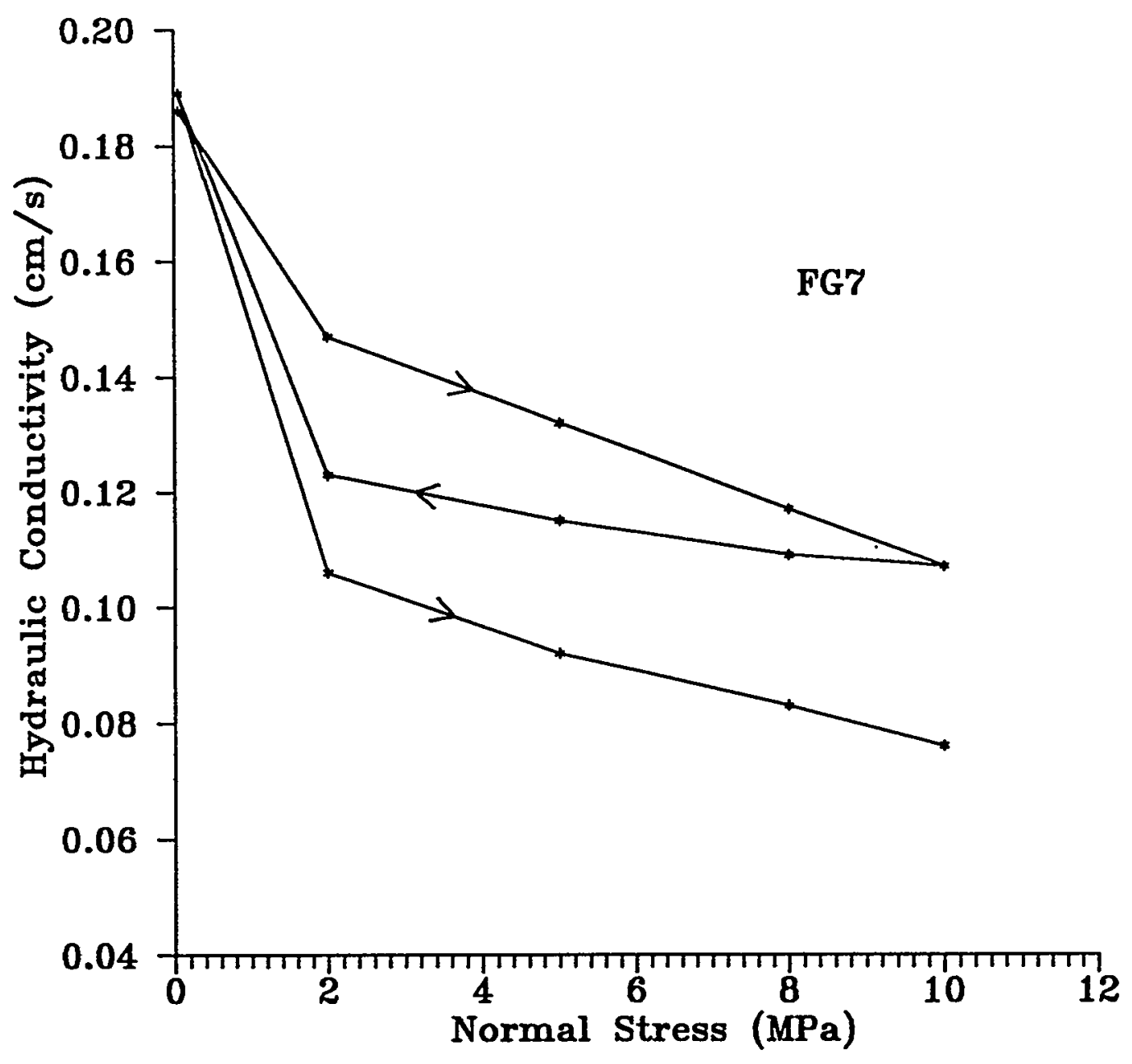

Figure 5.19 Hydraulic conductivity as a function of normal stress for sample AP2-1-6-FG7 (natural fracture). Arrows indicate the loading sequence. 


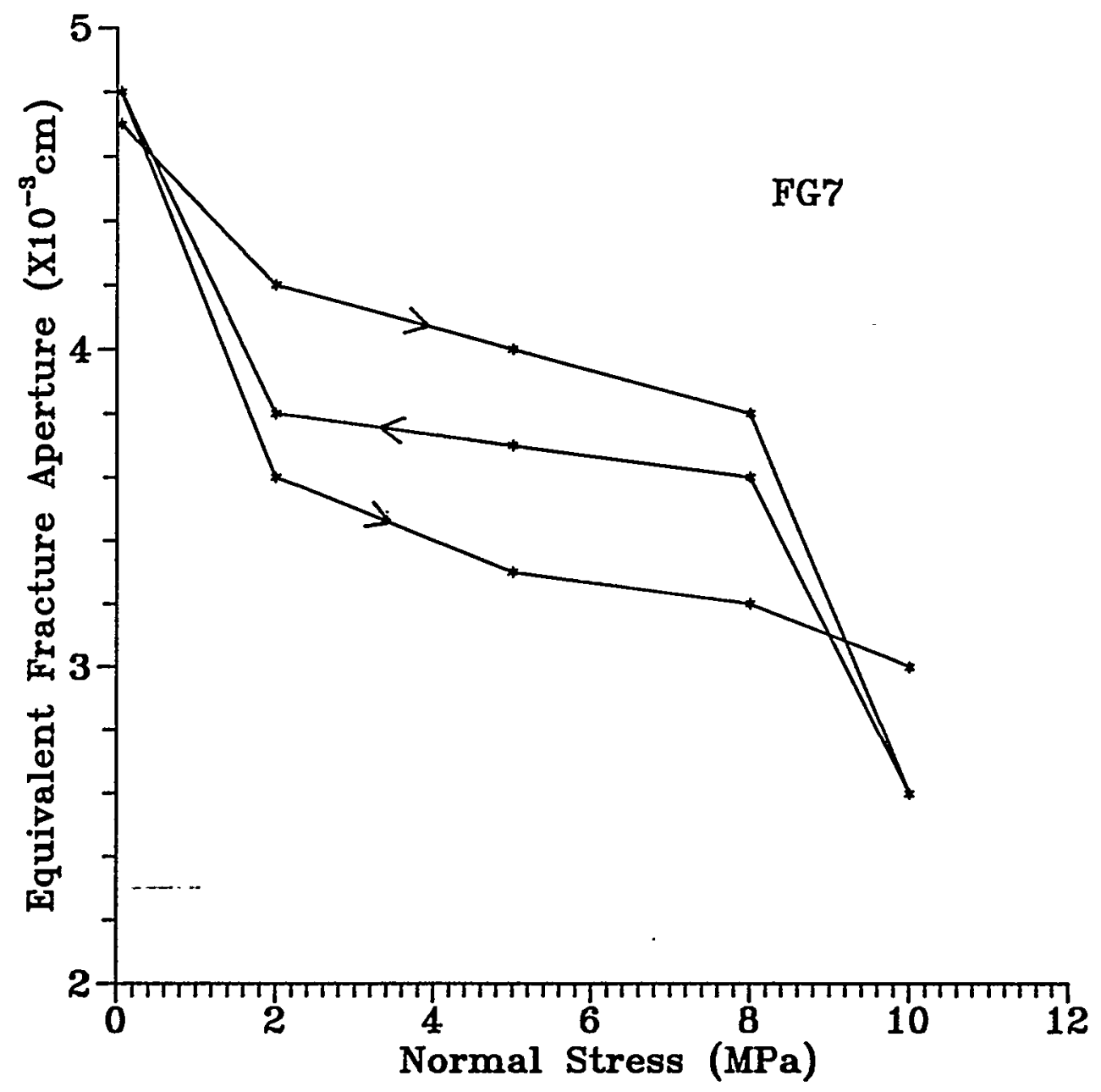

Figure 5.20 Equivalent fracture aperture as a function of normal stress for sample AP2-1-6-FG7 (natural fracture). Arrows indicate the loading sequence. 


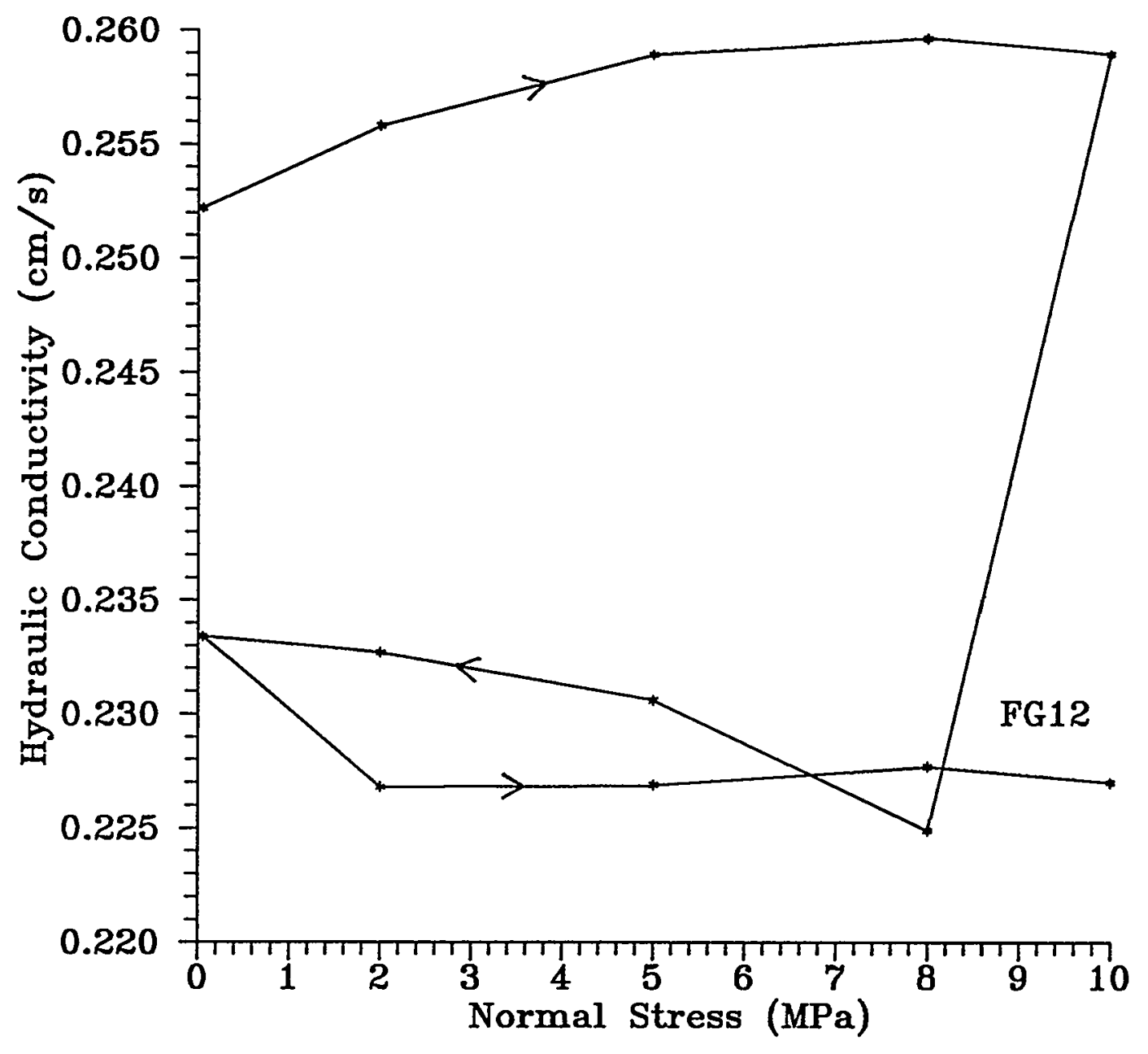

Figure 5.21 Hydraulic conductivity as a function of normal stress for sample AP56-5-6-FG12 (natural fracture). Arrows indicate the loading sequence. 


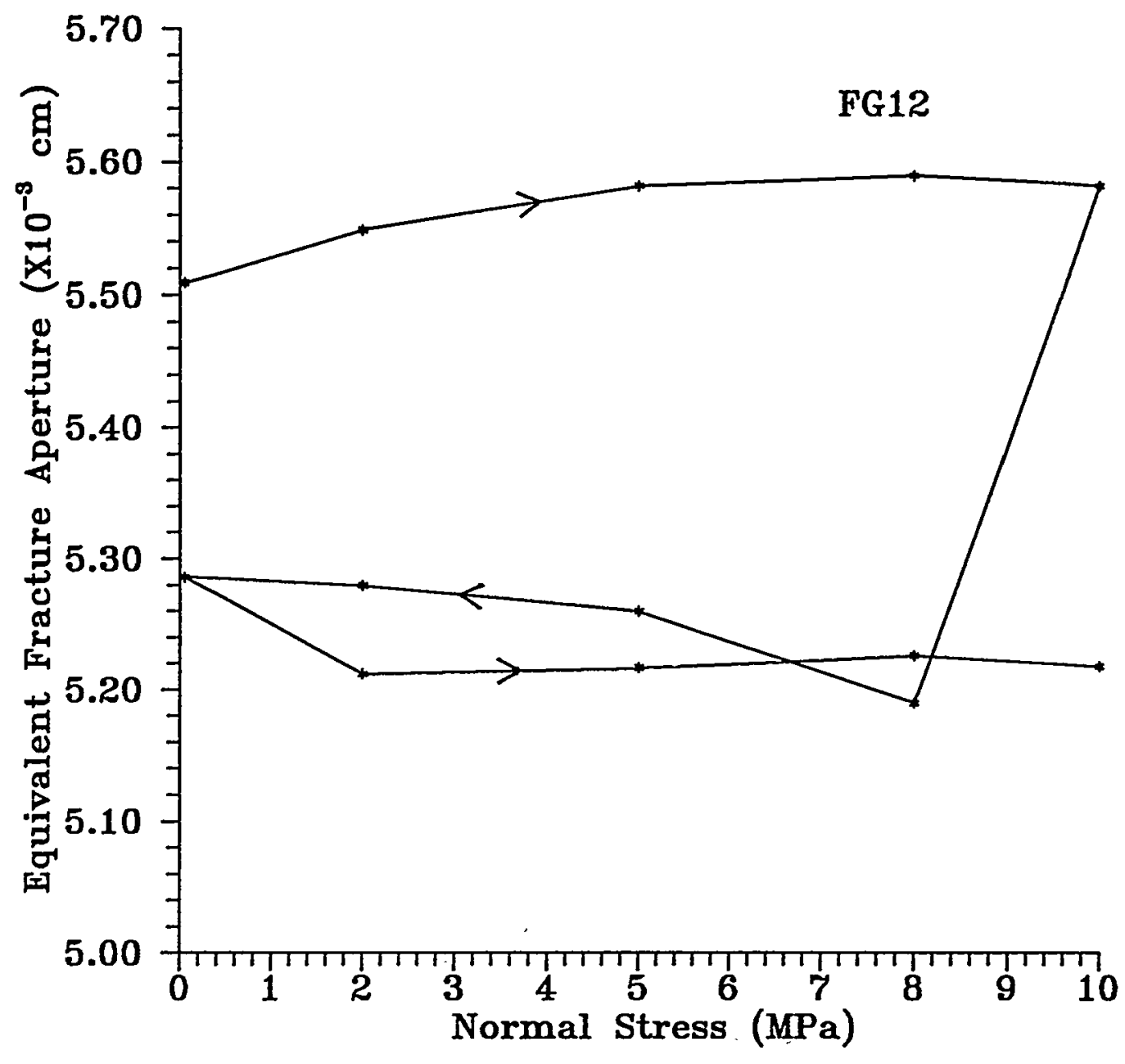

Figure 5.22 Equivalent fracture aperture as a function of normal stress for sample AP56-5-6-FG12 (natural fracture). Arrows indicate the loading sequence. 


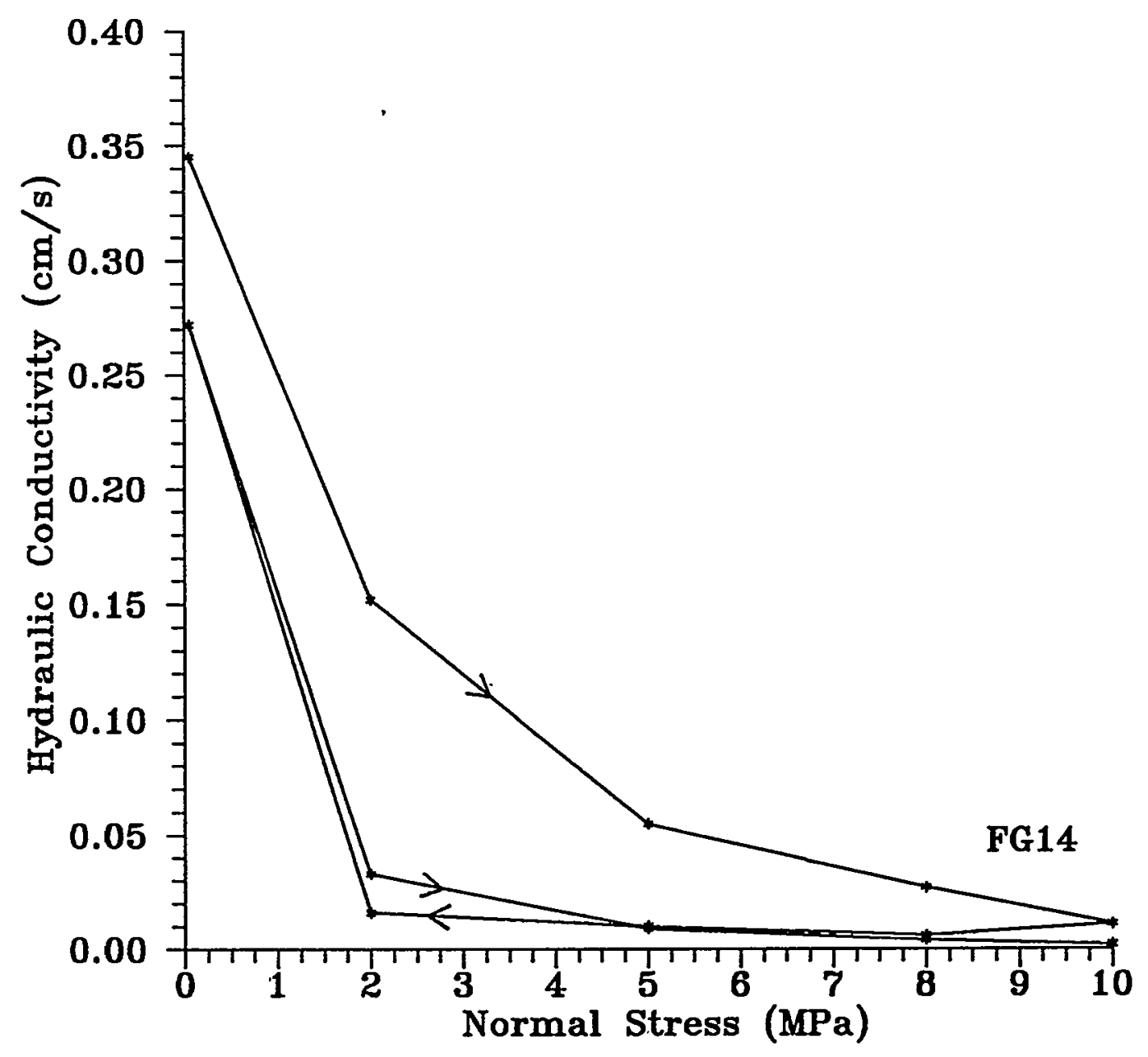

Figure 5.23 Hydraulic conductivity as a function of normal stress for sample AP56-2-6-FG14 (natural fracture). Arrows indicate the loading sequence. 


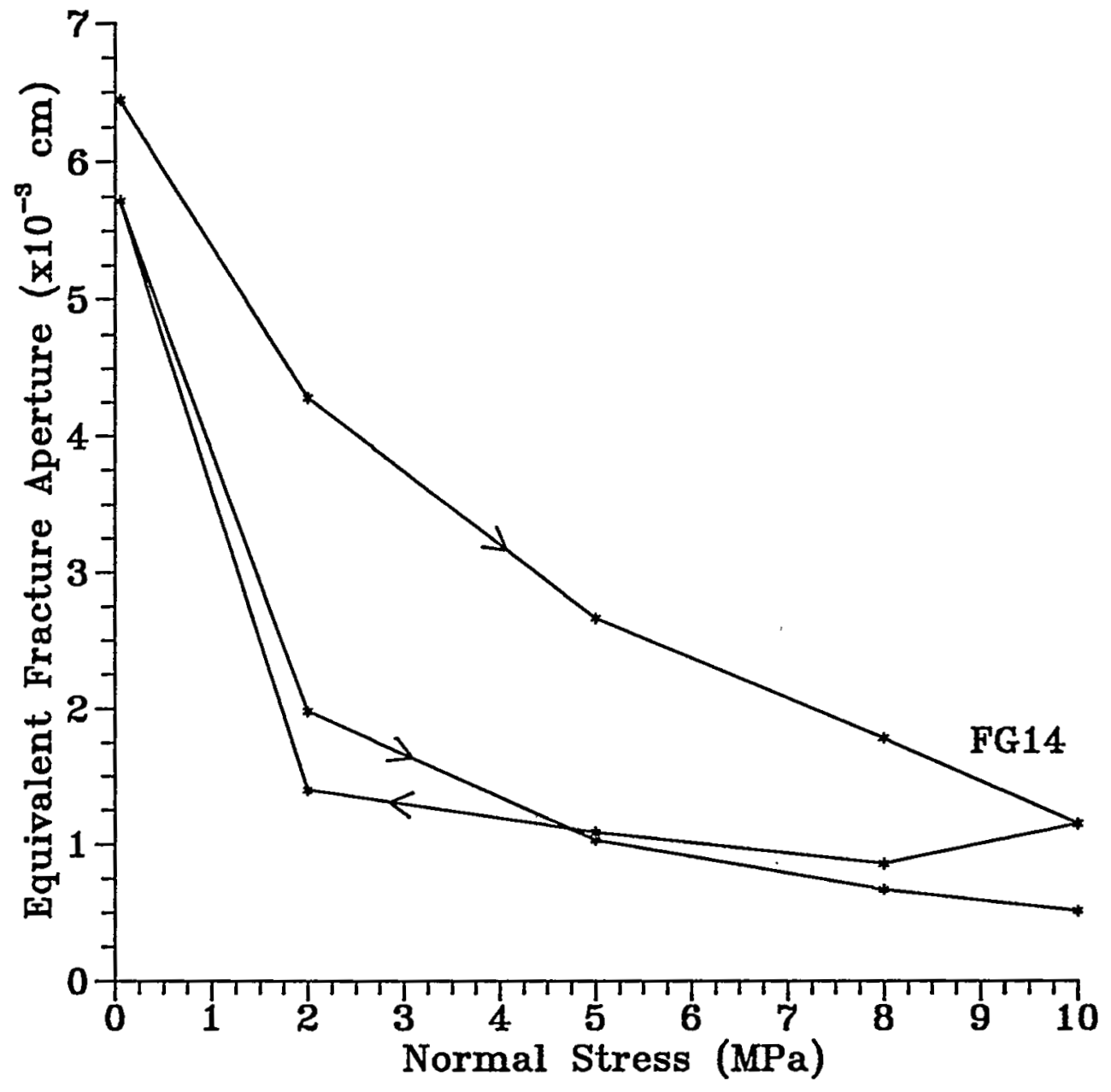

Figure 5.24 Equivalent fracture aperture as a function of normal stress for sample AP56-2-6-FG14 (natural fracture). Arrows indicate the loading sequence. 


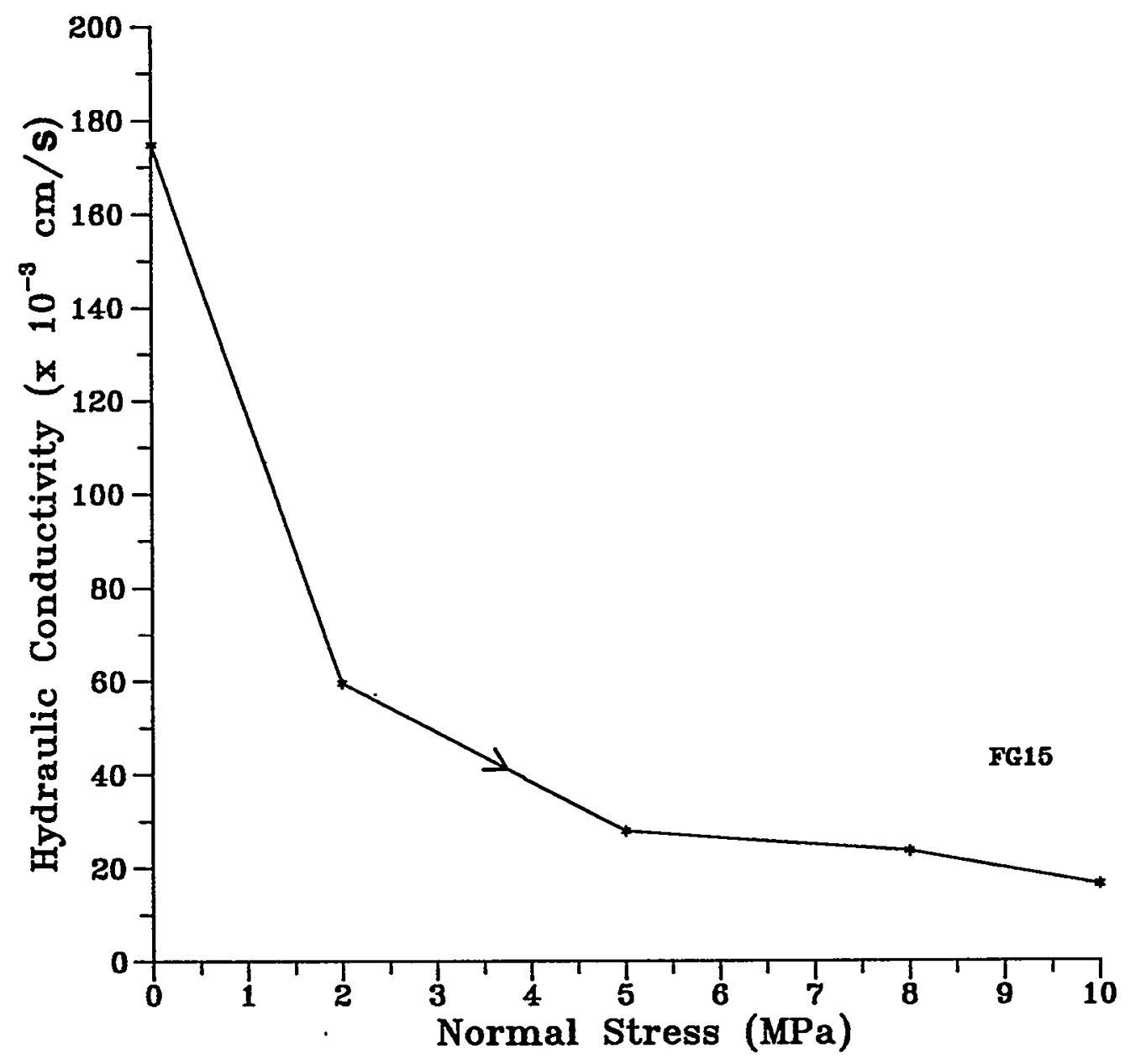

Figure 5.25 Hydraulic conductivity as a function of normal stress for sample AP56-3-6-FG15 (natural fracture). Arrows indicate the loading sequence. 

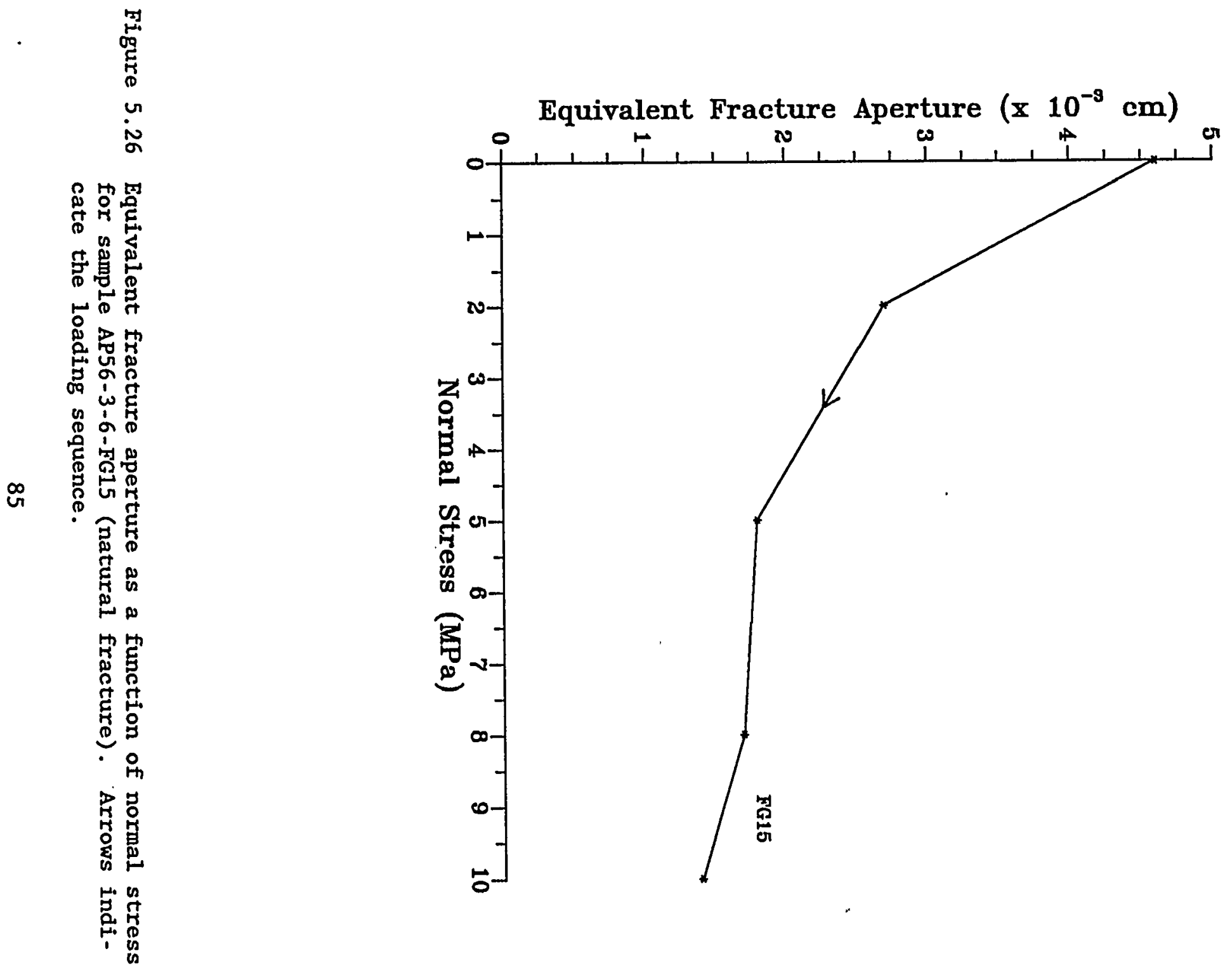
Table 5.9 Fracture Permeability and Equivalent Fracture Aperture for Sample AP21-3-6-FGI with a Tension Induced Fracture.

\begin{tabular}{|c|c|c|c|c|c|c|c|}
\hline $\begin{array}{c}\text { Number } \\
\text { of } \\
\text { Readings }\end{array}$ & $\begin{array}{c}\sigma_{\alpha x} \\
(\mathrm{MPa})\end{array}$ & $\left(x 10^{-3} \mathrm{~cm} / \mathrm{s}\right)$ & $\begin{array}{c}\mathrm{e} \\
\left(\mathrm{x} 10^{-3} \mathrm{~cm}\right)\end{array}$ & $\begin{array}{l}\mathrm{h}_{\mathrm{o}} \\
(\mathrm{cm})\end{array}$ & $\begin{array}{l}\mathrm{h}_{f} \\
(\mathrm{~cm})\end{array}$ & $\begin{array}{c}\operatorname{SD}\left(K_{j}\right) \\
\left(x \quad 10^{-6}\right)\end{array}$ & $\begin{array}{c}\operatorname{SD}(e) \\
\left(x 10^{-6}\right)\end{array}$ \\
\hline 3 & 0.05 & 315 & 6.15 & 183 & 131 & 0 & 0 \\
\hline 44 & 2 & 29 & 1.31 & 183 & 131 & 16000 & 700 \\
\hline 6 & 5 & 0.49 & 0.24 & 183 & 131 & 93 & 23 \\
\hline 4 & 8 & 0.34 & 0.20 & 183 & 131 & 10 & 2.7 \\
\hline 3 & 10 & 0.39 & 0.22 & 183 & 131 & 17 & 4.6 \\
\hline 3 & 8 & 0.31 & 0.19 & 183 & 131 & 62 & 20 \\
\hline 3 & 5 & 0.37 & 0.21 & 183 & 131 & 18 & 4.9 \\
\hline 3 & 2 & 0.43 & 0.23 & 183 & 131 & 6.8 & 21 \\
\hline 3 & 0.05 & 239 & 5.36 & 183 & 131 & 0 & 0 \\
\hline 5 & 2 & 1.6 & 0.44 & 183 & 131 & 300 & 42 \\
\hline 4 & 5 & 0.4 & 0.22 & 183 & 131 & 13 & 3.5 \\
\hline 4 & 8 & 0.34 & 0.20 & 183 & 131 & 21 & 6.1 \\
\hline 4 & 10 & 0.34 & 0.20 & 183 & 131 & 7.6 & 2.2 \\
\hline
\end{tabular}

\footnotetext{
$\sigma_{a x} \quad=$ axial stress

$\mathrm{K}_{\mathrm{j}} \quad=$ fracture permeability (mean)

$\mathrm{e} \quad=$ equivalent fracture aperture (mean)

$h_{0} \quad=$ starting height of water in falling head pipette

$h_{f}=$ final height of water in falling head pipette

$S D\left(K_{j}\right)=$ standard deviation about mean of the fracture permeability

$\mathrm{SD}(\mathrm{e})=$ standard deviation about mean of the equivalent fracture aperture.
} 
Table 5.10 Fracture Permeability and Equivalent Fracture Aperture for Sample AP30-2-6-FG10 with a Tension Induced Fracture.

\begin{tabular}{|c|c|c|c|c|c|c|c|}
\hline $\begin{array}{c}\text { Number } \\
\text { of } \\
\text { Readings }\end{array}$ & $\begin{array}{c}\sigma_{a x} \\
(\mathrm{MPa})\end{array}$ & $\left(x 10^{-3_{j}} \mathrm{~cm} / \mathrm{s}\right)$ & $\begin{array}{c}e \\
\left(x 10^{-3} \mathrm{~cm}\right)\end{array}$ & $\begin{array}{c}\mathrm{P}_{\mathbf{i}} \\
(\mathrm{MPa})\end{array}$ & $\begin{array}{c}\Delta h \\
(\mathrm{~cm})\end{array}$ & $\begin{array}{c}\operatorname{SD}\left(K_{j}\right) \\
\left(x 10^{-6}\right)\end{array}$ & $\begin{array}{c}\operatorname{SD}(e) \\
\left(x 10^{-6}\right)\end{array}$ \\
\hline 6 & 0.05 & 96178 & 3402 & 0.5 & 5002 & 990 & 18 \\
\hline 5 & 2 & 254 & 173 & 0.5 & 5003 & 21 & 0 \\
\hline 4 & 5 & 66 & 100 & 0.5 & 5005 & 7 & 0 \\
\hline 3 & 8 & 26 & 54 & 0.5 & 5006 & 9 & 9 \\
\hline 4 & 10 & 18 & 46 & 0.5 & 5007 & 7 & 11 \\
\hline 3 & 8 & 33 & 63 & 0.5 & 5007 & 8 & 8 \\
\hline 3 & 5 & 32 & 102 & 0.5 & 5007 & 14 & 13 \\
\hline 3 & 2 & 47 & 100 & 0.5 & 5001 & 2 & 13 \\
\hline 3 & 0.05 & 98090 & 3683 & 0.5 & 5004 & 4781 & 83 \\
\hline 3 & 2 & 123 & 114 & 0.5 & 5001 & 67 & 24 \\
\hline 3 & 5 & 36 & 73 & 0.5 & 5001 & 13 & 24 \\
\hline 2 & 8 & 23 & 52 & 0.5 & 5001 & 5 & 6 \\
\hline 2 & 10 & 12 & 38 & 0.5 & 5001 & 2.2 & 9 \\
\hline
\end{tabular}

$\sigma_{a x} \quad=$ axial stress

$\mathrm{K}_{\mathrm{j}} \quad$ - fracture permeability (mean)

e - equivalent fracture aperture (mean)

$\mathrm{P}_{i} \quad=$ injection pressure

$\Delta h \quad=$ water head difference used in falling head permeameter test $\left(P_{1} / \gamma_{\omega}-h_{0}\right)$

$\mathrm{SD}\left(\mathrm{K}_{j}\right)=$ standard deviation about mean of the fracture permeability

$\mathrm{SD}(\mathrm{e})$ = standard deviation about mean of the equivalent fracture aperture. 
Table 5.11 Fracture Permeability and Equivalent Fracture Aperture for Sample AP30-1-6-FG11 with a Tension Induced Fracture.

\begin{tabular}{|c|c|c|c|c|c|c|c|}
\hline $\begin{array}{c}\text { Number } \\
\text { of } \\
\text { Readings }\end{array}$ & $\begin{array}{c}\sigma_{a x} \\
(\mathrm{MPa})\end{array}$ & $\begin{array}{c}\mathrm{K}_{j} \\
\left(\times 10^{-6} \mathrm{~cm} / \mathrm{s}\right)\end{array}$ & $\begin{array}{c}\mathrm{e} \\
\left(\mathrm{x} 10^{-6} \mathrm{~cm}\right)\end{array}$ & $\begin{array}{c}h_{0} \\
(\mathrm{~cm})\end{array}$ & $\begin{array}{c}h_{f} \\
(\mathrm{~cm})\end{array}$ & $\begin{array}{c}S D\left(K_{j}\right) \\
\left(\times 10^{-6}\right)\end{array}$ & $\begin{array}{c}S D(e) \\
\left(\times 10^{-6}\right)\end{array}$ \\
\hline 18 & 0.05 & 335800 & 6357 & 170 & 131 & 6700 & 64 \\
\hline 20 & 2 & 5767 & 727 & 173 & 137 & 3500 & 260 \\
\hline 9 & 5 & 850 & 319 & 130 & 119 & 140 & 130 \\
\hline 6 & 8 & 320 & 206 & 129 & 127 & 55 & 16 \\
\hline 3 & 10 & 194 & 153 & 129 & 128 & 22 & 8.5 \\
\hline 4 & 8 & 294 & 189 & 128 & 127 & 12 & 3.3 \\
\hline 6 & 5 & 287 & 186 & 128 & 126 & 25 & 7.9 \\
\hline 4 & 2 & 441 & 230 & 129 & 127 & 47 & 12 \\
\hline 10 & 0.05 & 275000 & 5750 & 180 & 131 & 0 & 0 \\
\hline 7 & 2 & 1477 & 412 & 178 & 144 & 19 & 3.4 \\
\hline 3 & 5 & 458 & 235 & 130 & 128 & 28 & 7.6 \\
\hline 4 & 8 & 347 & 205 & 127 & 126 & 22 & 6.5 \\
\hline 3 & 10 & 288 & 186 & 129 & 120 & 27 & 8.7 \\
\hline
\end{tabular}

\footnotetext{
$\sigma_{a x} \quad=$ axial stress

$\mathrm{K}_{\mathrm{j}} \quad$ - fracture permeability (mean)

e = equivalent fracture aperture (mean)

$h_{0} \quad=$ starting height in falling head pipette

$h_{f} \quad=$ water head difference used in falling head permeameter test

$S D\left(K_{j}\right)$ = standard deviation about mean of the fracture permeability

$\mathrm{SD}(\mathrm{e})$ standard deviation about mean of the equivalent fracture aperture.
} 
Table 5.12 Fracture Permeability and Equivalent Fracture Aperture for Sample AP36-1-6-FG13 with a Tension Induced Fracture.

\begin{tabular}{|c|c|c|c|c|c|c|c|}
\hline $\begin{array}{c}\text { Number } \\
\text { of } \\
\text { Readings }\end{array}$ & $\begin{array}{c}\sigma_{N} \\
(\mathrm{MPa})\end{array}$ & $\begin{array}{c}\mathrm{K}_{\mathrm{j}} \\
\left(\mathrm{x} 10^{-3} \mathrm{~cm} / \mathrm{s}\right)\end{array}$ & $\begin{array}{c}\mathrm{e} \\
\left(\mathrm{x} 10^{-6} \mathrm{~cm}\right)\end{array}$ & $\begin{array}{c}\mathrm{h}_{\mathrm{o}} \\
(\mathrm{cm})\end{array}$ & $\begin{array}{c}\mathrm{h}_{\mathrm{f}} \\
(\mathrm{cm})\end{array}$ & $\begin{array}{c}\mathrm{SD}\left(\mathrm{K}_{j}\right) \\
\left(\mathrm{x} 10^{-6}\right)\end{array}$ & $\begin{array}{c}\mathrm{SD}(\mathrm{e}) \\
\left(\mathrm{x} 10^{-6}\right)\end{array}$ \\
\hline 3 & 0.05 & 163.70 & 4439 & 0.1 & 998 & 101.8 & 1.4 \\
\hline 4 & 2 & 29.40 & 1879 & 1.0 & 10013 & 2357.1 & 75.2 \\
\hline 4 & 5 & 3.50 & 646 & 1.0 & 10012 & 1011.1 & 93.5 \\
\hline 5 & 8 & 0.40 & 217.6 & 1.0 & 10018 & 70.7 & 19.5 \\
\hline 4 & 10 & 0.09 & 102.8 & 1.0 & 10018 & 28.7 & 15.7 \\
\hline 5 & 8 & 0.09 & 102.9 & 1.0 & 10019 & 1.7 & 1.0 \\
\hline 4 & 5 & 0.13 & 127.4 & 1.0 & 10019 & 1.7 & 0.8 \\
\hline 4 & 2 & 0.90 & 327.6 & 1.0 & 10019 & 179.2 & 32.3 \\
\hline 4 & 0.05 & 126.45 & 3901.2 & 0.1 & 10016 & 1023.6 & 15.8 \\
\hline 3 & 2 & 8.98 & 1039.5 & 1.0 & 10013 & 73.0 & 4.2 \\
\hline 3 & 5 & 0.66 & 280.1 & 1.0 & 10011 & 154.9 & 31.6 \\
\hline 3 & 8 & 0.29 & 187.1 & 1.0 & 10011 & 38.5 & 12.2 \\
\hline 4 & 10 & 0.15 & 132.7 & 1.0 & 10011 & 17.1 & 7.8 \\
\hline
\end{tabular}

$\sigma_{N} \quad=$ normal stress

$\mathrm{K}_{\mathrm{j}} \quad$ = fracture permeability (mean)

e - equivalent fracture aperture (mean)

$\mathrm{P}_{\mathbf{i}} \quad=$ injection pressure

$\Delta h \quad=$ water head difference used in falling head permeameter test $\left(P_{1} / Y_{w}-h_{0}\right)$

$\operatorname{SD}\left(k_{j}\right)=$ standard deviation about mean of the fracture permeability $\mathrm{SD}(e)$ - standard deviation about mean of the equivalent fracture aperture. 
Table 5.13 Fracture Permeability and Equivalent Fracture Aperture for Sample AP4-1-6-FG2 Sawcut Surfaces

\begin{tabular}{|c|c|c|c|c|c|c|c|}
\hline $\begin{array}{c}\text { Number } \\
\text { of } \\
\text { Readings }\end{array}$ & $\begin{array}{c}\sigma_{N} \\
(\mathrm{MPa})\end{array}$ & $\begin{array}{c}\mathrm{K}_{j} \\
\left(\mathrm{x} 10^{-6} \mathrm{~cm} / \mathrm{s}\right)\end{array}\left(\mathrm{x} 10^{-6} \mathrm{~cm}\right)$ & $\begin{array}{c}\mathrm{P}_{\mathrm{i}} \\
(\mathrm{MPa})\end{array}$ & $\begin{array}{c}\Delta h \\
(\mathrm{~cm})\end{array}$ & $\begin{array}{c}\mathrm{SD}\left(\mathrm{K}_{\mathrm{j}}\right) \\
\left(\mathrm{x} 10^{-6}\right)\end{array}$ & $\begin{array}{c}\mathrm{SD}(\mathrm{e}) \\
\left(\mathrm{x} 10^{-6}\right)\end{array}$ \\
\hline 4 & 0.05 & 51583.3 & 2496.5 & 0.5 & 5003 & 1103.0 & 26.5 \\
\hline 3 & 2 & 898.5 & 320.4 & 0.5 & 5008 & 523.0 & 94.1 \\
\hline 2 & 5 & 107.9 & 114.2 & 0.5 & 5008 & 7.2 & 3.8 \\
\hline 2 & 8 & 276.9 & 182.9 & 0.5 & 5008 & 1.4 & 0.5 \\
\hline 3 & 10 & 77.3 & 96.6 & 0.5 & 5008 & 5.1 & 3.2 \\
\hline 2 & 8 & 49.2 & 76.9 & 0.5 & 5008 & 9.3 & 7.3 \\
\hline 2 & 5 & 69.0 & 90.7 & 0.5 & 5008 & 23.2 & 15.4 \\
\hline 2 & 2 & 99.6 & 109.5 & 0.5 & 5008 & 18.5 & 10.2 \\
\hline 5 & 0.05 & 5100.7 & 784.1 & 0.5 & 4999 & 577.2 & 44.1 \\
\hline 3 & 2 & 143.2 & 131.6 & 0.5 & 5004 & 2.6 & 1.2 \\
\hline 3 & 5 & 61.8 & 86.4 & 0.5 & 5005 & 5.1 & 3.6 \\
\hline 3 & 8 & 95.4 & 102.1 & 0.5 & 5005 & 76.9 & 40.8 \\
\hline 3 & 10 & 69.7 & 91.4 & 0.5 & 5006 & 14.6 & 9.9 \\
\hline
\end{tabular}

\footnotetext{
$\sigma_{N} \quad=$ normal stress

$\mathrm{K}_{\mathrm{j}}=$ fracture permeability (mean)

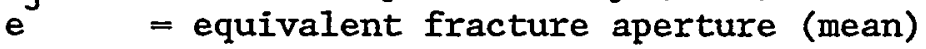

$\mathrm{P}_{\mathrm{i}} \quad=$ injection pressure

$\Delta h \quad=$ water head difference used in falling head permeameter test $\left(P_{1} / \gamma_{w}-h_{0}\right)$

$S D\left(K_{j}\right)=$ standard deviation about mean of the fracture permeability

$\mathrm{SD}(\mathrm{e})$ = standard deviation about mean of the equivalent fracture aperture.
} 
Table 5.14 Fracture Permeability and Equivalent Fracture Aperture for Sample AP7-2-6-FG5 with Sawcut Surfaces

\begin{tabular}{|c|c|c|c|c|c|c|c|}
\hline $\begin{array}{c}\text { Number } \\
\text { of } \\
\text { Readings }\end{array}$ & $\begin{array}{c}\sigma_{N} \\
(\mathrm{MPa})\end{array}$ & $\left(x 10^{-3} \mathrm{~cm} / \mathrm{s}\right)$ & $\left(\begin{array}{c}\mathrm{e} \\
\left(\mathrm{x} 10^{-3} \mathrm{~cm}\right)\end{array}\right.$ & $\begin{array}{c}\mathrm{P}_{\mathbf{i}} \\
(\mathrm{MPa})\end{array}$ & $\begin{array}{c}\Delta h \\
(\mathrm{~cm})\end{array}$ & $\begin{array}{c}\operatorname{SD}\left(K_{j}\right) \\
\left(x 10^{-6}\right)\end{array}$ & $\begin{array}{c}\operatorname{SD}(e) \\
\left(\times 10^{-6}\right)\end{array}$ \\
\hline 4 & 0.05 & 85.7 & 3.2 & 1.0 & 10016 & 7.7 & 0.1 \\
\hline 8 & 2 & 13.1 & 1.2 & 1.0 & 10015 & 4210.3 & 194.1 \\
\hline 4 & 5 & 2.1 & 0.5 & 1.0 & 10015 & 732.0 & 86.9 \\
\hline 3 & 8 & 0.7 & 0.3 & 1.0 & 10015 & 97.0 & 20.4 \\
\hline 3 & 8 & 42.2 & 2.3 & 0.1 & 10020 & 1736.0 & 46.5 \\
\hline
\end{tabular}

\footnotetext{
$\sigma_{N} \quad-$ normal stress

$\mathrm{K}_{\mathrm{j}} \quad$ - fracture permeability (mean)

$e^{-}=$equivalent fracture aperture (mean)

$P_{i} \quad=$ injection pressure

$\Delta h=$ water head difference used in falling head permeameter test $\left(P_{1} / \gamma_{\omega}-h_{0}\right)$

$\mathrm{SD}\left(\mathrm{K}_{\mathrm{j}}\right)=$ standard deviation about mean of the fracture permeability

$\mathrm{SD}(\mathrm{e})$ - standard deviation about mean of the equivalent fracture aperture.
} 
Table 5.15 Fracture Permeability and Equivalent Fracture. Aperture for Sample AP3-1-6-FG6 with Sawcut Surfaces.

\begin{tabular}{|c|c|c|c|c|c|c|c|}
\hline $\begin{array}{l}\text { Number } \\
\text { of } \\
\text { Readings }\end{array}$ & $\begin{array}{c}\sigma_{N} \\
(\mathrm{MPa})\end{array}$ & $\left(x 10^{-3_{j}} \mathrm{~cm} / \mathrm{s}\right)$ & $\begin{array}{c}e \\
\left(x 10^{-3} \mathrm{~cm}\right)\end{array}$ & $\begin{array}{c}P_{i} \\
(\mathrm{MPa})\end{array}$ & $\begin{array}{c}\Delta h \\
(\mathrm{~cm})\end{array}$ & $\begin{array}{c}S D\left(K_{j}\right) \\
\left(x 10^{-6}\right)\end{array}$ & $\begin{array}{c}S D(e) \\
\left(\times 10^{-6}\right)\end{array}$ \\
\hline 3 & 0.05 & 168.0 & 4.49 & 0.1 & 999 & 760 & 10 \\
\hline 3 & 2 & 8.40 & 1.00 & 1.0 & 10012 & 1400 & 860 \\
\hline 5 & 5 & 1.50 & 0.42 & 1.0 & 10012 & 660 & 98 \\
\hline 4 & 8 & 0.32 & 0.20 & 1.0 & 10012 & 58 & 18 \\
\hline 3 & 10 & 0.02 & 0.13 & 1.0 & 10012 & 37 & 17 \\
\hline 3 & 8 & 0.10 & 0.11 & 1.0 & 10012 & 3.9 & 2.1 \\
\hline 4 & 5 & 0.22 & 0.16 & 1.0 & 10012 & 92 & 35 \\
\hline 4 & 2 & 2.22 & 0.52 & 1.0 & 10017 & 240 & 28 \\
\hline 3 & 0.05 & 123 & 3.84 & 0.1 & 996 & 3900 & 60 \\
\hline 3 & 2 & 3.93 & 0.68 & 1.0 & 10011 & 1700 & 150 \\
\hline 3 & 5 & 0.70 & 0.29 & 1.0 & 10010 & 150 & 30 \\
\hline 4 & 8 & 0.17 & 0.14 & 1.0 & 10013 & 72 & 30 \\
\hline 3 & 10 & 0.31 & 0.19 & 1.0 & 10016 & 62 & 19 \\
\hline
\end{tabular}

\footnotetext{
$\sigma_{N} \quad=$ normal stress

$\mathrm{K}_{\mathrm{j}} \quad=$ fracture permeability (mean)

e = equivalent fracture aperture (mean)

$\mathrm{P}_{\mathbf{i}} \quad=$ injection pressure

$\Delta h \quad=$ water head difference used in falling head permeameter test $\left(P_{t} / \gamma_{\omega}-h_{0}\right)$

$\mathrm{SD}\left(\mathrm{K}_{j}\right)=$ standard deviation about mean of the fracture permeability

$S D(e)=$ standard deviation about mean of the equivalent fracture aperture.
} 
Table 5.16 Fracture Permeability and Equivalent Fracture Aperture for Sample AP2-1-6-FG7 with a Natural Fracture.

\begin{tabular}{|c|c|c|c|c|c|c|c|}
\hline $\begin{array}{c}\text { Number } \\
\text { of } \\
\text { Readings }\end{array}$ & $\begin{array}{c}\sigma_{N} \\
(\mathrm{MPa})\end{array}$ & $\left(\times 10^{-3_{j}} \mathrm{~cm} / \mathrm{s}\right)$ & $\left(\begin{array}{c}e \\
(x)-3 \\
c m\end{array}\right.$ & $\begin{array}{l}\mathrm{h}_{\mathrm{o}} \\
(\mathrm{cm})\end{array}$ & $\begin{array}{l}\mathrm{h}_{\mathfrak{f}} \\
(\mathrm{cm})\end{array}$ & $\begin{array}{c}\operatorname{SD}\left(K_{j}\right) \\
\left(x 10^{-6}\right)\end{array}$ & $\begin{array}{c}\text { SD (e) } \\
\left(\times 10^{-6}\right)\end{array}$ \\
\hline 3 & 0.05 & 186 & 4.7 & 155 & 129 & 0 & 0 \\
\hline 3 & 2 & 147 & 4.2 & 155 & 129 & 0 & 0 \\
\hline 3 & 5 & 132 & 4.0 & 155 & 129 & 1000 & 20 \\
\hline 3 & 8 & 117 & 3.8 & 155 & 129 & 0 & 0 \\
\hline 3 & 10 & 107 & 2.6 & 155 & 129 & 1000 & 10 \\
\hline 3 & 8 & 109 & 3.6 & 155 & 129 & 580 & 5.8 \\
\hline 4 & 5 & 115 & 3.7 & 155 & 129 & 1700 & 31 \\
\hline 4 & 2 & 123 & 3.8 & 155 & 129 & 820 & 13 \\
\hline 5 & 0.05 & 189 & 4.8 & 155 & 129 & 4500 & 54 \\
\hline 4 & 2 & 106 & 3.6 & 155 & 129 & 2200 & 39 \\
\hline 3 & 5 & 92 & 3.3 & 155 & 129 & 580 & 10 \\
\hline 3 & 8 & .83 & 3.2 & 155 & 129 & 1000 & 23 \\
\hline 3 & 10 & 76 & 3.0 & 155 & 129 & 1500 & 31 \\
\hline
\end{tabular}

\footnotetext{
$\sigma_{N} \quad-$ normal stress

$\mathrm{K}_{\mathrm{j}} \quad$ - fracture permeability (mean)

e - equivalent fracture aperture (mean)

$h_{0} \quad-$ starting height in falling head pipette

$h_{f} \quad$ - water head difference used in falling head pipette

$\mathrm{SD}\left(\mathrm{K}_{\mathrm{j}}\right)$ = standard deviation about mean of the fracture permeability

$\mathrm{SD}(\mathrm{e})$ = standard deviation about mean of the equivalent fracture aperture.
} 
Table 5.17 Fracture Permeability and Equivalent Fracture Aperture for Sample AP56-5-6-FG12 with a Natural Fracture.

\begin{tabular}{|c|c|c|c|c|c|c|c|}
\hline $\begin{array}{c}\text { Number } \\
\text { of } \\
\text { Readings }\end{array}$ & $\begin{array}{c}\sigma_{N} \\
(\mathrm{MPa})\end{array}$ & $\left(x 10^{-3} \mathrm{~km} / \mathrm{s}\right)$ & $\begin{array}{c}\mathrm{e} \\
\left(\mathrm{x} 10^{-3} \mathrm{~cm}\right)\end{array}$ & $\begin{array}{c}\mathrm{P}_{\mathrm{i}} \\
(\mathrm{MPa})\end{array}$ & $\begin{array}{c}\Delta h \\
(\mathrm{~cm})\end{array}$ & $\begin{array}{c}\mathrm{SD}\left(\mathrm{K}_{\mathrm{j}}\right) \\
\left(\mathrm{x} 10^{-3}\right)\end{array}$ & $\begin{array}{l}\text { SD (e) } \\
\left(\times 10^{-6}\right)\end{array}$ \\
\hline 5 & 0.05 & 252.2 & 5.51 & 0.05 & 495 & 4.2 & 45.4 \\
\hline 5 & 2 & 255.8 & 5.55 & .05 & 492 & 6.3 & 68.7 \\
\hline 4 & 5 & 258.9 & 5.58 & .05 & 494 & 1.1 & 11.4 \\
\hline 4 & 8 & 259.6 & 5.59 & .05 & 492 & 0.79 & 8.5 \\
\hline 3 & 10 & 258.9 & 5.58 & .05 & 494 & 1.40 & 4.0 \\
\hline 6 & 8 & 224.9 & 5.19 & .05 & 743 & 32.2 & 381.0 \\
\hline 7 & 5 & 230.6 & 5.26 & .05 & 707 & 28.3 & 326.7 \\
\hline 6 & 2 & 232.7 & 5.28 & .05 & 743 & 35.0 & 398.7 \\
\hline 6 & 0.05 & 233.4 & 5.29 & .05 & 743 & 37.6 & 427.7 \\
\hline 6 & 2 & 226.8 & 5.21 & .05 & 745 & 34.9 & 403.2 \\
\hline 6 & 5 & 226.9 & 5.22 & .05 & 743 & 30.2 & 348.6 \\
\hline 6 & 8 & 227.7 & 5.23 & .05 & 745 & 29.5 & 339.2 \\
\hline 6 & 10 & 227.0 & 5.22 & .05 & 741 & 29.1 & 337.8 \\
\hline
\end{tabular}

\footnotetext{
$\sigma_{N} \quad$ normal stress

$\mathrm{K}_{\mathrm{j}} \quad$ - fracture permeability (imean)

e - equivalent fracture aperture (mean)

$\mathrm{P}_{\mathrm{i}} \quad$ = injection pressure

$\Delta h \quad=$ water head difference used in falling head permeameter test$$
\left(P_{l} / Y_{\omega}-h_{0}\right)
$$

$S D\left(K_{j}\right)=$ standard deviation about mean of the fracture permeability

$S D(e)=$ standard deviation about mean of the equivalent fracture aperture.
} 
Table 5.18 Fracture Permeability and Equivalent Fracture Aperture for Sample AP56-2-6-FG14 with a Natural Fracture.

\begin{tabular}{|c|c|c|c|c|c|c|c|}
\hline $\begin{array}{l}\text { Number } \\
\text { of } \\
\text { Readings }\end{array}$ & $\begin{array}{c}\sigma_{N} \\
(\mathrm{MPa})\end{array}$ & $\left(\mathrm{x} 10^{-3} \mathrm{~cm} / \mathrm{s}\right)$ & $\left(\begin{array}{c}e \\
\left(x 10^{-3} \mathrm{~cm}\right.\end{array}\right.$ & $\begin{array}{l}h_{0} \\
(\mathrm{~cm})\end{array}$ & $\begin{array}{l}h_{f} \\
(\mathrm{~cm})\end{array}$ & $\begin{array}{c}\mathrm{SD}\left(\mathrm{K}_{\mathrm{j}}\right) \\
\left(\times 10^{-6}\right)\end{array}$ & $\begin{array}{l}\text { SD (e) } \\
\left(x 10^{-6}\right)\end{array}$ \\
\hline 8 & 0.05 & 345.38 & 6.45 & 180 & 131 & 10529.5 & 98.4 \\
\hline 8 & 2 & 152.89 & 4.29 & 180 & 131 & 3256.1 & 45.9 \\
\hline 14 & 5 & 59.52 & 2.67 & 175 & 131 & 10211.5 & 232.5 \\
\hline 4 & 8 & 26.55 & 1.79 & 180 & 131 & 2470.1 & 83.4 \\
\hline 3 & 10 & 11.18 & 1.15 & 180 & 138 & 4971.1 & 168.5 \\
\hline 4 & 8 & 6.29 & 0.86 & 170 & 153 & 1991.7 & 144.5 \\
\hline 5 & 5 & 10.00 & 1.09 & 180 & 155 & 2763.8 & 154.5 \\
\hline 3 & 2 & 16.41 & 1.40 & 180 & 145 & 3230.6 & 137.6 \\
\hline 7 & 0.05 & 271.65 & 5.72 & 180 & 131 & 1842.2 & 19.4 \\
\hline 4 & 2 & 32.60 & 1.98 & 180 & 131 & 1220.5 & 37.2 \\
\hline 4 & 5 & 8.95 & 1.04 & 180 & 161 & 1422.7 & 81.7 \\
\hline 4 & 8 & 3.75 & 0.67 & 177 & 170 & 490.3 & 44.9 \\
\hline 3 & 10 & 2.20 & 0.51 & 175 & 172 & 75.3 & 8.8 \\
\hline
\end{tabular}

$\sigma_{N} \quad=$ normal stress

$\mathrm{K}_{\mathrm{j}} \quad$ - fracture permeability (mean)

e - equivalent fracture aperture (mean)

$h_{0} \quad-$ starting height in falling head pipette

$h_{f}$ - water head difference used in falling head permeameter test

$S D\left(K_{j}\right)$ = standard deviation about mean of the fracture permeability

$\mathrm{SD}(e)$ = standard deviation about mean of the equivalent fracture aperture. 
Table 5.19 Fracture Permeability and Equivalent Fracture Aperture for Sample AP56-3-6-FG15 with a Natural Fracture.

\begin{tabular}{|c|c|c|c|c|c|c|c|}
\hline $\begin{array}{c}\text { Number } \\
\text { of } \\
\text { Readings }\end{array}$ & $\begin{array}{c}\sigma_{N} \\
(\mathrm{MPa})\end{array}$ & $\begin{array}{c}\mathrm{K}_{\mathrm{j}} \\
\left(\mathrm{x} 10^{-3} \mathrm{~cm} / \mathrm{s}\right)\end{array}$ & $\begin{array}{c}\mathrm{e} \\
\left(\mathrm{x} 10^{-3} \mathrm{~cm}\right)\end{array}$ & $\begin{array}{c}\mathrm{P}_{\mathrm{i}} \\
(\mathrm{MPa})\end{array}$ & $\begin{array}{c}\Delta h \\
(\mathrm{~cm})\end{array}$ & $\begin{array}{c}\mathrm{SD}\left(\mathrm{K}_{\mathrm{j}}\right) \\
\left(\mathrm{x} 10^{-3}\right)\end{array}$ & $\begin{array}{c}\mathrm{SD}(\mathrm{e}) \\
\left(\mathrm{x} 10^{-6}\right)\end{array}$ \\
\hline 4 & 0.05 & 174.8 & 4.6 & 0.1 & 999 & 2.7 & 36.0 \\
\hline 4 & 2 & 59.6 & 2.7 & 0.1 & 997 & 7.9 & 176.9 \\
\hline 4 & 5 & 27.9 & 1.8 & 0.1 & 999 & 2.4 & 77.7 \\
\hline 4 & 8 & 23.6 & 1.7 & 0.1 & 999 & 1.7 & 60.3 \\
\hline 4 & 10 & 16.4 & 1.4 & 0.1 & 997 & 3.5 & 150.0 \\
\hline
\end{tabular}

\footnotetext{
$\sigma_{N} \quad=$ normal stress

$\mathrm{K}_{\mathrm{j}} \quad$ = fracture permeability (mean)

e $\quad$ equivalent fracture aperture (mean)

$\mathrm{P}_{\mathrm{i}} \quad$ = injection pressure

$\Delta h \quad$ - water head difference used in falling head permeameter test $\left(P_{1} / \gamma_{u}-h_{0}\right)$

$\mathrm{SD}\left(\mathrm{K}_{j}\right)$ - standard deviation about mean of the fracture permeability

$\mathrm{SD}(\mathrm{e}) \quad=$ standard deviation about mean of the equivalent fracture aperture.
} 
Of the three types of fractures tested, natural fractures show the greatest hydraulic conductivities and equivalent fracture apertures, at all stress levels. For all types of fractures tested, permeabilities are within three orders of magnitude at any one stress level. Even at high normal stress, only distinct areas on these surfaces make contact. No fracture closes completely.

The second greatest flow rates are observed in tension induced fractures. Initially it had been expected that this type of fracture would have the lowest permeability due to tight interlocking of the surfaces.

Sawcut surfaces had the lowest permeability overall, presumably due to the very smooth and parallel surfaces created by the diamond saw. These surfaces have a large contact area (low effective flow area) even at low normal stress. As the stress levels are increased the surfaces deform together to create an even tighter interface. It is unlikely that this type of fracture surface occurs in nature in welded tuff.

\subsection{Fracture Compression}

Fracture permeability depends on the fracture aperture, which depends on the applied normal stress and stress history. Fracture compression or closure has been measured as a function of the applied normal stress under cyclic loading. Figure 5.27 shows the effect of normal stress on fracture compression for sample AP36-1-6-FG13. Each new loading cycle causes new surface deformation accompanied by some hysteresis. Two distinct stiffness regions are observed, with remarkable repeatability. for both, and a well defined transition stress between the two. The greatest aperture changes occur at low normal stress $(<1 \mathrm{MPa})$.

Figure 5.28 shows the fracture closure of sample AP36-1-6-FG13 (last loading cycle) as a function of normal stress in terms of calculated equivalent fracture aperture and measured fracture compression. Two different regions of stiffness are observed, both in compression testing and in flow testing. The behavior differs at the higher normal stresses, where the fracture appears to be much stiffer during flow testing than during compression testing.

\subsection{Surface Roughness Characterization}

Fracture surfaces can be characterized by their roughness or height of asperities, surface waviness, orientation, contact area, and flow paths. This report only gives a visual display of the surface, which illustrates the tortuous path that flow must follow. Roko et al. (1991) present a method whereby this data base might be used to identify specific flowpaths. Knowledge of these potential flow paths may allow calculations of actual flow lengths and the associated pressure drops away from the injection borehole.

Figures 5.29 and 5.30 show one surface of sample AP21-3-6-FG1. Figures 5.31 and 5.32 show plots of the top and bottom fracture surfaces of sample AP21-3-6-FG1 respectively. 


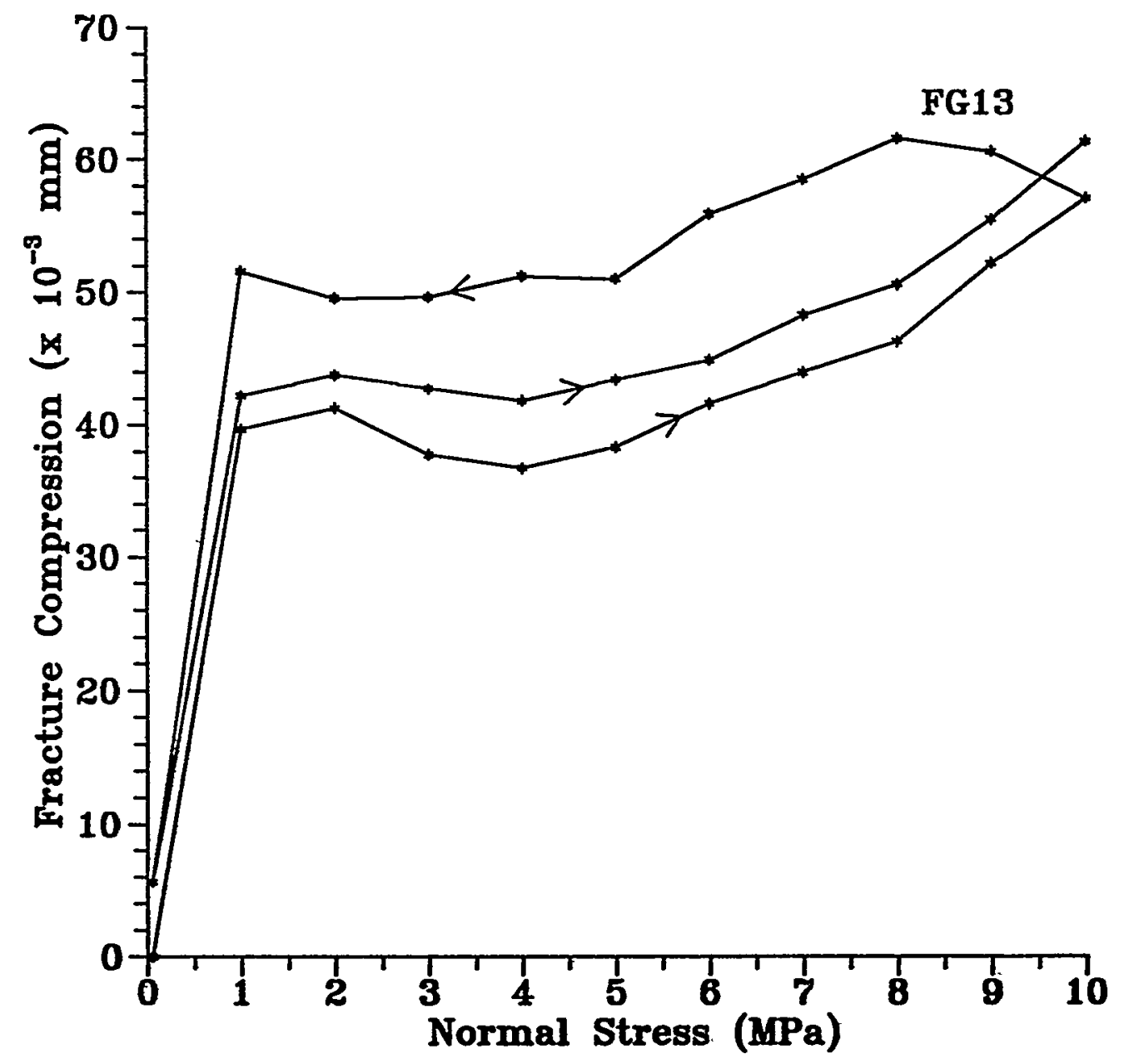

Figure 5.27 The effect of normal stress on fracture closure for Sample AP36-1-6-FG13. Arrows indicate loading and unloading paths. 


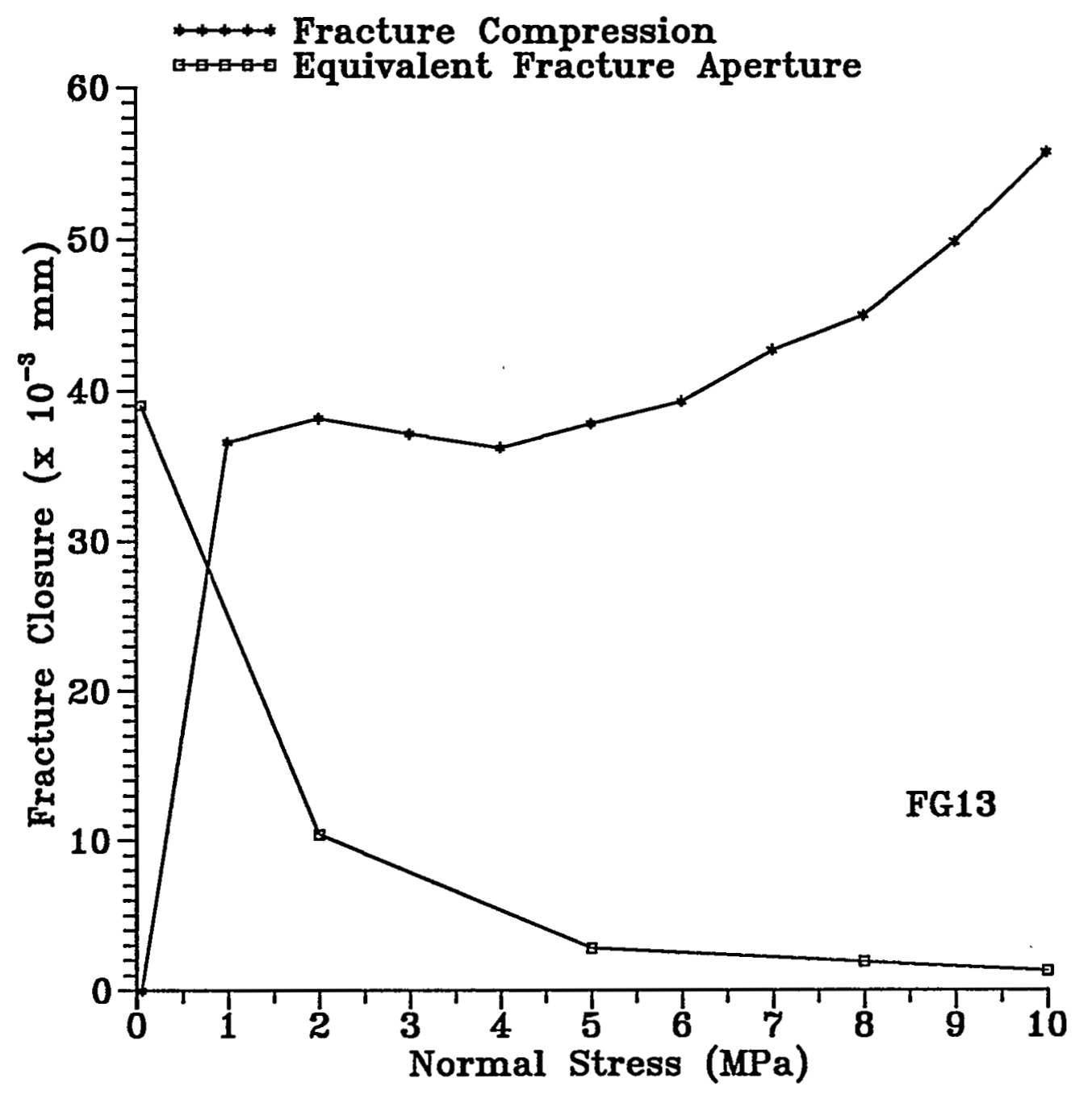

Figure 5.28 Fracture compression and equivalent fracture aperture for final loading cycle of Sample AP36-1-6-FG13. 


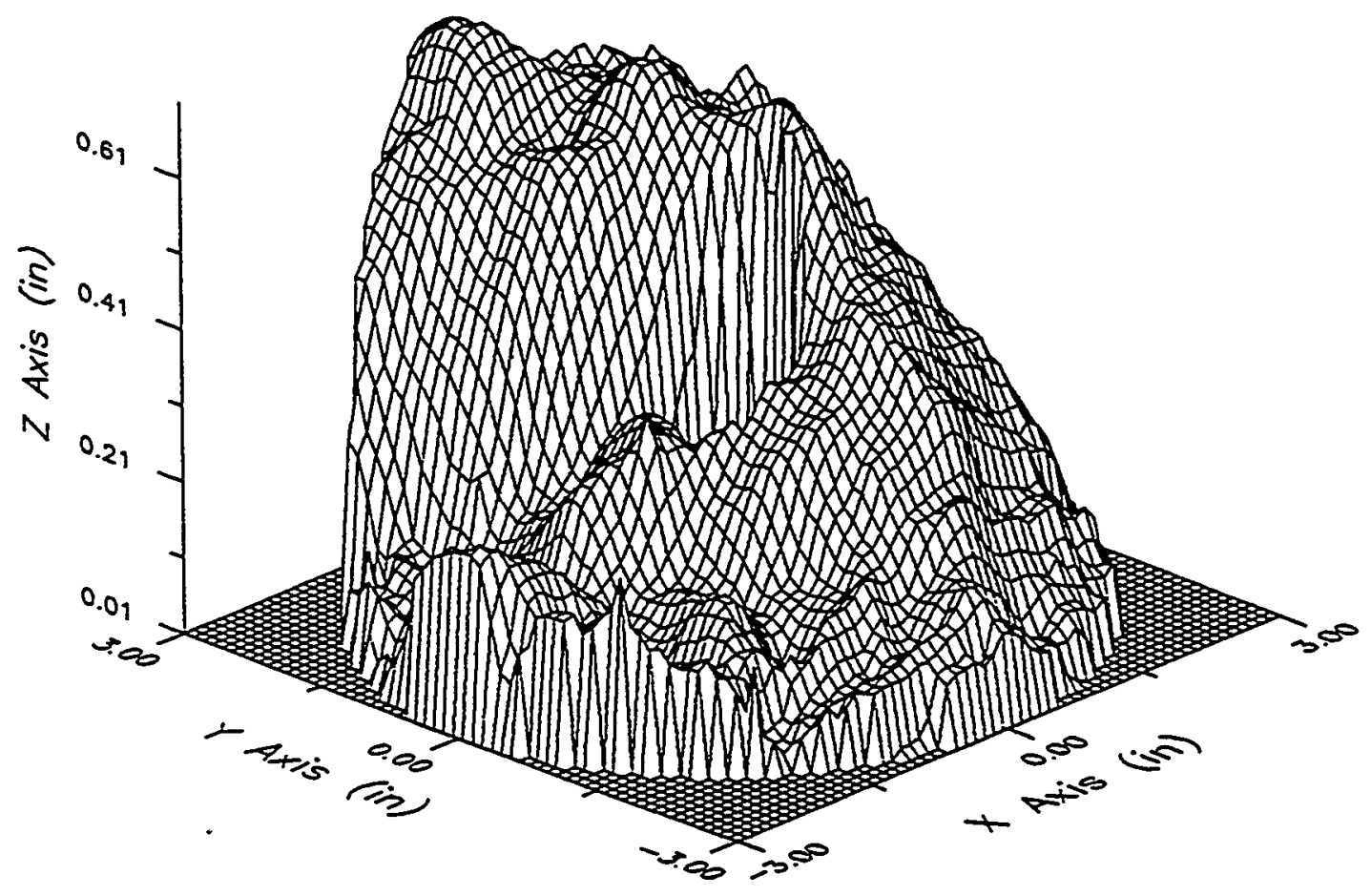

Figure 5.29 Three-dimensional image of the surface of Sample AP21-3-6FG1 (80 degree tilt off of the $z$-axis). Vertical scale is exaggerated. 


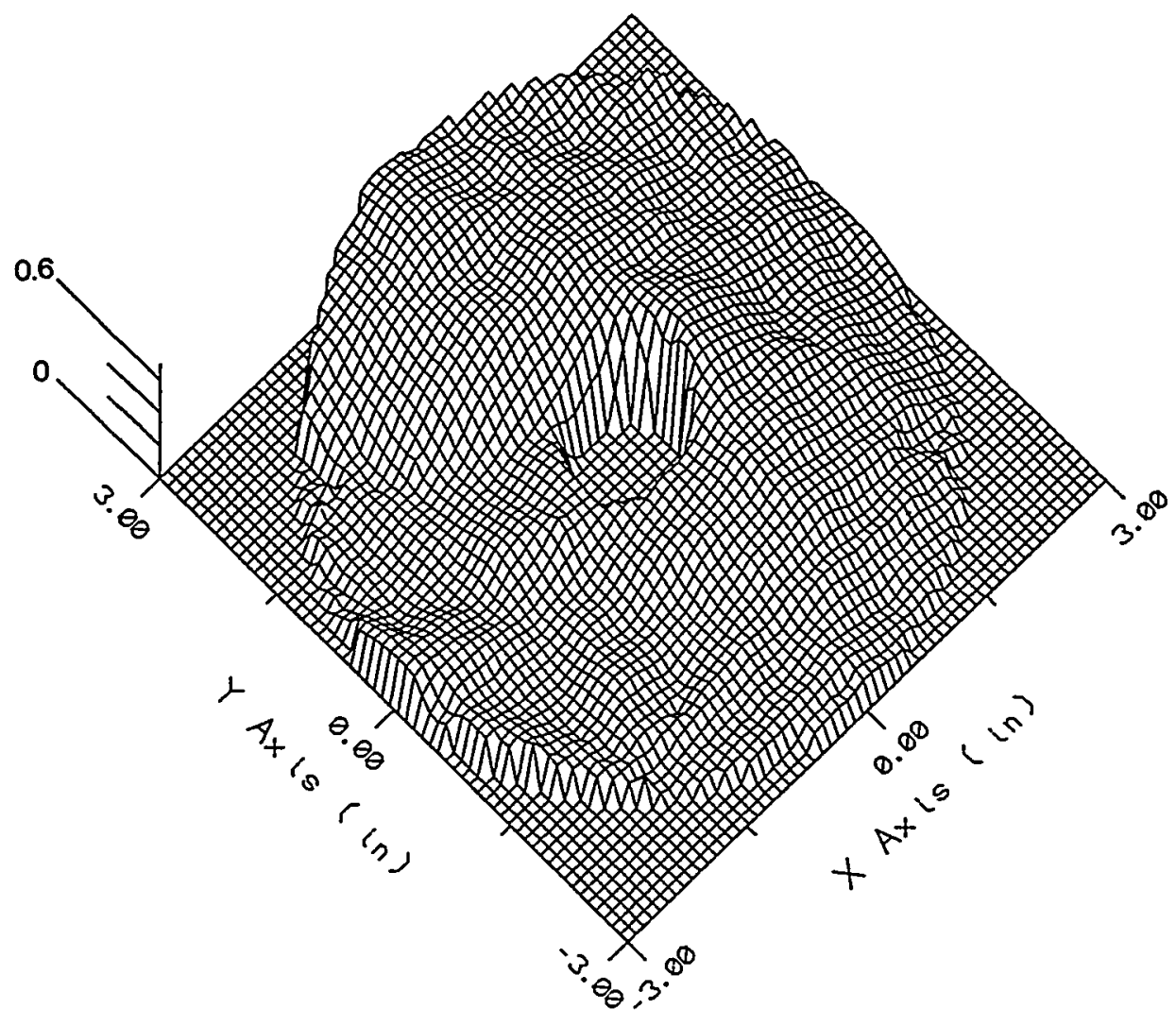

Figure 5.30 Three-dimensional image of the surface roughness of Sample AP21-3-6-FGI (30 degree tilt off of the $z$-axis). Vertical scale is exaggerated. 


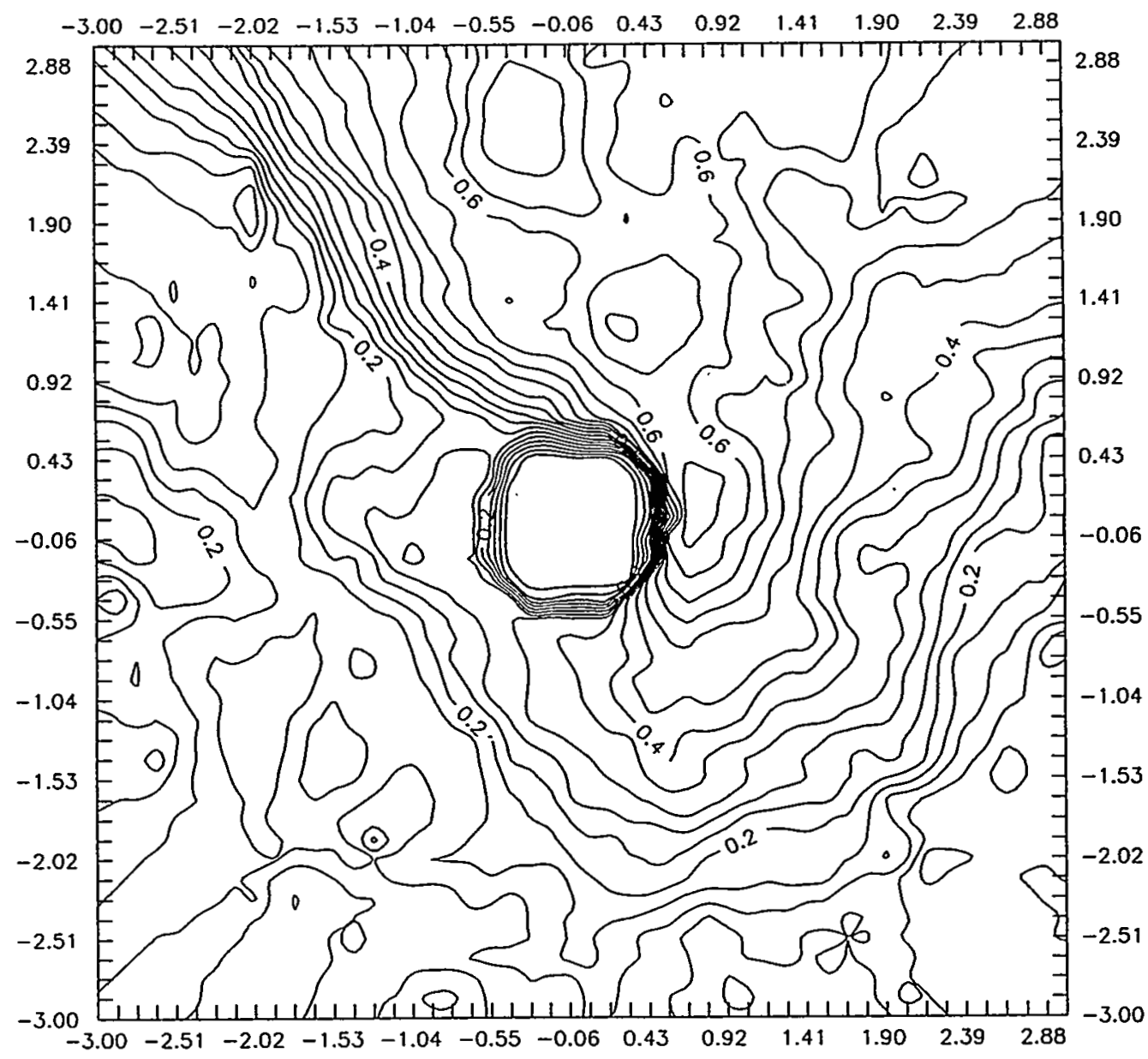

Figure 5.31 Topographic plot of the surface of sample AP21-3-6-FG1 (top fracture surface). Contour lines represent points of constant surface height. 


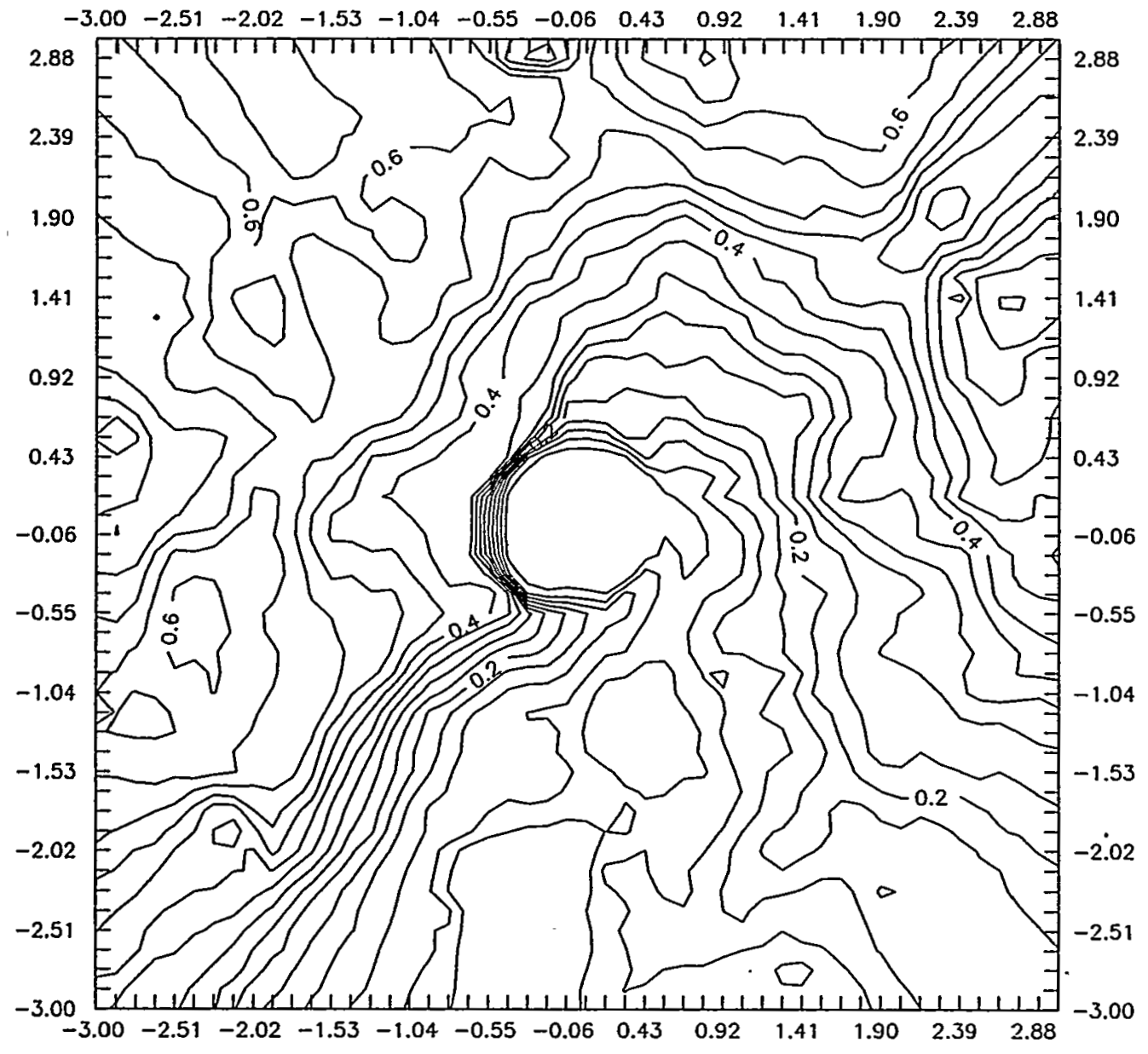

Figure 5.32 Topographic plot of the surface roughness of sample AP21-36-FG1 (bottom fracture surface). Contour lines represent points of constant surface height. 


\subsection{Grout Characterization}

Rheological properties, strength, and stability are important parameters in defining the behavior of a grout during pumping. They also may affect the useful lifetime of a grout. Cementitious grout characterization includes the determination of uniaxial compressive strength, density, viscosity, cohesion, Marsh flow time, and stability.

Table 5.20 contains results of 7,8 , and 28 day strength testing. Cylindrical grout specimens have a length-to-diameter ratio between 2.0 and 2.5. Mixing procedures can be found in section 4.4, curing conditions in section 4.5 .

Table 5.21 contains results of viscosity measurements as a function of rotor speed. Comparisons between grout formulations are difficult due to varying water to cement ratios as well as bentonite content. Figure 5.33 shows the effects of rotor speed on viscosity readings for all grout formulations. Table 5.22 contains results of plastic viscosity and cohesion calculations.

Table 5.23 contains Marsh funnel viscosities and bleed capacities. Test procedures can be found in section 4.5.

\subsection{Grouting Effectiveness}

Sample AP21-3-6-FG1:

Test 1

Grouting of the tension induced fracture in sample AP21-3-6-FG1 was conducted at an injection pressure of $5.0 \mathrm{MPa}$ and a normal stress of 2.0 $\mathrm{MPa}$. Due to the tight tension induced fracture it was decided to use mix formulation three (the thinnest 0.P.C. grout used in this study), which has a water to cement ratio of 0.9 with 5 percent bentonite. After ten minutes under pressure no grout flow was evident. It was not known if any grout was emplaced in the fracture. Water flow testing was initiated after a curing period of two days. Results are shown in Figure 5.34. The hydraulic conductivity during the last reloading cycle of the ungrouted sample is shown for comparison.

After testing, the sample was separated. Filter blockage at the periphery of the injection borehole reduces the flow. Figure 5.35 shows this blockage and the small amount of grout emplaced around the periphery of the borehole. This blockage results in a reduction in apparent permeability that is not indicative of the true permeability of the "grouted" fracture. Cement bonding around the periphery of the borehole was not strong and was easily broken away with the hand. 
Table 5.20 Uniaxial Compressive Strengths of Grouts

\begin{tabular}{|c|c|c|c|c|c|c|c|}
\hline $\begin{array}{c}\text { Number } \\
\text { of } \\
\text { Tests }\end{array}$ & $\begin{array}{c}\text { Mix } \\
\text { Type }\end{array}$ & $\begin{array}{c}\text { Strength/SD } \\
\text { (MPa) }\end{array}$ & $\begin{array}{c}\text { 8-Day } \\
\text { Strength/SD } \\
(\mathrm{MPa})\end{array}$ & $\begin{array}{c}28-\text { Day } \\
\text { Strength/SD( } \\
\text { MPa) }\end{array}$ & $\begin{array}{c}\text { w/c } \\
\text { Ratio }\end{array}$ & $\begin{array}{c}\text { \& } \\
\text { Bentonite }\end{array}$ & $\begin{array}{c}\text { Fluid } \\
\text { Density } \\
\text { (g/cc) }\end{array}$ \\
\hline 5 & MIX 1+ & - & $21.15 / 0.61$ & $22.99 / 1.47$ & 0.6 & 2 & 1.77 \\
\hline 5 & MIX 2+ & - & $14.33 / 0.52$ & $14.91 / 1.62$ & 0.7 & 3 & 1.70 \\
\hline 4 & MIX 3+ & - & $7.86 / 0.33$ & $11.47 / 0.16$ & 0.9 & 5 & 1.58 \\
\hline 3 & MIX 4+ & - & $20.62 / 1.03$ & $33.72 / 0.99$ & 0.45 & 0 & 1.90 \\
\hline 3 & MC-500* & $23.96 / 1.52$ & - & $30.51 / 1.73$ & 1.0 & 0 & 1.22 \\
\hline
\end{tabular}

옹

* 18 Napthalene Sulphonate (NS-200)

+18 Dispersant (D65)

SD = Standard Deviation 
Table 5.21 Results of Fann Viscosities for Different Grout Formulations.

\begin{tabular}{|c|c|c|c|c|c|c|c|c|}
\hline $\begin{array}{c}\text { Number } \\
\text { of } \\
\text { Tests }\end{array}$ & $\begin{array}{c}\text { Rotor } \\
\text { Speed } \\
\text { (rpm) }\end{array}$ & $\begin{array}{c}\text { Reading } \\
\text { Interval } \\
\text { after } \\
\text { Mixing }\end{array}$ & \multicolumn{6}{|c|}{ Viscosity Readings* } \\
\hline 3 & 300 & 60 & 50.2 & 42.4 & 39.8 & 28.5 & 5.0 & 17.5 \\
\hline 3 & 200 & 80 & 38.6 & 33.1 & 30.9 & 19.6 & 3.0 & 13.5 \\
\hline 3 & 100 & 100 & 22.5 & 22.7 & 22.7 & 10.6 & 1.9 & 8.9 \\
\hline 3 & 6 & 120 & 11.2 & 10.6 & 14.0 & 1.1 & 0.6 & 2.9 \\
\hline 3 & 3 & 140 & 10.6 & 10.1 & 13.8 & 0.9 & 0.63 & 2.5 \\
\hline $\begin{array}{c}\text { W/C } \\
\text { Ratio }\end{array}$ & & & 0.6 & 0.7 & 0.9 & 0.45 & 1.33 & 1.0 \\
\hline $\begin{array}{c}8 \\
\text { Bento- } \\
\text { nite }\end{array}$ & & & 2 & 3 & 5 & 0 & 2 & 0 \\
\hline
\end{tabular}

${ }^{*}$ Newtonian Viscosities (cp)

Table 5.22 Plastic Viscosity and Yield Value of Grout Formulations.

\begin{tabular}{|c|c|c|c|}
\hline $\begin{array}{c}\text { Number } \\
\text { of } \\
\text { Tests }\end{array}$ & $\begin{array}{c}\text { Mix } \\
\text { Number }\end{array}$ & $\begin{array}{c}\text { Plastic } \\
\text { Viscosity } \\
(\mathrm{cp})\end{array}$ & $\begin{array}{c}\text { Yield Value } \\
\left(\mathrm{N} / \mathrm{m}^{2}\right)\end{array}$ \\
\hline 3 & 1 & 41.5 & 4.2 \\
\hline 3 & 2 & 29.6 & 6.1 \\
\hline 3 & 3 & 25.7 & 6.8 \\
\hline 3 & 4 & 26.9 & 0.8 \\
\hline 3 & $5^{*}$ & 4.7 & 16.8 \\
\hline 3 & MC-500 & 12.9 & 2.2 \\
\hline
\end{tabular}

${ }^{*}$ Unstable mix 
Table 5.23 Marsh Funnel Viscosity and Bleed Capacity.

\begin{tabular}{|c|c|c|c|c|c|c|c|}
\hline \multicolumn{7}{|c|}{ Marsh Funne1 Viscosity (sec) } \\
\hline $\begin{array}{c}\text { Test } \\
\text { Number }\end{array}$ & Mix 1 & Mix 2 & Mix 3 & Mix 4 & Mix 5 & MC-500 & Water \\
\hline 1 & 35 & 34 & 36 & 37 & 28 & 29 & 26 \\
\hline 2 & 34 & 34 & 35 & 38 & 28 & 29 & 26 \\
\hline 3 & 35 & 34 & 34 & 37 & 28 & 29 & 26 \\
\hline $\begin{array}{c}\text { w/c } \\
\text { Ratio }\end{array}$ & 0.6 & 0.7 & 0.9 & 0.45 & 1.33 & 1.0 & - \\
\hline $\begin{array}{c}\text { \& } \\
\text { Bentonite }\end{array}$ & 2 & 3 & 5 & 0 & 2 & 0 & - \\
\hline $\begin{array}{c}\text { Bleed } \\
\text { capacity }\end{array}$ & $<1$ & $<1$ & $<1$ & 0 & $>10$ & 10 & - \\
\hline
\end{tabular}




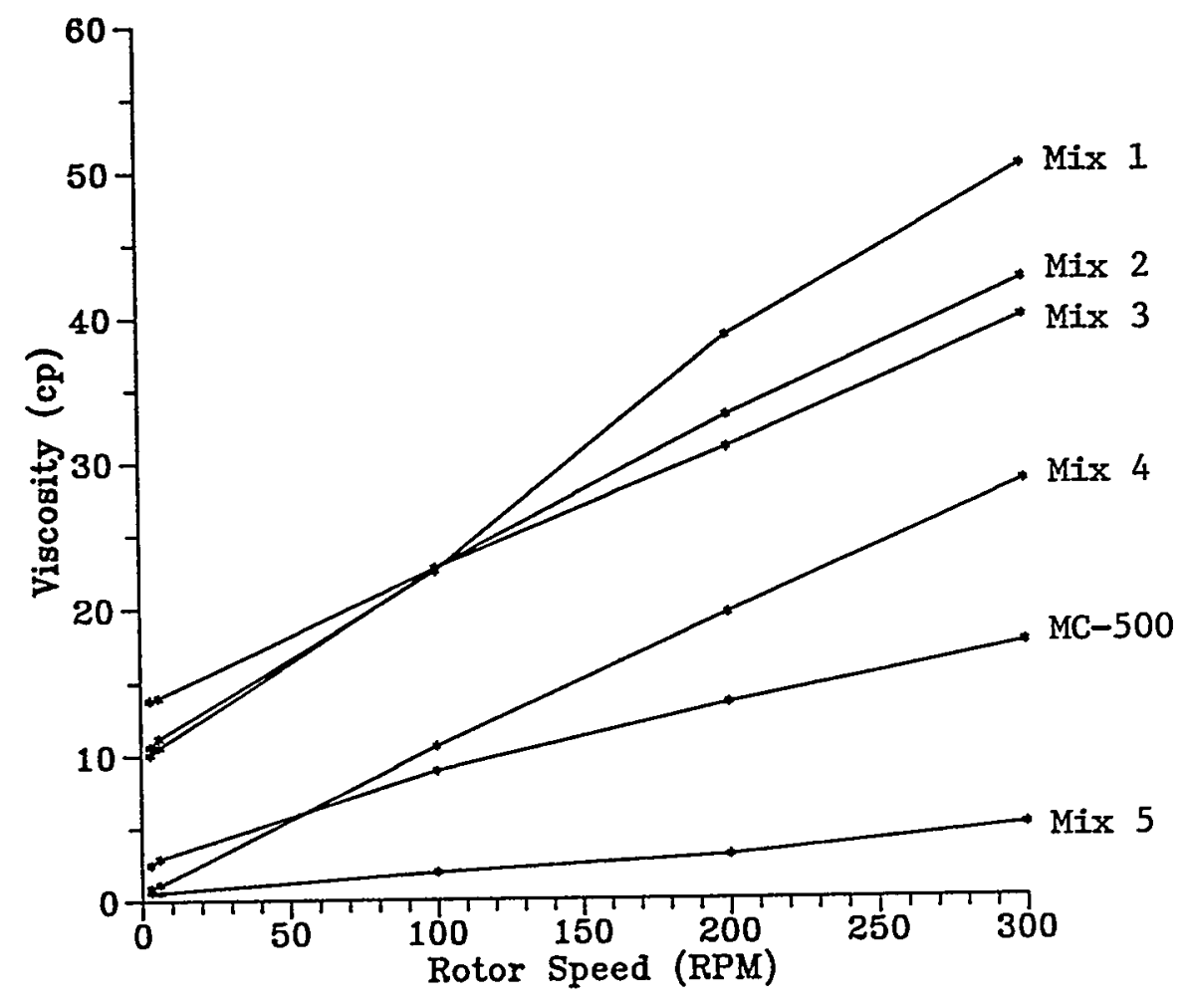

Figure 5.33 Fann viscosity readings as a function of rotor speed for various grout formulations. Mix compositions can be found in Table 4.1 . 


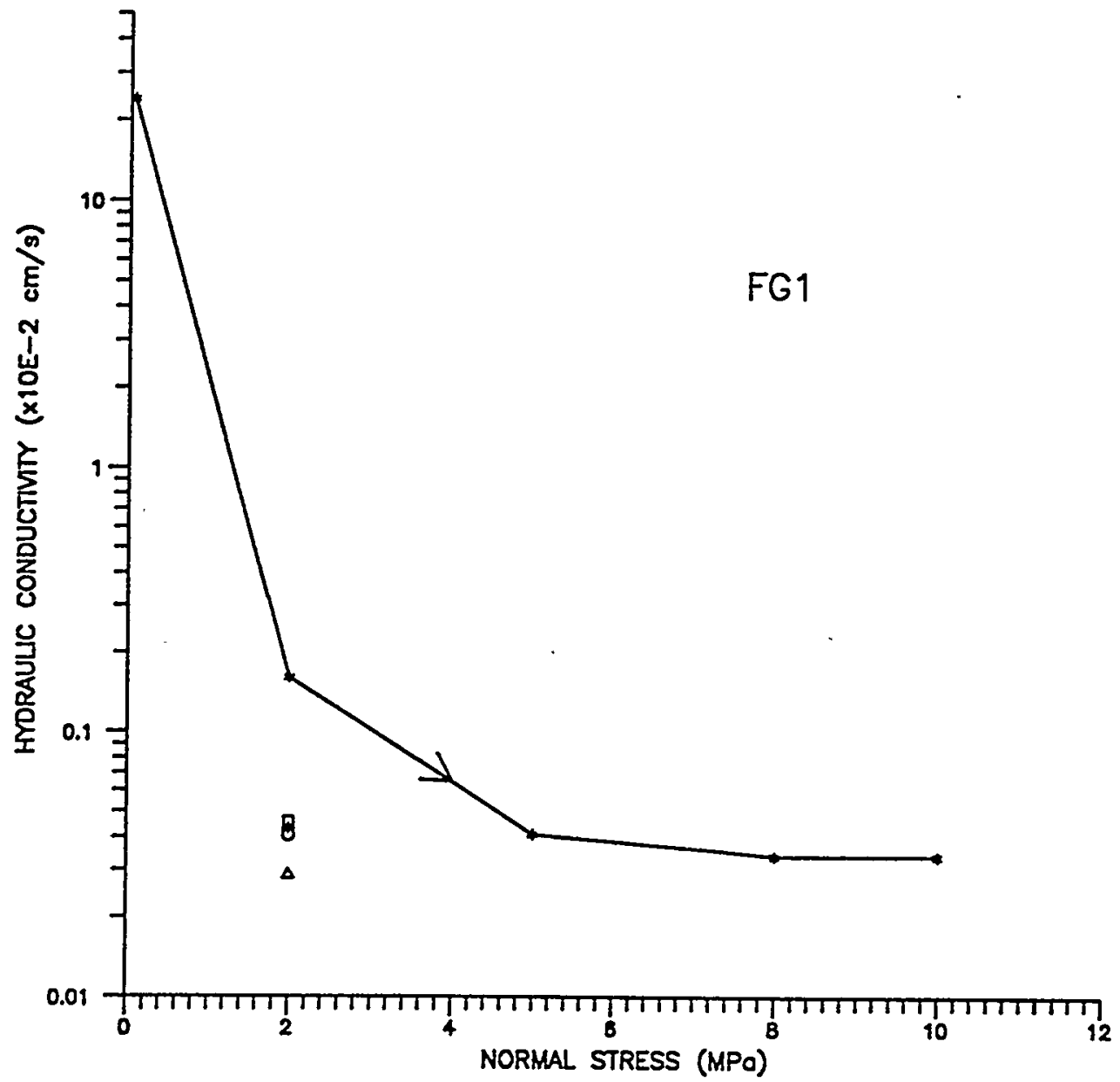

Figure 5.34 Hydraulic conductivity of Sample AP21-3-6-FG1 as a function of normal stress. Curve depicts last reloading cycle of ungrouted sample. Points under curve represent permeability after grouting ( $0: 2$ days of curing; $\Delta: 6$ days of curing; $\square: 7$ days of curing; $+: 8$ days of curing). 


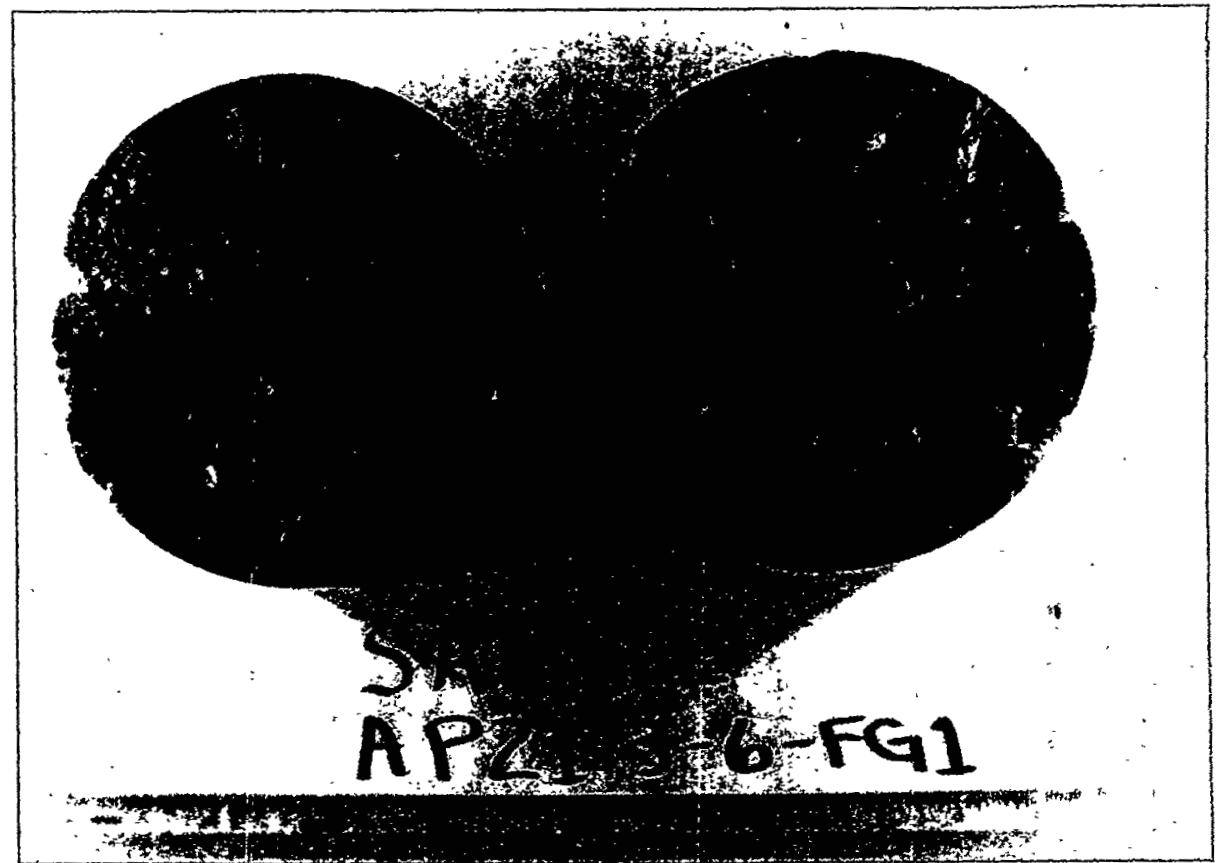

Figure 5.35 Filter blockage of sample AP21-3-6-FG1 showing the small amount of grout emplaced around the periphery of the one inch $(2.5 \mathrm{~cm})$ diameter borehole. 
Test 2

Grouting of the tension induced fracture in sample AP21-3-6-FG1 with MC-500 cement was conducted at a normal stress of $1.5 \mathrm{MPa}$ and an injection pressure of $0.62 \mathrm{MPa}$. Grout flowed from the fracture. After two days of curing, permeability measurements show an increase in flow through the fracture. This increase in flow is possibly attributed to a misalignment of the fracture prior to grouting or perhaps to a rock particle on the fracture surface propping open the fracture. Why this fracture was not sealed by the grout is unknown. Figure 5.36 shows the fracture permeability before and after grouting. Figure 5.37 shows sample FGI being grouted. Figure 5.38 shows the fracture surfaces after curing and testing. Grout placement in the vicinity of the borehole was non-existent, except for a few isolated pockets. Grout was well distributed on the fracture surfaces past this point, but exhibited a chalky characteristic and could be easily scratched with a fingernail. The absence of grout around the vicinity of the borehole could be attributed to bleed water channeling through the fracture or perhaps to the washing of the borehole after grouting.

Sample AP30-2-6-FG10:

Tests 1 and 2

The first attempt to grout sample AP30-2-6-FG10 (tension induced fracture) using MC-500 grout was performed at a normal stress of $1 \mathrm{MPa}$ and at an injection pressure greater than $2 \mathrm{MPa}$. The exact injection pressure was unknown because cement clogged the tube leading to the pressure gauge. Immediately after borehole washing and inspection this sample was found to have filter blockage (Figure 5.39a). No grout was emplaced on the fracture surfaces. The second attempt to grout sample FG10 was performed at I MPa normal stress but at an injection pressure of $4.1 \mathrm{MPa}$. Filter blockage was evident (Figure 5.39b).

Test 3

To increase the aperture of sample AP30-2-6-FG10, six shims were placed 60 degrees apart around the fracture. Shims had a thickness of 25.4 $\mu \mathrm{m}$. Grouting was performed at $0.5 \mathrm{MPa}$ normal stress and $4.1 \mathrm{MPa}$ injection pressure. No grout could be seen exiting the fracture. Upon inspection, filter blockage was evident with no grout emplaced in the fracture (Figure 5.40). Figure 5.41 shows the apparent decrease in permeability due to filter blockage.

Sample AP36-1-6-FG13:

The aperture of this sample was increased by placing eight 76.2-1m thick shims $45^{\circ}$ apart around the fracture surface. The hydraulic conductivity for this sample was $0.19 \mathrm{~cm} / \mathrm{s}$ at an axial stress of $1.0 \mathrm{MPa}$. The groutability ratio was calculated to be 4.8 . 


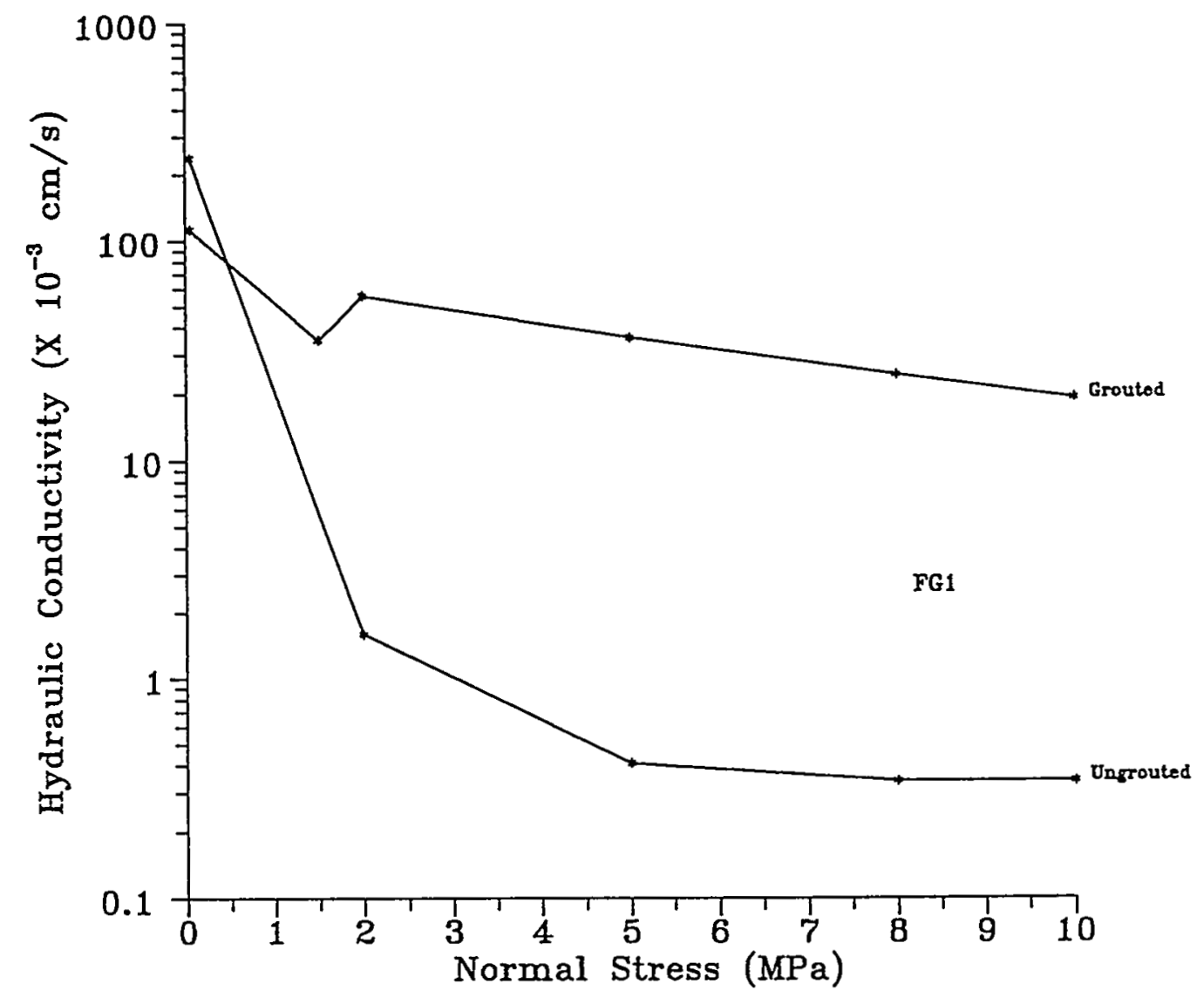

Figure 5.36 Hydraulic conductivity of Sample AP21-3-6-FG1 before and after grouting. 


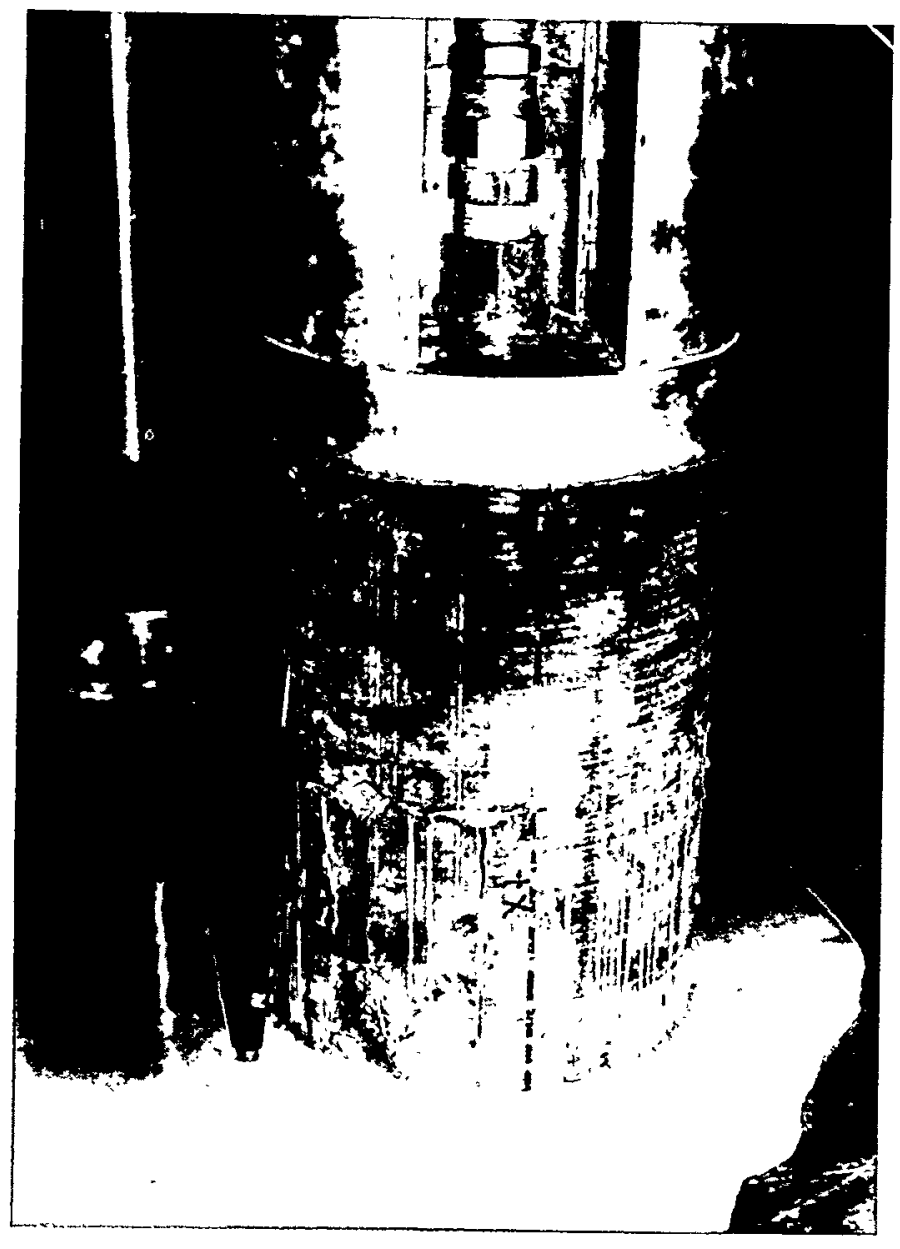

Figure 5.37 MC-500 grout flowing from the fracture of Sample AP21-3-6FGI. 


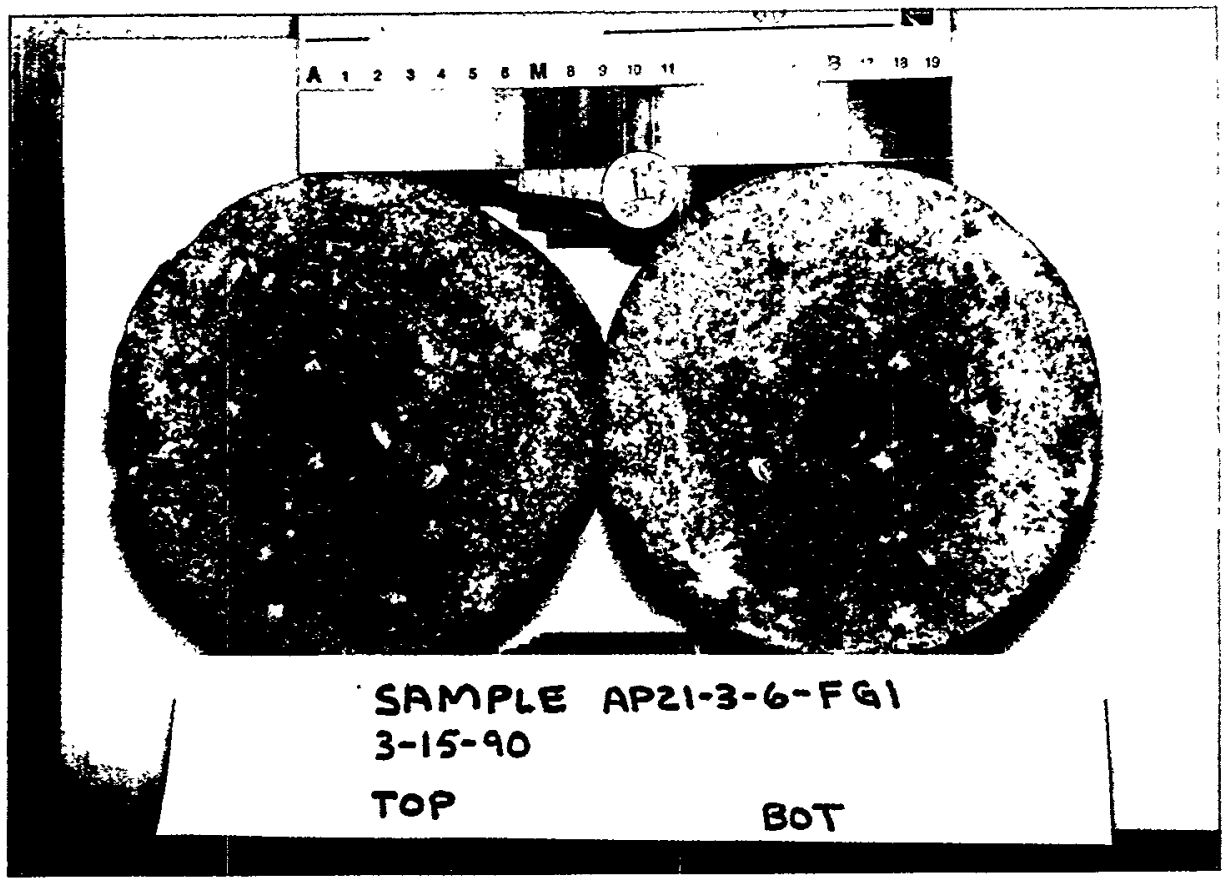

Figure 5.38 Surfaces of Sample AP21-3-6-FG1 after grouting, curing and permeability testing. 

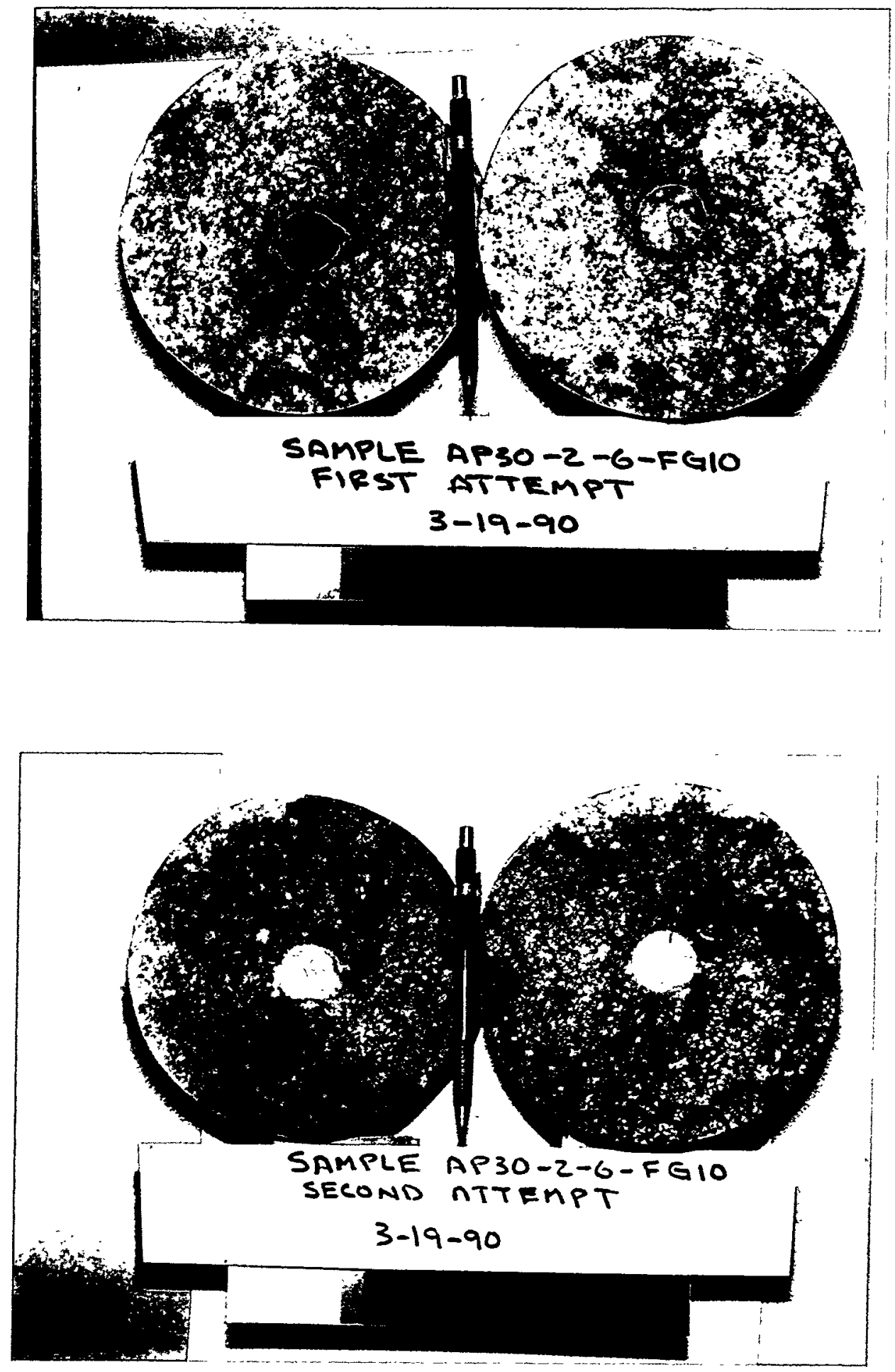

Figure 5.39 Filter blockage of Sample AP30-2-6-FG10. 


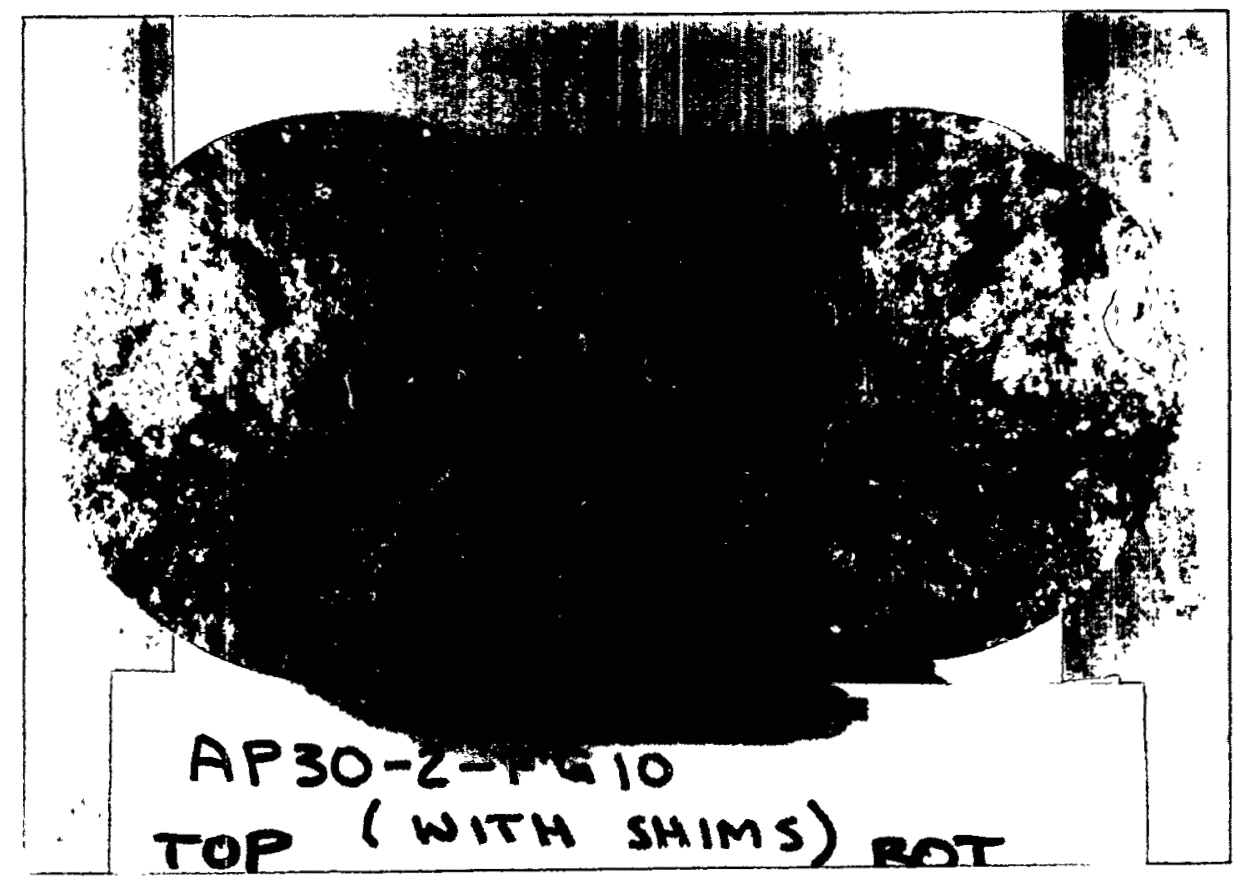

Figure 5.40 Filter blockage of shimmed sample AP30-2-FG10. 


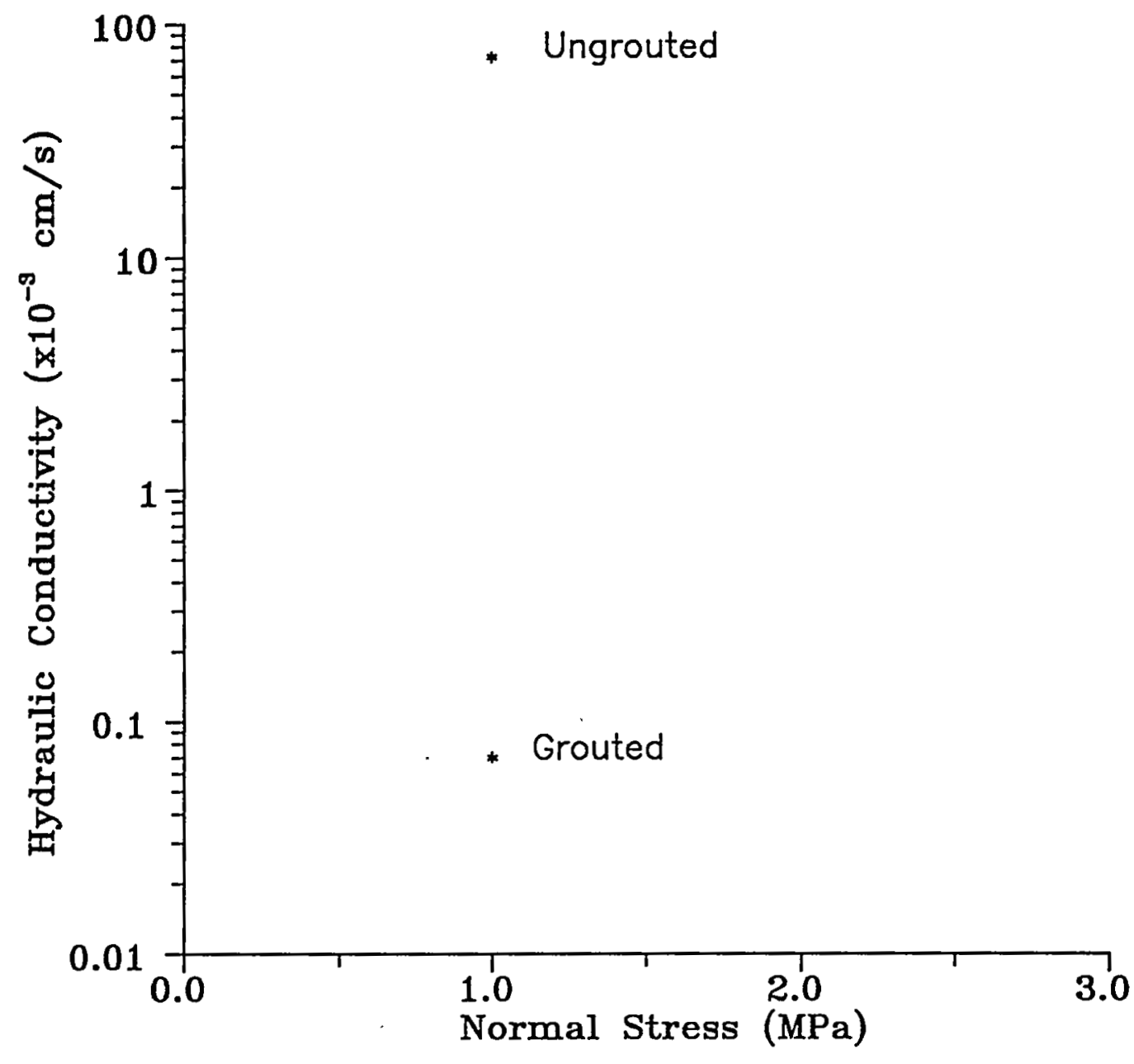

Figure 5.41 Decrease in hydraulic conductivity of shimmed sample AP302-6-FG10 due to filter blockage. 
Grouting of this sample was accomplished at an injection pressure of $0.34 \mathrm{MPa}$ under an axial stress of $1.0 \mathrm{MPa}$. MC-500 grout at a water-tocement ratio of 1.0 was used to grout this tension-induced fracture. Grout flowed easily from the fracture for 4 minutes.

Examination of the grout film after curing and flow testing showed the displacement of grout on the fracture surfaces with an area around the borehole containing no grout at all. Figure 5.42 shows the resulting grouted surfaces.

Sample AP4-1-6-FG2:

Sample AP4-1-6-FG2 (sawcut) was loaded with a normal stress of $2.0 \mathrm{MPa}$ and grouted at an injection pressure of $4.5 \mathrm{MPa}$ with mix formulation one. After ten minutes under pressure clear water could be seen dribbling out around the periphery of the sample. No grout could be seen exiting the sample. After separation of the sample, it could be seen that the injection borehole was clogged with grout at the fracture entrance. No grout was emplaced on the sawcut surfaces. Figure 5.43 shows that no grout has entered the sawcut. This borehole was not washed after grouting.

Sample AP3-1-6-FG6:

Tests 1 and 2

Sample AP3-1-6-FG6 (sawcut) was held in place with a normal stress of $0.43 \mathrm{MPa}$ and grouted at an injection pressure of $4.0 \mathrm{MPa}$ with mix formulation two. After ten minutes under this injection pressure no flow was evident. Inspection of the sample showed filter blockage of the injection hole, with no further grout travel along the sawcut surface. A second attempt to grout was made after the sample was washed to remove any grout remaining in the borehole. Grouting progressed at an injection pressure of $3.5 \mathrm{MPa}$ and normal stress of $0.23 \mathrm{MPa}$. Mix formulation 3 was used and was mixed for an additional two minutes to ensure thorough mixing. As before, clogging of the borehole occurred, with no grout entering the sawcut. The ring of cement causing filter blockage can be seen in Figure 5.44. In the first grouting attempt of sample FG6, clear water could be seen exiting the sawcut fracture. It was not known whether this water originated from washing the borehole surfaces prior to grouting or was the result of bleed water filtering through the cement ring causing filter blockage. For the second grouting attempt, no washing of the borehole was performed so that any water leaving the system would have to come from the slurry. Figure $5.45 \mathrm{a}$ shows the second grouting of sample FG6. Figure 5.45b shows the clear bleed water filtering out of the sample through the cement ring. This test raises questions about the extent of grout travel in fine fissures and the possibility that only bleed water travels through the fracture system. The apparent grout take during grouting may not be indicative of the actual volume of grout being emplaced along the fracture. Schaffer and Daemen (1987, p. 70) also had difficulty with grouting sawcut fractures 


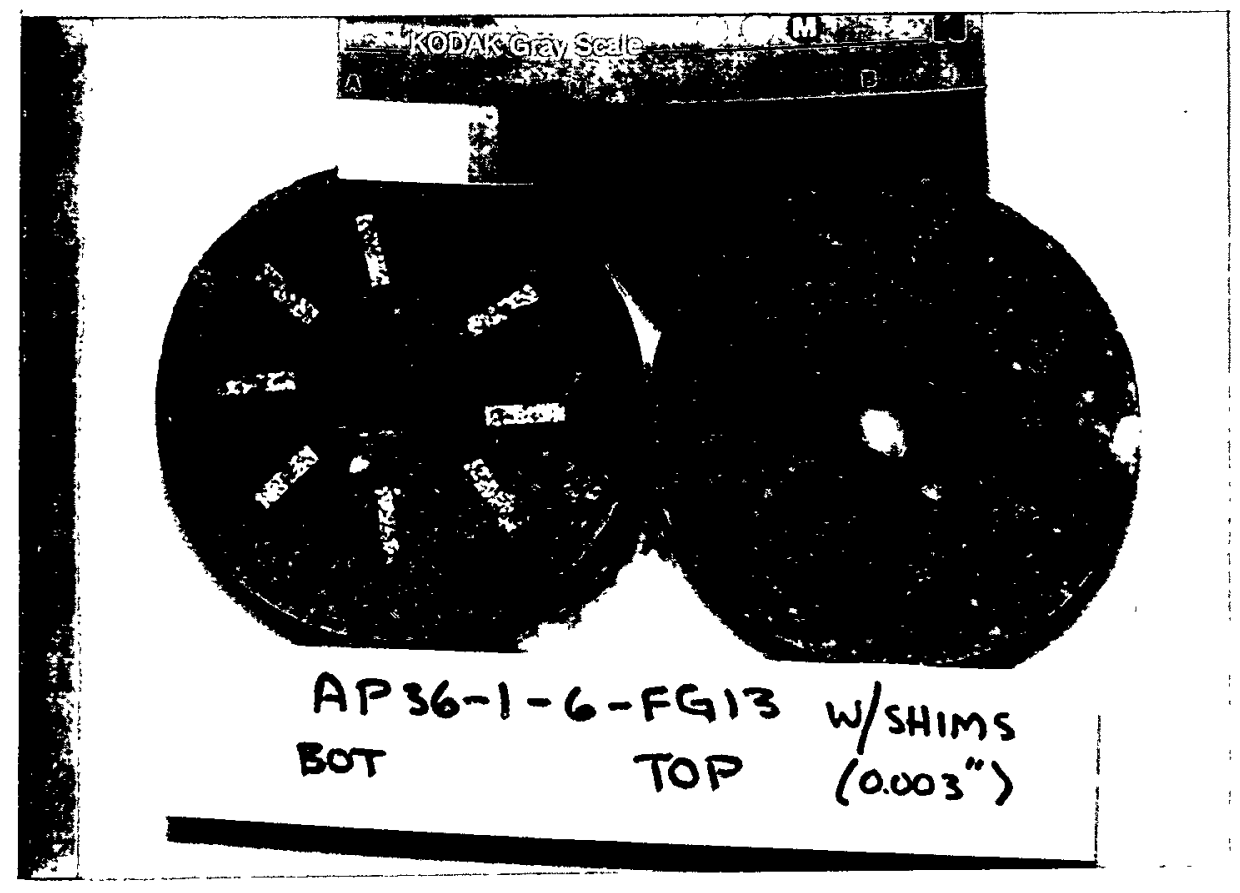

Figure 5.42 Post-grouting surfaces of shimmed sample AP36-1-6-FG13. 


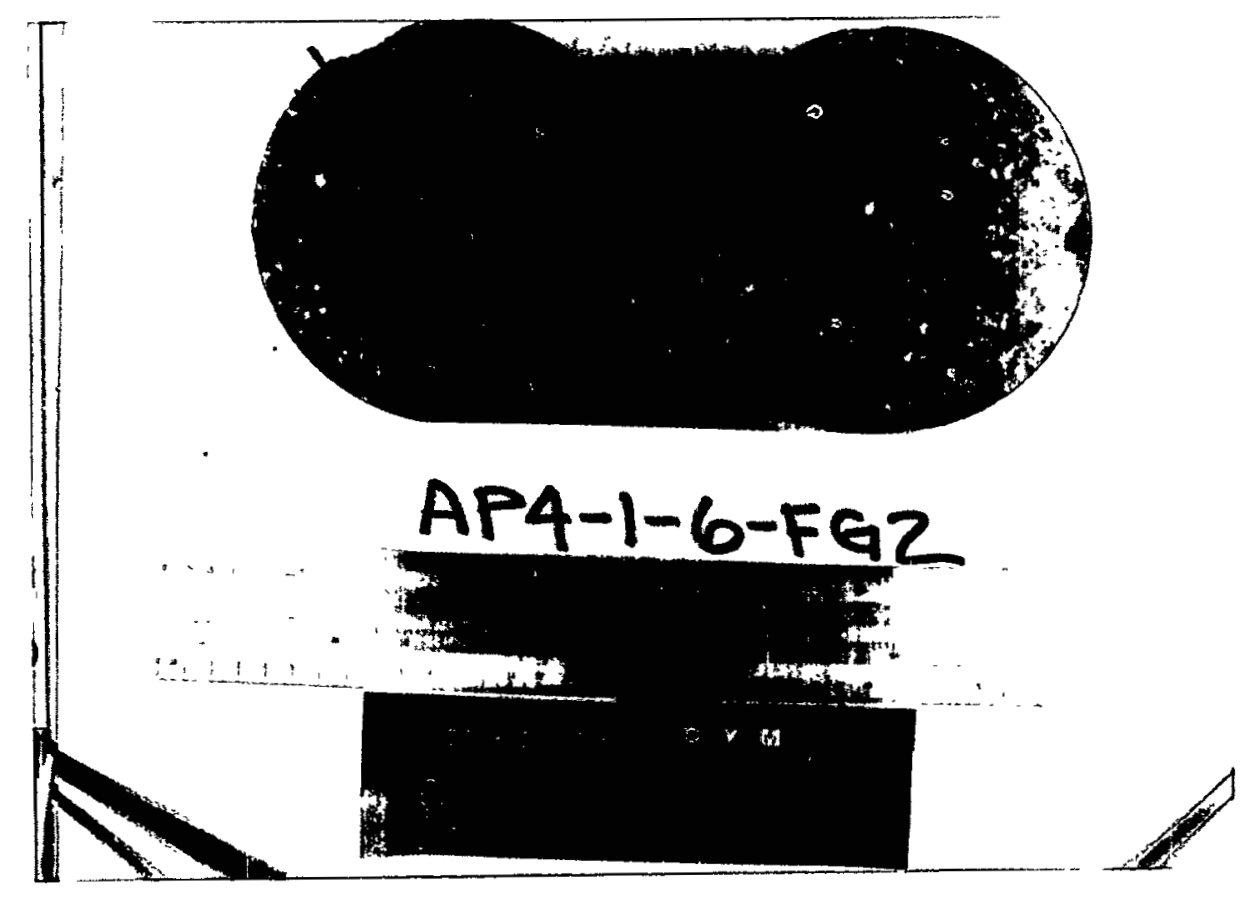

Figure 5.43 Clogging of one inch borehole of sawcut sample AP4-1-6-FG2. 


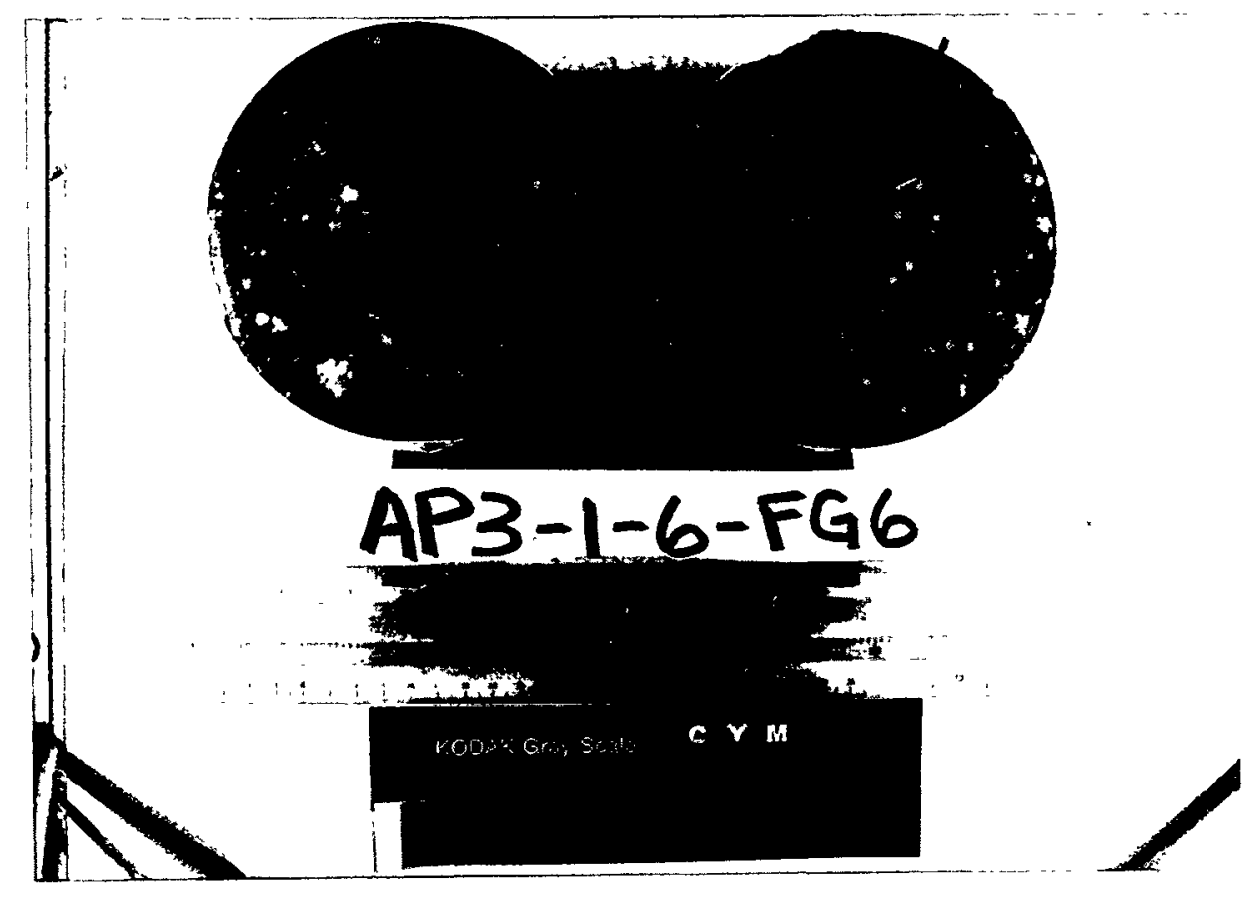

Figure 5.44 Ring of cement causing filter blockage of sample AP3-1-6FG6. 


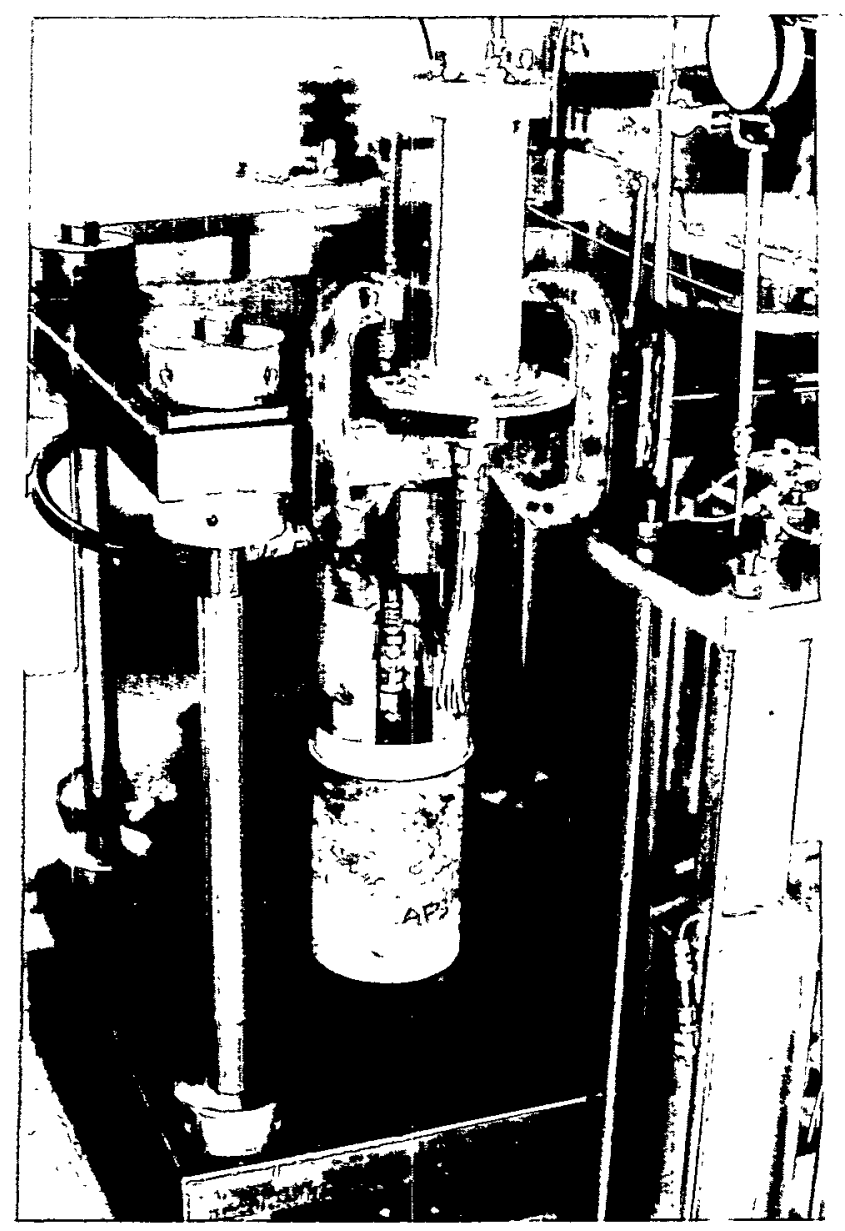

(a)

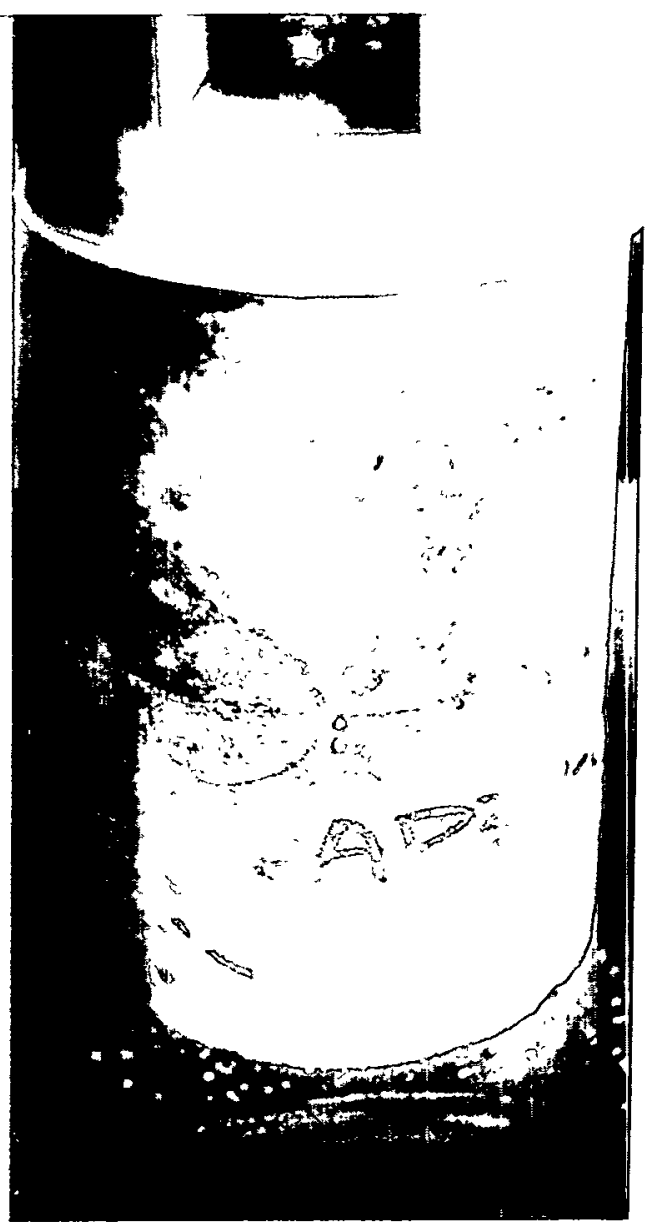

(b)

Figure 5.45 (a) Grouting of sawcut sample AP3-1-6-FG6. (b) Bleed water being squeezed out of sample AP3-1-6-FG6 during grouting. 
with this type of cement and report similar borehole clogging and the formation of a cement ring at the entrances of the fracture as well as an apparent reduction in permeability.

Sample AP-SHAFT6-FG16:

Test 1

Sawcut sample AP-SHAFT6-FG16 was grouted at a normal stress of $1 \mathrm{MPa}$ and $2.1 \mathrm{MPa}$ injection pressure with MC-500 grout. $25.4 \mu \mathrm{m}$ thick shims were used to increase the aperture. Figure 5.46 shows the shimmed fracture prior to grouting. Figure 5.47 shows the grouted surfaces of this sample. Note the flow channels where grout has been washed away. These channels are presumably created by bleed water filtering through the grout film. Also note the poor bonding on the top half of the sample, probably a result of the high water content of the grout. The bleed water rises to the top of the grout film not allowing grout to come in contact with the upper surface. Figure 5.48 shows the decrease in permeability due to grouting.

\section{Test 2}

The aperture of this sample was increased by placing eight 76.2-pm thick shims around the fracture surface. The hydraulic conductivity for this shimmed sample was $0.19 \mathrm{~cm} / \mathrm{s}$ at an axial stress of $0.5 \mathrm{MPa}$. The groutability ratio was calculated to be 4.8 , which predicts successful grout penetration.

Grouting of this sample progressed at an injection pressure of $2.1 \mathrm{MPa}$ under $0.5 \mathrm{MPa}$ axial stress. Due to the high bleed capacity of previous MC-500 grout formulations, the water-to-cement ratio was decreased to 0.6. A water-to-cement ratio of 1.0 was found previously to result in the formation of bleed channels through the grout film. Grout displacement results in an inadequate reduction in hydraulic conductivity. The grout flowed easily from the sawcut surfaces for several minutes, after which only bleed water exited from the fracture.

Examination of the grout films after curing and flow testing showed the formation of bleed channel and displaced grout even at this lower waterto-cement ratio. Grout bonding to the upper sawcut surface was minimal. The reduction in hydraulic conductivity was found to be only $0.024 \mathrm{~cm} / \mathrm{s}$ and is presumably due to the ability of water to flow along the upper surface of the grout film as well as along bleed channels. Figure 5.49 shows the resulting grouted surfaces.

Sample AP56-2-6-FG14:

Grouting of natural fracture sample AP56-2-6-FG14 emplaced little grout in the transverse fracture. This sample was grouted at a final injection pressure of $6 \mathrm{MPa}$ under $5 \mathrm{MPa}$ normal stress. Grout formulation one containing 2 percent bentonite was used. Because of the high injection pressure used to force grout flow, a vertical crack developed in the top 


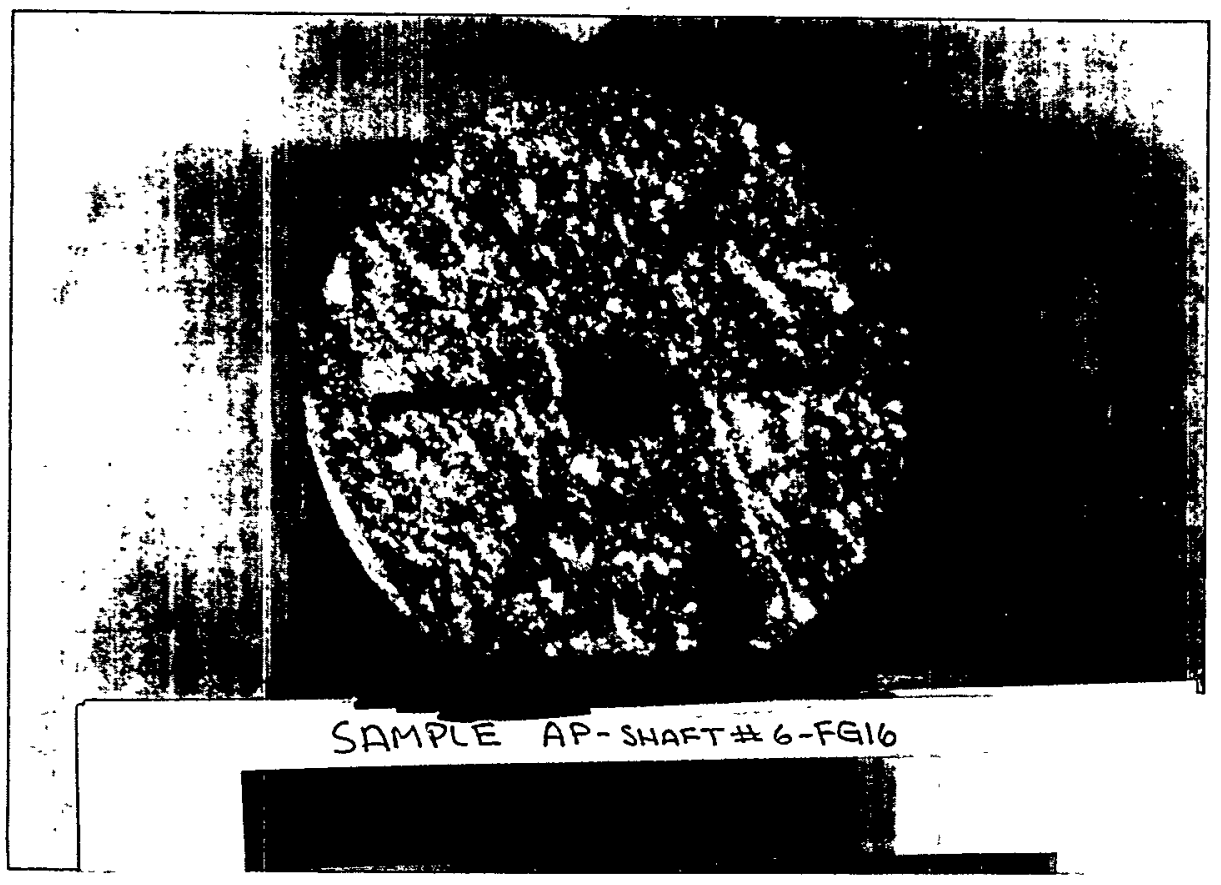

Figure 5.46 Shims used to prop open the aperture of sawcut sample AP-SHAFT6-FG16. 


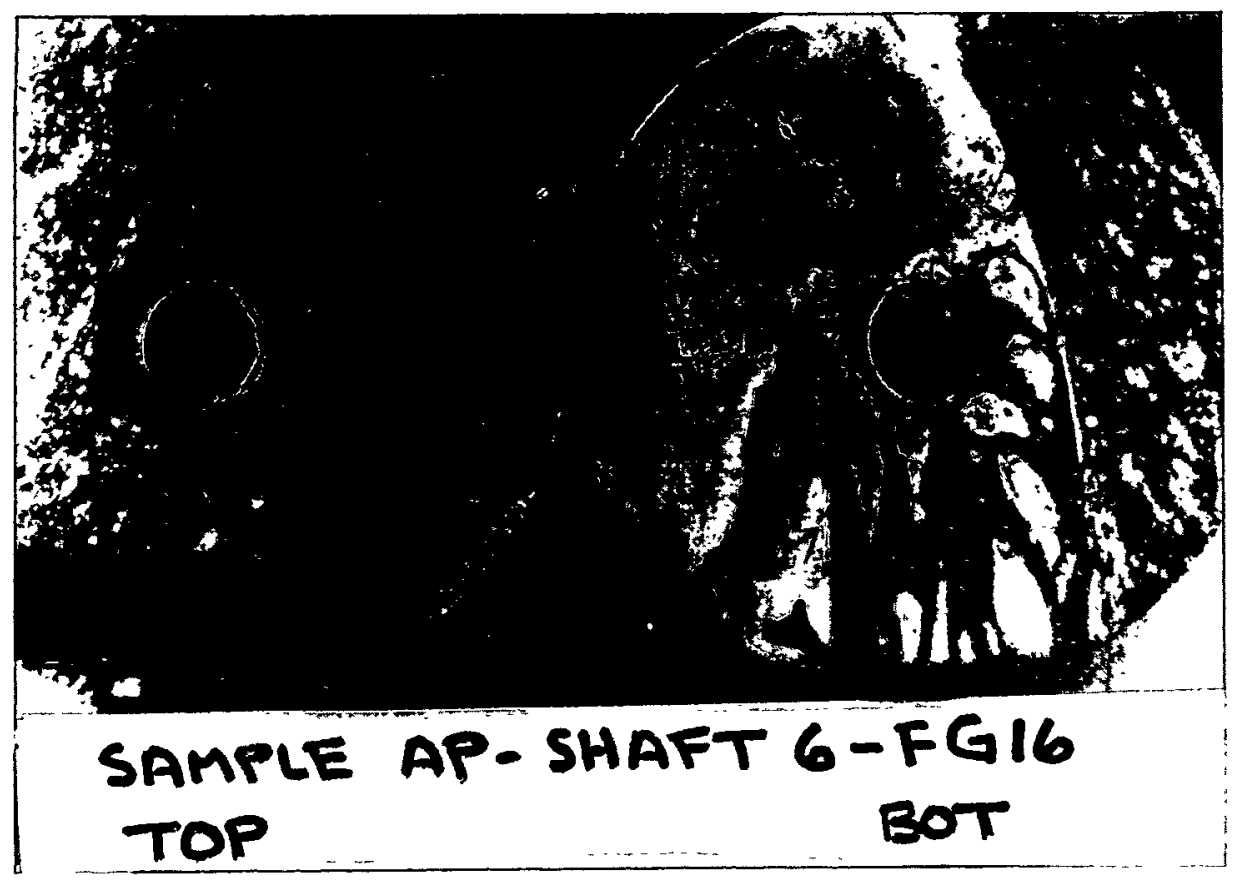

Figure 5.47 Grouted surfaces of shimmed sample AP-SHAFT6-FG16. 


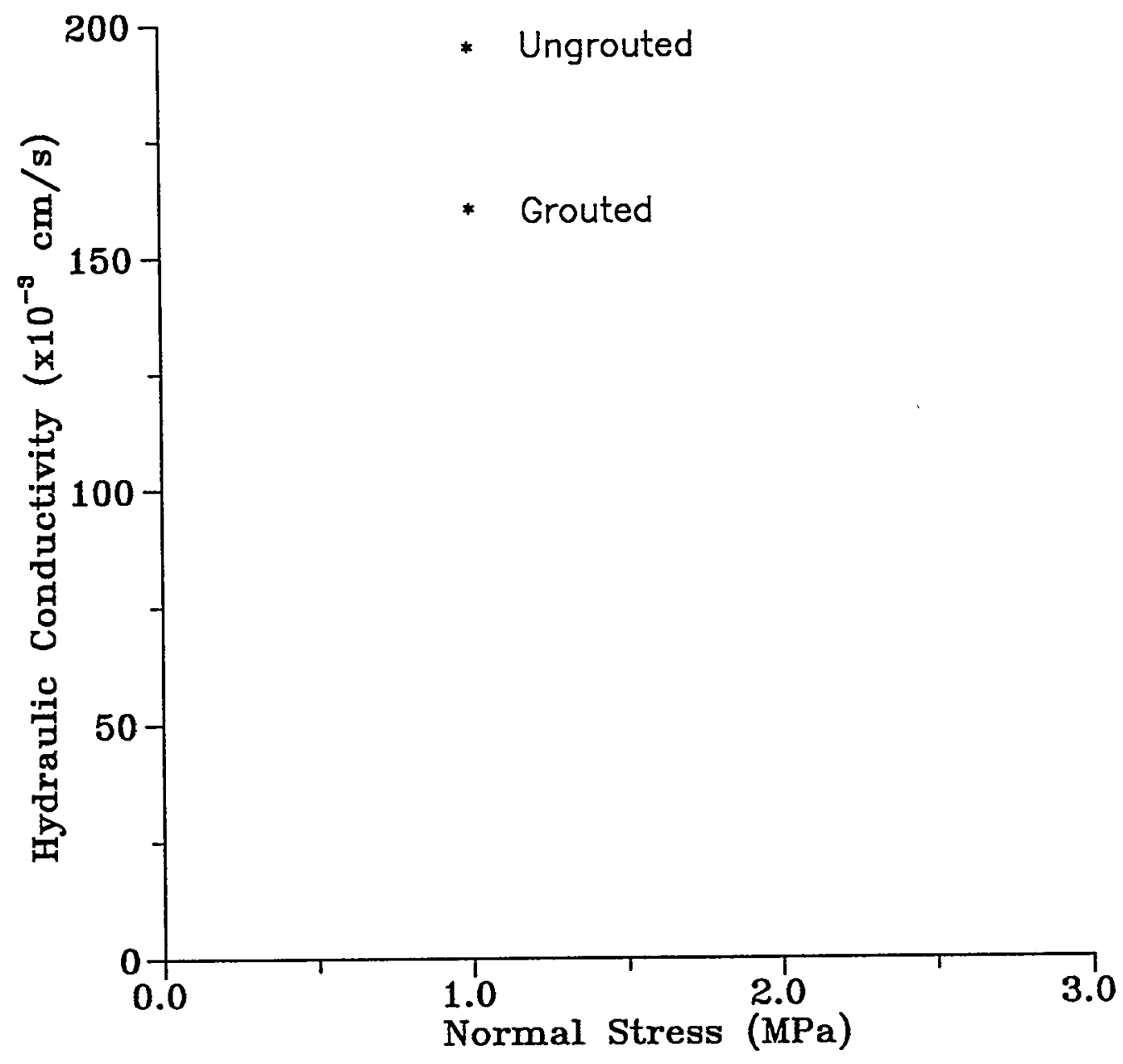

Figure 5.48 Reduction in permeability resulting from grouting sawcut sample AP-SHAFT6-FG16 (shimmed). 


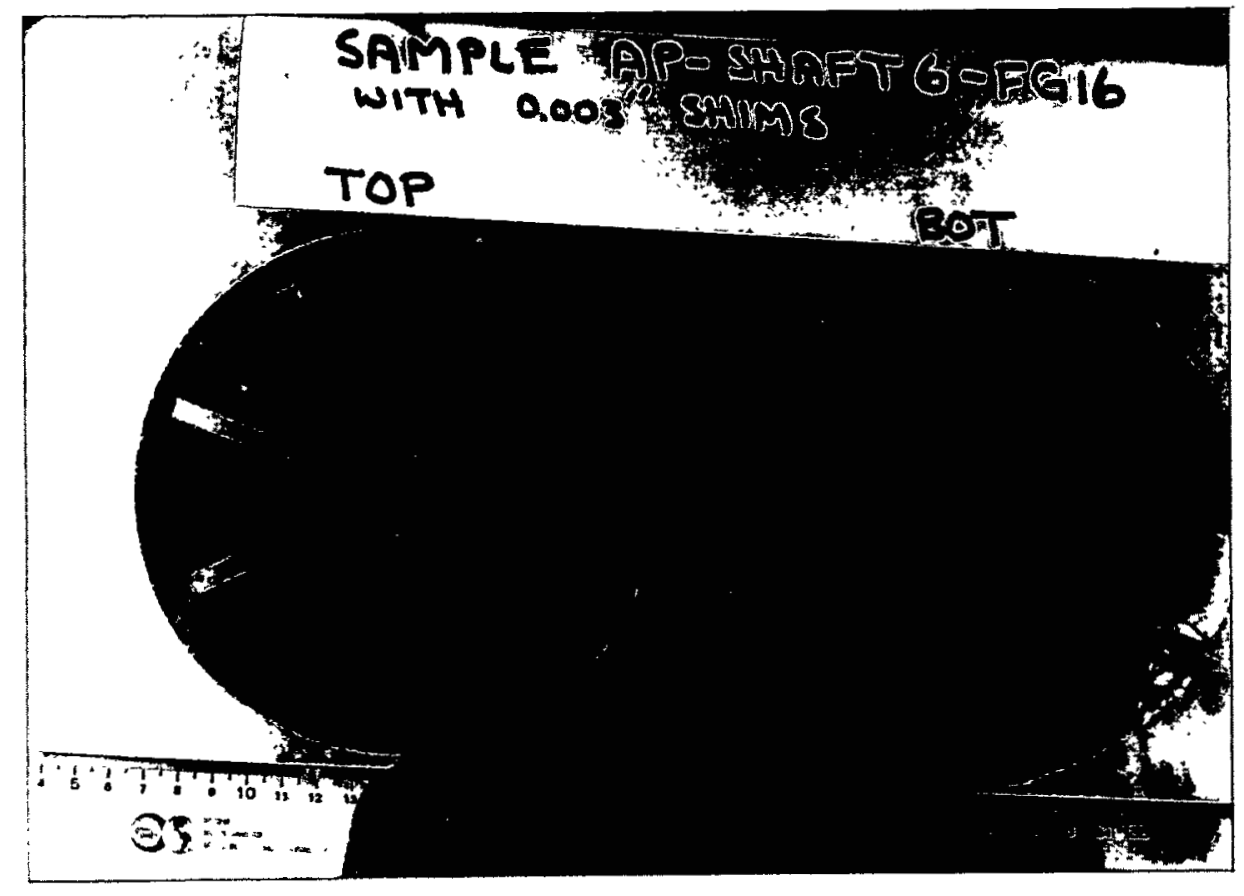

Figure 5.49 Post-grouting surface appearance of sample AP-SHAFT6-FG16. Note extensive channeling, and lack of bonding to top surface. 
half of the sample. Grout penetration along the horizontal fracture ranged from 0.5 to $1.5 \mathrm{~cm}$. Bonding appeared good as well as durable to both top and bottom surfaces of the fracture. Grout was visible in the vertical fracture but apparently did not seal it. Figure 5.50 shows the increase in permeability due to the development of this fracture by hydrofracturing. This is a good example of how overpressurizing a borehole can do more harm than good. Figure 5.51 a shows the grout penetration of the pre-existing horizontal sample. Figure $5.51 \mathrm{~b}$ shows the vertical crack caused by hydrofracturing.

Sample AP56-3-6-FG15:

Test 1

Sample AP56-3-6-FG15 containing a single natural fracture was grouted with MC-500 grout at an injection pressure of $2.8 \mathrm{MPa}$ under $1 \mathrm{MPa}$ normal stress. No grout flow was evident. After separation of the sample halves, filter blockage was observed. No grout was emplaced along the fracture.

Test 2

The second attempt to grout sample AP56-3-6-FG15 with MC-500 grout was conducted at $3.1 \mathrm{MPa}$ under $0.5 \mathrm{MPa}$ normal stress. After flow testing and inspection, small pockets of grout were evident on the fracture surfaces. Figure 5.52 shows the resulting emplaced grout. In the places where grout was present bonding appeared good between the top and bottom surfaces. Figure 5.53 shows the reduction in hydraulic conductivity resulting from grouting.

Table 5.24 shows the results of all grouting experiments as a function of injection pressure, equivalent fracture aperture and groutability ratio. 


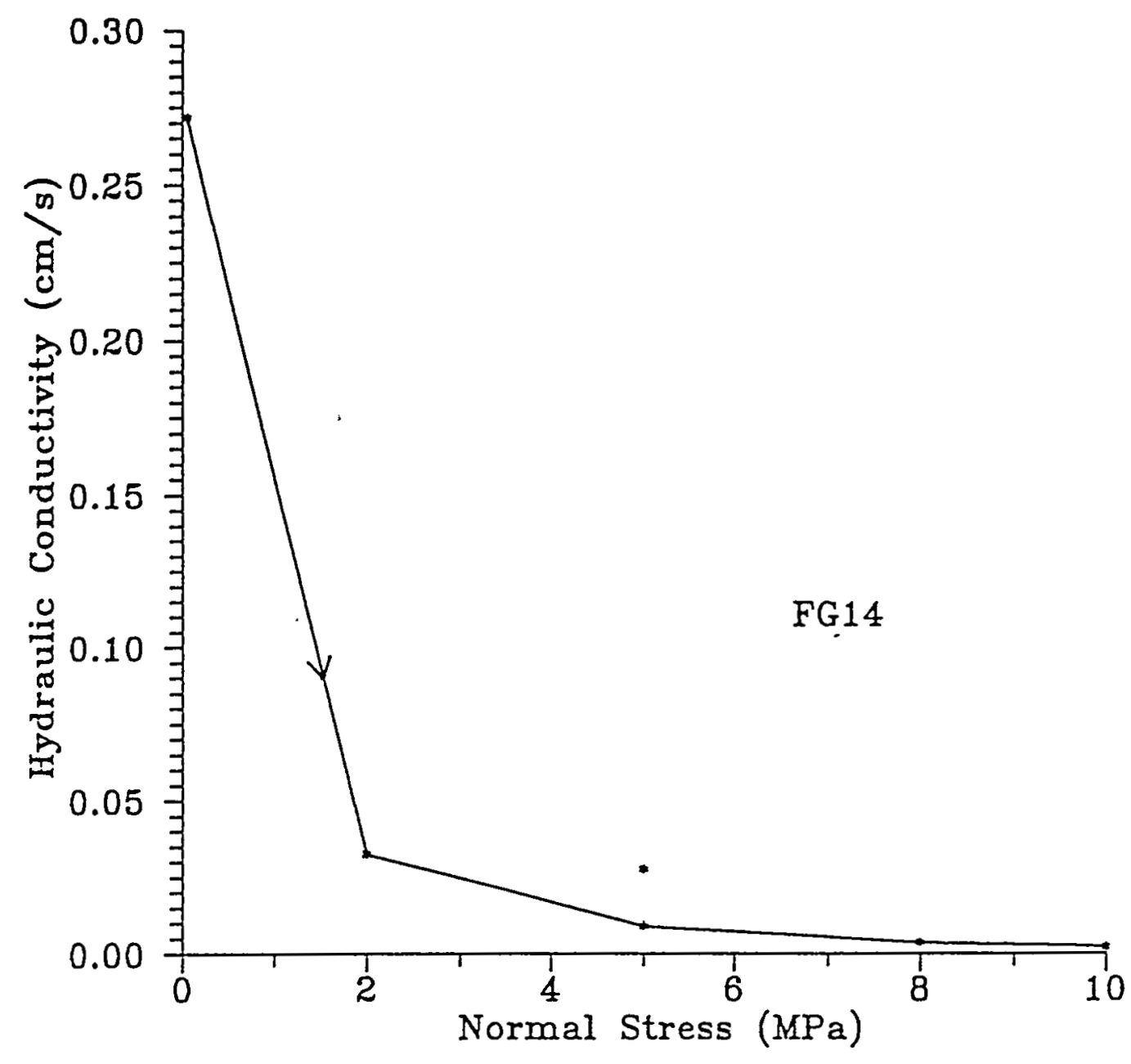

Figure 5.50 Hydraulic conductivity vs. normal stress for sample AP56-26-FG14. Apparent increase in permeability at $5 \mathrm{MPa}$ due to hydrofracturing. 

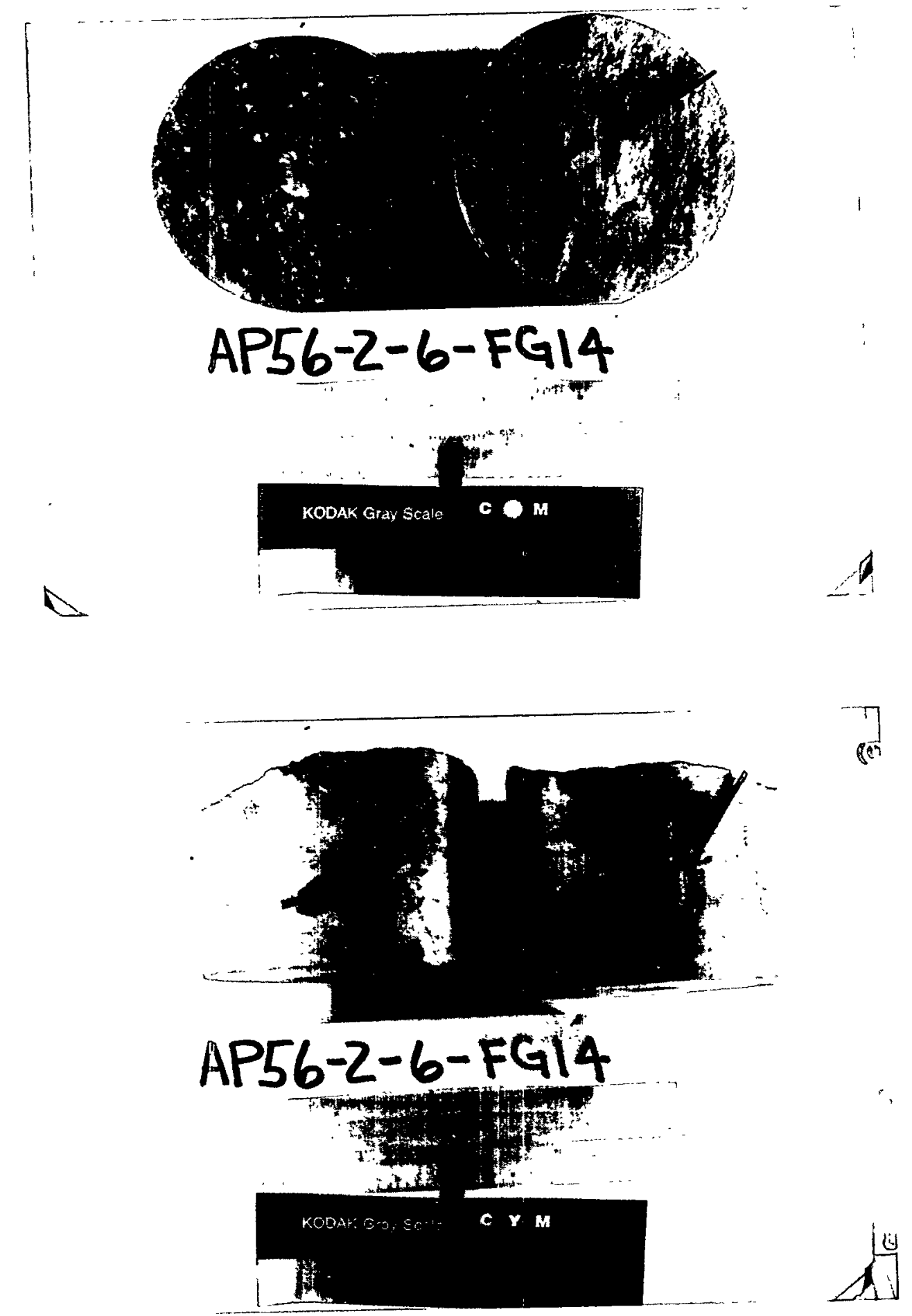

Figure 5.51 (a) Filter blockage of one inch borehole of sample AP56-26-FG14, a natural fracture. (b) Vertical fracture caused by overpressurizing borehole during pressure grouting. 


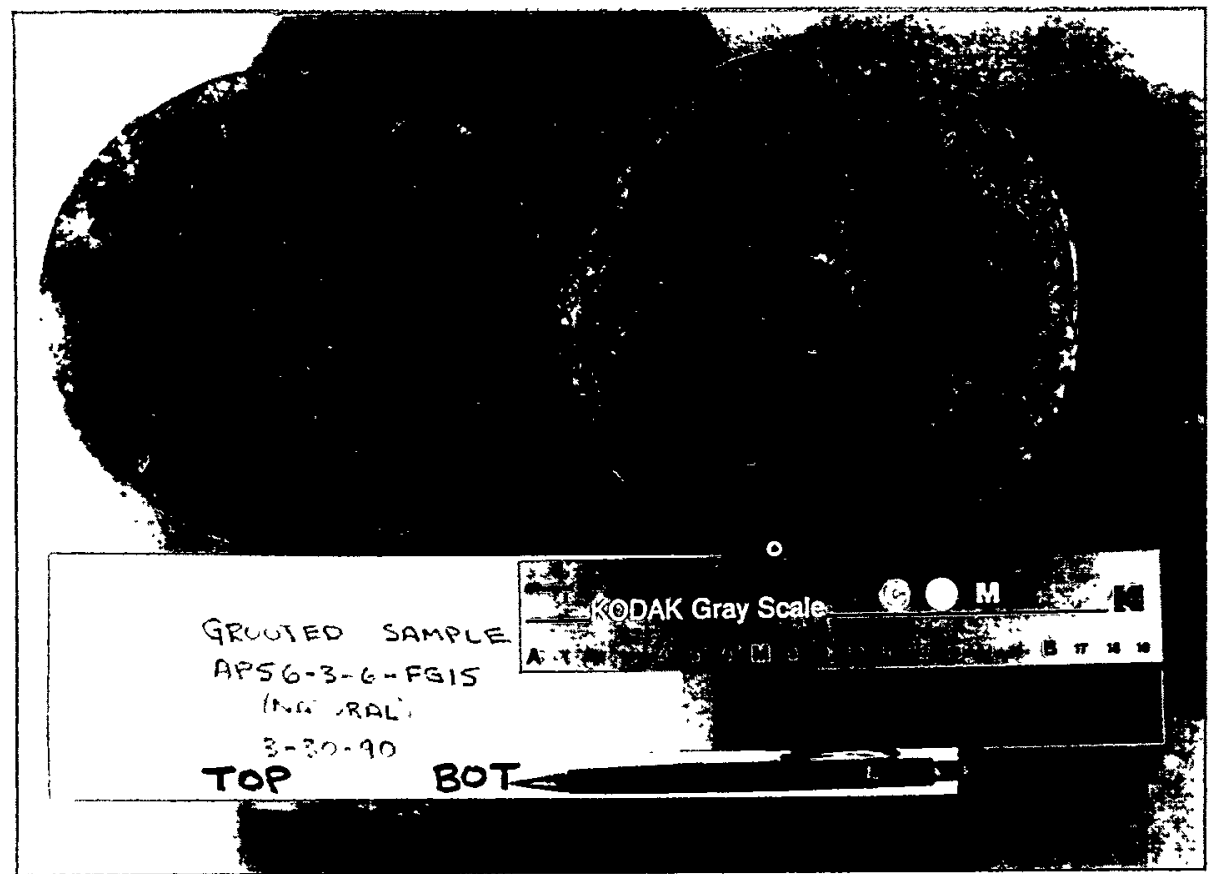

Figure 5.52 Pockets of grout emplaced in sample AP56-3-6-FG15. 


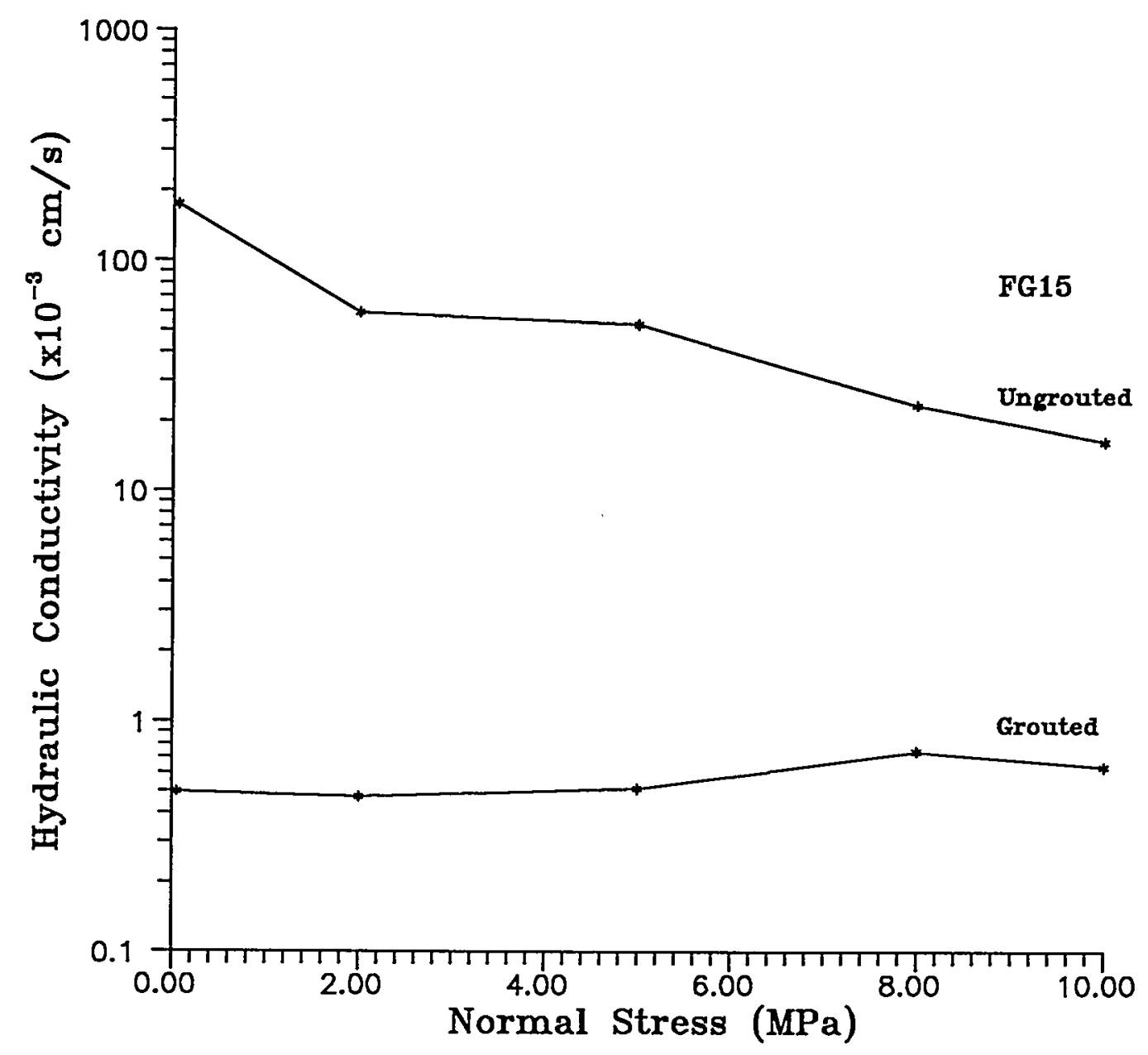

Figure 5.53 Reduction in hydraulic conductivity from grouting sample AP56-3-6-FG15 with MC-500 grout. 
Table 5.24 Groutability Ratios Corresponding to Penetration.

\begin{tabular}{|c|c|c|c|c|c|c|}
\hline $\begin{array}{l}\text { Sample } \\
\text { Number }\end{array}$ & $\begin{array}{c}\text { Normal } \\
\text { Stress } \\
\text { (MPa) }\end{array}$ & $\begin{array}{l}\text { Injection } \\
\text { Pressure } \\
\text { (MPa) }\end{array}$ & $\begin{array}{c}\text { Equivalent } \\
\text { Fracture } \\
\text { Aperture }(\mu \mathrm{m})\end{array}$ & $\begin{array}{l}\text { Cement } \\
\text { Type }\end{array}$ & $\begin{array}{l}\text { Groutability } \\
\text { Ratio* }\end{array}$ & $\begin{array}{c}\text { Actual } \\
\text { Penetration }\end{array}$ \\
\hline FG1 & 2.0 & 5.0 & 4.4 & OPC & 0.04 & No \\
\hline FG1 & 1.5 & 0.62 & 18.3 & $M G-500$ & 1.83 & YES \\
\hline FG10 & 1.0 & $>2$ & 6.5 & $M C-500$ & 0.65 & No \\
\hline FG10 & 1.0 & 4.1 & 6.5 & $M C-500$ & 0.65 & NO \\
\hline FGI0 w/shims & 0.5 & 4.1 & 41.9 & $M G-500$ & 4.19 & No \\
\hline FG14 & 5.0 & 6.0 & 10.4 & OPC & 0.10 & SLIGHT \\
\hline FG15 & 1.0 & 2.8 & 34.7 & $M C-500$ & 3.47 & NO \\
\hline FG15 & 0.5 & 3.1 & 41.8 & $M C-500$ & 4.18 & YES \\
\hline FG2 & 2.0 & 4.5 & 1.3 & OPC & 0.01 & No \\
\hline FG6 & 0.43 & 4.0 & 32.0 & $\mathrm{OPC}$ & 0.32 & No \\
\hline FG6 & 0.23 & 3.5 & 36.0 & OPC & 0.36 & No \\
\hline FG6 & 2.0 & 0.34 & 6.8 & $M C-500$ & 0.68 & No \\
\hline FG16 w/shims & 1.0 & 2.1 & 79.0 & $M C-500$ & 4.80 & YES \\
\hline
\end{tabular}

*Equation (3.1), Section 3.3.2. 
CHAPTER SIX

CONCLUSIONS AND RECOMMENDATIONS

\subsection{Flow testing}

Intact welded tuff cylinders show a decrease in hydraulic conductivity with increasing uniaxial compressive stress in the direction normal to the flowpath. This decrease is presumably due to closing of pore spaces and pre-existing microfractures. Intact rock permeabilities are four to eight orders of magnitude lower than those of fractures, even at high normal stress across the fractures, and are therefore neglected in fracture permeability calculations.

Permeability testing confirms that fracture closure depends on the stress history of the fracture. Testing shows aperture reductions with each of two loading cycles, presumably due to fracture deformation, although the maximum normal stress never exceeded 35 percent of the uniaxial compressive strength of the rock.

Equivalent fracture apertures are calculated from the measured inflow through the application of the cubic law. A change in the degree of saturation could be responsible for the apparent reduction in equivalent fracture aperture. Future testing should include measurement of outflows as well as of the degree of saturation.

Fracture closure has been observed to be time dependent. This phenomenon is evident from the waiting time needed to allow permeability measurements to become quasi steady-state. Time dependency is most severe at each initial change in normal stress. Measurements of this time dependence have not been obtained due to the initial interest in the steady-state flow only. Further testing should include some measure of these transient effects, in particular aimed at identifying whether any creep of the welded tuff might be taking place.

The greatest reduction in flow through fractures is observed at low normal stress, presumably due to initial surface mating. This closing behavior is similar to fracture compression results (Section 5.3). Two distinct stiffness regions are observed, with remarkable repeatability for both, and a well defined transition stress between the two.

\subsection{Grouting}

Grouts with high water to cement (w/c) ratios suffer from excess bleed water which in turn decreases, or even eliminates, bonding to the upper fracture surfaces. The use of ordinary portland cement (0.P.C.) grouts with greater w/c ratios (up to 0.9 ) has not increased grout admittance, suggesting that blockage is related more to grain size than to water content. 
The addition of bentonite (2-58) to O.P.C. grouts with increased w/c ratios ( 0.6 to 0.9$)$ reduces bleed water to less than one percent but causes a marked decrease in uniaxial compressive strength. This decrease in strength is due to the increase in bentonite content as well as in the $w / c$ ratio.

Comparisons between rheologic properties of the grout slurries are hardly possible due to differing $\mathrm{w} / \mathrm{c}$ ratios and bentonite contents. Future testing should include characterization of grout properties at similar $\mathrm{w} / \mathrm{c}$ ratios.

Grouting tests confirm the extreme difficulty in emplacing 0.P.C. grouts in tight fractures. Attempts at emplacing ultra fine grout (MC-500) fair somewhat better than O.P.C. grouts, although filter blockage occurs with all grouting attempts when the groutability ratio is less than three.

Filter blockage is a prevailing problem, with the formation of a characteristic ring of cement at the entrance to the fracture. This type of blockage is accompanied by an apparent reduction in permeability not indicative of the permeability of the surrounding fracture. In the field, post grouting core holes should be drilled to confirm the extent of grout travel.

Future laboratory grouting experiments should incorporate evaluation of pulse or dynamic injection techniques (Pusch et al., 1988). Permeability, durability, and longevity testing should be performed to confirm the usefulness of cementitious grouts for nuclear waste repository sealing.

The main objective of laboratory grouting testing is to identify, and where possible, model, the basic factors and mechanisms that govern grout penetration and grout performance. This requires a determination of the true flowpaths. An approach in this direction has been taken by the detailed mapping of fracture surfaces, with the intent to correlate aperture distribution with grout distribution. Future research in this direction should include a more efficient and reliable method to determine the asperity distribution. From the asperity distribution, one should be able to calculate the distribution of the apertures.

A significant issue within the context of HLW repository sealing is the longevity of grout emplaced in fractures. The present study is preliminary, at best, to an in-depth investigation of this real issue. It is postulated that grout durability depends upon grout distribution, quality of emplaced grout, and grout bonding, variables that remain to be investigated. 



\section{REFERENCES}

American Petroleum Institute, 1986, Specifications for Materials and Testing for Well Cements, Third Edition, American Petroleum Institute, Production Department, Dallas, Texas.

ASTM C305-82, "Standard Method for Mechanical Mixing of Hydraulic Cement Pastes and Mortars of Plastic Consistency," Annual Book of ASTM Standards, Vol. 04-01, American Society for Testing and Materials, Philadelphia.

ASTM D2938-79, "Standard Test Method for Unconfined Compressive Strength of Intact Rock Core Specimens," Annual Book of ASTM Standards, Vol. 04-08, American Society for Testing and Materials, Philadelphia.

Banks, D.C., 1972, "In Situ Measurements of Permeability in Basalt," Proceedings of the Symposium on Percolation Through Fissured Rock, I. Wittke, ed., Deutsche Gesellschaft fuer Erdund Grundbau, Essen, Stuttgart, pp. T1-A-1 through T1-A-6.

Bawden, W.F. and J.C. Roegiers, 1979, "Discussion and Interpretation of the Mathematics Governing Radial Flow in A Single Horizontal Rock Fracture", Prepared for Energy, Mines and Resources, Canada, Earth Physics Branch, Division of Seismology and Geothermal Studies, Ottawa, Ontario, contract \#191-3-79, by Dept. of Civil Engrg., Univ. of Toronto.

Bear, J., 1972, Dynamics of Fluids in Porous Media, American Elsevier Publishing Co., Inc., New York.

Bear, J., 1979, "Hydraulics of Pumping and Recharging Wells," Hydraulics of Groundwater, McGraw-Hill Book Co., N.Y., pp. 300-307.

Cambefort, H., 1977, "The Principles and Applications of Grouting," Quarterly Journal of Engineering Geology, Vol. 10, The Geological Society, London, pp. 57-95.

Chapman, N.A. and I.G. McKinley, 1987, "The Geological Disposal of Nuclear Waste," John Wiley and Sons, New York.

Cobb, S.L. and J.J.K. Daemen, 1982, "Polyaxial Testing of Borehole Plug Performance," Topical Report to the U.S. Nuclear Regulatory Commission, Contract No. NRC-04-78-271, prepared by the Department of Mining and Geological Engineering, University of Arizona, Tucson. 
Deere, D.U., 1982, "Cement-Bentonite Grouting for Dams," Grouting in Geotechnical Engineering, W.H. Baker, editor, Proceedings of the Conference on Feb. 10-12, New Orleans, LA, pp. 279-300.

Published by the American Society of Civil Engineers, New York.

Deere, D. and G. Lombardi, 1985, "Grout Slurries - Thick or Thin?," pp. 156-164, Issues in Dam Grouting, W.H. Baker, editor, American Society of Civil Engineers, New York.

Detournay, E., 1980, "Hydraulic Conductivity of Closed Rock Fracture: An Experimental and Analytical Study," pp. 168-173 of Underground Rock Engineering, 13th Canadian Rock Mechanics Symposium (The H.R. Rice Memorial Symposium), Toronto, Ontario, May 28-29. CIM Special Volume 22, The Canadian Institute of Mining and Metallurgy, Montreal, Quebec.

Englman, R., Y. Gur and Z. Jaeger, 1983, "Fluid Flow Through a Crack Network in Rocks," Journal of Applied Mechanics, Vol. 50, pp. $707-711$.

Farmer, I.W., 1970, "Design of Cement Grouts," Research Report R.17/70, University of Newcastle upon Tyne, England, 69 pp.

Fernandez, J.A., 1985, "Repository Sealing Plan for the Nevada Nuclear Waste Storage Investigations Project Fiscal Years 1984 through 1990," Sandia Report SAND84-0910, prepared by Sandia National Laboratories, Albuquerque, NM.

Fernandez, J.A. and M.D. Freshley, 1984, "Repository Sealing Concepts for the Nevada Nuclear Waste Storage Investigations Project," Sandia Report SAND83-1778, prepared by Sandia National Laboratories, Albuquerque, NM.

Freeze, A. and J. Cherry, 1979, "Groundwater," Groundwater Resource Evaluation, Prentice-Hall Inc., N.J., pp. 335-339.

Fuenkajorn, K. and J.J.K. Daemen, 1986, "Experimental Assessment of Borehole Wal1 Drilling Damage in Basaltic Rocks," Technical Report, NUREG/CR-4641, Prepared for U. S. Nuclear Regulatory Commission, Divison of Radiation Programs and Earth Sciences by the Department of Mining and Geological Engineering, University of Arizona, Tucson.

Fuenkajorn, K. and J.J.K. Daemen, 1991, "Mechanical Characterization of Densely Welded Apache Leap Tuff," NUREG/CR-5688, Technical Report, prepared for U.S. Nuclear Regulatory Commission, Division of Engineering, by the Department of Mining and Geological Engineering, University of Arizona, Tucson.

Gale, J.E., A. Rouleau and L.C. Atkinson, 1985, "Hydraulic Properties of Fractures," pp. 1-16, Vo1. 17, Part 1, Hydrogeology of Rocks of Low Permeability, Memoires, International Association of Hydrogeologists, Tucson, Arizona, Congress. 
Gnirk, P., 1988, "State-of-the-Art Evaluation of Repository Sealing Materials and Techniques," Materials Research Society Symposium, Proc. Vol. 112, Scientific Basis for Nuclear Waste Management XI, M.J. Adted and R.E. Westerman, eds., Materials Research Society, Pittsburgh, PA, pp. 219-231.

Gupta, D.C., J.T. Buckley, 1989, "Technical Position on Postclosure Seals, Barriers, and Drainage System in an Unsaturated Medium," NUREG-1373. Division of High-Level Waste Management, Office of Nuclear Material Safety and Safeguards, U.S. Nuclear Regulatory Commission, Washington, D.C.

Gyenge, M., 1980, "Nuclear Waste Vault Sealing," pp. 181-192, Underground Rock Engineering, 13th Canadian Rock Mechanics Symposium (The H.R. Rice Memorial Symposium), Toronto, Ontario, May 28-29. GIM Special Volume 22, The Ganadian Institute of Mining and Metallurgy, Montreal, Quebec.

Holtz, R.D. and W.D. Kovacs, 1981, Geotechnical Engineering, PrenticeHal1, Inc., Englewood Cliffs, N.J.

Houlsby, A.C., 1977, "Towards Appropriate Metric Units for Grouting", Ground Engineering, July, Vol. 10, pp. 39-42.

Houlsby, A.C. 1982a. "Cement Grouting for Dams". Proceedings of the Conference on Grouting in Geotechnical Engineering, New Orleans, Louisiana, pp. 1-34, ASCE, New York.

Houlsby, A.C. 1982b. "Optimum Water-Cement Ratios for Rock Grouting". Proceedings of the Conference on Grouting in Geotechnical Engineering, New Orleans, Louisiana, pp. 317-331, ASCE, New York.

Houlsby, A.C. 1985. "Cement Grouting: Water Minimizing Practices". Proceedings of the Session Sponsored by the A.S.C.E. Geotechnical Engineering Division on "Issues in Dam Grouting", Denver, Colorado, pp. 34-75, ASCE, New York.

Hsieh, P.A. and S.P. Neuman, 1985, "Field Determination of the ThreeDimensional Hydraulic Conductivity Tensor of Anisotropic Media", Water Resources Research, Vo1. 21, No. 11, Pages 1655-1665, November.

Iwai, K., 1976, Fundamental Studies of Fluid Flow Through a Single Fracture, Ph.D. thesis, Univ. of Calif., Berkeley, 208 pp.

Jaeger, J.C. and N.G.W. Cook, 1984, Eundamentals of Rock Mechanics, Chapman and Hall Inc., New York, N.Y., 593 pp.

Johnson, B., 1983, "Permeability of a Simulated-Fracture as a Function of Normal Stress," pp. 519-523, Rock Mechanics - Theory Experiment - Practice, Proceedings of the 24th Symposium on Rock Mechanics, Texas A\&M University, June. Published by the Association of Engineering Geologists. 
Karol, R.H., 1982, "Chemical Grouts and Their Properties," Proceedings of the Conference on Grouting in Geotechnical Engineering, American Society of Civil Engineers, New York, N.Y., pp. 359-377.

Karol, R.H., 1985, "Grout Penetrability," Issues in Dam Grouting, Proceedings of the Session sponsored by the Geotechnical Engrg. Div. of ASCE in conjunction with the ASCE convention in Denver, CO, April 30; W. Baker, ed., pp. 27-33, American Society of Civil Engineers, New York.

Kelsall, P.C., W.E. Coons, and D. Meyer, 1983, "Repository Sealing Program Plan: Repository in Salt," ONWI-414, prepared by D'Appolonia Consulting Engineers, Inc., for Office of Nuclear Waste Isolation, Battelle Memorial Institute, Columbus, $\mathrm{OH}$.

Kelsall, P.C., J.B. Case, D. Meyer, J.G. Franzone, and W.E. Coons, 1985a, "Schematic Designs for Penetration Seals for a Repository in Richton Dome," ONWI-562, prepared by IT Corporation for Office of Nuclear Waste Isolation, Battelle Memorial Institute, Columbus,' $\mathrm{OH}$, December.

Kelsall, P.G., D. Meyer, J.B. Case, and W.E. Coons, 1985b, "Schematic Designs for Penetration Seals for a Repository in the Paradox Basin," ONWI-563, prepared by IT Corporation for Office of Nuclear Waste Isolation, Battelle Memorial Institute, Columbus, $\mathrm{OH}$, December.

Kelsall, P.C., J.B. Case, W.E. Coons, J.G. Franzone, and D. Meyer, 1985c, "Schematic Designs for Penetration Seals for a Repository in the Permian Basin," ONWI-564, prepared by IT Corporation for Office of Nuclear Waste Isolation, Battelle Memorial Institute, Columbus, $\mathrm{OH}$, December.

Kennedy, T.B., 1958, "Pressure Grouting Fine Fissures," Journal of the Soil Mechanics and Foundations Division, ASCE, Vol. 84, no. SM3, August, Paper 1731.

Koplick, C.M., D.L. Pentz, and R. Talbot, 1979, "Information Base for Waste Repository Design, Vo1. 7, Executive Summary," NUREG/CR0495. Prepared for U.S. Nuclear Regulatory Commission, Division of Waste Management, Office of Nuclear Material Safety and Safeguards, by the Analytical Sciences Corp., Reading, MA, NTIS: PB 293407.

Lambe, T.W., 1951, Soil Testing for Engineers, John Wiley and Sons, N.Y., 165 pp.

Littlejohn, G.S., 1982, "Design of Cement Based Grouts," Proceedings of the Conference on Grouting in Geotechnical Engineering, New Orleans, February 10-12, pp. 35-48, American Society of Civil Engineers, New York, N.Y. 
Lombardi, G., 1985, "The Role of Cohesion in Cement Grouting of Rock," pp. 253-261, Q. 58, R. 13, vol. 3, Transactions, 15th Inter. Cong. on Large Dams, Lausanne, Switzerland, June, pp. 235-261. International Commission on Large Dams, Paris.

Lomize, 1951, Eiltratsiya u Treshchinovatyk Porodakh (Flow in fractured rock), Gosenergoizdat, Moscow.

Louis, C. 1969. "A Study of Groudwater Flow in Jointed Rock and Its Influence on the Stability of Rock Masses". Rock Mechanics Report No. 10, Imperial College, University of London, England.

Louis, C., 1976, "Introduction A L'Hydraulique Des Roches" (Introduction to rock hydraulics), Ph.D Thesis, University of Pierre et Marie Curie, Paris.

Louis, C.L., 1974, "Rock Hydraulics", Bureau of Geology and Mining Research, National Geologic Service, Orleans, CEDEX.

Maini, Y.N.T., 1971, "In-situ Hydraulic Parameters in Jointed Rock-Their Measurement and Interpretation," Ph.D. Thesis, University of London, Imp. Coll. of Sci. and Technology.

Mitche11, J.K., 1970, "In-Place Treatment of Foundation Soils," Journal of the Soil Mechanics and. Foundations Division, Proceedings of the ASCE, Vol. 96, No. SM1, pp. 73-110.

Mongan, C.E., 1985, "Validity of Darcy's Law Under Transient Conditions, U.S. Geological Survey, Paper 1331, United States Printing Office, Washington.

Nonveiller, E., 1989, "Grouting Theory and Practice," Elsevier Science Publishing Company Inc., New York.

Pusch, R., L. Borgesson, A. Fredrikson, I. Markstrom, M. Erlstrom, G. Ramqvist, M. Gray, and W. Coon, 1988, Rock Sealing-Interim Report on the Rock Sealing Project (Stage 1), Stripa Project Report 88-11, Stockholm, Sweden.

Roko, R.O., J.J.K. Daemen, and D.E. Myers, 1991, "Variogram Characterization of Joint Surface Morphology and Asperity Deformation During Shearing", to be published.

Ruiz, M.D. and P.C. Leone, 1970, "The Importance of Grout Properties in Grouting Jointed Rock Masses," 1st International Congress of the International Association of Engineering Geology, September 8-11, Paris, Vol. 1, pp. 616-635.

Sagar, B. and A. Runchal, 1982, "Permeability of Fractured Rock: Effect of Fracture Size and Data Uncertainties," Water Resources Research, Vo1. 18, No. 2, pp. 266-274, April. 
Schaffer, A. and J.J.K. Daemen, 1987, "Experimental Assessment of the Sealing Effectiveness of Rock Fracture Grouting, " NUREG/CR-4541, prepared for the U.S. Nuclear Regulatory Commission, by the Dept. of Mining and Geological Engineering, University of Arizona, Tucson.

Shannon and Wilson, Inc., 1987, "Cement Grout Flow Behavior in Fractured Rock," for the Bureau of Reclamation, Denver, CO, and the Army Corps of Engineers, Omaha, NE.

Sharp, J.C. and Y.N.T. Maini, 1972, "Fundamental Considerations on the Hydraulic Characteristics of Joints in Rock," Paper T1-F, Percelation Through Fissured Rock, Proceedings, Internat. Soc. for Rock Mechanics, Internat. Assoc. of Engrg. Geology Symposium, Stuttgart, 1972, Prof. Dr.-Ing. Wittke, ed. Published by Deutsche Gesellschaft fuer Erdund Grundbau, Essen.

Shimoda, M. and H. Ohmori, 1982, "Ultra Fine Grouting Material," Grouting in Geotechnical Engineering, W.H. Baker, editor, proceedings of the conference on February 10-12, New Orleans, LA, Vo1. 1, pp. 77-91. Published by ASCE, New York.

Snow, D.T., 1965, A Parallel Plate Model of Fractured Permeable Media, $\mathrm{Ph} . \mathrm{D}$. thesis, Univ. of Calif., Berkeley.

The Consulting Engineer, 1969, "Grouting Design and Practice," The Consulting Engineer, London, Vol. 33, No. 10, October, 40 p. insert.

Tsang, Y.W. and P.A., Witherspoon, 1981, "Hydromechanical Behavior of A Deformable Rock Fracture Subject to Normal Stress" Journal of Geophysical Research Vo1. 86, No. B10, pp. 9287-9298, October.

Wallner, M. and W. Wittke, 1974, "Theory and Experiment of a New Grouting Procedure," Proc., 3rd Cong. of the Inter. Soc. of Rock Mechanics, Denver, Vol. II, Part B, pp. 744-750. (In German)

Wilson, C. R. and Witherspoon, P. A., 1970, An Investigation of Laminar Flow in Fractured Rocks, Geotechnical Report No. 70-7, University of California, Berkeley.

Witherspoon, P.A., J.S.Y. Wang, K. Iwai and J.E. Gale, 1980, "Validity of the Cubic Law for Fluid Flow in a Deformable Rock Fracture," Water Resources Research, Vol. 16, No. 6, December pp. 1016-1024.

Zeigler, T.W., 1976, "Determination of Rock Mass Permeability," U.S. Army Engr. Waterways Experiment Station, Technical Report S-76-2. 


\section{APPENDIX A}

\section{PERMEABILITY CALCULATIONS}

\section{A.1 Axial Stress on Sample}

The normal stress $\sigma_{a x}$ is calculated from the oil pressure in the hydraulic load cell.

$$
\sigma_{a x}=\left(P \cdot A_{p}\right) / A_{s}
$$

where $P=0$ il injection pressure

$A_{p}=$ cross-sectional area of the piston in the load cell

$A_{S}=$ area of the sample.

\section{A.2 Permeability of Rock Matrix}

The rock permeability is calculated by assuming that the flow is laminar, all connective voids are filled with water, and Darcy's law is valid. For falling head tests, the hydraulic conductivity (k) of the rock sample is calculated from an equation derived from Bear (1979, pp. 305-306) and Freeze and Cherry (1979, p. 336):

$$
k=\frac{a \ln \left(R_{o} / R_{i}\right) \ln \left(h_{0} / h_{1}\right)}{2 \pi L_{H}\left(t_{1}-t_{0}\right)}
$$

$\mathrm{cm} / \mathrm{s}$

$$
\begin{aligned}
\text { where } \alpha & =\text { cross-sectional area of the pipette in } \mathrm{cm}^{2} \\
\mathrm{R}_{0}, \mathrm{R}_{i} & =\text { outer and inner radii of the hollow cylinder } \\
\mathrm{L}_{\mathrm{H}} & =\text { length of the center hole } \\
t_{1}, t_{0} & =\text { time in seconds } \\
\mathrm{h}_{0} & =\text { initial height of water in the pipette measured from the } \\
\mathrm{h}_{1} & =\text { midsection of the cylinder at time } t_{0}
\end{aligned}
$$

For steady-state flow tests, the hydraulic conductivity of the rock cylinder is calculated using an equation modified from Bear (1979, pp. 305-306):

$$
k=\frac{Q \ln \left(R_{o} / R_{i}\right)}{2 \pi L_{H} \Delta h}
$$

$$
\begin{aligned}
\text { where } Q & =\text { flow rate in } \mathrm{cm}^{3} / \text { second } \\
\mathrm{R}_{\mathrm{O}}, \mathrm{R}_{\mathrm{i}} & =\text { outer and inner radii of the hollow cylinder } \\
\mathrm{L}_{\mathrm{H}}= & \text { length of the borehole in } \mathrm{cm} \\
\Delta h & =\text { difference of water head between inner hole and cylinder } \\
& \text { outer surface }
\end{aligned}
$$




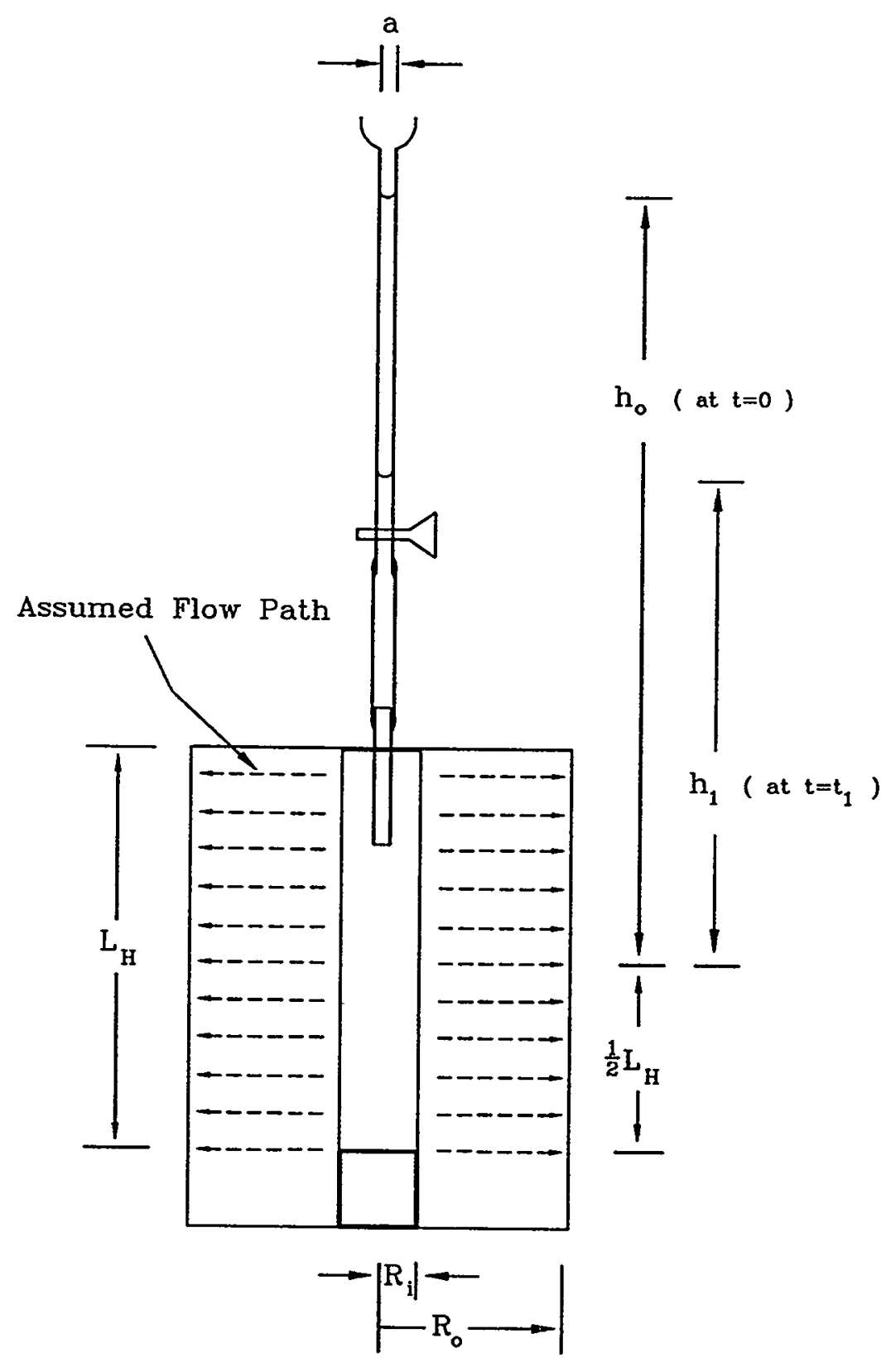

Figure A.I Parameters involved in a falling head test. 
The inflow rate, $Q$, is calculated from

$$
Q=A_{l}(\Delta S / \Delta t)
$$

$\mathrm{cc} / \mathrm{s}$

where $A_{1}=$ cross-sectional area of the pistion in the intensifier $\left(\mathrm{cm}^{2}\right)$

$\Delta S$ - travel distance of the push-rod in $\mathrm{cm}$

$\Delta t=$ travel time in seconds.

The water head difference $(\Delta h)$ is calculated from the injection pressure $\left(P_{i}\right)$,

$$
\Delta h=\left(P_{i} / y\right)-h_{0}
$$

$\mathrm{cm}$

where $y$ is the unit weight of water, $h_{0}$ the height of water in plastic pan measured from the midsection of the sample.

\section{A. 3 Fracture Permeability}

The permeability of a fracture is calculated by assuming that the rock permeability is negligible, flow is radial from the borehole, the fracture surfaces are smooth parallel planes, and Darcy's law applies. The equivalent fracture aperture (e) is calculated using an equation given by Witherspoon et al. (1980):

$$
e=[Q /(\Delta h C)]^{\frac{1}{3}}
$$

where $Q=$ flow rate in $c c /$ second

$\Delta h=$ head difference in $\mathrm{cm}$

$C$ - constant representing flow geometry and fluid properties.

For radial flow, the constant $C$ is

$$
C=\frac{2 \pi}{\ln \left(R_{0} / R_{i}\right)} \frac{\gamma}{12 \mu}
$$

where $R_{0}, R_{i}=$ outer and inner radii of the hollow cylinder

$\gamma$ - unit weight of water in $\mathrm{g} / \mathrm{cm}^{3}$

$\mu=$ viscosity of water in $\mathrm{g} \cdot \mathrm{s} / \mathrm{cm}^{2}$.

The permeability of the fracture $\left(k_{f}\right)$ is calculated using an equation (modified from Zeigler, 1976, p. 10, as cited by Schaffer and Daemen, 1987, p. 18):

$$
k_{f}=(\gamma / 12 \mu) e^{2}
$$

$\mathrm{cm} / \mathrm{s}$ 
For the falling head test, the equivalent fracture aperture is given by (Schaffer and Daemen, 1987, p. 64):

$$
e=\left[\frac{\ln \left(h_{0} / h_{1}\right) a \ln \left(R_{o} / R_{i}\right) 6 \mu}{\pi\left(t_{l}-t_{0}\right) \gamma}\right]^{1 / 3}
$$

For the steady-state flow test, the fracture aperture is calculated using equation:

$$
e=\left[\frac{Q \ln \left(R_{o} / R_{i}\right) 6 \mu}{\Delta h \pi \gamma}\right]^{1 / 3}
$$

where $Q=$ inflow rate in $\mathrm{cm}^{3} /$ second

$\Delta h=$ difference of water head between the inner hole and cylinder outer surface in $\mathrm{cm}$. 
APPENDIX B

ROGR SAMPLE DESIGNATION CODING SYSTEM

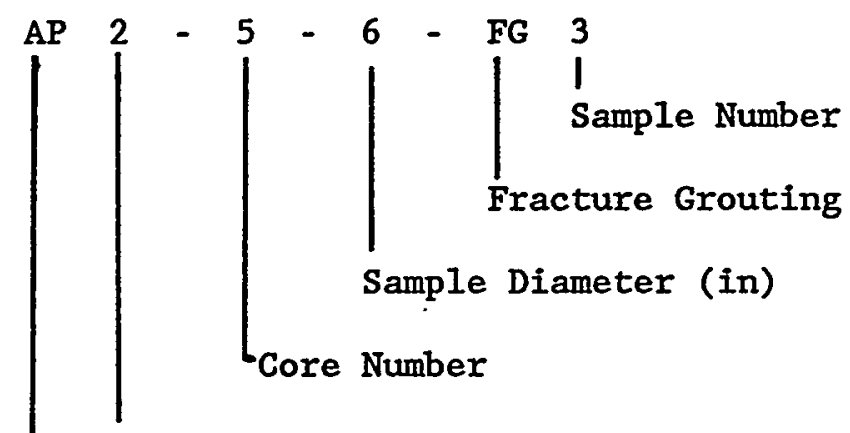

Block Number

Rock Type:

AP - Apache Leap tuff

T - A-Mountain tuff 


\begin{tabular}{|c|c|}
\hline $\begin{array}{l}\text { U.S. NUCLEAR REGULATORY COMMISSION } \\
\text { BIBLIOGRAPHIC DATA SHEET } \\
\text { (see instructions on the reverse) }\end{array}$ & \multirow[t]{2}{*}{ 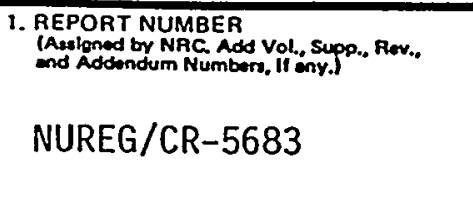 } \\
\hline \multirow{4}{*}{$\begin{array}{l}\text { 2. TITLE AND SUBTITLE } \\
\text { Laboratory Testing of Cement Grouting of Fractures in } \\
\text { Welded Tuff }\end{array}$} & \\
\hline & 3. DATE REPORT PUBLISHED \\
\hline & \begin{tabular}{|l|l|} 
MONTH & YEAR \\
March & 1991 \\
\end{tabular} \\
\hline & \\
\hline \multirow[t]{2}{*}{$\begin{array}{l}\text { 5. AUTHOR(S) } \\
\text { C.J. Sharpe, J.J. Daemen }\end{array}$} & $\begin{array}{l}\text { 6. TYPE OF REPORT } \\
\text { Technical }\end{array}$ \\
\hline & $\begin{array}{l}\text { 7. PERIOD COVERED (Inclusive Dares) } \\
1988-1990\end{array}$ \\
\hline \multicolumn{2}{|l|}{ 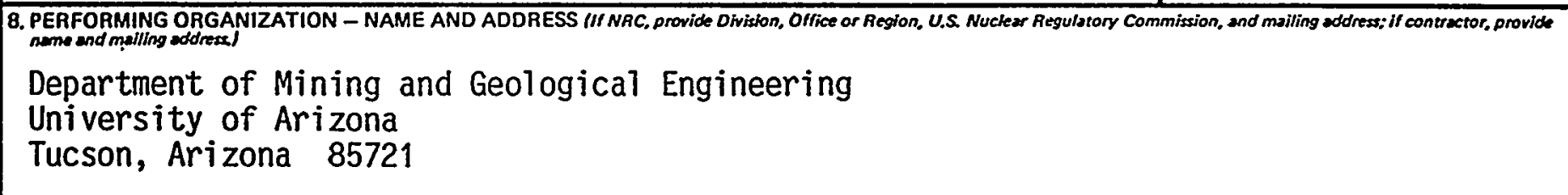 } \\
\hline \multicolumn{2}{|c|}{ 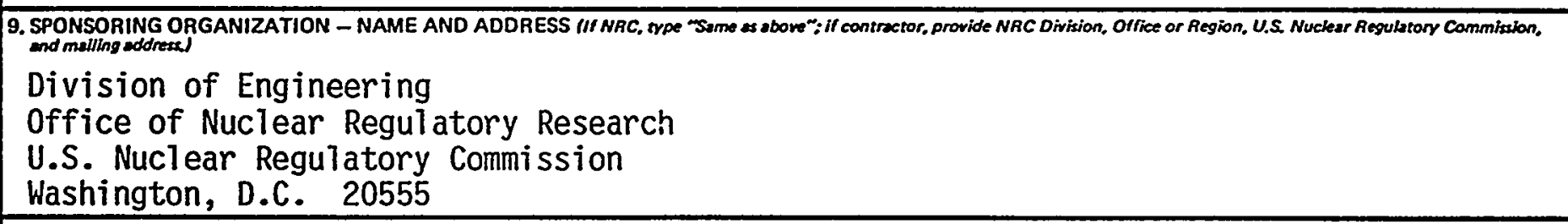 } \\
\hline \multicolumn{2}{|c|}{ 10. SUPPLEMENTARY NOTES } \\
\hline \multicolumn{2}{|c|}{$\begin{array}{l}\text { The objective of this investigation is to experimentally determine the effectiveness of } \\
\text { fracture sealing in welded tuff using ordinary portlana cement and microfine cement } \\
\text { grouts. } \\
\text { Laboratory experiments have been performed on seventeen tuff cylinders with three types } \\
\text { of fractures; If tension-indiced cracks, 2) natural fractures, ard } 3 \text { ) sawcuts. Prior } \\
\text { to grouting, the hydraulic conductivity of the intact rock and of the fractures is } \\
\text { measured under a range of normal stresses. The surface topography of the fracture is } \\
\text { mapped,and the results are used to determine aperture distributions across the fractures } \\
\text { Grouts are injected through axial boreholes at pressures of } 0.3 \text { to } 4.1 \text { MPa while holding } \\
\text { fractures under a constant normal stress. Five group formulations have been tested. } \\
\text { Bentonite ( } 0 \text { to } 5 \text { percent by weight) has been-added to these grouts to increase their } \\
\text { stability. Water-to-cement ratios range from } 0.45 \text { to } 1.0 \text {. Permeability testing of } \\
\text { grouted fractures is used to evaluate the effectiveness of fracture grouting. Post-test } \\
\text { visual inspection of grout distribution confirms that permeability testing in an } \\
\text { injection hoije is not a reliable method to assess the effectiveness of grouting. } \\
\text { Grout distribution is highly non-uniform. }\end{array}$} \\
\hline \multirow[t]{2}{*}{$\begin{array}{ll}\text { 12. KEY WOADS/DESCA!PTORS (Liss words or phrases that will essist reseschers in locating she report.) } \\
\text { Fracture seal ing } & \text { Fracture types } \\
\text { Grouting } & \text { Fracture characterization } \\
\text { Cement grout } & \text { Tuff permeability } \\
\text { Grout characterization } & \text { Welded tuff } \\
\text { Fracture permeability } & \text { Repository sealing }\end{array}$} & $\begin{array}{l}\text { 13. AVAILABILLTY STATEMENT } \\
\text { Unl imited } \\
\text { 14. SECUAITY CLASSIFICATION } \\
\text { (This PaSe) } \\
\text { Uncl ass if ied } \\
\text { Unhis Reporl } \\
\text { Unclass ified } \\
\text { 15. NUMBER OF PAGES }\end{array}$ \\
\hline & \\
\hline
\end{tabular}

